AN ACTION RESEARCH ON DESIGN, DELIVERY AND EVALUATION OF A DISTANCE COURSE IN A VOCATIONAL HIGHER EDUCATION INSTITUTION

\author{
A THESIS SUBMITTED TO \\ THE GRADUATE SCHOOL OF NATURAL AND APPLIED SCIENCES \\ OF \\ MIDDLE EAST TECHNICAL UNIVERSITY
}

BY

ERMAN UZUN

IN PARTIAL FULFILLMENT OF THE REQUIREMENTS

FOR

THE DEGREE OF DOCTOR OF PHILOSOPHY

IN

COMPUTER EDUCATION AND INSTRUCTIONAL TECHNOLOGY

DECEMBER 2012 
Approval of the thesis:

\section{AN ACTION RESEARCH ON DESIGN, DELIVERY AND EVALUATION OF A DISTANCE COURSE IN A VOCATIONAL HIGHER EDUCATION INSTITUTION}

submitted by ERMAN UZUN in partial fulfillment of the requirements for the degree of Doctor of Philosophy in Computer Education and Instructional Technology Department, Middle East Technical University by,

Prof. Dr. Canan Özgen

Dean, Graduate School of Natural and Applied Sciences

Prof. Dr. Soner Yildırım

Head of Department, Computer Edu. \& Instruct. Tech., METU

Prof. Dr. M. Yaşar Özden

Supervisor, Computer Edu. \& Instruct. Tech., METU

Prof. Dr. Ali Yıldırım

Co-Supervisor, Department of Educational Sciences, METU

Examining Committee Members:

Prof. Dr. Zahide Yildırım

Computer Edu. \& Instruct. Tech., METU

Prof. Dr. M. Yaşar Özden

Computer Edu. \& Instruct. Tech., METU

Assoc. Prof. Dr. Özgül Yılmaz Tüzün

Elementary Education, METU

Assist. Prof. Dr. Ömer Delialioğlu

Computer Edu. \& Instruct. Tech., METU

Assist. Prof. Dr. Halil Ersoy

Computer Edu. \& Instruct. Tech., Başkent University

Date:

December 182012 
I hereby declare that all information in this document has been obtained and presented in accordance with academic rules and ethical conduct. I also declare that, as required by these rules and conduct, I have fully cited and referenced all material and results that are not original to this work.

Name, Last name: Erman Uzun

Signature 


\title{
ABSTRACT \\ AN ACTION RESEARCH ON DESIGN, DELIVERY AND EVALUATION OF A DISTANCE COURSE IN A VOCATIONAL HIGHER EDUCATION INSTITUTION
}

\author{
Uzun, Erman \\ Ph.D., Department of Computer Education and Instructional Technology \\ Supervisor: Prof. Dr. M. Yaşar Özden \\ Co-Supervisor: Prof. Dr. Ali Yıldırım
}

December 2012, 314 pages

The main purpose of the study was to design, develop, deliver and evaluate a new distance web design course for the needs of students in a vocational higher education institution. Proactive action research was used as a framework during the research process. This research focused on the analysis of the existing face-to-face course to mitigate its problems in the new design. Then, accomplishments and insufficiencies of the new design in the new context were investigated.

For this study, data were collected in two different semesters, in a vocational higher education institution. In the first semester, an existing course was investigated to see the problems and the needs. The results revealed that there were problems associated with "motivational", "interactional”, "instructional activities", "support materials", "up-to-date content", "technologic", and "non-technologic" aspects of the existing course. Before the delivery of the new distance course in the second semester, it was completely redesigned with the new characteristics to mitigate some of the predetermined problems of the existing course. In this new structure, an instructor from Ankara gave the course via smart class to this vocational institution located in another city. 
In the second semester, data were collected to understand what the accomplishments of the new course, and what aspects of the new course needed to be modified. To triangulate qualitative findings, two questionnaire were conducted to see the students' attitude towards web-based instruction and students' perceptions about learning environment. With the findings of these data collection procedures, the accomplishments of the new design can be categorized in five main headings. These are "working with an experienced instructor", "extended learning opportunities", "increased future expectations of students", "fulfilled software requirements", and "applicability of a distance vocational course". On the other hand, in the new structure of the course, new problems emerged such as "course delivery problems" and “students' readiness", because technology use in education sometimes comes with its unique problems including the solutions. Those accomplishments and insufficiencies points of the new design would be helpful in the new distance course design projects.

Keywords: Proactive Action Research, Distance Course Design, Vocational Higher Education, Vocational Course Design, Distance Vocational Education, Technology Enhanced Learning. 


\title{
ÖZ
}

\section{BİR MESLEKI YÜKSEKÖĞRENIM KURUMU ICÇIN UZAKTAN VERILECEK DERSIN TASARLANMASI, GELISSTIRILMESİ VE DEĞERLENDİRILMESINE YÖNELIKK BİR EYLEM ARAŞTIRMASI}

\author{
Uzun, Erman \\ Doktora, Bilgisayar ve Öğretim Teknolojileri Eğitimi Bölümü \\ Tez Yöneticisi: Prof. Dr. M. Yaşar Özden \\ Ortak Tez Yöneticisi: Prof. Dr. Ali Yıldırım
}

Aralık 2012, 314 sayfa

$\mathrm{Bu}$ çalışmanın temel amacı bir mesleki yüksek öğretim kurumundaki öğrencilerin ihtiyaçlarına yönelik olarak, yeni bir web tasarımı dersini tasarlamak, geliştirmek, sunmak ve değerlendirmektir. Bu araştırma proaktif eylem araştırması çerçevesinde gerçekleştirilmiştir. Bu kapsamda halihazırda yüz yüze olarak verilmekte olan bir ders analiz edilerek, yeni tasarımda varolan bu problemleri azaltmak amaçlanmıştır. Ardından yeni tasarlanan dersin başarıları, eksiklikleri araştırılmıştır.

Çalışma kapsamında bir mesleki yüksek öğretim kurumundan iki farklı dönemde veri toplanmıştır. İlk dönemde var olan bir ders ve o dersteki ihtiyaçlar ve eksiklikleri belirlemek amaçlanmıştır. Analiz sonuçları derste "motivasyon”, “etkileşim”, “öğretim aktiviteleri”, “destek materyalleri”, "güncel içerik”, ve "teknolojik" konularda problemler olduğunu ortaya koymaktadır. Yeni dersi vermeye başlamadan önce tasarım aşamasındayken, daha önceden belirlenmiş olan problemleri azaltmak için alternatif yaklaşımların kullanılmıştır. Bu yeni yapıda Ankara' daki öğretim üyesi, akıllı sınıfı kullanarak başka bir şehirdeki mesleki yüksek öğretim kurumuna dersi vermiştir. 
İkinci dönemde ise uzaktan verilen bu yeni dersin başarılı olduğu ve değişiklik yapılması gereken yönleri araştırılmıştır. Bu amaçla çalışma kapsamında toplanan nitel verileri desteklemek için, öğrencilerin web tabanlı öğrenmeye karşı tutumları ve yeni öğretim ortamına yönelik algılarına yönelik 2 anket uygulanmıştır. Bu veriler ile belirlenen yeni dersin kazanımları 5 ana başlıkta toplanabilir. Bunlar "öğrencilerin tecrübeli bir eğitimci ile çalışma olanağı", "geliştirilen ve iyileştirilen öğrenme olanakları”, "öğrencilerin gelecekten beklentilerinin artması”, “yazılımsal pek çok ihtiyacın karşılanması" ve "uzaktan verilen mesleki bir dersin uygulanabilirliği". Diğer yandan ise bu yeni derste bazı farklı problemler ortaya çıkmıştır. Bunlar ise “dersin iletimi ile ilgili” ve "öğrencilerin hazır bulunuşluğu ile ilgili“" problemlerdir. Bazen eğitimde teknoloji kullanımı, çözümün yanında kendine has bazı problemleri de beraberinde getirmektedir. Bu çalışmadaki yeni ders tasarım sürecinin ortaya koyduğu kazanımlar ve eksiklikler, bundan sonra uzaktan verilecek derslerin tasarım süreçlerine de katkı sağlayacaktır.

Anahtar Kelimeler: Eylem Araştırması, Uzaktan Eğitimle Ders Tasarımı, Mesleki Yüksek Öğrenim, Mesleki Ders Tasarımı, Uzaktan Mesleki Eğitim, Teknoloji Destekli Öğrenme. 
To my parents,

UZUN, CAN families

and to my everything

Özlem and Nil Mira UZUN 


\section{ACKNOWLEDGEMENTS}

First of all, this dissertation could not have been written without Prof. Dr. M. Yaşar Özden who not only served as my supervisor but also encouraged and challenged me throughout my academic maturation as a supervisor with his guidance, advice, criticism, encouragement and insight through the research. He had a great effort during the implementation process, and sometimes motivated me to continue working on this topic during the problems that I have faced. He was always there when I need his advice, and guidance. In addition, I was also lucky enough to work with Prof. Dr. Ali Yıldırım, my co-supervisor, and receive his constructive, supportive, wellstructured feedbacks and encouragement. I would also like to thanks to Assoc. Prof. Dr. Fethi İnan for his understanding during my short cooperative study in U.S. as a visitor researcher. In addition, his suggestions and comments at the critical point of my research were very beneficial for me.

I would like to express my sincere appreciation to the examination committee members, Prof. Dr. M. Yaşar Özden, Assoc. Prof. Dr. Zahide Yıldırım, Assoc. Prof. Dr. Özgül Yılmaz Tüzün, Assist Prof. Dr. Ömer Delialioğlu, and Assist. Prof. Dr. Halil Ersoy for their comments and suggestions. Their timely feedbacks guided me to see different perspectives when I was stucked on an issue. These feedbacks created new opportunities, solutions during the research.

In addition, I would like to thank to my professors in METU in helping me in broaden my view in the field of instructional technology. Many demanding courses and research projects guide me to be a part of this field.

I should also express my appreciation to Deniz Üstün for his great support during my study, and my friends in CEIT 436 "Project Management" course for their support in developing instructional materials. 
I owe great thankfulness to my friends Engin Kursun, İsmail Yıldız, Ali Gök, Ayşe Gül Kara, İsmihan Arslan Arı, Fatih Arı, Murat Duman, Nuri Kara, Derya Başer, Neşet Mutlu, Evren Şumuer, Mukaddes Can for their pleasant support, guidance and friendship. In addition, I should thank to my roommate Duygu Nazire Kaşıcçı for her cheers and laughs.

I owe great many thanks to great many people but the most important people in my life my beloved wife Özlem and my baby Mira; for their understanding and endless love, through the duration of this study. 


\section{TABLE OF CONTENTS}

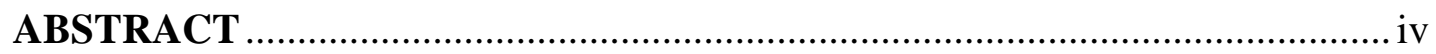

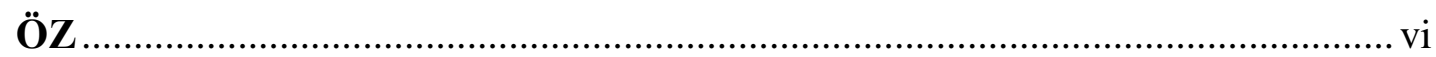

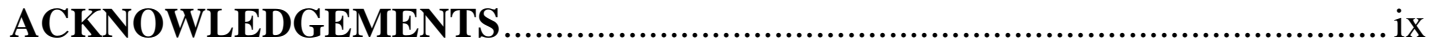

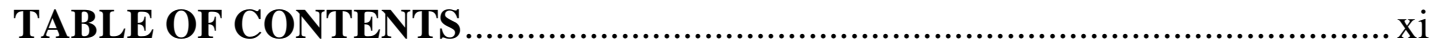

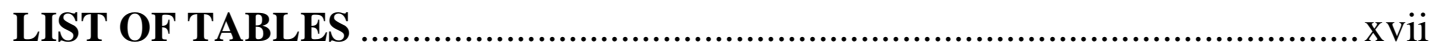

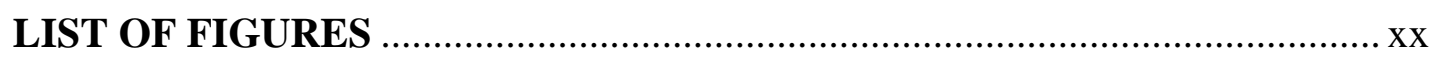

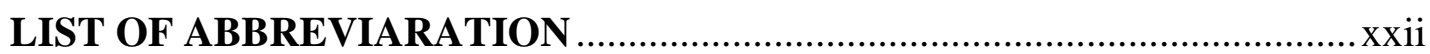

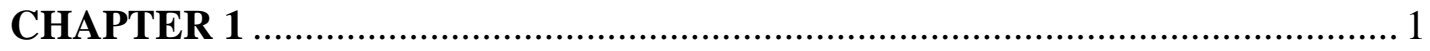

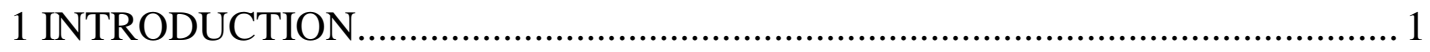

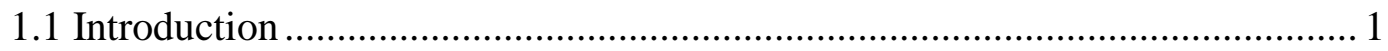

1.2 Background of the Problem ............................................................................... 1

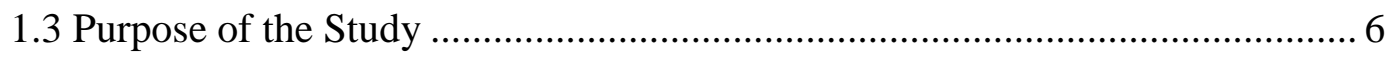

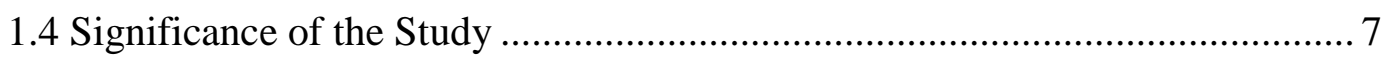

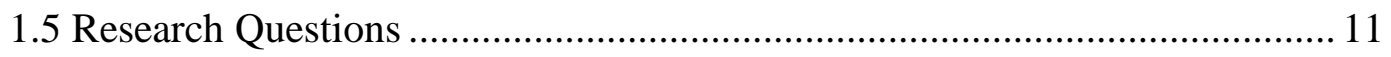

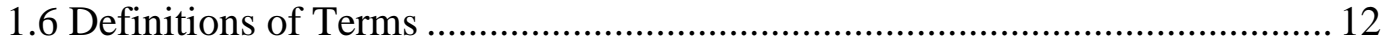

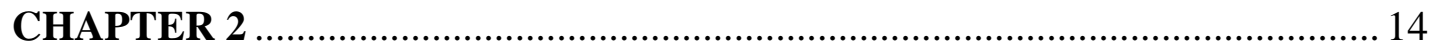

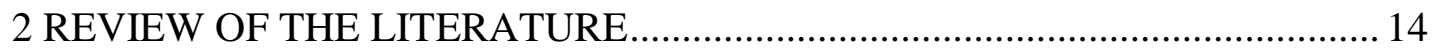

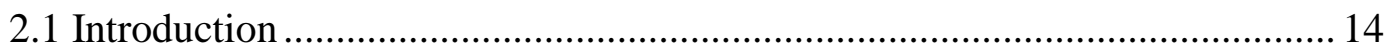

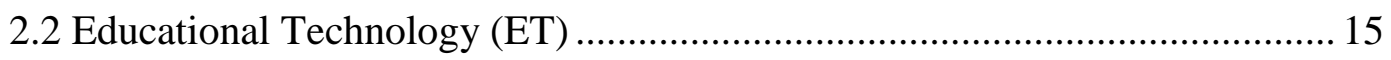

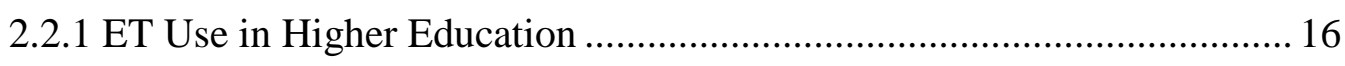

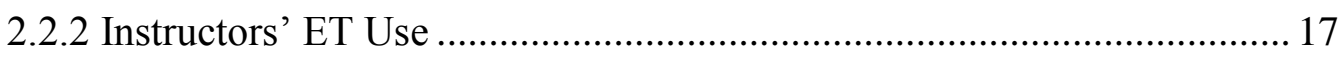

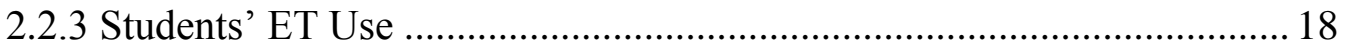

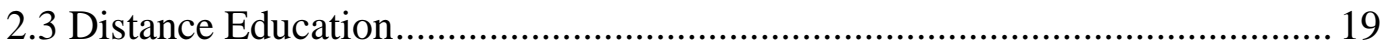

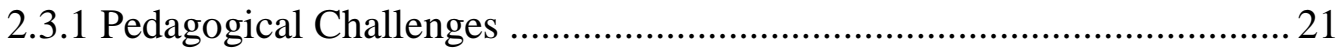

2.3.2 Institutional Challenges..................................................................... 24

2.4 E-Learning in Higher Education ............................................................. 25

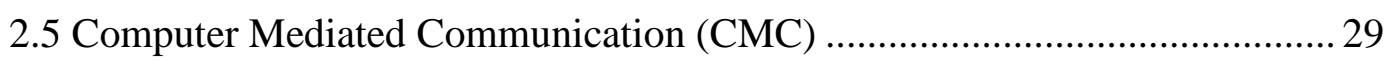

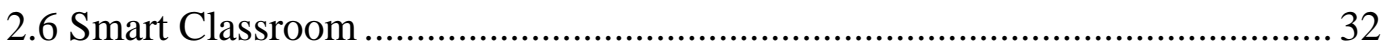




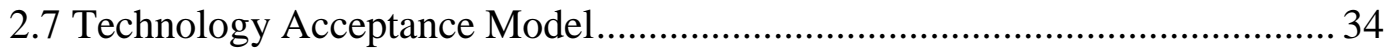

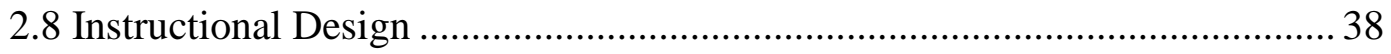

2.8.1 Morrison, Ross and Kemp ID Model ....................................................... 40

2.8.1.1 Identifying the Need for Instruction.............................................. 42

2.8.1.2 Learner and Contextual Analysis .................................................. 43

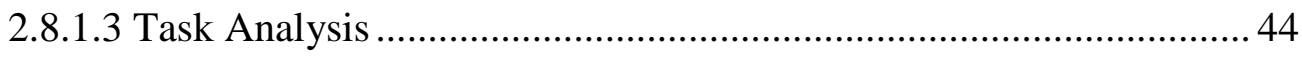

2.8.1.4 Instructional Objectives ................................................................ 44

2.8.1.5 Designing the Instruction: Sequencing …...................................... 45

2.8.1.6 Designing the Instructional Strategies .......................................... 45

2.8.1.7 Designing the Instructional Message .............................................. 45

2.8.1.8 Developing Instructional Materials ................................................... 45

2.8.1.9 Evaluation .............................................................................. 46

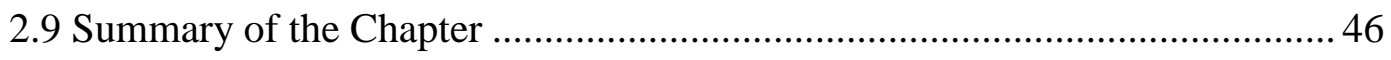

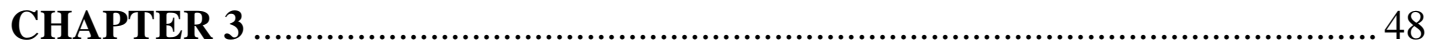

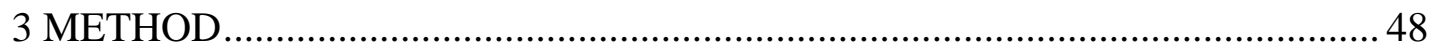

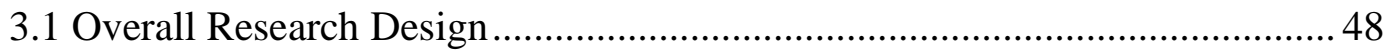

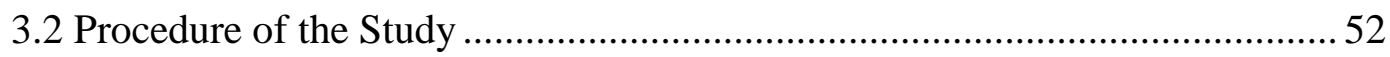

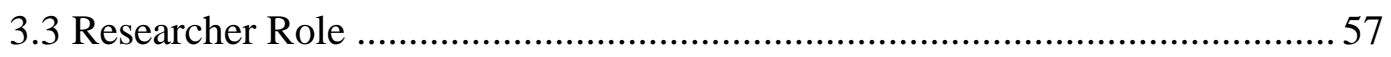

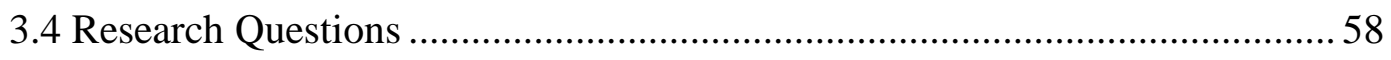

3.5 Context and Participant Selection …........................................................... 59

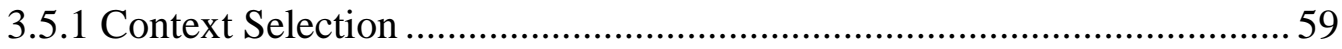

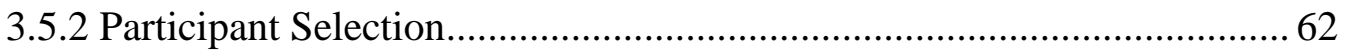

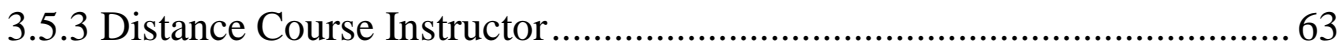

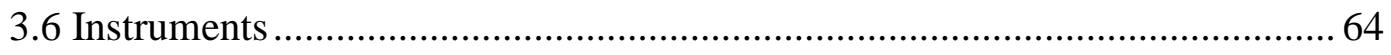

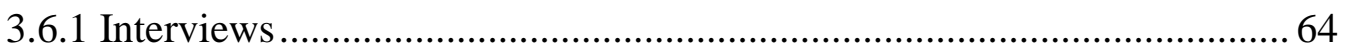

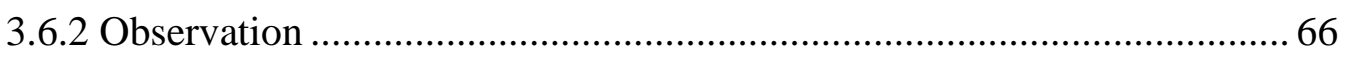

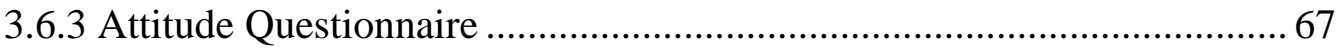

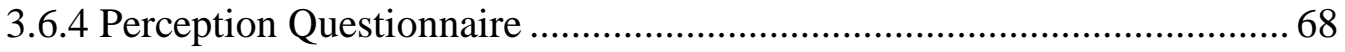

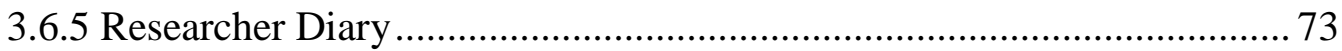

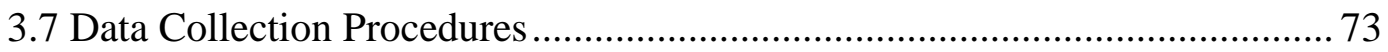

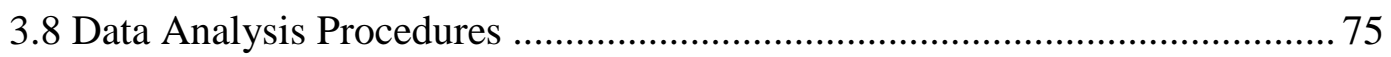

3.8.1 Qualitative Data Analysis with Constant Comparison............................. 75

3.8.1.1 Open Coding ........................................................................... 77 


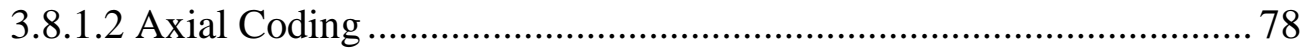

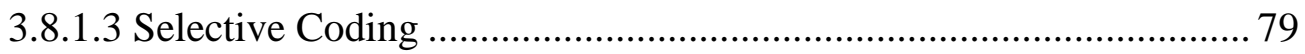

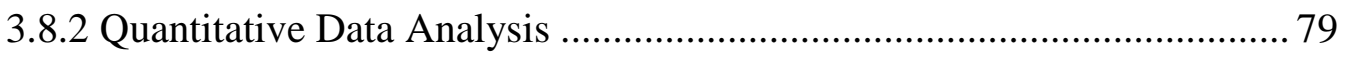

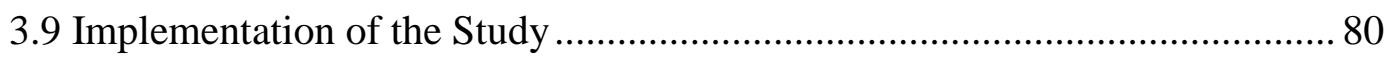

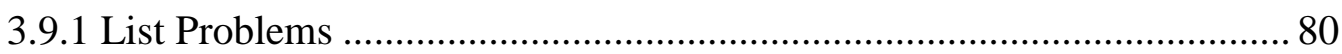

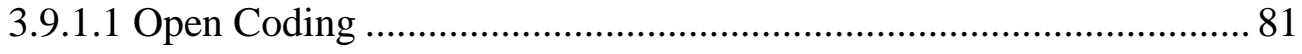

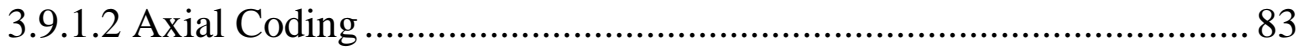

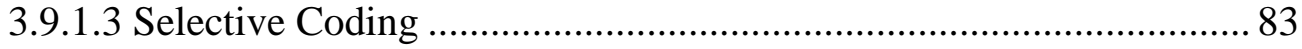

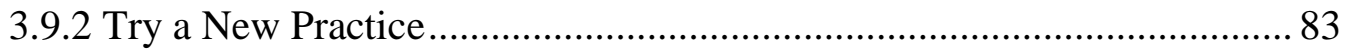

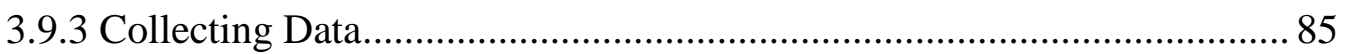

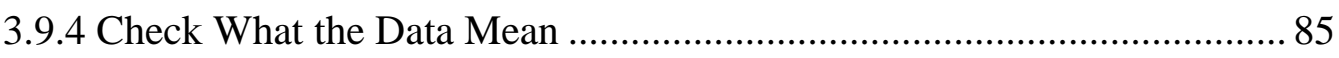

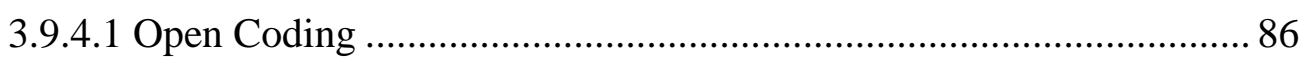

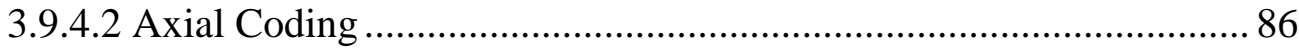

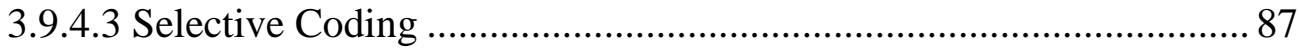

3.9.5 Alternate Ways to Behave and Fine Tuning ........................................... 87

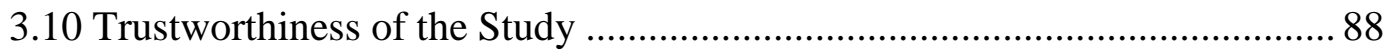

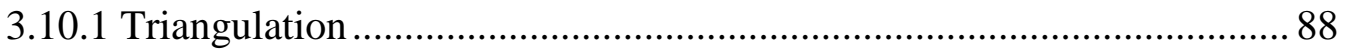

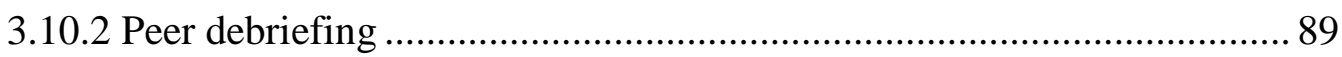

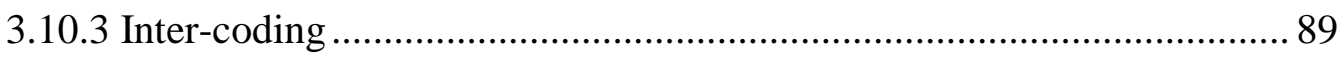

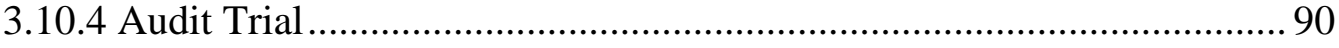

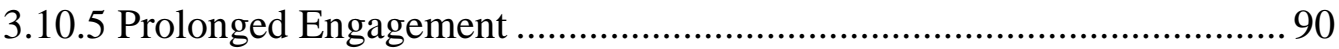

3.10.6 Context, Participant, and Researcher Definition ................................... 90

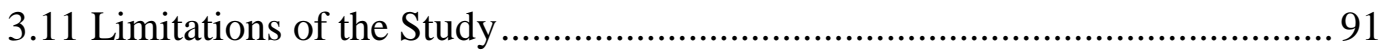

3.12 Summary of the Chapter ........................................................................... 92

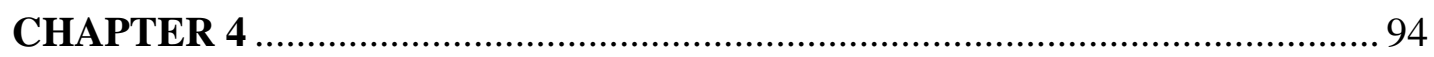

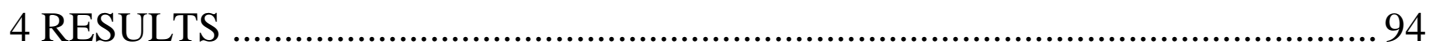

4.1 Problems of Traditional F2F Course ........................................................... 94

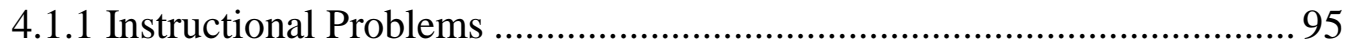

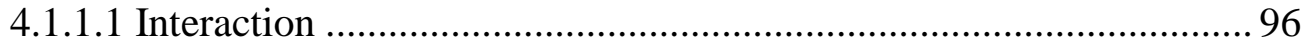

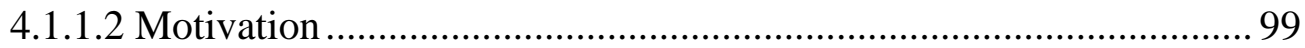

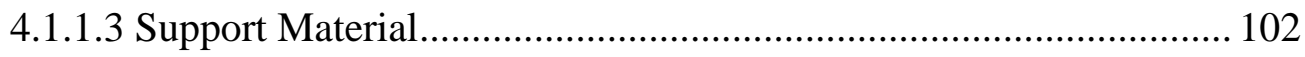

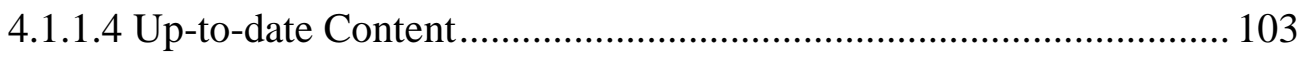

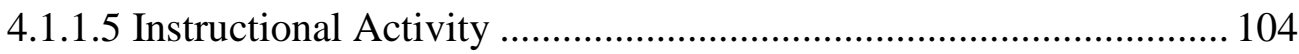




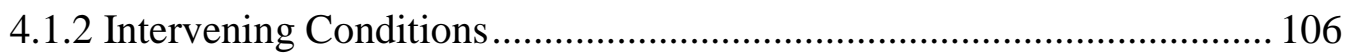

4.1.2.1 Technologic Problems..................................................................... 106

4.1.2.2 Non-Technologic Problems …………………………………….... 109

4.2 Design Characteristics for the New Course .................................................. 111

4.3 Students' Attitude towards WBI ............................................................... 115

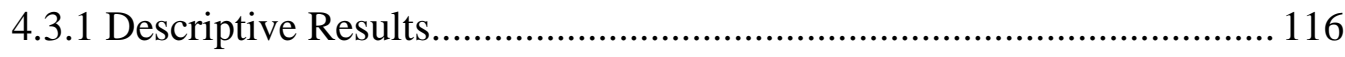

4.3.2 Overall Attitude towards WBI ............................................................ 121

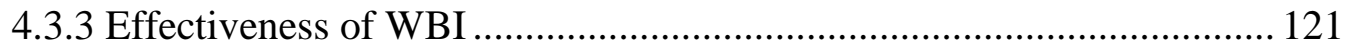

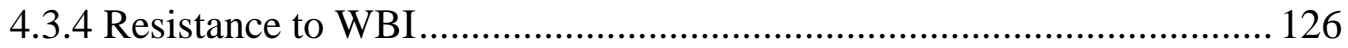

4.3.5 Comparisons with Some Demographic Data .......................................... 128

4.3.5.1 Gender Difference on Students' Attitude towards WBI .................. 128

4.3.5.2 Computer Experience on Students' Attitude towards WBI ............ 128

4.3.5.3 High School Graduation on Students' Attitude towards WBI ........ 130

4.3.5.4 Household Internet Connection on Students' Attitude towards WBI

4.4 Students' Perceptions about Learning Environment of the New Course...... 134

4.4.1 Students' Computer Competency ........................................................... 134

4.4.2 Self-Reported E-Learning Background.................................................. 137

4.4.3 Students' Perceptions about Learning Environment.............................. 138

4.4.3.1 Perceived Effects of Motivation....................................................... 138

4.4.3.2 Perceived Usefulness .................................................................... 144

4.4.3.3 Perceived Ease of Use ................................................................ 150

4.5 Accomplishments of the New Design ......................................................... 154

4.5.1 Instructional Accomplishment ............................................................. 156

4.5.1.1 Experienced Instructor .................................................................. 156

4.5.1.2 Learning Opportunities ............................................................ 157

4.5.1.3 Students' Future Expectations...................................................... 158

4.5.2 Technical Accomplishments ............................................................... 159

4.5.2.1 Software Problems ...................................................................... 159

4.5.2.2 Applicability of a Distance Vocational Course................................. 160

4.6 Critical Elements of New Distance Course Needed to be Improved ............. 161

4.6.1 Course Delivery Problems ........................................................................ 162

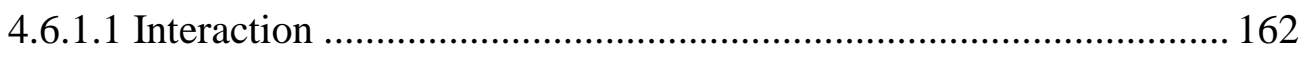


4.6.1.2 Institutional Barriers 164

4.6.2 Students' Readiness .............................................................................. 167

4.6.2.1 Students' Socio Economic Status...................................................... 167

4.6.2.2 Students' Skills and Experiences .................................................. 168

4.6.2.3 Students' Beliefs ......................................................................... 169

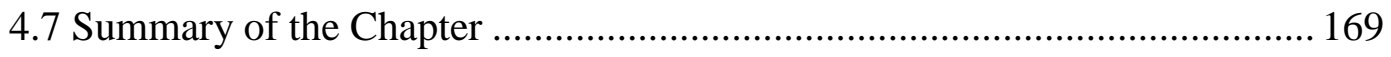

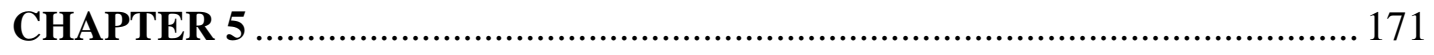

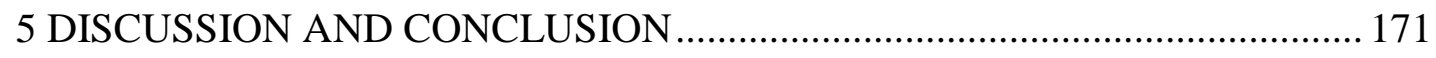

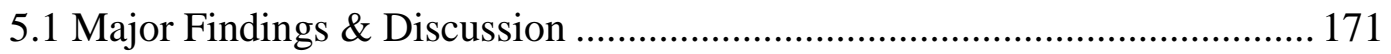

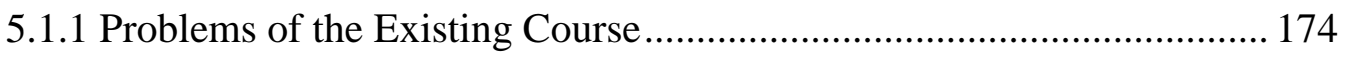

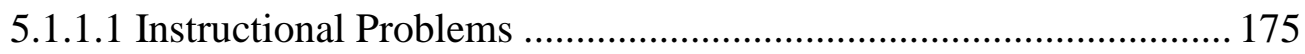

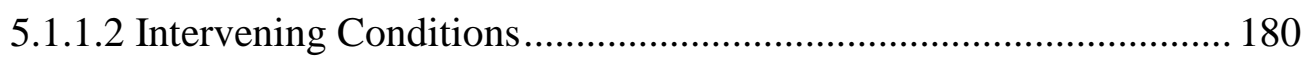

5.1.2 Decision-Making Process of the New Course Design .......................... 181

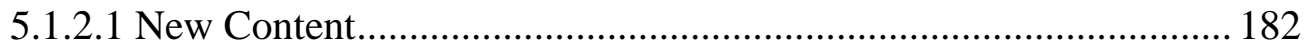

5.1.2.2 New Instructor \& New Medium Selection for the Delivery of the

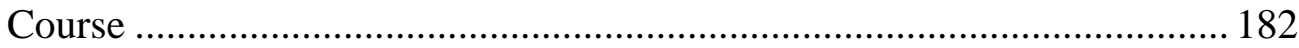

5.1.2.3 New Instructional Design Process ................................................ 184

5.1.3 Thoughts on the Design Characteristic of the New Course .................. 189

5.2 Recommendations for the Future Researches ............................................ 195

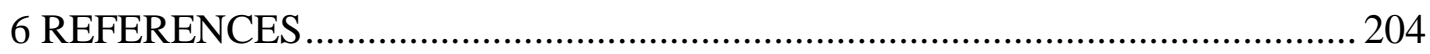

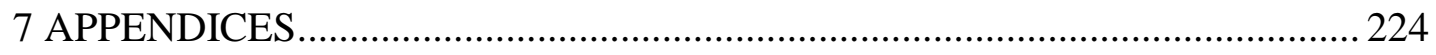

INFORMED CONSENT FORM FOR INTERVIEW .............................. 224

INFORMED CONSENT FORM FOR OBSERVATION ........................ 226

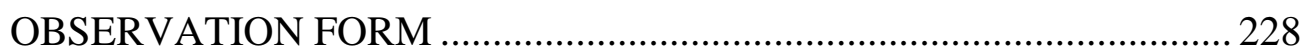

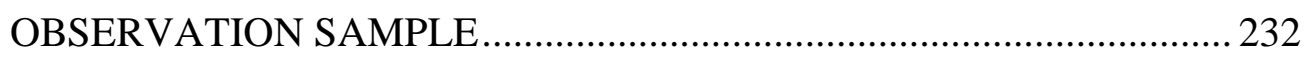

INTERVIEW PROTOCOL (FOR INSTRUCTOR) ............................... 238

INTERVIEW PROTOCOL (FOR STUDENT) ..................................... 240

SAMPLE STATEMENT-BY-STAEMENT ANALYSIS ........................ 243

OPEN CODING RESULTS OF THE FIRST DATA COLLECTION ...... 246

AXIAL CODING FROM DIFFERENT INSTRUMENTS ...................... 248

INSTRUCTIONAL DESIGN PROCESS .............................................. 251

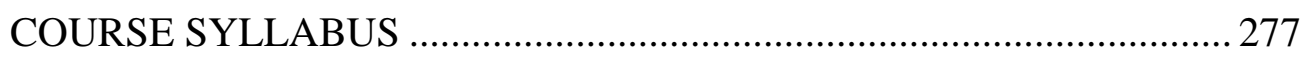

INFORMED CONSENT FORM FOR NEW DESIGN............................. 284 
WEB BASED INSTRUCTION ATTITUDES SCALE-(WBI-AS) ............ 286 STUDENTS' PERCEPTION TOWARDS NEW LEARNING

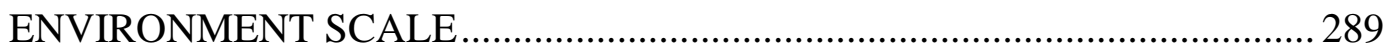

INTERVIEW PROTOCOL (FOR STUDENTS).......................................... 295 OPEN CODING RESULTS (ACCOMPLISHMENTS OF THE NEW

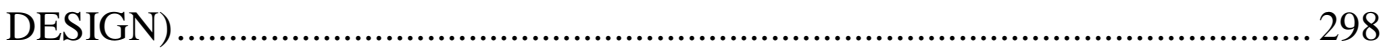

OPEN CODING RESULTS (PROBLEMS OF THE NEW DESIGN) ...... 299 TURKISH TRANSLATIONS OF THE QUOTES........................................ 301

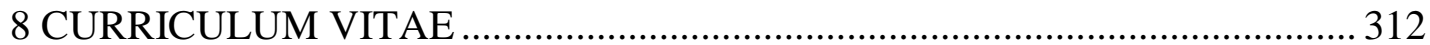




\section{LIST OF TABLES}

\section{TABLES}

Table 2-1: Barriers to widespread adoption of online learning.

Table 2-2: A developmental history of distance education

Table 2-3: Percentage of academic leaders who stated that online education is critical to their long-term strategy from 2003 to 2006 28

Table 2-4: Number of students enrolled in online education in 2003 and 2004 ....... 28

Table 3-1: Timeline of the Study and Procedure ....................................................... 56

Table 3-2: General characteristic of "Web Technologies" course .............................6 60

Table 3-3: Questions and Related Factors of Attitude Questionnaire....................... 67

Table 3-4: Students' Perseption Realiablity Statistics ............................................ 69

Table 3-5: Perceived Effects on Students' Motivation towards Educational Activities

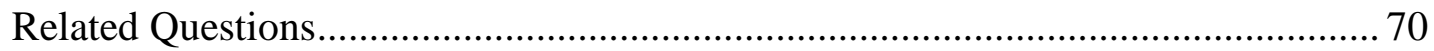

Table 3-6: Perceived Usefulness Questions and related TAM Factors..................... 71

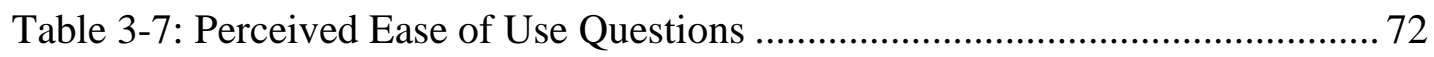

Table 3-8: Sections and Number of Questions in Perception Questionnaire ............ 73

Table 3-9: Data Collection Instruments and Procedure Indicating Related Research

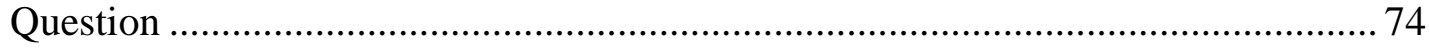

Table 4-1 : Summary of the Findings and Proposed Solution's ............................ 112

Table 4-2 Descriptive Results (Gender)............................................................. 116

Table 4-3 Descriptive Results (Internet Connection)........................................... 116

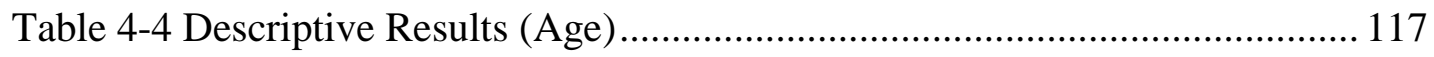

Table 4-5 Descriptive Results (High School Graduation) ..................................... 117

Table 4-6 Descriptive Results (Monthly Income) .................................................. 118

Table 4-7 Descriptive Results (Computer Experience) …..................................... 118

Table 4-8 Descriptive Results (Computer Access At Home) ................................. 119

Table 4-9 Descriptive Results (Daily Computer Usage)......................................... 119

Table 4-10 Descriptive Results (Household Internet)........................................... 120 
Table 4-11 Descriptive Results (Daily Internet Usage). 120

Table 4-12 Descriptive Statistics of Attitude Constructs

Table 4-13 Statistics about Effectiveness of WBI ..................................................... 123

Table 4-14 Statistics about Resistance to WBI .................................................... 127

Table 4-15 Mean Scores of Attitudes towards WBI with Respect to Gender ........ 128

Table 4-16 Post-hoc Results, Mean and Standard Deviation Scores for Effectiveness of WBI

Table 4-17 Post-hoc Results, Mean and Standard Deviation Scores for Students' Overall Attitude towards WBI

Table 4-18 Post-hoc Results, Mean and Standard Deviation Scores for Effectiveness of WBI

Table 4-19 Post-hoc Results, Mean and Standard Deviation Scores for Students'

Overall Attitude towards WBI

Table 4-20 T-test Results for Household Internet Belonging on Students' View on Effectiveness of WBI

Table 4-21 T-test Results for Household Internet Belonging on Students' Overall Attitude towards WBI

Table 4-22 Statistics of Students' Self-Reported Computer Competencies ............. 136

Table 4-23 Statistics of Students' Self-Reported E-Learning Background.............. 137

Table 4-24 Descriptive Statistics of Perception Constructs .................................. 138

Table 4-25 Mean Scores, and Standard Deviations of Sub-factors of Perceived Effects of Motivation.

Table 4-26 Frequencies, Mean Scores, and Standard Deviations for "Interest \& Enjoyment" 140

Table 4-27 Frequencies, Mean Scores, and Standard Deviations for "Perceived Competence" 141

Table 4-28 Frequencies, Mean Scores, and Standard Deviations for "Willingness" 142

Table 4-29 Frequencies, Mean Scores, and Standard Deviations for "Participation" 143

Table 4-30 Mean Scores and Standard Deviation of Sub-factors of Perceived Usefulness 
Table 4-31 Frequencies, Mean Scores, and Standard Deviations for "Work More Quickly"

Table 4-32 Frequencies, Mean Scores, and Standard Deviations for "Job Performance"

Table 4-33 Frequencies, Mean Score, and Standard Deviation for "Productivity" 147

Table 4-34 Frequencies, Mean Score, and Standard Deviation for "Effectiveness"

Table 4-35 Frequencies, Mean Score, and Standard Deviation for "Makes Job Easier" 148

Table 4-36 Frequencies, Mean Score, and Standard Deviation for "Useful" 149

Table 4-37 Mean Scores and Standard Deviation of Sub-factors of Perceived Ease of Use.

Table 4-38 Frequencies, Mean Score, and Standard Deviation for "Easy to Learn"

Table 4-39 Frequencies, Mean Score, and Standard Deviation for "Easy to Use". 151

Table 4-40 Frequencies, Mean Score, and Standard Deviation for "Easy to Become Skillful"

Table 4-41 Frequencies, Mean Score, and Standard Deviation for "Clear \&

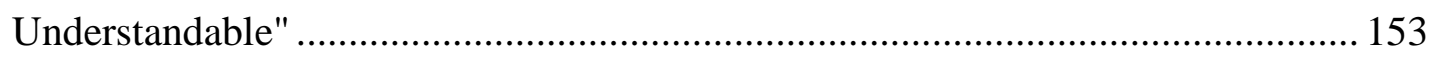

Table 7-1: Sequence of the content for the new design ....................................... 259

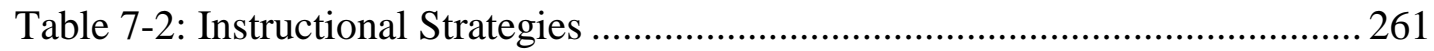

Table 7-3: Instructional strategies that were used in the course...................280

Table 7-4: Course Content..................................................281 


\section{LIST OF FIGURES}

\section{FIGURES}

Figure 2-1: The Technology Acceptance Model (TAM) ......................................... 35

Figure 2-2 : Extended Version of Technology Acceptance Model............................ 38

Figure 2-3: Components of the instructional design plan ...................................... 41

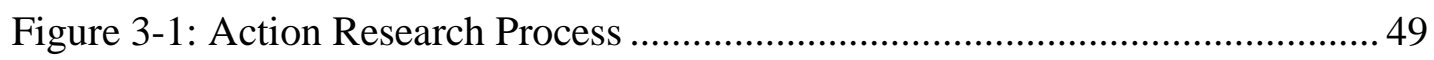

Figure 3-2: Proactive Action Research Cycle...................................................... 51

Figure 3-3: Research Process Parallel with the Proactive Action Research Cycle... 53

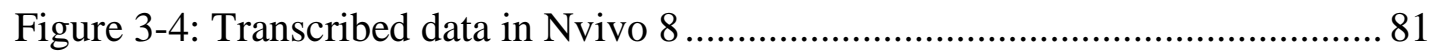

Figure 3-5: Statement-by-statement analysis in open coding with Nvivo 8 ............. 82

Figure 4-1 (a) : View of the Computer Laboratory ................................................. 109

Figure 4-2 (b): View of the Computer Laboratory................................................. 110

Figure 4-3 : Proposed Solution to Minimize Existing Problems ............................ 114

Figure 4-4 : Tentative Accomplishments of the Study ........................................... 155

Figure 4-5: Sample Visual Material in the Course Web Site .................................. 158

Figure 5-1: Framework for the $21^{\text {st }}$ century learning. ........................................... 186

Figure 7-1: Existing structure of the computer laboratory .................................... 254

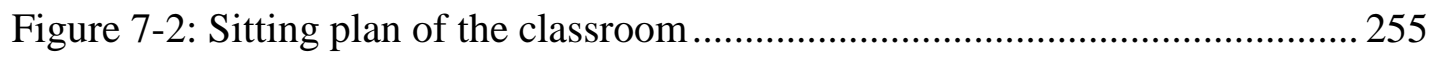

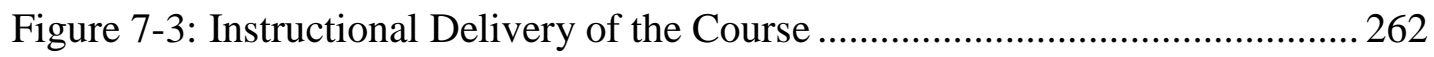

Figure 7-4: Components of Microsoft Learning Gateway ..................................... 264

Figure 7-5: A screenshot from ITL Learning Gateway's Welcome Screen............ 265

Figure 7-6: A screenshot from ITL Learning Gateway's Lecture Notes Section.... 266

Figure 7-7: A screenshot from ITL Learning Gateway's Homework Upload Section 266

Figure 7-8: A screenshot from ITL Learning Gateway's Previous Courses Section

Figure 7-9: A screenshot from ITL Learning Gateway's Sample Video Support

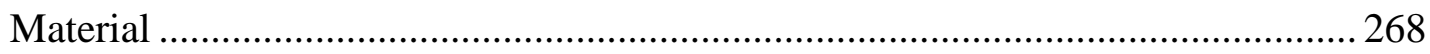


Figure 7-10: A screenshot from discussion board in ITL Learning Gateway ........ 269

Figure 7-11: A screenshot from synchronous CMC tool in ITL Learning Gateway 270

Figure 7-12: Aethra Video Conferencing Device .................................................. 271

Figure 7-13: Aethra Video Conferencing Device Connection Diagram................. 272

Figure 7-14: Physical Structure of the Smart Class in Vocational Higher Education

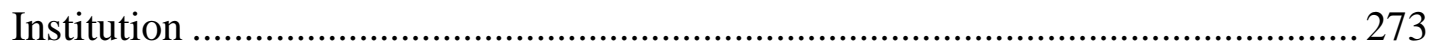

Figure 7-15: Preview from the video conferencing session of the course .............. 274

Figure 7-16: Instructor view in the smart class ............................................... 275 


\section{LIST OF ABBREVIARATION}

CMS: $\quad$ Content Management System

LMS: $\quad$ Learning Management System

ITL: $\quad$ Instructional Technology Laboratory

ICT: $\quad$ Information and Communication Technologies

IT: $\quad$ Instructional Technology

MEB: $\quad$ Ministry of National Education

METU: $\quad$ Middle East Technical University

OECD: $\quad$ Organization for Economic Co-operation and Development

ID: $\quad$ Instructional Design

WBI: $\quad$ Web Based Instruction

UNESCO: United Nations, Educational, Scientific and Cultural Organization

YÖK: $\quad$ The Council of Higher Education

F2F: $\quad$ Face to Face

DE: $\quad$ Distance Education

VE: $\quad$ Vocational Education

TVET Technical and Vocational Education and Training

CMC Computer Mediated Communication

ISTE International Society for Technology in Education 


\section{CHAPTER 1}

\section{INTRODUCTION}

"The real voyage of discovery consists not in seeking new landscapes, but in having new eyes" Marcel Proust

\subsection{Introduction}

This sections starts with the background information of the problems in vocational education compatible with the action research process. In action research, the aim is to define and determine the existing problem and solve it with the researcher's action plan. After this background information, purpose of the study, significance of the study, and research questions will be presented in this section of the document. At the end, definitions of the terms that were used in this study can be seen.

\subsection{Background of the Problem}

There is a great shift from the industrial economy to knowledge economy in the industrial age. Developed countries earn most of their income from "knowledge intense products" such as computer and communication technologies (Laudon \& Laudon, 2000). This technology based global economy changes the needs of the "worldwide labor market" (Gürüz, 2003). The emergence of new and advanced technologies has led to different field specific jobs that require more knowledgeable people in their field than ever before. Therefore, Technical and Vocational Education and Training (TVET) has turned out to have a key role in knowledge economy to produce knowledge intense products, because today in many corporations, there is a lack of qualified staff who are knowledgeable on their job. This situation highlights the importance of vocational education for the labor market. In the economic 
perspective, each period has its own symbol that explain the characteristic of it (see Table 1.1). In these periods, the demands of the market changed dramatically with respect to the needs of the economic needs (Norton, 1999).

Table 1.1 The period of new economies and their symbols

\begin{tabular}{lcl}
\hline Also known as & Period & Main Symbol \\
\hline Industrial Revolution & $1787-1842$ & Cotton textiles, iron, steam power \\
The Bourgenois Kondratieff & $1842-1897$ & Railroads \\
The New-Merchantalist & $1897-1939$ & Electricity, automobile \\
Kondratieff & & \\
The Cold-war Kondratieff & $1939-1989$ & Defence, television, mainframe \\
& & computers \\
The Information Age & $1989-? ? ? ?$ & Personal computers, \\
& & telecommunications \\
\hline
\end{tabular}

Although the history of vocational education in Turkey goes back to $12^{\text {th }}$ century Ahi associations, these institutions could not be adapted to the current educational needs, approaches and opportunities as expected. Vocational education institutions have important responsibilities with respect to social and economic life of the society, but today it is somehow underestimated. The graduates of these institutions should have enough abilities, knowledge and skills for the needs of the market. That is why the modernization of vocational education to the current needs of society, market, and technology is vital. To cope with these issues special attention should be given because of its unique structure and needs. Most of the time, recipe for the general education system tried to be adapted to the vocational education, but this underestimation hindered the development of TVET. 
In Turkey, the main problem of TVET is staff and resource problems. Resources are not only related to physical infrastructure, or hardware. It is also, about how these resources can be effectively used to facilitate learning opportunities. In this regard, educational resources and approaches need revision for the requirements of the $21^{\text {st }}$ century learning skills. Market demands should be taken into consideration while developing curricula in these institutions. According to Kayır \& Kılıç (2008), $58.1 \%$ of instructors in vocational schools stated that the curriculum partially or completely insufficient. Curriculum does not respond to the realities of the market, and the graduates do not transfer their abilities and skills that they have learnt in their courses to their business life (Buğday, 2007). That is why knowledge sharing with to those institutions is vital to improve the quality of instruction in those institutions.

As stated above, the current situation of the TVET is not very optimistic. Some of the problems are related to the general problems of the Turkish higher education system, but some of them are specifically related to TVET itself and its being underestimated (Özy1lmaz, 2008; Y1lmaz et al., 2004). Staff problem of vocational higher education institutions were presented in the report of the YÖK (Higher Education Council). In that report, it was highlighted that the number of students per each academic staff in Faculty of Technical Education is 33. In contrast, in the US this number is 21, in Belgium 10, in Japan 9, and in Germany 5 (Şahin \&Fındık, 2008).

Although vocational higher education has staff problems, there is still an increasing demand for these schools. Actually, the percentage of the vocational schools in higher education (Technical Vocational School of Higher Education and Faculty of Technical Education) is more than $30 \%$ of total students in higher education (YÖK, 2004). It covers approximately one third of the students in current Turkish higher education system. Nonetheless, this number is much lower than that of the developed countries. For instance, the percentages in Taiwan (55\%), Swiss (47\%), and US (55 $\%$ ) are much higher than Turkey (YÖK, 2004; TISK, 2005). There is a great demand from the students to be a part of these schools, but still the percentage of these schools in the Turkish higher education system is much lower than that of the developed countries. 
Moreover, qualities of those vocational schools are not in the desired level. Therefore, in order to improve the quality of these schools, well-educated staff and integrating some technological support would be important for the solution of the quality issues in those institutions (Özsoy, 2004). According to the survey results of Kayır and Kılıç (2008), only $30.1 \%$ of students think that instructors have sufficient professional knowledge and skills. Teachers cannot adapt themselves to changing conditions of their field and education.

In the YÖK (2004), strategic report it was emphasized that in Turkey traditional approaches were widely used in higher education. However, in all over the world virtual or online programs have become widespread over the last decade and now enroll millions of students. For instance, the researches that Allen and Seaman conducted $(2003 ; 2004 ; 2005 ; 2006)$ revealed that in United States there is an increasing demand for online higher education and the number of schools that offer online higher education programs gradually increased from 2003 to 2006. Information and communication technologies are dominating and penetrating all areas of education, and it can also be seen in higher education with more use of the distance education especially with e-learning (Scurry, Couturier \& Newman, 2004).

However, in Turkey TVET is not significantly affected from the continuous change in the information and communication technologies (ICT). Technological improvements are continuously changing course contents, and academic research interests but that is not the case for vocational education. Today, the changes in the vocational education and technologies used in vocational institutions do not meet the changing needs of the society (Özyılmaz, 2008). In this regard, the development of online programs or distance programs in vocational education is not growing as expected in Turkey. In some departments of online vocational higher education, quotas cannot be filled as expected because of limited interest of students to these departments (ÖSYM, 2011). The reason for this current situation in this distance education programs are inadequate curricula, transferring traditional approaches to teaching online courses, poorly equipped laboratory activities, poorly designed handson exercises, and inadequate ICT environments. In order to select and implement 
appropriate instructional approaches, continuous theory development is needed in Distance Education (DE), because of ever changing communication technologies (Gunawardena \& McIsaac, 2003). For that reason, continuous researches should be repeated frequently on pedagogical challenges of DE. Adaptation of course content, teachers, and students to the changing theories and strategies is not an easy task. This requires great effort of all stakeholders of DE such as researchers, teachers, students, administrators, designers etc.

In fact, in DE courses learners should appear in the center of the design process. Therefore, designers should go beyond the traditional approaches. Adapting traditional approaches to education or just directly replicating face-to-face experiences to the online environments should be avoided. The needs of the learners should go beyond the traditional 3Rs (reading, writing, and arithmetic) knowledge. Today $3 R$ s do not meet the needs of the information age namely $21^{\text {st }}$ century learning skills. These skills are critical thinking, creativity, collaboration, cross-cultural understanding, communication, computing, career and learning self-reliance. At this point constructivism as a learning theory can increase the probability of success of these new programs. By this way, students construct their own knowledge with the help of the technologically enhanced course materials, and discussions with their peers or tutors.

That is why the modernization of vocational education to the current needs is vital, and special attention should be given because of its unique structure and needs. In order to improve the effectiveness of those educational institutions, new technological and methodological approaches should support those activities. That means, with the wise integration of information and communication technologies in the courses of vocational higher education institutions are needed to provide students with easy access to knowledge and different learning opportunities (Barlas, Y1lmaz \& Findık, 2004). In other word, a new approach to instructional design with integrating technology enhanced learning environment to meet the needs of students' and the course are important to improve the quality of instruction. New approaches, new contents, new tools, new strategies will guide new learning opportunities. 


\subsection{Purpose of the Study}

Vocational higher education has its unique structure and needs. In its unique structure, these institutions needed to be supported with additional resources. These resources are not only related to its physical structure, but they are also instructional such as course designs, contents, materials, and ways of instruction etc. Therefore, new perspective into the courses is needed to be brought. For that reason, it is important to integrate a new course design, tools, and instructional strategies to overcome their different problems. In order to achieve this, researcher tried to go beyond traditional approaches like just directly replacing face-to-face course with the online environment. All the course content, support materials, activities, course delivery methods were revised from beginning to the end in accordance with the needs. All this instructional design, development, delivery, and evaluation process will be explained in this study.

The ultimate aim of this study was to share design, delivery and evaluation experience of a distance "web design" course for the needs of a vocational higher education institution. In order to achieve the goals above, the following research interests (RI) were underlined in this study:

- RI-1: Specifying the existing problems of the F2F course

- RI-2: Designing a new distance course to mitigate existing problems of the F2F course.

- RI-3: Assessing students' attitudes towards web-based instruction to support evaluation of this new distance course.

- RI-4: Assessing students' perceptions about the learning environment that were used in this distance course with respect to usefulness, ease of use, and its effect on motivation to support evaluation of this new distance course.

- RI-5: Specifying what aspects of the new distance "web design" course works well or not. 


\subsection{Significance of the Study}

More and more graduates of vocational schools are demanded in the labor market. In the information and knowledge age, there is a growing need for technicians (blue collars) (Laudon \& Laudon, 2003). Because of this increasing demand, many new schools were established in many different universities. In the same line, European Union, Ministry of Education, and Higher Education Council emphasize the importance of TVET in their reports, but Turkish vocational education can neither satisfy the demand of the labor market, nor have the desired effect on the society. In fact, the aim of this study is not to generalize findings, since each vocational institution has different needs and problems. Nonetheless, with this study, some general problems and needs of courses might be elicited. This will guide researchers to work in this field, and draw their attention to these institutions.

In recent years, most popular departments in vocational higher education institutions are computer and electronic departments. As a result of this, many new computer and electronic departments were opened because of students' demand for these schools. In 2003-2004, semester 5880 students were accepted to the Faculty of Vocational Education, and $23 \%$ of those students were accepted to electronic-computer education departments (Özsoy, 2004). Therefore, it is not wrong to say electronic and computer education departments are the most popular departments in these schools.

This study was conducted in this department to address the problems of an existing course, and to improve course design. Many studies revealed that in vocational schools content is outdated, courses were based on rote memorization and direct instruction. This is a contradictory situation to the foundational purposes of Faculty of Technical Education. A technical teacher should know the theory as well as an engineer and should have job related hands-on skills as well as a workman (Y1lmaz et. al., 2004). However, existing structure of courses with limited or lack of up-to-date course content with insufficient hands-on exercise causes vocational education institutions to fail in foundational purposes. In this study, we specifically design a distance course to overcome these problems of the courses. This new course was supported with many activities, handouts, homework with new technological opportunities. With these new technological and methodological approaches, it is 
possible to support these hands-on activities, and provide students easy access to knowledge and different learning opportunities.

Apart from the problems of students' inability to develop their hands-on skills in those institutions, the other problem is unequal allocation of educational opportunities (Buğday, 2007). However, this study enabled us to realize that it is somehow possible to overcome these inequalities with a good instructional design. This study confirmed that it was possible for, it became possible for different universities and departments to work collaboratively. Numerous classrooms were equipped with video conferencing capabilities in various universities. Most of them are originally used as a seminar room not compatible with their real purpose. With this study, it became possible to demonstrate that some courses might be restructured and could be given online from one university to other via videoconferencing. An experienced distance instructor can share his/her knowledge with students who do not have the opportunity to reach a subject matter expert. Moreover, Attwell (2007) pointed out that there has been many studies conducted on the use of information and communication technologies in higher education, but there has been only limited work on ICT's potential impact on TVET.

It is a fact that the current situation of vocational education needs to be studied more not only owing to the unique problems, but also to those of Turkish higher education system in general. Focusing on specific course related problems could be possible with the help of instructional design support. This may resolve some of the deficiencies of vocational education, and could increase the student and staff satisfaction. In current situation, integrating relevant and necessary educational tools to support and redesign the courses may contribute to the development of vocational higher education in Turkey. In this way, the inadequacy of staff, resource, and quality is aimed to be compensated for.

With this study, new learning environment and resources were formed in response to the challenges and technical obstacles that we faced. This might be useful for practitioners, because information technologies have been becoming widespread in all fields of education with more use of the distance education especially with e- 
learning (Scurry, Couturier \& Newman, 2004). Virtual or online programs have become widespread over the last decade and now enroll millions of students all over the world including Turkey. Some universities prefer to establish e-learning programs for technical vocational school of higher education. These universities are (Uzem, 2012):

- Afyon Kocatepe,

- Anadolu,

- Ankara,

- Atılım,

- Bahçeşehir,

- Balıkesir,

- Beykent,

- Çukurova,

- Gazi,

- Hoca Ahmet Yesevi Uluslararası Türk-Kazak,

- İstanbul Aydin,

- İstanbul Bilgi,

- Kirikkale,

- Maltepe,

- Mersin,

- Sakarya,

- Süleyman Demirel,

- Trakya,

- Türkiye Lojistik Araştırmaları ve Eğitim Vakfı,

- Uşak

Now, in these internet-based technical vocational schools of higher education, tens of thousands of students are educated every year. It is clear that these institutions represent the attempt and intention to support vocational education students with the advantages of information technologies. This study aimed to provide information about every step of a distance course design process and how to set up technical infrastructure. It is obvious that in designing a course, the problems with respect to pedagogical and technological aspect of the distance course are more challenging than 
designing a F2F course. To provide continuity on these distance courses, especially in vocational education, requires ongoing development and improvement. For this reason, continuous research is being done on pedagogical, technological, social challenges of distance vocational courses. Adaptation of course content, teachers and students to the changing theories, approaches and strategies is not an easy task. This requires great effort on the part of stakeholders such as researchers, teachers, students, administrators, designers. In these type of studies, taking students' views into account on the technology used is a must, and in our study this was managed to some extent. Especially, students' perceptions and attitudes should be considered during the design and development process. As can be seen from other studies conducted in other universities or departments, student profile was diverse with respect to limited computer competency, limited internet and computer access, low social economic status. Therefore, the proposed solutions should consider these limitations.

In this study, the researcher worked cooperatively with a university in another city. The course was designed for the vocational higher education institution in that university. This faculty is not on the central campus of the university, so students in this school have problems in reaching facilities of central campus like computer center resources, library, and support services. This kind of distance course was a great opportunity for students to access another instructor in one of the best university in Turkey. Moreover, students felling of ignorance and alienation would be somehow eliminated. This will have positive effect on their future expectations and achievements, because as it was stated by Keleşoğlu \& Aksoy (2006) Faculty of Technical Education students' thought that the reason of their low achievement in their courses based on the instructor and facility problems of their schools. When the faculty is located out of the campus, there might have more problems with respect to technical, reaching facilities and the maintenance of them. The use of smartclass, ITL Learning Gateway Content Management System (CMS), and CMC (Computer Mediated Communication) tools were dramatically changed their ways of teaching that is completely different from traditional courses, and would be beneficial for their future expectations and vision to teaching and learning. This system weredevelopped gradually from 1999 to today, and were used in many studies to assess its effectiveness 
from different aspects (Özden, 2002; Koç, Yıldırım, and Özden, 2006; Işık, Aşkun, and Özden, 2010).

In this regard, this project does not comprise of directly changing a F2F course to a distance course. The changing needs of these institutions, students and course was taken into consideration in a holistic manner. With this project, the aim is to design, implement, and enhance a new distance course by considering the limited resources of this vocational institution. Another claim of this study, owing to the needs of such courses a new technology enhanced learning environment were planned to be integrated during the research project within the collective work with students and the instructor. In this process students' attitude, perceptions and wishes give us the path to the design of a new web design course. In-depth analysis of students' experiences of the course enables us to see the current situation of the course. Thus, this study might be significant for instructors or researchers in vocational schools who wants to design a distance course.

\subsection{Research Questions}

Research questions are categorized as the continuum of the research process with analysis, design, implementation and evaluation. In this research process, researcher tries to find answers to the following questions.

\section{Analysis}

- What are the problems that students and the instructor faced in an existing F2F course?

\section{Design}

- What are the design characteristics of new distance "Web Design" course to mitigate problems identified for the existing F2F course?

\section{Implementation}

- What are students attitude towards web based instruction that they use in new distance "Web Design" course?

- What are the students' perceptions about the learning environment that were used in new distance "Web Design" course? 
○ How do the students perceive their motivation to the learning environment in distance "Web Design" course?

- How do the students perceive the usefulness of the learning environment in distance "Web Design" course?

○ How do the students perceive the ease of use of the learning environment in distance "Web Design" course?

\section{Evaluation}

- What are the accomplishments of the new distance "Web Design" course?

- What aspects of the new distance "Web Design" course need to be improved or changed?

\subsection{Definitions of Terms}

Vocational Education: Training and educating students to give especially technical skills to bring skills of a specific occupation or vocation.

Technical and Vocational Education and Training: This is a brooder term than vocational education and covers life-long-learning in vocational education from staff training to software certificate programs.

Faculty of Technical Education: The mission of these higher educational institutions is to prepare technical teachers for employment in vocational high schools, in industry, and government. Those faculties offer four-year higher education degree for technical teachers to equipped with not only theoretical and scientific knowledge in their field, but also skilled in hands-on laboratory components and practical work.

Instructional Design: A process provides a framework for thoroughly planning, developing, adapting instruction and evaluating, based on learner needs and content requirements.

Distance Education: It is an umbrella term that covers learning environments that students' and teachers' cannot meet face-to-face. 
E-Learning: Learning that is facilitated with information and communications technology. E-learning covers different level of technology use in education from blended learning to full online courses

Smart Class: A classroom is integrated with information and communication technologies to deliver and receive educational content.

Computer Mediated Communication $(C M C)$ : Communication that occur between users via text messaging or video messaging with information and communication technologies like computers, Smartphone etc.

Faculty Members: Faculty members are stakeholder group whose main responsibilities are research, teaching, learning support and service in higher educational institutions.

Face-to-face Instruction: It is a traditional instructional strategy where the teacher and students come together in a specific location for the aim of instruction.

Web-based Instruction: It is an information technology facilitated instructional strategy, which uses web-based tools, like Learning Management System, World Wide Web pages, emails, chat and forums.

Content Management System (CMS): A web site to publish, edit, modify an existing content to the users and provide more collaborative environment to the users.

Microsoft SharePoint: It is a web-based tool that provides content management system capabilities to facilitate collaboration among users. 


\section{CHAPTER 2}

\section{REVIEW OF THE LITERATURE}

"The best way to predict the future is to invent it"

Alan Kay

\subsection{Introduction}

Today technology integration to the educational settings is still an important concern for educators. With the advent of every new technology, educators try to integrate it. Although there have been many technological advances and they have been widely applied in educational settings, only a few of them can be effectively integrated into education according to their initial purposes (Surry \& Ely, 2001). One of these new trends is technologically enhanced distance education (DE). The popularity of distance education applications both in educational institutions and in the corporate sector has been increasing. That is the reason why, top 500 companies spend annually 40 billion dollars to the DE programs in the corporate sector (Gunawardena \& McIsaac, 2003). However, the turnover of these investments has not met the expectations. One of these underlying reasons is supposition that media is the only tool to enhance learning opportunities. In fact, media does not directly influence learning. According to Clark (1994), media are just vehicles, but the method is the catalyst that influences learning. Therefore, it is obvious that, just using e-learning applications or technologically enhanced learning environments are not perfect delivery method, so they seem to be enhanced with some methodological improvements. In this section, both technologic and method aspect of DE will be explained in detail. 


\subsection{Educational Technology (ET)}

Information processing is increasing with new technologies. According to a report of the UC Berkeley School of Information Management and Systems (2003) people generate an estimated 5.6 Exabyte of information each year. It can be argued that the level of information overload is higher than any time of human history, therefore how can humankind handle and improve this amount of information is at the hearth of questions (Chadwick, 2002). The answer is that humanity uses several media, theories and techniques for learning, but technology is a great stimulator according to Peck \& Dorricott (1994). They stated that "Technology can stimulate children capacities, revolutionize their ways of thinking and working and give them new access to the world..." (p.12).

Although there is a continuing debate on the effect of technological advances, many people thought that these new technological improvements would provide solutions to many educational problems. Computers, WWW and other technological resources have been improved their capabilities and user-friendliness for educators. Some of the most innovative and promising practices in education today involve technology, and possible use of these technologies is a precursor of greater benefits for teachers (Roblyer \& Edwards, 2000).

In the early studies of educational technologies, tools are used for the direct transmission of knowledge, and many research revealed that traditional lecturing method is much more effective than the use of new technologies in this way. That is why we have to integrate new technology with adequate pedagogical and instructional models. Each new medium has thought to be as the answer for solving educational problems. Usually only a few years after its emergence, they gradually lost their popularity (Chadwick, 2002). The most common example to this situation is televised education. In 1950s, with the funding of the Ford Foundation, Instructional Television increased its popularity, but later it was not adapted to students' needs (Reiser, 2002). Many field experts foreseen that, Internet will have the same inevitable future. For instance, Molenda \& Sullivan (2003) consider Internet as a "bursting bubble", and many research findings presented the ineffectiveness of Internet. That is the reason why theoretical support with social aspect of learning should not be underestimated 
in educational technologies. Different from early attempts to integrate technology, today what the theoretical base of this integration should be is also discussed in educational technology.

\subsubsection{ET Use in Higher Education}

As a popular technology that tried to be integrated to higher education is computer and information technologies, which is defined by Cuban, Kirkpatrick and Peck (2001) as "oversold and underused". Same thought was emphasized by Molenda and Sullivan (2003) stating that technology investment in education "hit the plateau". Although there are proponents of this view, Allen and Seaman's (2006) study manifested that online enrollment to online courses increase from 1,2 million to 3,2 million, from 2002 to 2005 in US. Another study of Allen and Seaman (2006) revealed that $72 \%$ of people believed that online education provides opportunity to access higher education that otherwise cannot be able to attend higher education. Therefore, it can be argued that people still have several expectations from technology even some aspects of it fails sometimes.

Higher education is significantly affected from the information and communication technologies. Scientific and technological developments are continuously changing course contents, and academic research interests of the higher education. However, integrating ET needs to be made with careful planning. Planning should begin with the awareness and readiness of users of technology and the view of all stakeholders should be considered. Instructors' and students' attitudes and motivations towards these technologies and their use play critical role to diffuse these technologies into educational settings. Understanding their attitudes and the reasons of avoidance provide us to present solutions. For that reason opinions and expectations of these active users of educational technology is very important. Effective technology integration can be occured, if the technology is indeed available, if people are aware of it, and if people are motivated (Perkins, 1985). For instance, in a study chief academic officers that participate to the survey of Allen and Seaman (2006) expressed that, faculty have yet to accept the value of online instruction. On the other hand, in the Turkey case results of another study showed most of university students wanted 
blended environments, and then classroom learning (Baran, Kılıç, Bakar, and Çağıltay, 2005).

\subsubsection{Instructors' ET Use}

When we looked at educational technology use in higher education, we should consider the perspective of students and instructors. In the Table 2-1, barriers to adoption of online learning will be presented.

Table 2-1: Barriers to widespread adoption of online learning (Allen \& Seaman, 2006)

\begin{tabular}{|c|c|c|c|c|c|}
\hline & $\begin{array}{c}\text { Doctoral } \\
\text { or } \\
\text { Research }\end{array}$ & Masters & Baccalaureate & Associates & Specialized \\
\hline $\begin{array}{l}\text { Students need more } \\
\text { discipline to } \\
\text { succeed in online } \\
\text { courses }\end{array}$ & $38.4 \%$ & $57.7 \%$ & $52.0 \%$ & $74.0 \%$ & $55.8 \%$ \\
\hline $\begin{array}{lr}\text { Greater faculty } \\
\text { time and effort } \\
\text { required to teach } \\
\text { online }\end{array}$ & $37.8 \%$ & $34.4 \%$ & $32.8 \%$ & $27.0 \%$ & $37.1 \%$ \\
\hline $\begin{array}{l}\text { Lack of acceptance } \\
\text { of } \\
\text { instruction } \\
\text { faculty }\end{array}$ & $31.1 \%$ & $33.3 \%$ & $42.7 \%$ & $17.5 \%$ & $29.3 \%$ \\
\hline $\begin{array}{l}\text { Online education } \\
\text { costs more to } \\
\text { develop and deliver }\end{array}$ & $22.3 \%$ & $22.7 \%$ & $21.4 \%$ & $27.7 \%$ & $16.7 \%$ \\
\hline $\begin{array}{l}\text { Lack of acceptance } \\
\text { of online degrees } \\
\text { by potential } \\
\text { employers }\end{array}$ & $10.2 \%$ & $11.5 \%$ & $22.5 \%$ & $7.9 \%$ & $25.0 \%$ \\
\hline $\begin{array}{l}\text { Lack of student } \\
\text { demand for online } \\
\text { courses and degrees }\end{array}$ & $1.7 \%$ & $1.5 \%$ & $5.9 \%$ & $2.3 \%$ & $12.3 \%$ \\
\hline
\end{tabular}


Chief academic officers that participate to survey of Allen and Seaman (2006) express that, online courses demands more time and effort than face-to-face (F2F) courses and students need more discipline to succeed in online courses. Moreover, in a comparison study that was conducted by Shi and Bichelmeyer (2007), they found 6 main effects on computer use and teachers' experiences with school environment. These are:

- Accessibility of computers

- Availability of technical support

- Perceptions regarding usefulness of computers

- Appropriate programs for teachers' use

- Factors' facilitating teachers use of computers

- Factors inhibiting teachers' use of computer

According to the same study, most of the teachers are not clearly stated that one-day computers will be useful tools for education. Nonetheless, it is still generally used for administrative tasks (Shi \& Bichelmeyer, 2007). Although there has been this kind of demotivating researches about educational technology use, another aspect of educational technology online education is becoming widespread gradually with the technological capabilities and the needs of schools and students. According to Allen and Seaman (2006), the proportion of teachers' who view online education superior to F2F increased $40 \%$ from 2002 to 2005 . Although the current situation represents the increasing use of technology, in the higher education councils strategic report it was emphasized that in Turkey still traditional approaches were widely used in higher education. Because most teachers tend to teach as they were taught, but today the roles and responsibilities for instructors are different.

\subsubsection{Students' ET Use}

Successful technology integration to the educational environment needs planning and planning should begin with gathering information about the views and needs of the potential users. For technology integration to higher education, we should consider the perspectives of students.

Faculty responses revealed that most students would have trouble in adaptation to elearning. $37 \%$ stated students would have little or no trouble; $32 \%$ said that most students would have some, but not a lot of trouble; and $31 \%$ said that most students 
could have a lot of trouble with the substitution (Zemsky \& Massy, 2004). As it can clearly be seen in this research results, students have problems to adapt themselves to electronic learning resources. For that reason, student support is necessary for effective implementation of technology enhanced learning. Different technologies should be used as a support tool, because students are independent but not lonely during learning process. Students construct their knowledge with the help of the content, experiment sets, interaction between peers and tutors etc (Hawkridge, 2002).

Moreover, students' attitudes towards these technologies, their reasons to avoid and their reasons to use them provide us information to finding solutions to this resistance. As it was cited Surry \& Land (2000), Perkins stated that effective technology integration could be provided if the technology is indeed available, if people are aware of it and if people are motivated.

Currently students prefer to use new technologies for education, while instructors tend to use traditional technologies in their courses. Online courses are limited with representing online resources and assignments so underlying reason of students' less preference for online must courses might be the quality issues. For example, metaanalysis of comparisons of traditional and distance education experiences of students showed that students have similar success rates and they prefer distance education because of poor quality of face-to-face education (Allen, Bourhis, Burrel, Mabry, 2002). Students expect fast feedback, fast answers about course context, and effective guidance of facilitator, broad content, more social interaction and communication opportunities (Y1ldiz et al., 2007). Therefore, universities should improve the quality of online courses by considering students' expectations.

\subsection{Distance Education}

Distance education is a quite old approach in education with a history over a century starting from correspondence studies. This type of education followed technological evolution closely, and tightly connected with the technological improvements to support delivery of educational materials and communication opportunities. 
Table 2-2: A developmental history of distance education (Passerini \& Granger, 2000)

\begin{tabular}{|c|c|c|c|}
\hline Generation & Time & Features & Technologies \\
\hline First & $\begin{array}{l}\text { End of } 19^{\text {th }} \\
\text { century } \\
\text { beginning of } 20^{\text {th }} \\
\text { century }\end{array}$ & $\begin{array}{l}\text { Correspondence } \\
\text { Learning }\end{array}$ & $\begin{array}{l}\text { Printed materials, } \\
\text { customized } \\
\text { textbooks }\end{array}$ \\
\hline Second & Early 1970s & $\begin{array}{l}\text { Teleconference } \\
\text { (Radio \& Audio) }\end{array}$ & $\begin{array}{l}\text { Correspondence, } \\
\text { radio, television, } \\
\text { audio-tapes, } \\
\text { telephone }\end{array}$ \\
\hline Third & Early 1980s & $\begin{array}{l}\text { One-way video, } \\
\text { two-way audio } \\
\text { communication, } \\
\text { real time } \\
\text { interaction, two- } \\
\text { way } \\
\text { videoconference }\end{array}$ & $\begin{array}{l}\text { Communication } \\
\text { networks } \\
\text { (satellites), audio, } \\
\text { video, CD-ROMs, } \\
\text { bulletin boards }\end{array}$ \\
\hline Fourth & 1996- & $\begin{array}{l}\text { Interaction and } \\
\text { collaboration, shift } \\
\text { from instructor-led } \\
\text { to learner centered } \\
\text { approach, student- } \\
\text { student interaction }\end{array}$ & $\begin{array}{l}\text { Telecommunication, } \\
\text { Internet }\end{array}$ \\
\hline
\end{tabular}

As it can be seen from the Table 2-2, DE is technology driven and its features shaped by the technology used, but in earlier studies about DE pedagogical aspect were underestimated. In recent studies interaction, collaboration and learner-centered approaches tried to be integrated to DE. Nonetheless, even now technology drives the pedagogic principles that are exploited in DE systems. In modern sense, according to UNESCO (2002) DE defined as an:

"educational process in which all or most of the teaching is conducted by someone removed in space and/or time from the learner, with the effect that all or most of the communication between teachers and 
learners is through an artificial medium, either electronic or print" $(p$.

22).

With this definition of DE, now education is eligible for everyone, wherever they live, how old he/she is, whatever they are dealing with. With the emergence of "life-long learning", the popularity of distance education (DE) has been increased. Therefore, many universities and commercial institution open DE programs to meet these needs. However, this commercialization increases the challenges in front of DE. In order to adapt DE to the changing and challenging needs of the world, field experts should look the field more critically and in a wider perspective. In my point of view, there are two critical challenges for the development of distance education. These are pedagogical challenges and institutional challenges.

\subsubsection{Pedagogical Challenges}

As an interdisciplinary field, DE experts should overcome many challenges, and one of them is pedagogical issues. With respect to pedagogical perspective, Open University is a well-designed, structured example of DE with over 200.000 students all over the world (Hawkridge, 2002). It is important to mention that thirty years ago, in the foundation of Open University, Europe's largest group of instructional designers and technologists were employed in order to create well-designed courses (Hawkridge, 2002). This shows us the importance of selecting and implementing appropriate instructional strategies during design. In this design process, Open University instructional designers and technologists prefer to implement different instructional theories different approaches. Generally, in Open University, students construct their own knowledge with the help of the course materials, and discussions with their peers or tutors (Hawkridge, 2002). In order to select and implement appropriate instructional strategies continues theory development is needed in DE, because of developing communication technologies (Gunawardena \& McIsaac, 2003). For that reason, continuous research is being done on pedagogical challenges of DE. Adaptation of course content, teachers and students to the changing theories and strategies is not an easy task. This needs great effort of all stakeholders of DE such as researchers, teachers, students, administrators, designers etc. 
In fact, DE programs learners appear to be in the center of the design process. Therefore, designers should go beyond traditional approaches. Adapting traditional approaches to education or just directly replicating face-to-face experiences to the online environments should be avoided. At this point constructivism as a learning theory can increase the probability of success of the new programs and courses. With the help of this, students construct their own knowledge with course materials, and discussions. As it was mentioned above, Open University case is a successful implementation of DE, so some it is not wrong to borrow applied approaches in Open University case to a new DE program like applying constructivist learning theory. In order to select and implement appropriate instructional strategies, continues theory development is needed in DE, because of developing communication technologies (Gunawardena \& McIsaac, 2003). For that reason, continuous research is being done on pedagogical challenges of DE. Theories are important for distance education because theories have direct impacts on practice. Gunawardena and McIsaac (2003) mentioned about theories of autonomy and independence, and theories of interaction and communication.

Distance education theory proposed by Holmberg (1989) (the centrality and independence of learner) places learner in the center, and proposes that real learning is an individual activity and attained through internalizing process. In DE students are independent, but not lonely during learning process. Students construct their knowledge with the help of the content, experiment sets, interaction between peers and tutors etc. Furthermore, individuals' expectations and diversity among learners should be taken into consideration because learners' experiences may range widely. Therefore, constructivist-learning theory seems to be more applicable for supporting independence of learners with problem-based activities and different supportive materials to support this process. For instance, Jonassen's "learning with technology" perspective is based on constructivist view and the aim of this perspective is to use technology as a partner, not an aim. In this approach, technology and the tools are used as a vehicle for delivery of information that helps students' knowledge construction process. In that learning process teacher is not the source of information, he/she is the facilitator of the process by monitoring, bridging between the contentstudent, and increasing the interaction between student-student, student-content, 
student-teacher (Gunawardena \& McIsaac, 2003). Moore (2007) comes up with "Transactional Distance" theory, which says the term distance is not a geographical phenomenon it is a pedagogical concern. He advocates that this distance stems from lack of dialogue among the learners, instructors and course content. In that sense, interaction plays a key role to overcome this transactional distance. Interaction as a major concern in distance education, Moore (2007) emphasized this issue and categorized it into three: learner-learner interaction which also associates collaboration between learners, learner-instructor interaction which is thought to increase student motivation and lastly learner-content interaction which refers learners' intellectual process when s/he gains new perspectives or changing understanding.

How interaction can be increased is one of the major concern in DE. Group projects can enhance interaction between students and instructor. In fact, group projects are very demanding process for both learners and instructor. Students should always be in interaction with others to take project one step further, and also this process needs good project development skills. Therefore, both instructor and students have to be knowledgeable about increasing and facilitating interaction student-student, studentcontent, student-teacher.

This interaction issue can be solved by using a well-designed and structured Learning Management Systems (LMS) and related communication tools. Although many research studies reveals that these tools do not have direct additional impact on learning, absence or bad design (both instructional and visual) of these tools may cause limited interaction between distance learners.

On the contrary to the success of Open University, Anadolu University can be viewed as a bad example of mega universities, and it looks like a distance exam center, not a DE institution (Çağıltay, 2001). The main concern of this institution is not quality, only quantity (Çağıltay, 2001). In fact, there is an opposite relationship between increases in the number of students and the quality of instruction. The courses prepared by Anadolu University consist of "talking head" in the television, in order to serve to educate more and more students (Çağıltay, 2001). However, this decreases 
the quality of the university. Although Anadolu University as an open university has more than 20-year history with approximately 600.000 students, the increase in the number of students, gradually decreases the quality of the courses. In the desired system of DE, designer of the course, field expert, pedagogic expert, and other team members work together to create effective learning. Moreover, students have chance to interact with peers and tutors. However, in the case of Anadolu University same amount of employee try to overcome the responsibility of increasing number of students, and in that case the amount of time spent on each student decreases. Therefore, quality of instruction decreases. Actually, today this institute suffers from not only pedagogical issues that affect the quality of instruction, but also organizational.

\subsubsection{Institutional Challenges}

The successful integration of DE to a program requires analyzing its performance not only from learners and instructors perspective, but also from the strategic perspective and capabilities of the institution. However, there has been a few studies were conducted to emphasize the organizational issues related to DE. That is the fact that, apart from instructor and student related issues, school-related variables likely to play a role in the success of an on-line teaching activity. It is obvious that, institutions must have clear, well-planned strategies to maximize their students' learning experiences and overall satisfaction.

In the information age, information has itself has monetary value and providing related information for their staff or students is the aim of the institutions. In order to obtain and improve information, education and training viewed as a primary way to informed about a topic of interest. As it was emphasized by Meyer (2005), one of the stated goals of the Western Governers' Virtual University is expand the marketplace for instructional materials, courseware, and programs utilizing advanced technology. This represents the aim of the university administrators about the commercialization of education, especially with DE in higher education. In this profit-based structure, many more universities are increasingly turning to distance education technologies to deliver the curriculum at all levels to capture attention of more people. Also, this trend is forcing universities to examine closely how to offer distance education courses 
effectively and efficiently. In addition to that, universities should consider how institutions can serve their distance students so that they are being satisfied.

In this sense, institutional challenges were highlighted in some studies to increase student satisfaction in this competitive field. According to El-Mansour (2011), institutional challenges of DE can be categorized in six main heading. These are:

- Infrastructure and space allocation

- Faculty training

- Faculty workload

- Students' preparedness

- Academic honesty

- Copyright

That means in order to adapt distance education opportunities to an institution, their existing capabilities should be regarded as an important concern from different perspectives. In addition, Buchanan (2002) recommended that the faculty, staff, and administrators should receive formal training in distance education pedagogy and its use.

Although DE is getting popular day by day, offering a qualified DE program depends on overcoming many challenges. In order to overcome these challenges many things should be considered. It needs teamwork, time, money and eager administrator and students.

\subsection{E-Learning in Higher Education}

The impact of information and telecommunication technologies can also be seen in higher education with more use of e-learning (Scurry, Couturier \& Newman, 2004). Virtual or online programs have widespread over the last decade and now enroll millions of students all over the world. For instance, in US 33 percent of the higher education institutions have offered distance education, whereas in 199760 percent employed asynchronous Internet-based technologies (Gürüz, 2003). These findings clearly revealed that acceptance and distribution of technology in higher education institutions. Also, in Europe many institutions try to integrate technology to their existing facilities. In a special meeting of European Union (EU) determine "Lisbon 
Strategies" to compete in the global information society in March 2000 (MEB, 2005). The policy of the EU (MEB, 2005):

- Education should be redesign with learner-centered approaches.

- Using new technologies in education should be broadened.

- Individual teaching learning strategies should be highlighted.

As it was cited by Culp, Honey, and Mandinach (2005), in the report of "A Nation at Risk" five new high school graduation requirements have been recommended in 1983. These skills are English, mathematics, science, social studies, and computer science. Today it is obvious that computers are viewed as an information and communication device with the help of the internet and other digital resources. For that reason, being a technology literate is necessary for all educational level. Higher education is also significantly affected from the information and communication technologies. Scientific and technological developments are continuously changing course contents, and academic research interests of the higher education. Especially, internet causes dramatic changes in higher education. Gürüz (2003) summarize these changes from the literature:

- Distributed learning and virtual universities

- Positioning of institutions in the market

- Reshaping of teaching and pedagogy

- Restructuring of libraries

- Organizational change

- The nature of students.

Although these changes were highlighted, in universities instructors mostly use printed materials; computer and projectors in classroom and not many of them use Internet. On the other hand, instructors have limited interest on computer, Internet, and other technologic tools. This situation shows that instructors are aware of need for new technologies while they do not tend to use them frequently. While instructors use online technologies less, students mostly use online tools for their courses, and they also expect more online tools from instructors. 
Most of students think that technology provides motivation. For instance, Toral, Barrero and Torres (2007) emphasize the motivational aspect of technology integration to education. While most instructors do not tend to think in this way. This view of instructors might cause their insufficient use of new technologies. Although students have high expectations from new technologies, instructors' resistances result in limited use of new instructional technologies. In many other fields technology provide several benefits and this might provide them to grow a positive way, but in education acceptance of technology always takes time.

Students mostly emphasize web based support tools. On the contrary, instructors especially wanted to use in-class tools to support their instruction. Web tools are commonly expected to used by students, so that they may have easy access to the educational resources on the web. Although students' have high expectation to reach web-based resources, instructors tend to use of online resources less. Moreover, some instructors think that best learning could be achieved in F2F instruction and they think that they need in-class technologies to support F2F instruction more than DE tools.

That is the reason why teachers do not prefer to fully integrate online technologies to their courses. General thought about quality of online courses could never reached F2F courses. However, in recent studies that was conducted in US, approximately $62 \%$ of the academic leaders continues to believe online is as good as or better than face-to-face (Allen \& Seaman, 2006). Moreover, academic leaders stated that online education is critical to their long-term strategy. Percentage of accepting that situation has been increasing from 2003 to 2006 (see Table 2-3). 
Table 2-3: Percentage of academic leaders who stated that online education is critical to their long-term strategy from 2003 to 2006

\begin{tabular}{lcccc}
\hline & $\mathbf{2 0 0 3}$ & $\mathbf{2 0 0 4}$ & $\mathbf{2 0 0 5}$ & $\mathbf{2 0 0 6}$ \\
\hline Agree & $48.8 \%$ & $53.5 \%$ & $56.0 \%$ & $58.4 \%$ \\
\hline Neutral & $38.1 \%$ & $33.7 \%$ & $30.9 \%$ & $27.4 \%$ \\
\hline Disagree & $13.1 \%$ & $12.9 \%$ & $13.1 \%$ & $14.2 \%$ \\
\hline
\end{tabular}

In a study that is conducted in 2004 revealed that in US, a $22.9 \%$ overall increase in the number of students taking one or more online courses, growing from 1.60 to 1.98 million students and recently in 2006 this number exceeds 3 million students (Allen $\&$ Seaman, 2005 ; 2006). That numbers represent that there is an increasing interest to online education in higher education (see Table 2-4). This increasing interest reveals similar continuum with diffusion of innovation process. In fact, integration of an innovation takes some time, so many organizations tried to speed up this process.

Table 2-4: Number of students enrolled in online education in 2003 and 2004

\begin{tabular}{lc}
\hline \multicolumn{1}{c}{ Time Period } & Number of Students \\
\hline Reported for Fall 2002 & $1,602,970$ \\
\hline Predicted for Fall 2013 & $1,920,734$ \\
\hline Reported Fall 2003 & $1,971,397$ \\
\hline Predicted for Fall 2004 & $2,634,189$ \\
\hline Reported for Fall 2004 & $2,329,783$ \\
\hline
\end{tabular}


The contradiction starts with that students want online technologies while instructors believe that the classroom technologies are more important. Initially, students want to see and use those technologies and believe that this will improve the quality of education. However, teachers generally have more conservative point of view on this. In order to overcome the conservative view of teachers, decision makers should locate and improve access and use of different techniques and technologies. Interaction and collaboration between individuals contributes to fostering change and transformation of this change in the organization. Technology integration is a long-lasting process and it needs support of the both decision-makers and users. Therefore, the important thing in this process is conducting continuous researches and feedbacks from students and academic staffs should be taken into consideration, and with the help of these adaptation process might be shorten.

\subsection{Computer Mediated Communication (CMC)}

The educational needs of the students deeply changed with the light of the developing technologies. As it was cited by the National Aeronautics and Space Administration (NASA) (2006) learning technologies report, Trilling and Hood emphasis " $21^{\text {st }}$ Century, Knowledge Age Skills". In this age mastering on reading, writing, and arithmetic (3Rs) do not meet the needs of the information age. " $21^{\text {st }}$ Century, Knowledge Age skills" should be empowered with 7Cs beyond 3Rs. Seven clusters of $21^{\text {st }}$ Century skills are:

- Critical Thinking-and-Doing

- Creativity

- Collaboration

- Cross-cultural Understanding

- Communication

- Computing

- Career and Learning Self-reliance

This reveals the social and human aspect of learning. That is the reason why e-learning does not mean and have to be an isolating experience for the learner. In fact, an effective e-learning experience should provide plenty of interactions opportunities based on the content, context, and the skills of the students and instructor of the 
instruction. The Internet and related technologies provide a range of options for this purpose through what has come to be called computer-mediated communication (CMC). CMC is a type of communication that occur between users via text messaging or video messaging with information and communication technologies like computers, smartphone etc.

CMC makes it easy to construct students' own understanding by collaborating with each other. While designing and controlling online discussion teacher have to consider some important points. It was recommended that CMC moderators be prepared to act as assistant, consultant, coordinator, facilitator, goal setter, helper, intermediary, lecturer, manager, observer, pacesetter, participant, promoter, provocateur, tutor, and so forth (Berge \& Colins, 1995). In other words, becoming proficient at communicating via computers in a structured learning environment requires practice and flexibility. At this point, the role of teacher is focusing discussion, guiding approaches adopted by the participants, using natural group dynamics to stimulate interest, promoting and supporting participation, pulling together what has been learned in the final. Related to this in order to create well-structured community Nachmias (2002) stated that teachers should;

- Moderate group's work in a way that enables student to interact

- Encourage participants to create relax and calm atmosphere

- Be attentive to participants' social needs

- Enhance atmosphere by using supportive feedback

Beaudin(1999) identifies various techniques recommended and used by online instructors for keeping online learners on topic.

- Carefully design questions that specifically elicit on-topic discussion

- Provide guidelines to help online learners prepare on-topic responses

- Orient the responses which are going in the wrong direction

- Provide discussion summary on regular basis

Group interaction is another issue in education. It helped students to learn from their peers skills, and experiences. Computer supports complex interactions needed for productive collaboration by providing appropriate external memories and 
communication media that allow participants to interact. CMC effectively supports complex interaction with active learning and collaboration. Collaborative learning includes actively exchanging ideas within small groups not only increases interest among the participants but also promotes critical thinking. Moreover, strong interpersonal ties shared by community members increase the flow of information among all members, the availability of support, commitment to group goals, cooperation among group members, and satisfaction with group efforts (Romiszowski \& Mason, 2005).

Using asynchronous and synchronous $\mathrm{CMC}$ at the same time will improve its effectiveness, because both of these techniques have its own advantages and disadvantages. In an asynchronous communication, learners read a response and decide whether or not to respond, how to respond, and the likely consequences of such a response. Time to think increases the reflection of students' own ideas. Asynchronous communication also focuses on activity and decreases the off-task comments compared with F2F discussion. Apart from asynchronous communication, when synchronous communication is used it may minimize the limitations of asynchronous communication. Synchronous communication usually occurs F2F, with two or more people communicating with each other at the same time and typically, not necessarily in the same place.

Social interaction is recognized as increasingly critical in the e-learning process. Meaningful learning is less focused on transmission of knowledge and more committed to discussion and discourse. Internet can provide students with the ability to develop their social, reading, writing, and communication skills through participating in online discussions (Romiszowski \& Mason, 2005). From knowledge transformation aspects, it is possible for students to externalizes and internalize their knowledge through writing and reading. Collaboration, communication, and interaction turn to be key terms in learning. As it was cited by Romiszowski and Mason (2005), some research results show some gains of CMC:

- more satisfied with the web course

- ability to study at one's own convenience

- opportunity to gain experience about internet 
- faster assignment return, more immediate feedback

- increased interaction with tutor and students

- extending learning experience beyond tutorials

\subsection{Smart Classroom}

The changes in the field of educational technology caused fundamental changes in the way of instruction. Education is always considered in relation to technology since the beginning of correspondence studies, to the development of televised education. Today with the development in information and communication technologies, we have gained the opportunity to use digital age technologies. In recent years, the use of smart classes have become widespread all over Turkey with the support of YÖK, which look for collaboration between higher educational institutions. As it was defined in the Middle East Technical University (METU) computer center website (2010)

\section{The Smart Class is a system designed to bring the teacher and students at different physical locations together in an interactive environment, using videoconferencing and live broadcasting techniques.}

Some people do not prefer to use the term "smart' for those classes and a new term emerged in the field. Nowadays many people call those classrooms as a technology enhanced classroom. Those classes integrate learning technologies with video conferencing possibilities to foster teaching and learning activities. Those classes can be used for distance courses with its video conferencing capabilities or it can be used in order to improve the quality of face-to-face teaching learning activities.

The term classference is also used to integrate video conferencing possibility of smart classrooms with teaching learning activities. There are some research studies in which the term is used to explain the technologically enhanced classrooms. Classference is defined as classroom with two-way video conferencing devices, smartboard, document camera, PowerPoint presenter PC to communicate with two different locations (Öz, 2005). Some other equipment's can be added to those systems to create 
more realistic communication between students and teachers who are far from each other.

In my opinion, smart classroom is a classroom that is integrated with information and communication technologies to deliver and receive educational content. Those technologies may differ with respect to the budget to be spent on those classrooms. A smartboard, sound system, recording system, computer structure highly related to the budget of the smart classrooms structure. For that reason, it is important to design a smart class for the needs of the students and teachers. In fact, those classrooms should be supplemented with technologies to fill the gap between distance education and face-to-face education. With those classrooms, it is possible to create increased interaction that is similar to face-to-face classrooms.

Apart from that, it gives valuable opportunities for instructors to enhance their faceto-face education with its technological capabilities. In fact, a study that presents the main use of smart classrooms reveals that projection, projection remote controller and internet connection are the mostly used technologies in smart classroom (Zhao, 2006). Moreover, the same study reveals that $78 \%$ of the respondents believe that teaching with smart classroom technologies was better than teaching in traditional classroom environment. Therefore, the use of smart classroom technologies is not only effective for distance education with due to video conferencing capabilities, but it is also effective for improving the quality of face-to-face instruction.

As it was stated by McKamey (2008), students and faculty perceived that there is high level of satisfaction and high level of instructional effectiveness to the smart classrooms. Similarly, in a study that was conducted in Turkey students' view smart classrooms as effective learning environment (Sevindik \& Gürol, 2009). In a similar study that was conducted among nursing students in Turkey, lectures given through smart classroom significantly increase the students' achievement with respect to control group (Sevindik, 2009). 
There are some problems in integration of smart classes to the educational settings. Some of them are (Guthrie \& Navarrete, 2002):

- Faculty members may not be competent

- Time would not be enough to develop and maintain content

- Highly dependent on technology

- Some instructors believe that only some courses and some subjects can be given via smart classrooms.

Although using these classrooms possibly cause unique problems in the integration process, it is important to improve the effective use of those classrooms in both faceto-face and distance learning environments. The effective use of these classrooms is very important for our country to be able to transfer intellectual accumulation available in one city or university to other cities or universities. However, in order to provide this intellectual sharing, more studies should be done to achieve successful integration of those technologies, because it is still new and unknown for many instructors and students, as well as researchers.

\subsection{Technology Acceptance Model}

Technology extensively used in every part of life like education. Now, technology is not only in the classroom. Especially with the development in the information and communication technologies, it diffused in every part of life. However, to which extend those technologies were accepted by the students and instructors is an important concerns for a long time. As it was cited by Davis, Bangozzi, and Warshaw (1989), Swanson stated that the underlying reason about the technology acceptance had been one of the most challenging problems in the information systems. This technology acceptance decision were affected some important concepts like users' beliefs, attitude, satisfaction, adaptation to change, and culture etc.

One of the most explanatory model to see why users accept or reject technology was Technology Acceptance Model (TAM). This is one of the most successful measurements for effective computer usage among practitioners and researchers. Davis introduced it in 1989. TAM describes users' technology acceptance or actual use depends on distinct constructs of "perceived ease of use" and "perceived 
usefulness" (Davis, 1993). Davis, Bagozzi, and Warshaw (1989) developed the TAM by adapting the Theory of Reasoned Action (TRA), to understand the relations to IT usage in a workplace. Since the model was developed by Davis, this model has been used in several projects from computer science, information systems, management, information science, business, and educational technology. Moreover, several modifications have been done to increase its explanatory feature of users' technology acceptance. According to Venkatesh and Bala (2008), over the last two decades, there has been substantial empirical support in favor of TAM. For instance, in some studies factors of TAM explains approximately $40 \%$ of the variance in users' intention to use a technology in some studies (Venkatesh \& Bala, 2008).

In original TAM, perceived usefulness and perceived ease of use appear as two of the most important individual beliefs about using an information technology. In the Figure 2-1, factors of the model and its relations can be seen.

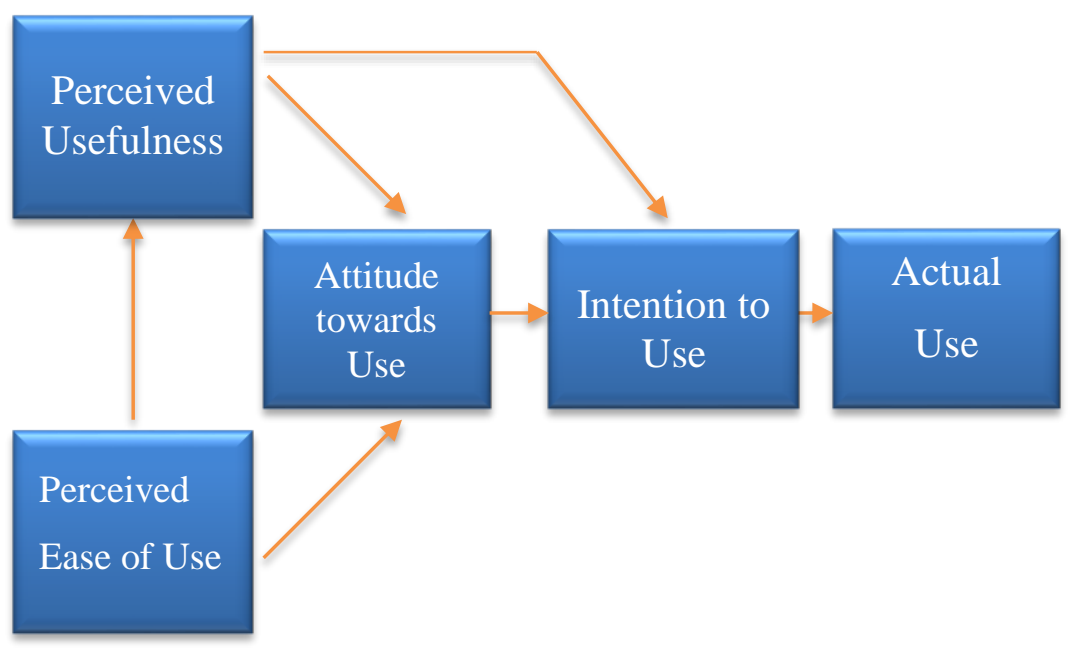

Figure 2-1: The Technology Acceptance Model (TAM)

In this model, it was proposed that perceived ease of use and perceived usefulness were good predictors of actual use of the technology. Perceived usefulness is the users 
perceptions about that using a specific application system will increase his/her job performance within an organizational context. Perceived ease of use is the degree to which the individual believes that using the system would require little or no mental and physical effort (Davis, 1993).

Perceived usefulness is the strongest predictor of an individual's intention to use an information technology. According to Sun and Zhang (2006), 71 out of 72 studies to indicate the effects of perceived usefulness had statistically significant influence on attitude, behavioral intention, or usage. Ndubisi, Gupta, and Ndubisi (2005) researched the relationship between different factors of TAM, and in this research it was discovered that perceived usefulness has a strong influence on an entrepreneur's use of a new technology system. As a major determinant of people's intentions to use technology, several sub-factors were analyzed to be informed about overall perceived usefulness. These sub-factors are:

- Work more quickly

- Job performance

- Increased productivity

- Effectiveness

- Makes job easier

- Useful

As a secondary determinant of people's technology acceptance perceived ease of use has a significant influence on perceived usefulness, behavior attitude, intention, and actual use (see Figure 2-1). Perceived ease of use analyzed with some contributive sub-factors like:

- Easy to learn

- Clear and understandable

- Easy to become skillful

- Easy to use

- Controllable

- Easy to remember

After Davis introduced TAM in 1989, it was applied in different disciplines with different purposes. Some researchers focused on the main factors of TAM, and their 
effects on technology use (Karahanna \& Straub, 1999; Koufaris, 2003), and some others work on extended version of TAM with supporting other theories (Dishaw \& Strong, 1999; Venkatesh et al., 2003; Gefen, 2004). With the emergence of modified versions of TAM with motivational, social presence, facilitating conditions, perceive computer competence etc. (Karahanna \& Straub, 1999; Venkatesh, 2000; Venkatesh \& Davis, 2000; Koufaris, 2003; Venkatesh, Speier, and Morris, 2002).

A number of meta-analyses that was conducted in different periods about the TAM, and those analysis demonstrated that this model help to understand and explain the use of information technologies. Initially, Lederer, Maupin, Sena, and Zhuang (2000) analyzed more than 15 studies to see existing relations between perceived ease of use, perceived usefulness, attitude towards use, and usage of information technologies over a 10-year period from 1989 to 1999. In Legris, Ingham and Collerette (2003) study, they were found 22 studies that were tested TAM. In addition, King and $\mathrm{He}$ (2006) analyzed 88 studies published on the TAM. The results of this meta-analysis reveal that the model can be used in a wide variety of contexts to explain the use of information technologies.

Although many research studies indicates TAM as a good way to see acceptance of technology, in some critical reviews on the original TAM it was thought to be too simple and has a limited number of factors to describe intention to use technology. Mathieson (1991) pointed out that the TAM does not provide detailed information, but general opinions about the users and the system. These criticisms suggest a need to expand the TAM in new ways, and this situation caused the use of TAM in different disciplines with some different ways. An extended version of TAM can be seen in the Figure 2-2 below. In this modified version external factors added to the original model 


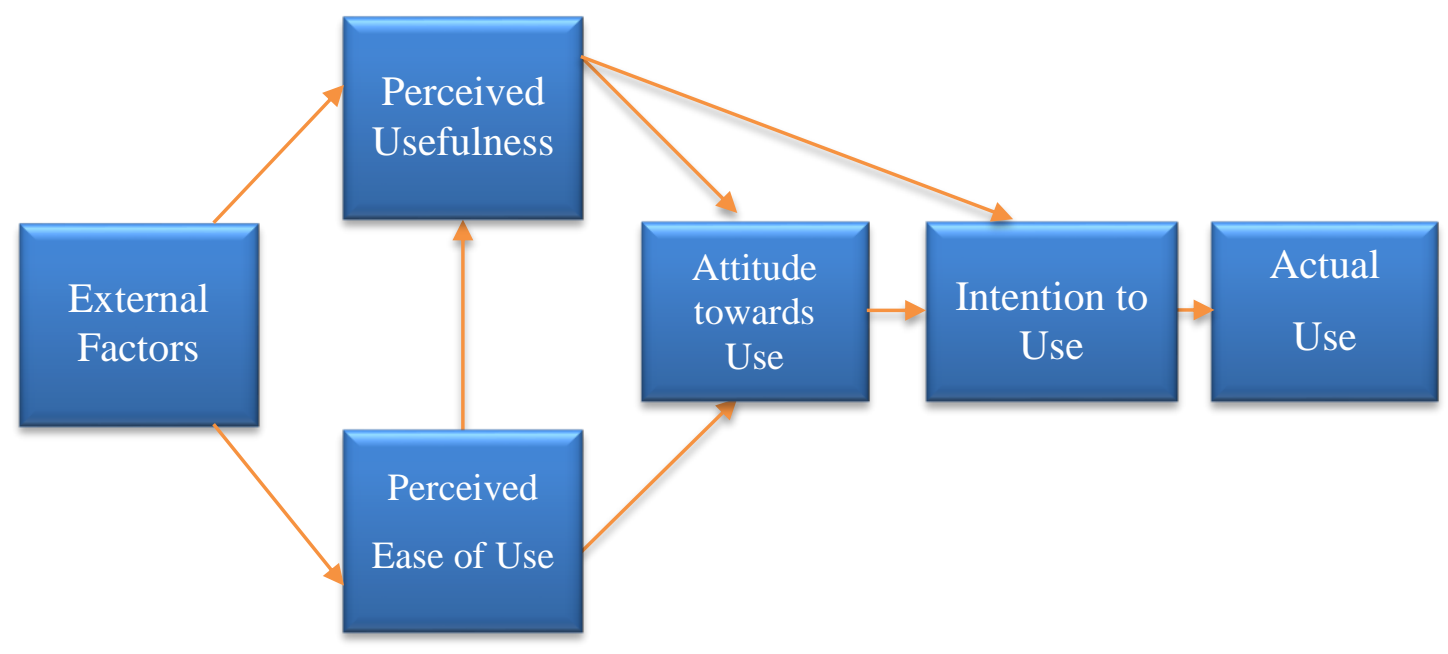

Figure 2-2 : Extended Version of Technology Acceptance Model

When we looked at the number of studies that used TAM as a framework, it was gradually increased from 2000 to now, because this kind of modifications on TAM contributes to the extended use of the model. In a literature review on citation database of "Social Sciences Citation Index (SSCI)" and "Science Citation Index (SCI)" on Web of Science determined 689 papers which topic is related of TAM from 1991 to 2009 (Chang, Chou, and Yang, 2010).

TAM is also extensively used in educational technology to see the students' acceptance of an e-learning technology, multi-media, course management system, social presence studies. (Sivo \& Pan, 2005; Smith, 2006 ; Yang, 2007). This would be helpful for instructional technologists to determine what factors contribute to the students' intention to use technology. Especially motivational factors contribute to the educational technology use as an external factor.

\subsection{Instructional Design}

ID models are conceptual representations of reality. They are simple representation of more complex processes, and functions of a phenomena or ideas (Gustafson \& Branch, 2002). Real life situations are too complex to solve, and models make easy to 
reach simplified forms of these complex situations. Today in many problem-solving strategies "KISS"(Keep It Simple Stupid) is the keyword. Simplicity is the best way to handle complex situations, and in this sense design models make the process easy, simple, and manageable. For that reason, using an Instructional Design (ID) model is a necessity. There are two main views about ID Models. In one of these views, ID models are thought as just boxes and arrows, and they have no practical value in real life instructional design, development projects. The others think that these boxes are essential and we need be more informed about those boxes.

As an evolving and changing field, people may have different ideas. During this evolution these different views contribute to the development of the field. Actually, evolution is a necessity to accommodate increasing needs for rapid development, continuous change, worldwide needs, and cost savings (Sink, 2002). In this evolving field many instructional design models tried to blend many different fields like psychology, education, communication, management, system theory, and social science, to see the whole picture of complex real life situations (Schiffman, 1995).

As a developing and evolving field, ID tries to find solution to current instructional problems. However, when doing this, different views emerged and some people thought that "ID Models have no practical value". However, instructional design models provide conceptual tools that can visualize and manage processes for creating high quality instruction (Gustafson \& Branch, 1997). There may be different view but the truth is ID models are still viable and useful in ID projects.

As it was stated above, many linear approaches in ID criticized because of its "cookbook" like flow (Schiffman, 1995). Although ID models often seem to be too rigid and linear process, it has an easily designable character with an experienced designer. Therefore, there is no need to an adventure like "never use ID Models". Actually, universities and industrial personnel who usually adhere closely to the model procedure accomplish many successful ISD implementations (McCombs, 1986). Most of the criticisms are based on poor implementation of ID model. When we think about surgeons, they do not always successfully do surgery, but we cannot say "surgery is a waste of time. We should find a new way." (Zemke \& Rossett, 2002). In 
fact, when we examine literature, more successful examples can be seen than failures of ID.

The instructional design process provides a framework for thoroughly planning, developing, and adapting instruction, based on learner needs and content requirements. Although this process is essential in distance education, where the instructor and students may share limited common background and typically have minimal face-to-face contact, it is also important in traditional classroom environments where new instructional technology is being used to teach.

\subsubsection{Morrison, Ross and Kemp ID Model}

As an eclectic design model, Morrison, Ross and Kemp ID model borrows ideas from many different disciplines and approaches. Apart from this eclectic structure, in this model presents a holistic approach to instructional design. According to Morrison, Ross and Kemp (2004), there is hardly any perfect approach to solving an instructional design problem so an effective instructional design model should be flexible and adaptable for accommodating demands of the job and maintaining the logic to produce an effective product. The model follows a circular flow rather than a more linear "cook book" approaches.

They define instructional design as how to plan, develop, evaluate and manage the instructional process effectively so that it will ensure instructional learning opportunity. It is closely related with the knowledge of learning theories, information technologies, systematic analysis, and management methods. Conventional instructional design approach considers instruction from the perspective of the content rather than from the perspective of the learner and context, but this model propose a different view to ID. Morrison, Ross and Kemp (2004) present the key elements of instructional design process as four fundamental components; learners or trainees, objectives, instructional strategies, and evaluation procedures, which form the framework for instructional planning. Today students expected "just in time", "just for me", and "just right content" in the "right time", "right place", and "right format" (Langenberg \& Spicer, 2001). These needs of students can be achievable with the complementary use of the educational technologies and pedagogical approaches. 
Therefore, both media and method dually important for a better instructional design process. Morrison, Ross and Kemp's (2004) ID model includes nine elements:

- Identify instructional problems and specify goals for designing an instructional program.

- Examine learner characteristics that will influence instructional decisions.

- Identify subject content; analyze task components related to stated goals and purposes.

- Specify instructional objectives

- Sequence content within each instructional unit for logical learning.

- Design instructional strategies so that each learner can master the objectives.

- Plan the instructional message and develop the instruction.

- Develop evaluation instruments to assess objectives.

- Select resources to support instruction and learning activities.

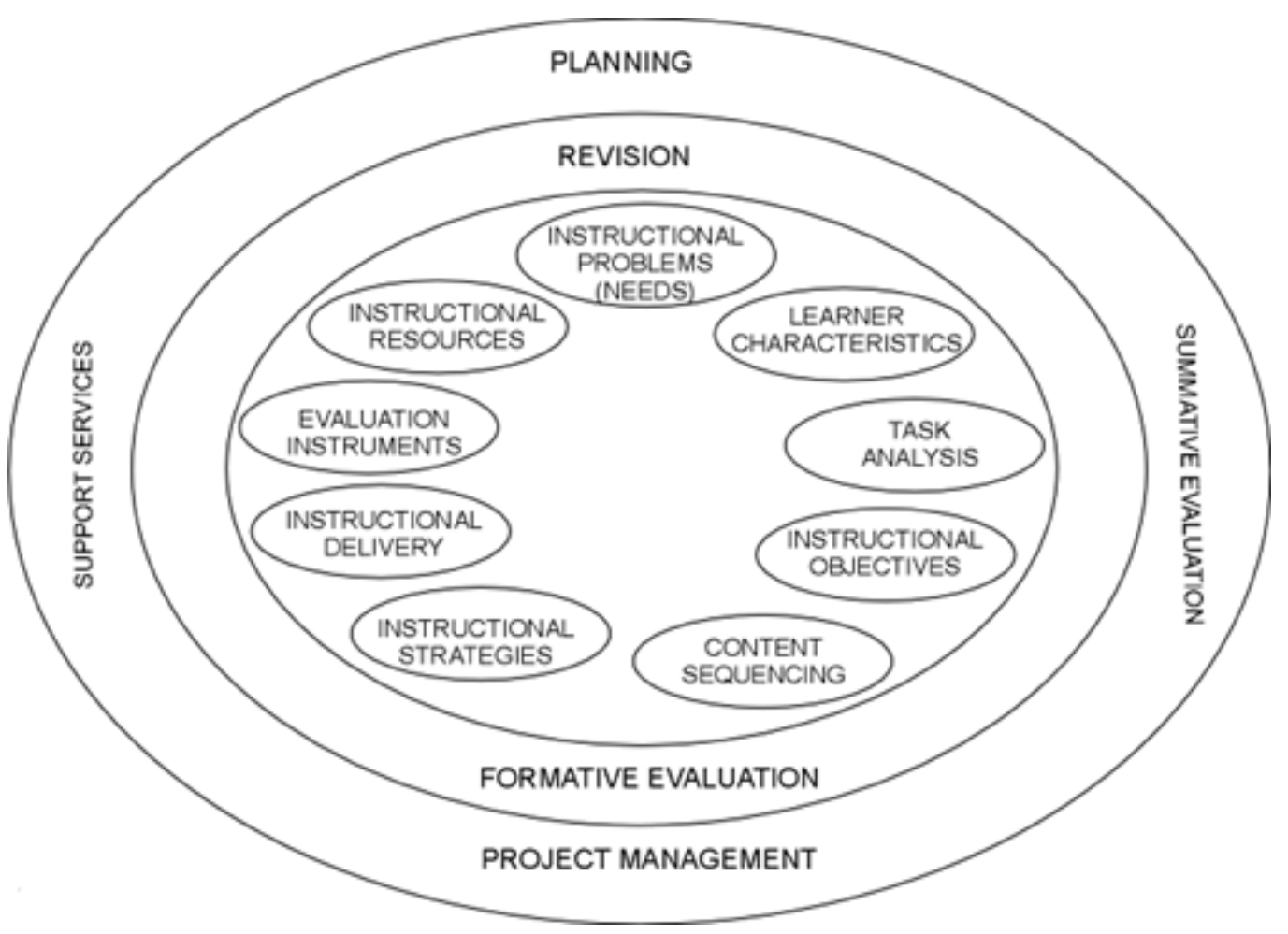

Figure 2-3: Components of the instructional design plan (Reprinted from Designing effective instruction by Morrisson, Ross and Kemp, 2004) 
Although the list of nine elements forms a logical, clockwise sequence as illustrated, the order of individual elements is not predetermined and a flexible interdependence exists among the nine elements so for these reasons they used an oval pattern. Moreover, they identified seven basic premises underlying the design process to better understand and apply the instructional design process:

- The ID process requires attention to both systematic procedure and specificity.

- The ID process usually starts at the course development level.

- The instructional designer and planning team develop an ID plan primarily for use.

- While planning, every effort should be made to provide for a level of satisfactory achievement for all learners.

- The success of an instructional product is depended on the accuracy of the information flowing into the ID process.

- The ID process focuses on the individual rather than the content.

- There is no single best way to design instruction.

\subsubsection{Identifying the Need for Instruction}

The instructional design process begins with the identification of a problem or verification whether instruction should be part of the solution or not. There are three ways proposed to identify instructional problems namely: needs assessment, goal analysis, and performance assessment.

\subsection{Needs Assessment}

Needs are defined as the gaps between what is and what should be. Needs assessment is defined as a tool for identifying the problem and then selecting an appropriate intervention. Needs assessment process is comprised by four phases; planning, collecting data, analyzing data and preparing the final report which are including different individual steps under each phase. 


\subsection{Goal Analysis}

A goal analysis is an attempt to define the indefinable. In needs assessment the aim is to identify problems, but goal analysis starts with suggestion to the problem and could use data from a conducted needs assessment. There are six steps for goal analysis process;

- Identify an aim: Using a group of experts to determine one or more related aims.

- Set goals: Generate a number of goals for each aim.

- Refine goals: Delete duplicates, combine similar goals and refine the vague ones.

- Rank goals: Rank and select the most salient goals.

- Refine goals again: Identify the discrepancies between the goals and existing performance.

- Make a final ranking: Develop a final ranking of the goals.

\subsection{Performance Assessment}

A performance analysis is used as a way to identify performance problems or finding the source of these problems.

\subsubsection{Learner and Contextual Analysis}

Students have different learning styles. That is the reason why different learning methods seem to be more effective for different students. For instance, some students could learn better from a visual; others from verbal; and others from physical activities and the manipulation of objects. Even for the same person, it also varies related tasks and content. Therefore, it is essential early in the planning process, to pay attention to the characteristics, abilities and experiences of the learners. Therefore, during the design of an instruction, one of the important tasks for the designer is to identify learner and context. 


\subsubsection{Task Analysis}

Task analysis is one of the most critical steps in ID process. It was defined as the collection of procedures for defining the content compatible with the previously done needs assessment of the course. A task analysis should allow the instructional designer to see the content from the learner's perspective while thinking about appropriate teaching strategies. If the content is not defined properly then there is little value for designing an instructional strategy, producing appropriate media, or conducting and evaluating. Task analysis solves three problems for the designer:

- Defining the content needed to address the instructional problem or need

- Facilitating to identify subtle steps in the designing process

- Providing opportunities for the designer to view the content from the learner's perspective and to develop appropriate teaching strategies.

In order to conduct a task analysis designers often work with subject-matter experts to provide accurate, detailed information to use in developing the instructional unit.

\subsubsection{Instructional Objectives}

An instructional designer doesn't have to know what to include into instruction because this is not his/her concern, but he/she should be informed about this to some extent. In addition to decide on the sequence of the content, defining instructional objectives also important concern for designers. In fact, instructional objectives are the expression of the benefits of the instruction, have an important role in planning instruction systematically. Stating instructional objectives is useful for measuring the specific learning achieved. It provides a framework for devising ways to evaluate student learning, defining optimum instructional strategies to facilitate the learners' achievement of the objectives, and guide the learner. In brief, instructional objectives are essential to design, because they define content, document the intended outcomes, and set standards for success. 


\subsubsection{Designing the Instruction: Sequencing}

Sequencing the content comes after task analysis and writing objectives and the purpose is to define the most appropriate sequence for presenting the information. Sequencing is defining the efficient content order in an attempt to facilitate learners' to achieve objectives or laying out the instructional progression of proposed lesson.

\subsubsection{Designing the Instructional Strategies}

After completing the decision of determining the instructional objectives and the sequence of the instruction, instructional designers should decide on the instructional strategies. Instructional strategies start with determining the content and the way of presenting this content and knowledge to the learners. A well-designed instructional strategy prompts learner to actively make connections between his/her prior knowledge and the new information. This learning process is defined as generative learning. Generative learning provides learner's deeper understanding and longer retention of what is learned.

\subsubsection{Designing the Instructional Message}

The next step is concentrating how to lay out and present the information. This matter can be handled under three headings:

- pre-instructional strategies that aims to focus learner's attention to instruction.

- how to signal different aspects of the instruction through words or typography.

- how to use pictures to enhance learner's understanding.

\subsubsection{Developing Instructional Materials}

At this point instructional designer is responsible for the development of material that meets the findings of the previous steps of the instructional design process. The instructional material must focus on content that addresses the objectives and must not be over the heads of the audience. Specific words and/or images should be used that provide a mental image and that will direct the learner. The development of the instructional materials is the implementation of the instructional design plan. In the 
development process, instructional designer should take into consideration to the problem and objectives in an attempt to ensure the instruction supports the resolution of the problem.

\subsubsection{Evaluation}

Evaluation is an essential part of instructional design process. There are three types of evaluation, which are used in different stages of design process for different purposes.

- Formative Evaluation: Formative evaluation should be performed early in the design process. This type of evaluation informs the instructor or planning team about how well the instructional program is serving the objectives as it progresses. It provides opportunities to the instructional designer to make changes before the full-scale implementation.

- Summative Evaluation: This type of evaluation is done when the instruction is completed. It is used to measure to what degree the major outcomes attained by the end of the course.

- Confirmative Evaluation: Confirmative evaluation is performed after the instruction has completed to assess the degree of which outcomes is still achieved after a period time.

Continuous evaluation should be a primary component of the initial plan. Formative, summative, and confirmative evaluations serve the complementary purposes of assessing developing and completed instructional programs.

\subsection{Summary of the Chapter}

As an evolving and rapidly changing field, instructional technology should meet the increasing demands of the society. In order to answer those demands, researcher should decided to work on the problem with the effective and efficient ways of solutions. In this section, the solutions for the research context were explained from general to specific to remediate the existing problems of vocational education from the educational technology perspective. 
The use of educational technology in higher education were explained from different point of view. In fact, instructors and students technology use in higher education is not a new concept but it is getting ordinary ways of instruction day-by-day. Especially, with the increasing technological capabilities of these institutions students and instructors demands more educational technology in their courses.

Students demands on technology use in the instruction results in emergence of more flexible ways of learning. There is a fact that in this competitive world students expected to reach instructional resources whenever, wherever they want. Although the history of distance education dates back to correspondence studies, today with the developing technologies there is an increasing popularity of the way of instruction. This situation necessitates integrating more electronic resources to the learning environment. That is an important concern for higher education with the relevant theoretical support, because distance education is not converting existing F2F course documents to pdf or html files. In this regard, pedagogical and institutional challenges of distance education were explained briefly.

In the remaining section, the development of e-learning in higher education were presented with related literature. Moreover, as a supportive technologies the use and the explanations of CMC and smart classrooms were explained briefly.

In the last section of the literature review, technology acceptance model and instructional design process highlighted. TAM is a useful way to learn whether students accept or reject the use of an educational technology with respect to motivation, usefulness, and ease of use. Learning students' perception may guide instructional designers during the design process. That is why in the last section the importance of instructional design process were highlighted. Specifically, Morisson, Ross, and Kemp's ID model were used as a framework during the design process, and in this section benefits and the steps of this model were presented. 


\section{CHAPTER 3}

\section{METHOD}

"All our final decisions are made in a state of mind that is not going to last."

Marcel Proust

This chapter will describe the research methodology utilized in answering the research questions. Within this context, it elaborates on the overall research design, data sources, data collection procedures, and data analysis procedures. Details of the proactive action research process will be explained in the implementation of the study section because of complicated nature of the research methodology. The chapter concludes with the discussion of the trustworthiness and limitations of the study.

\subsection{Overall Research Design}

In this study, proactive action research used as a methodology, and both qualitative and quantitative findings helped in interpretation of the phenomena. Today, in educational research quantitative findings do not sufficiently explain what occurs in educational settings. For instance understanding or knowing to what extent or how well something is done is not possible with traditional approaches like quantitative research (Fraenkel \& Wallen, 2006). Quantitative research does not give this kind of gain into the problems. The phenomenon of education are too complex to handle with classical research methods. Qualitative research delves in depth into complexities and processes (Patton, 1990). Therefore, this gap can be filled by using qualitative research. Educational research increasingly uses qualitative research to investigate the quality of relationships, activities, situations, or materials (Fraenkel \& Wallen, 2006).

One of the methods that can be used in qualitative research is action research. Generally, action research is name differently such as participatory research, 
collaborative inquiry, emancipatory research, action learning, and contextual action research (O'Brein, 1998). It is based on improving the practice of education to eliminate problems in education. Those problems can be related to teachers' own problems in a course or they can be related to schoolwide problems (Cresswell, 2005). In this way, action research gives opportunity for practitioners to investigate and evaluate their work (Mcniff \& Whitehead, 2005). However, it is also stated by Stringer (2007) that "Action research is not a panacea for all ills... but it formulates effective solutions to problems..." (p.8).

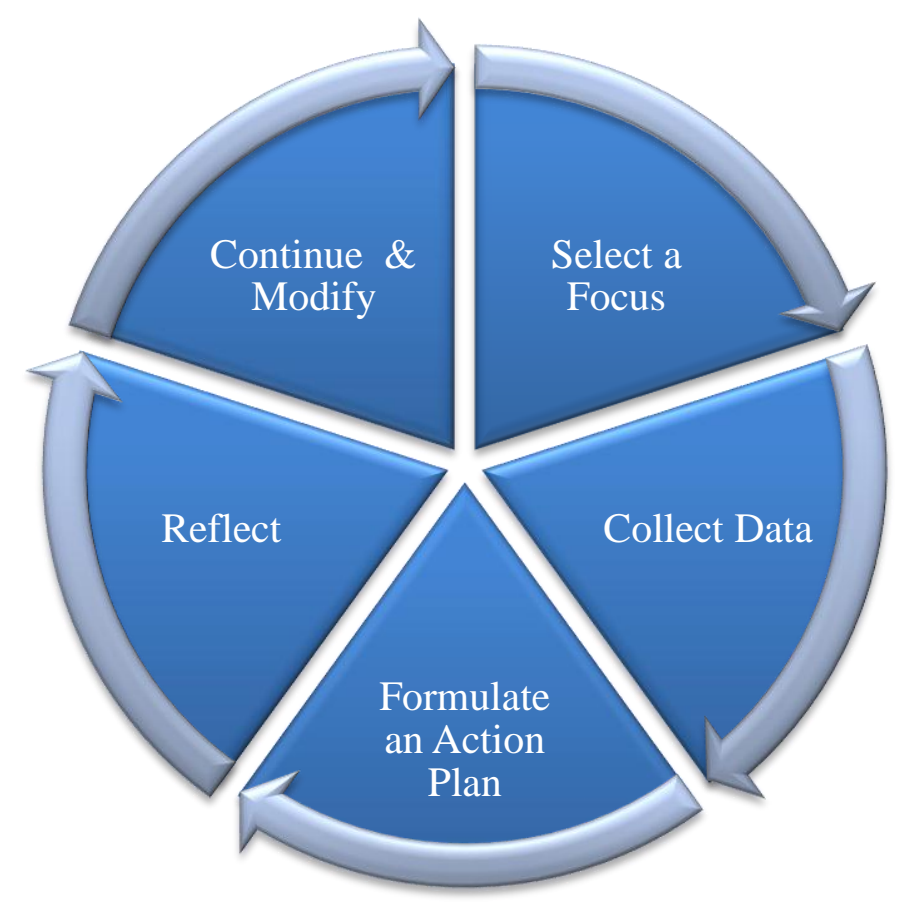

Figure 3-1: Action Research Process (Gall, Gall, and Borg, 2003)

Action research has a circular structure and this makes it more powerful in terms of providing the opportunity to make revisions in the problem solving process (see Figure 3-1). In linear models, only one intervention can be made, but the cyclic structure of action research gives the opportunity to improve process more than once, the decision of how many times that research process follows cycles is the decision of 
researcher. In action research, if one cycle does not solve the problem, it is possible to turn to a new iteration. Although turning more cycles gives the opportunity to integrate more actions, it is not a must. It is the researcher's decision to turn to a new cycle or finalize the process to report the outcome of the action plan. As explained by Cresswell (2005), the cyclic structure of action research does not reflect as an evaluation criteria. Some more important criterion are listed below:

- Research should clearly address the problem

- During the research process sufficient data should be collected

- Collaboration with others

- The action plan derived logically from the data

- Action plan should contribute to the participants

- It should lead to a solution or change

- The author should report it to audiences.

Therefore, it is possible to integrate more improvements in one action plan and one cycle by taking into consideration the above-mentioned criteria's. Actually, it is the researcher's decision to continue to a new cycle, or stop the process and report it. Moreover, many action research studies were conducted in one action research cycle with several improvements (Erginel, 2006; Angelides, Evangelou \& Leigh, 2005, Akçay, 2009).

According to Schmuck (2006), action research has two types. The first one is "Proactive Action Research" which concentrates on application and investigation of a new practice. The second one is "Responsive Action Research" which intends to improve the existing situation. It can be conducted to solve problems or obtain information for local practice (Fraenkel \& Wallen, 2006). This research approach encourages people to examine problems reflectively. As it was cited by Tüzün (2004), Hart and Bond stated that in action research, the researcher acts as a catalyst, and helps the participants being researched by identifying local problems and offering interventions to solve those problems (1995). 


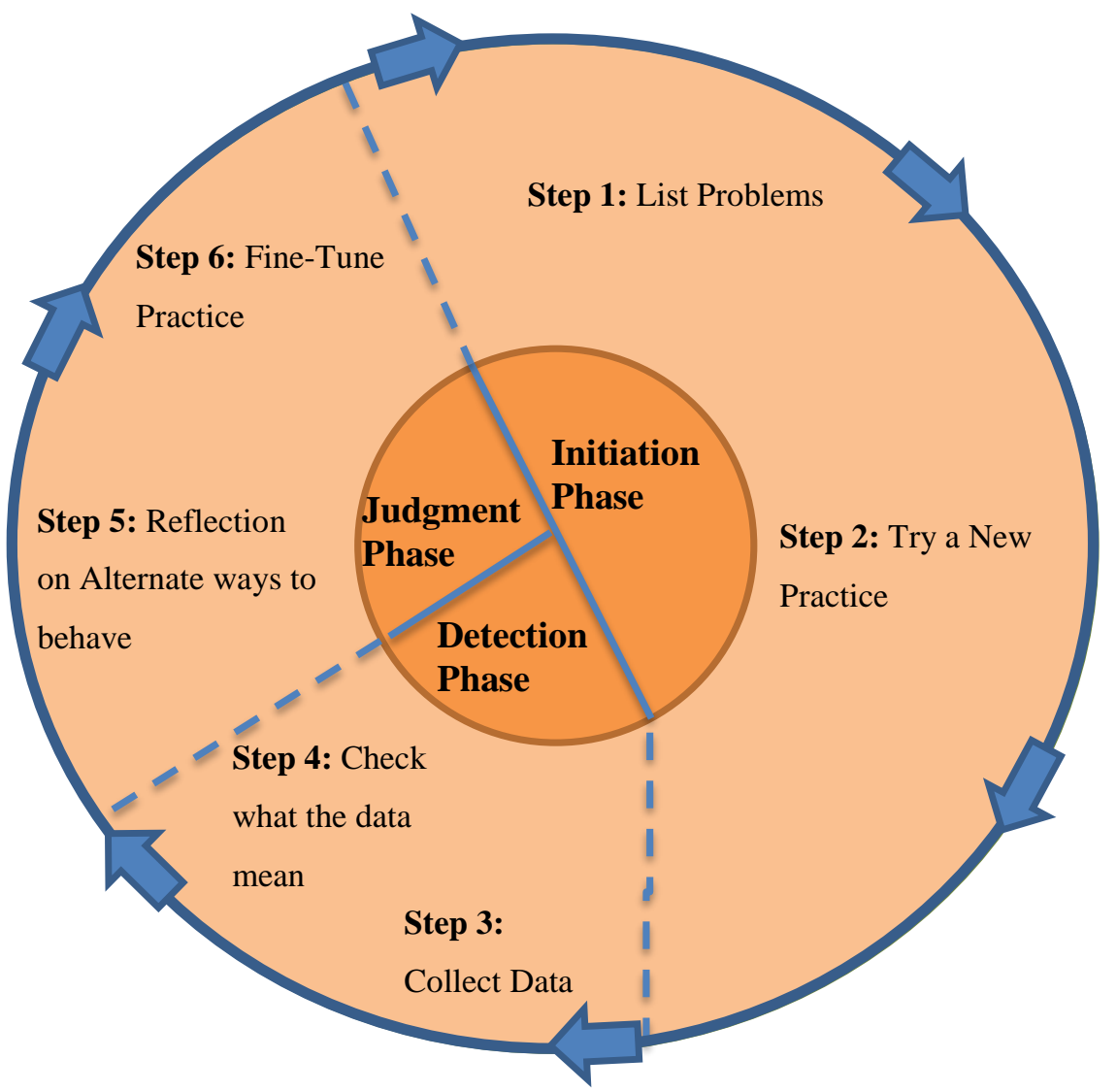

Figure 3-2: Proactive Action Research Cycle (Schmuck, 2006)

In this research, our local practice is a new distance "Web Design" course that will be given from one university to the other university in different cities. With this purpose in mind, there needs to be a new practice and new design of an effective distance "web design" course and instructional environment for the needs of the vocational higher education institution. Therefore, "Proactive Action research" was conducted in this study (Schmuck, 2006). As it was stated above, action research focuses on change (in our case it is a new distance course) and the changes in this change process. In this study, this new distance web design course includes a change or a new approach to the problem situation. Moreover, this instructional design needs to be changed and revised during the research process to achieve a better integration of new web design course. As discussed above, action research focuses on change in action and that is 
concerned with the purpose of research. It entails understanding the current situation, improving it with the new practice, evaluating to make it better with active involvement to this process.

\subsection{Procedure of the Study}

In this part of the study, six main steps of one proactive action research cycle with six steps will be explained briefly (see Figure 3-3). These are:

- Listing Problems

- Trying a new practice

- Collecting data

- Checking what the data mean

- Reflecting on an alternate ways to behave

- Fine tune practice 


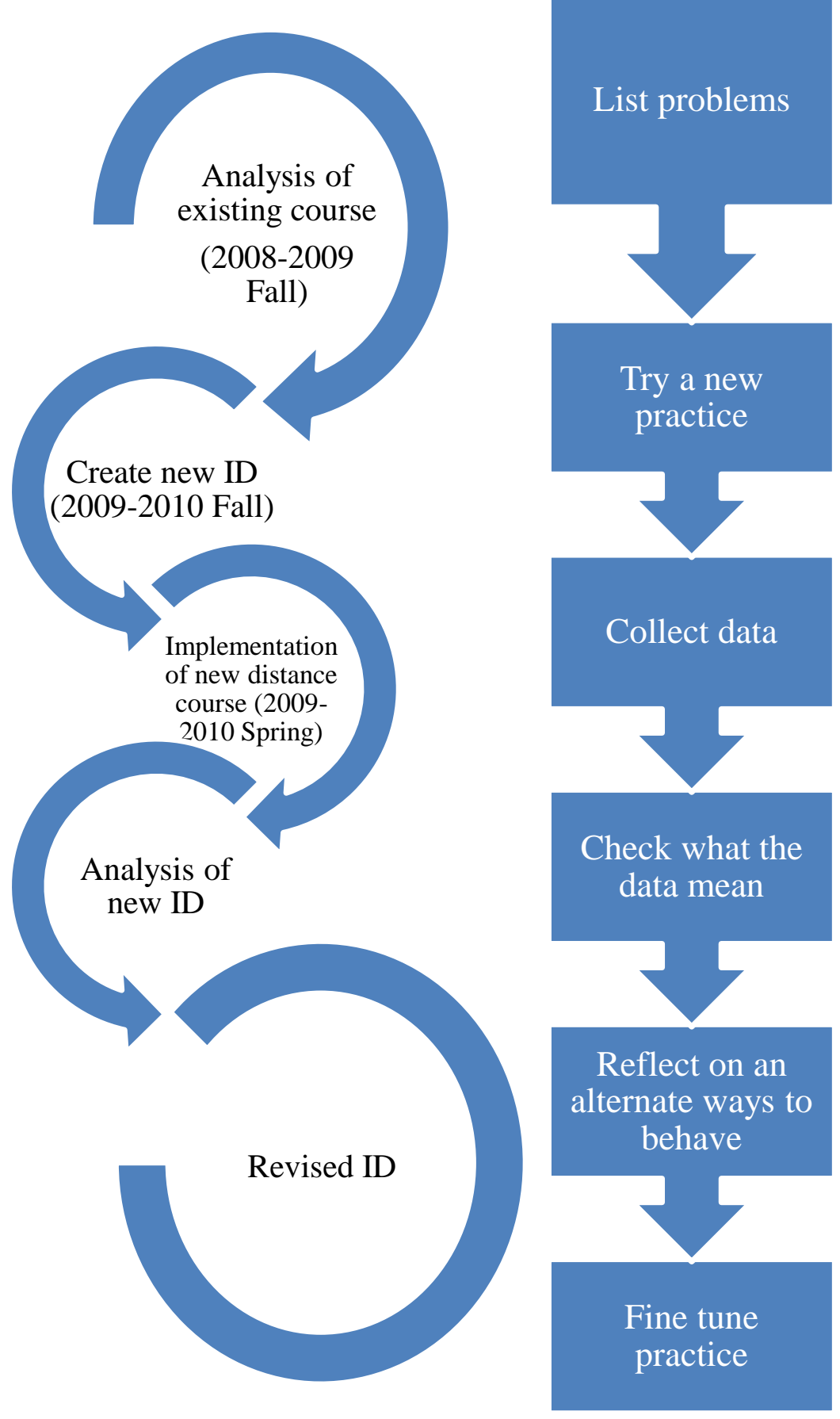

Figure 3-3: Research Process Parallel with the Proactive Action Research Cycle

1. List problems: In the first step, the purpose is to see the current situation of a course to determine problems. Better understanding the existing situation results in being explicit about your goals for the new practice and realistic about obstacles 
(Schmuck, 2006). Creatively problem solving and innovative practice depends on true diagnosis of concerns in the existing situation. Moreover, the data gathered from this step come in useful in the design of the new course.

Some observations and interviews were conducted to determine problems in a course at the vocational higher education institution. It is important to see students' and instructor's problems that they both face in the classroom and computer laboratory sessions and needs in the course. With this process, we can determine the needs and gather information about the context of the school with the help of students and instructor. Data collected by the researcher with observing the classroom and laboratory context and interviewing with the students and instructor. The gathered data from the existing course were transcribed, and then were exported to the Nvivo 8 to analyze. Researcher analyzed the data with constant comparison technique to understand problems in the traditional delivery of the course.

2. Try a new practice: In the second step, the "web design" course were designed with the guidance of Morrison, Ross and Kemp's instructional design model. The results of the first step revealed a framework of problems in existing course. The researcher considered this information gathered from previous step, researcher's advisor's previous experiences, and related literature in the design of the new course. After the design was finalized, it was implemented in the spring semester of 2009-2010 by an instructor from one university to the other as a distance course.

3. Collect Data: As an integral element of qualitative research paradigm, the data was obtained from multiple sources on a continuing basis in order to provide rich description of the phenomenon in this study. This allowed the researcher to explore and understand the complex phenomenon, within the complex context, in an in-depth manner, and also it contributed to the accuracy of the meaning making process (Bogdan \& Biklen, 1998; Marshall \& Rossman, 1999; Yıldırım \& Şimşek, 2001). During the distance course, researcher take field notes, and interviewed with the students. Also, researcher evaluates students' attitudes to web based 
instruction and perceptions about the tool that were used in the course. That means in this study, in addition to the qualitative paradigm, quantitative research paradigm was also used. In fact, According to Patton (1990), combining different methodological strategies in data inquiry and analysis approaches will increase the methodological power of the study.

4. What the data mean: After data collected from the new design of the course, researcher analyzed the collected data. Interviews were analyzed with constant comparison technique to see the in depth understanding about the data. Also, analysis were checked by two peer debriefing, one inter-rating inter-coding and many audit trials to provide trustworthiness of the study. Those data were analyzed by Nvivo 8 to see the codes and categories. In addition to qualitative data, quantitative data were collected with perception and attitude questionnaires. Those instruments were previously used in many researches by different researchers and those instruments are valid and reliable (Turşak, 2007; Iş1k, Aşkun, Özden, 2010; Erdoğan, Bayram \& Deniz, 2008). Questionnaires were analyzed with SPSS 15.

5. Reflect on alternate ways to behave: With the data collected from the new design of the course, researcher evaluate the course and fine-tune the practice to see the good working and accepted properties of the new design and eliminate problematic aspects of this distance web design course. Related literature and our finding guide us to find alternative solutions to current issues of the new design.

6. Fine Tune: Those alternative ways were integrated to our current design to eliminate missing or problematic aspects of the design. 
Table 3-1: Timeline of the Study and Procedure

\begin{tabular}{|c|c|c|c|}
\hline Time & Process & Procedure & Explanation \\
\hline $\begin{array}{l}2008-2009 \\
\text { Fall }\end{array}$ & List Problems & 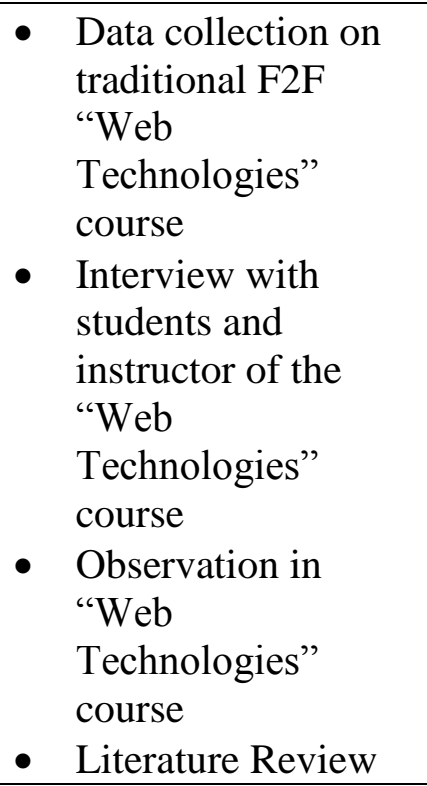 & $\begin{array}{l}\text { Prelimenary study } \\
\text { on context of the } \\
\text { course and explore } \\
\text { needs of a similar } \\
\text { course }\end{array}$ \\
\hline $\begin{array}{l}\text { 2008-2009 } \\
\text { Spring }\end{array}$ & $\begin{array}{l}\text { Instructional } \\
\text { Design }\end{array}$ & $\begin{array}{l}\text { - Analysis of the data } \\
\text { gathered from "Web } \\
\text { Technologies" } \\
\text { course } \\
\text { - Interpreting the } \\
\text { results } \\
\text { - Revision of research } \\
\text { questions } \\
\text { - Literature Review }\end{array}$ & $\begin{array}{l}\text { Qualitative data } \\
\text { were transcribed } \\
\text { and analyzed } \\
\text { Data was used to } \\
\text { determine problems } \\
\text { of the existing } \\
\text { course as an initial } \\
\text { steps of design }\end{array}$ \\
\hline $\begin{array}{l}2009-2010 \\
\text { Fall }\end{array}$ & $\begin{array}{l}\text { Instructional } \\
\text { Design and } \\
\text { Material } \\
\text { Development }\end{array}$ & 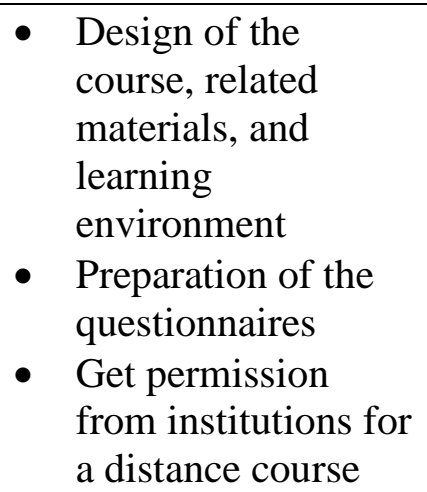 & $\begin{array}{l}\text { New course were } \\
\text { designed } \\
\text { Development of } \\
\text { learning } \\
\text { environments and } \\
\text { course materials for } \\
\text { the needs of a new } \\
\text { course }\end{array}$ \\
\hline $\begin{array}{l}2009-2010 \\
\text { Spring }\end{array}$ & $\begin{array}{l}\text { Try a new } \\
\text { practice }\end{array}$ & $\begin{array}{l}\text { The implementation } \\
\text { of actual study }\end{array}$ & $\begin{array}{l}\text { - New distance "Web } \\
\text { Design" course had } \\
\text { begun from one } \\
\text { university to the } \\
\text { other via Smart } \\
\text { Class }\end{array}$ \\
\hline
\end{tabular}


Table 3-1 (cont'd)

\begin{tabular}{llll}
\hline Time & Process & Procedure & Explanation \\
\hline $\begin{array}{l}\text { 2009-2010 } \\
\text { Spring }\end{array}$ & Collect Data & $\bullet \begin{array}{l}\text { Data collection } \\
\text { from students in the } \\
\text { actual study }\end{array}$ & $\begin{array}{l}\text { Data collected by } \\
\text { the researcher } \\
\text { during the site } \\
\text { visits of the actual } \\
\text { study }\end{array}$ \\
\hline $2011-2012$ & $\begin{array}{lll}\text { What the data } \\
\text { mean? }\end{array}$ & $\begin{array}{l}\text { Analysis of the data } \\
\text { gathered from new } \\
\text { distance "Web } \\
\text { Design" course }\end{array}$ & $\begin{array}{l}\text { Qualitative and } \\
\text { quantitative data } \\
\text { were analyzed to } \\
\text { see what was going } \\
\text { on the new design }\end{array}$ \\
& & &
\end{tabular}

\subsection{Researcher Role}

In this study researcher is an insider in the research process. Researcher works in Middle East Technical University as a research assistant on behalf of another university within an exchange program that is supported by the government. However, researcher has never worked in that university. Therefore, the researcher did not know the context of the other university at the beginning of the study.

In this research, the researcher assumed multiple roles and responsibilities. As an insider of the course, researcher acted as an instructional designer, teaching assistant, data collector and data analyzer in this action research process. All research process was determined and planned with the collaboration of instructor, and authorities from each side of the study. Permission of the authorities in each of the university to give a distance course was very important and the first important challenge for the researcher, because arranging a course in a different university to observe the course and change the course design to deliver it from a distance required great effort and patience. Researcher could overcome this difficulty with a close collaboration of the researcher with the staff of vocational higher education institution in another university. Throughout the practicum process, researcher made an effort to maintain good relations with this institution. 
Within the context of this research, he was responsible for the design, development and initiation of the course. At the same time, as a qualitative researcher who was engaged in action research, he aimed to collect data from multiple sources utilizing multiple methods of data collection. He was always in the research context in participant's side and in instructor side. This enabled a direct access to data source to interpret and understand the phenomenon effectively (Yıldırım \& Şimşek, 2001). Moreover, the researcher did data collection and analysis procedures. In this action research process researcher tried to produce a consensus to balance demands of instructor and students.

As a teaching assistant of the course, the researcher had an active role in the planning and implementation of the course with collaborative work of the instructor and subject matter expert. In this process, researcher revised or developed the course design, content and course materials. He could collaboratively design and develop course and related materials and mediums for the course. Some of the course materials were developed in coordination with students who took CEIT 435 "Project Management Course" as a part of a project. Those students have valuable background in web design and related tools to develop course materials. Also researcher was always in cooperation with the students who takes this course as a teaching assistant to try to inform students about the course, answer their questions, overcome technologic problems, and coordinate the course.

\subsection{Research Questions}

Research questions are categorized as the continuum of the research process with analysis, design, implementation and evaluation. In this research process, researcher tries to find answers to the following questions.

\section{Analysis}

- What are the problems that students and the instructor faced in an existing F2F course?

\section{Design}

- What are the design characteristics of new distance "Web Design" course to mitigate problems identified for the existing F2F course? 


\section{Implementation}

- What are students attitude towards web based instruction that they use in new distance "Web Design" course?

- What are the students' perceptions about the learning environment that were used in new distance "Web Design" course?

- How do the students perceive their motivation to the learning environment in distance "Web Design" course?

- How do the students perceive the usefulness of the learning environment in distance "Web Design" course?

○ How do the students perceive the ease of use of the learning environment in distance "Web Design" course?

\section{Evaluation}

- What are the accomplishments of the new distance "Web Design" course?

- What aspects of the new distance "Web Design" course need to be improved or changed?

\subsection{Context and Participant Selection}

As it was stated above, in qualitative research the researcher intention is not to generalize findings. This is one of the basic distinctions between qualitative and quantitative research. In quantitative research, the purpose is random sampling to reach representative individuals, and then generalize the findings that were obtained from that sample to a population. In contrast to quantitative research, the purpose of qualitative research is to gain in-depth understanding of the phenomenon. Therefore, qualitative research is context dependent, so framing this context is very important for the replacibility of findings.

\subsubsection{Context Selection}

In the first data collection step of the study, our aim is to learn problems of the students in an existing course. For this purpose, researcher determines three criteria for the context selection in this initial step. Those criteria are: 
- This step was conducted in the third-year vocational higher education students in another university because those students have valuable background in the department and their experiences improve the quality of data.

- BiO-313 course was used as a data source for the initial part of the instructional design process because this course includes both theory and practice. This course has 3 hours in-class session and 2 hours laboratory session. Therefore, it is possible to see the current situation in classroom and laboratory.

Table 3-2: General characteristic of "Web Technologies" course

\begin{tabular}{ll}
\hline Course Name & Web Technologies \\
\hline Course Code & BİÖ -313 \\
\hline Credits & Theory: $3 \quad$ Lab:2 Credits:4 \\
\hline Course Type & Must \\
\hline Semester & Fall \\
\hline Prerequisite & No \\
\hline Aim of the course & $\begin{array}{l}\text { Inform students about the interface of web site design } \\
\text { tools, the development of web technologies, and } \\
\text { maturation of programming languages in this } \\
\text { development process. }\end{array}$ \\
\hline Teaching and & $\begin{array}{l}\text { Question and answer } \\
\text { Problem solving } \\
\text { Discussion } \\
\text { Active learning } \\
\text { Examples } \\
\text { Project based learning }\end{array}$ \\
\hline Wearning techniques Teknolojileri, O.Ayhan Erdem, M. Ali Akcayol, \\
& Öğretim Elemanı ders notları \\
\hline Evaluation & $\begin{array}{l}\text { Midterm: 40 \% } \\
\text { Final: 60 \% }\end{array}$ \\
\hline
\end{tabular}

What we did in this study is to create a technology enhanced distance web design course for the special needs of vocational education institution. In order to achieve this, we had to observe and see both laboratory, and classroom settings with respect 
to facilities, strategies, content, activities, context, student, and teacher. The observed course did not have any prerequisite to eliminate the effect of prior knowledge. Also, web technologies are a generic course that is given in many vocational schools. Selecting a generic course would be good way to see the general picture of this institution. Moreover, different researchers may take it a step further, and benefit from our findings of the first step of the study to use it in different contexts.

For the second data collection step, there are three criteria for the context selection in the implementation of the new course.

- This course was designed for the first year students.

- The data were collected from vocational higher education institution in another university.

- BİÖ - 106 (2009-2010 spring semester) course content included web design components. For that reason implementation of this new web design course was replaced with the traditional F2F BIO 106 course.

Although the course names and stages are different in the first and second step of the study, the content and objectives were similar. In the first step, researcher collected data to see the existing structure of a course in vocational education, and decided to design a new distance course for the first grade students. In fact, the new course content was compatible with the BİÖ - 106. Moreover, the instructor of the two courses were the same and his eagerness to participate in this study guided us to study on these courses.

During distance course design, researcher wants to offer this course to the first grades, because of its content and future benefits of the course. Introducing these students with this new tool and presenting its capabilities may have positive effect on their future web design tool selection. They can differentiate and compare the capabilities of MS Expression Studio with other web tools. This is very important for new students of the field in deciding the career path. Even, according to Tucker et. Al (2003) vast majority of career opportunities in the $21^{\text {st }}$ century is in the field of computer technologies. 
More importantly, those new students are not a part of the existing structure of the school. They are new and they are less familiarized with the traditional F2F course structure in this vocational institution. Therefore, they can be considerably easy to adapt themselves to the new structure of a distance course. The use of smartclass, CMS, CMC tools were dramatically change their ways of teaching on the contrary to traditional courses, and would be beneficial for their future expectations and vision to teaching and learning.

\subsubsection{Participant Selection}

The first data collection step of the study includes 40 third year students from the vocational higher education institution. Students from Computer Education department were participated to this study in 2008-2009 fall semesters students who have taken "Web Technologies" course. 33 of these students were male. 7 of them were female. Researcher interviewed with 13 students using a convenience sampling method to reach as many student as possible to learn their problems. With this sampling strategy researcher could reach almost one-third of the participants, this situation is compatible with our aim. Moreover, interviewing with many students necessitates visiting the schools several times and researcher has opportunity to prolonged engagement in the context of the study.

The second step of the study includes 32 first year students from vocational higher education institution. Students from Computer Education department were participated to this study in 2009-2010 spring semesters students who take "Web Design" course. 22 of these students were male. 10 of them were female. 18 of them were graduated from Vocational High Schools, 5 of them graduated from Anatolian High Schools, 4 of them graduated from High School. Almost all students were from low or middle socio-economic status. Only eight of them has internet connection in their homes.

In the second data collection step of the study, six interviewees were selected by purposeful sampling strategy. This study requires qualitative data to provide to indepth understanding of the phenomenon. The phenomenon will be illuminated with the information that will be given from participants, so participant selection to reach 
rich data is very important. With purposeful sampling, it is possible to reach information rich participants (Patton, 1990). Also, purposeful sampling technique is suitable for small-scale and in-depth research projects (Tashakkori \& Teddlie, 1998).

As a type of purposeful sampling intensity sampling is a type of purposeful sampling and works well in when random sample cannot be drawn because researcher can select a small number of rich cases that provide in depth information and knowledge of a phenomenon of interest. In intensity sampling, researcher selects a small number of participants to reach answers to the relevant research question. The researcher used the following criteria for the selection of participants (Patton, 2002): 3 active student, 3 gradually passive participant in online learning environment. Active students were selected with their contribution to the ITL Learning Gateway CMS of the course, also these students are voluntarily helped researcher during video conferencing sessions of the course. Therefore, they have experience on what was going on in the backstage of the course. The other three students had limited contribution in this learning environment. In addition, two of them voluntarily participate to interview, so they had something to say about the new course.

\subsubsection{Distance Course Instructor}

An experienced instructor from Ankara voluntarily contributed to the study. For that reason, course had to be designed as a distance course. During design, delivery and modification of the course he had great contribution with his experience and leadership. While delivering the course, there were many technical or non-technical problems, but those problems could be fixed with his experience in distance courses.

He is professor in Computer Education and Instructional Technology Department in METU. He taught students in vocational higher education institution through his great experience, expertise and knowledge as an instructor in this study. He has great experience in instructional technology field, especially from technical side. Also, he was instructing Special Problems in Computer Education \& Instructional Technology, Web Design, Applications of Authoring Languages in Instructional Technology courses in each semester. He is the editor of many educational web sites. Some of them are 
- http://guide.ceit.metu.edu.tr

- http://ideas.ceit.metu.edu.tr

- http://ideas.ceit.metu.edu.tr/BotebOnline

- http://itl.ceit.metu.edu.tr

- $\quad$ http://www.tbm.metu.edu.tr

- http://itl.ceit.metu.edu.tr/websearch/

- http://egm.ceit.metu.edu.tr

Moreover, he has valuable e-learning background both as an expert and as an instructor. Each course that is given by him was supported with an e-learning support system. Therefore, he knows how to manage technology enhanced courses in blended and online environments.

\subsection{Instruments}

In action research the aim is to see the change in action to achieve improvement of practice, and understanding the existing situation. Both qualitative and quantitative data collection techniques were used in this study to answer research questions. Questionnaires, interviews, forum transcripts, observation notes, researcher diaries and course related documents (sample of students work project performances) were the main sources of data. In addition, two questionnaires were administered for answering perception of students about the tools and attitude towards WBI. In this regard, the quantitative data were used as a way to support the qualitative data in this study. Patton (1990) underlines that combining different data sources to inquiry and analysis will increasing methodological power of the study.

\subsubsection{Interviews}

Interviews, like questionnaires, provide to collect data about any phenomena that cannot be observed directly, like thoughts, opinions, experiences about the course (Gall, Gall \& Borg, 2003). In this study, interviews are important data collection tool. The interview is a conversation, the art of asking questions and listening (Straus \& Corbin, 1998). It produces situated understandings grounded in specific interactional episodes. Interviewing is one of the most common and powerful ways in which we try to understand our fellow human beings. The purpose of interviewing people is to 
find out what is on their mind-what they think or how they feel about something. It allows us to enter the other person's perspective. Semi structured interviews were conducted with students in the first and second step of the study

For the first data collection step, the researcher created students and instructor interviews during the research process (see Appendix E; Appendix F). In order to create an interview schedule initially, researcher tried to create a question pool with the aim of specifying the existing situation and problems of traditional F2F "Web Technologies" course. Researcher wrote down questions somehow related to course evaluation. Some of them were eliminated in early phase of the interview schedule creation process, and some of them were combined in one question. In the early drafts, the aim was to sequencing the questions to simple ones to complex ones. However, in preparing the latest version of interview schedule most of the questions have changed, because of researcher gain insight about the topic and related literature. Many questions have changed in the latest version with the guidance of the peer review sessions and pilot test of the interview. It was piloted with two volunteer students of CEIT 419 "Web Design” course.

The sequence of the latest version of interview schedule is general to specific and easy questions to loaded questions. When the latest interview schedule of the first step was analyzed, some questions do not directly serve as an answer to specific research questions. However, with these questions researcher wants to encourage interviewee to talk freely and try to create a warm environment.

Another change between two versions is in the introduction part of the schedule. In the first draft, the scope of the project still had not shaped, so introduction part is a little bit tentative. During the maturation of the research, this part took its final form.

Interview protocol for the second data collection step of the study is a modified version of the first step of the study to see students' views, problems they faced, beneficial parts of the new course, and recommendations on the new distance "web design" course (see Appendix O). During the creation of the interview schedule, the findings of the first phase played a significant role. Predetermined problems tried to 
be understood with many additional questions. It was extended with the literature, pilot study and expert opinions. It was piloted with two students of CEIT 321 "Foundations of Distance Education" course. Researcher preferred to pilot interview schedule in this course, because in this course instructor use the LMS of Middle East Technical University called METU-Online.

\subsubsection{Observation}

Observations were also used as an instrument for this study, because sometime nonverbal clues help researcher to have a deeper understanding about the context. Apart from that, for taking self-reports of participants, observation can be used to eliminate biases of individuals about themselves, or they may not give any clue that researcher concern (Gall, Gall \& Borg, 2003). Observational variables might be inferential, researcher should make inference from behavior to produce a construct which is supposed to underlying behavior (Gall, Gall \& Borg, 2003). Researcher as observer used an observation form to guide him what to record. In this study, researcher observed and recorded the daily activities of participants and interaction between them. Also, all meetings were recorded by audio recorder to listen again.

During the creation of observation form, there were no critical changes in its structure, but in the early drafts there were some missing parts because of lack of experience. In latter drafts researcher integrate importance of the study. Writing this section took too much time because this section created the framework for this study. Moreover, researcher needed to review other researches and observation forms to write this section. The most challenging thing in creation of the observation form is to create a list that includes what to observe. Some observation form samples in some books and researchers increasing knowledge base guided him to realize what can be observed compatible with the research questions. Researcher created a list of observation codes. However, there is a fact that during the observation some additional codes can be emerged in observation form (see Appendix C). Its pilot tests were carried out in CEIT 133 "Web Design" course. Some more observations code emerged and added to the existing form. Nonetheless, it seems to create a valuable guideline in observation process. 


\subsubsection{Attitude Questionnaire (Web Based Instruction Attitudes Scale-WBI-AS)}

Attitude questionnaire was conducted to the students who take this new distance course in order to obtain their views on the web-based instruction (see Appendix M). Originally, it was developed by Erdoğan, Bayram, and Deniz (2007) in Turkish. It is 5-level likert type questionnaire from "totally disagree" to "totally agree". During the development of this questionnaire, initially 58 questions were created with the help of expert opinions and related literature. 13 items were eliminated with respect to expert opinions. After exploratory factor analysis, 19 items were excluded because of multiple factor loadings. Questionnaire was reduced to 26 items with 2 factors. One factor is called "Efficiency of web based instruction", the other one is "Resistance to web based instruction". Cronbach Alfa internal consistency coefficient was found to be 0.917 , and this value considered widely acceptable according to Garson (2007).

Table 3-3: Questions and Related Factors of Attitude Questionnaire (Erdoğan, Bayram, and Deniz, 2007)

\begin{tabular}{|c|c|c|c|}
\hline Subscales & Section & $\begin{array}{l}\text { Number of } \\
\text { Questions }\end{array}$ & $\begin{array}{l}\text { Item Numbers in } \\
\text { the Questionnaire }\end{array}$ \\
\hline $\begin{array}{l}\text { Demographic } \\
\text { Questions }\end{array}$ & Section 1 & 10 & $\begin{array}{l}1,2,3,4,5,6,7,8 \\
9,10\end{array}$ \\
\hline $\begin{array}{l}\text { Efficiency of web } \\
\text { based instruction }\end{array}$ & Section 2 & 17 & $\begin{array}{l}1,2,4,5,6,8,10 \\
11,12,15,16,17 \\
19,21,22,24,26\end{array}$ \\
\hline $\begin{array}{l}\text { Resistance to web } \\
\text { based instruction }\end{array}$ & Section 2 & 9 & $\begin{array}{l}3,7,9,13,14,18 \\
20,23,25\end{array}$ \\
\hline TOTAL Questions & & 36 & \\
\hline
\end{tabular}

After exploratory factor analysis, the scale was tested by using confirmatory factor analysis. The measurements revealed that the result had high goodness of fit. This scale was selected to measure students' attitudes towards web based instruction.

Moreover, a demographic information questions was integrated to the existing by the questionnaire by the researcher in order to specify demographic information of the students. 10 questions added by asking: 
- Gender

- Where do you connect to internet

- Age

- High school graduation

- Monthly income of your family

- How long have you been using computer?

- Do you have computer where you live?

- Average daily computer use

- Do you have internet connection where you live?

- Average daily internet use.

\subsubsection{Perception Questionnaire}

Students' perceptions about the learning environment were asked with a questionnaire based on Technology Acceptance Model (TAM). According to TAM user acceptance of technology highly depended on perceived usefulness and perceived ease of use. Perceived usefulness is defined as the extent to which a person believes that using an IT will enhance his/her job performance. Perceived ease of use is defined as the degree to which a person believes that using an IT will be free of effort. Perceived ease of use was also considered to influence perceived usefulness of technology. In this study, we have used courses were delivered via video conferencing and it was supported with CMS and CMC tools. Students' perceptions about this system has important effect on its usage. If they did not accept and use it, with the help of TAM it is possible to get information about the underlying reasons of this low-level use of the system.

In order to obtain students' perceptions about the tools that were used in web based instruction, students' perceptions towards tools that were used in web based instruction questionnaire was used (see Appendix N). Originally, it was developed in English, but because of the low English level of the students, researcher preferred to use Turkish version while applying the questionnaire to the students. First, researcher examined the questionnaires that were developed and tested before in Turkish. Then, he decided on an extended version of TAM with highly reliable score. This questionnaire is a extended version of the original TAM scale and includes some more questions about computer competency, e-learning experience, and motivation. 
Because in recent studies, motivation is considered as an important contributor to the use of technology (Lee, Cheung \& Chen, 2005; Bertrand \& Bouchard, 2008). This extended and previously tested questionnaire adapted by the researcher from previous studies of Turşak (2007), and Işı (2009). The reliability coefficient alpha value was calculated as 0.892. According to Garson (2007) this alpha value is widely accepted in social sciences.

Table 3-4: Students' Perseption Realiablity Statistics (Iş1k, 2009)

\begin{tabular}{lll}
\hline Subscales & Number of Questions & Cronbach's Alpha \\
\hline $\begin{array}{l}\text { Self-Reported Computer } \\
\text { Competency }\end{array}$ & 7 & .804 \\
Self-Reported E-learning & 4 & .753 \\
Experience & & \\
Perceived effects on & 9 & .777 \\
Students' Motivation & & \\
Perceived Usefulness & 10 & .787 \\
Perceived Ease of Use & 8 & .689 \\
\hline $\begin{array}{l}\text { Overall Perception } \\
\text { Construct }\end{array}$ & 38 & .892 \\
\hline
\end{tabular}

The questionnaire consists of 4 sections and there are 5 subscales. These are:

- self-reported computer competency of the participants to see current competency level including e-learning experiences were asked in Section 1 of the questionnaire. In this subscale there is 7 questions about different technologies.

- self-reported e-learning experience to see participants' background experiences were asked in section 2 of the questionnaire. 4 questions were asked to see students' online or web based course experiences.

- perceived effects on students' motivation towards educational activities to learn how perceived motivation towards educational activities influence the use of this technology. As it was stated above, this subscale is a new modified 
version of TAM, and many researchers are working over other contributing factors to technology acceptance. For instance, as it was cited by Turşak (2007), interest/enjoyment and perceived competence variables which has a strong effect on motivation were introduced by the studies of Deci and Ryan (1991). Also, willingness and participation were found to have influence on the motivation by McAuley, Duncan, and Tammen (1989). That is why, those items added to this scale during the maturation of the questionnaire.

Table 3-5: Perceived Effects on Students' Motivation towards Educational Activities Related Questions

\begin{tabular}{|c|c|c|}
\hline & Questions & Factors \\
\hline Section 3-Q4 & $\begin{array}{l}\ldots \text { increased } \underline{\text { my interest }} \text { on our } \\
\text { educational activities. }\end{array}$ & \multirow{3}{*}{ Interest/Enjoyment } \\
\hline Section 3-Q6 & $\begin{array}{l}\text {... made our educational activities } \\
\text { enjoyable. }\end{array}$ & \\
\hline Section 3-Q19 & $\begin{array}{l}\text {... made our educational activities } \\
\text { boring. }\end{array}$ & \\
\hline Section 3-Q16 & $\begin{array}{l}\text {... increased my satisfaction about our } \\
\text { educational activities. }\end{array}$ & Perceived Competence \\
\hline Section 3-Q7 & $\begin{array}{l}\text {... decreased my willingness to work on } \\
\text { our educational activities. }\end{array}$ & \multirow{3}{*}{ Willingness } \\
\hline Section 3-Q11 & $\begin{array}{l}\text {... increased my motivation towards our } \\
\text { educational activities. }\end{array}$ & \\
\hline Section 3-Q18 & $\begin{array}{l}\text {... increased willingness to work on our } \\
\text { educational activities. }\end{array}$ & \\
\hline Section 3-Q3 & $\begin{array}{l}\text {... increased my participation to our } \\
\text { educational activities. }\end{array}$ & \multirow[t]{2}{*}{ Participation } \\
\hline Section 3-Q12 & $\begin{array}{l}\text {... increased my study time on our } \\
\text { educational activities. }\end{array}$ & \\
\hline
\end{tabular}

- perceived usefulness to see user's subjective probability that whether using a specific system will increase his or her job performance within an organizational context. In other words, it refers to the degree to which the user 
believes that using the technology will improve his or her work performance.

This factor consists of 10 questions with 6 variables for perceived usefulness;

- Work more quickly

- Job performance

- Increase productivity

- Effectiveness

- Makes job easier

- Useful

Table 3-6: Perceived Usefulness Questions and related TAM Factors

\begin{tabular}{|c|c|c|}
\hline & Questions & Factors \\
\hline Section 3-Q1 & $\begin{array}{l}\text {... enabled us to accomplish educational } \\
\text { activities more quickly. }\end{array}$ & \multirow[t]{2}{*}{ Work more quickly } \\
\hline Section 3-Q15 & $\begin{array}{l}\text {... decreased my work speed in our } \\
\text { educational activities. }\end{array}$ & \\
\hline Section 3-Q2 & $\begin{array}{l}\text {... improved my performance in our } \\
\text { educational activities. }\end{array}$ & \multirow[t]{2}{*}{ Job performance } \\
\hline Section 3-Q14 & $\begin{array}{l}\text {... has decreased my performance in our } \\
\text { educational activities. }\end{array}$ & \\
\hline Section 3-Q5 & $\begin{array}{l}\text {... increased my productivity in our } \\
\text { educational activities. }\end{array}$ & Increase productivity \\
\hline Section 3-Q8 & $\begin{array}{l}\text {... enhanced my effectiveness in our } \\
\text { educational activities. }\end{array}$ & Effectiveness \\
\hline Section 3-Q9 & $\begin{array}{l}\text {... made it easier to study on our } \\
\text { educational activities. }\end{array}$ & Makes job easier \\
\hline Section 3-Q10 & $\begin{array}{l}\text { w.. was beneficial to access our } \\
\text { educational activities }\end{array}$ & \multirow{3}{*}{ Useful } \\
\hline Section 3-Q13 & $\begin{array}{l}\text {... improved our opportunity to work on } \\
\text { our educational activities. }\end{array}$ & \\
\hline Section 3-Q17 & $\begin{array}{l}\text {... was useful in our educational } \\
\text { activities. }\end{array}$ & \\
\hline
\end{tabular}


- perceived ease of use were used the degree to which the prospective user expects the target system to be free of effort (Davis, Bagozzi, \& Warshaw, 1989). This factor consists of 4 variables and 8 questions. Related questions are given in Table 3-7. The variables will be listed below.

- Easy to learn

- Clear \& Understandable

- Easy to become skillful

- Easy to use

Table 3-7: Perceived Ease of Use Questions

\begin{tabular}{|c|c|c|}
\hline & Questions & Factors \\
\hline Section 4-Q1 & $\begin{array}{l}\text { Learning to use e-learning environment } \\
\text { was easy for me. }\end{array}$ & Easy to learn \\
\hline Section 4-Q5 & $\begin{array}{l}\text { It was difficult to learn to use e- } \\
\text { learning environment. }\end{array}$ & \\
\hline Section 4-Q2 & $\begin{array}{l}\text { It was easy to become skillful at using } \\
\text { e-learning environment. }\end{array}$ & Easy to become skillful \\
\hline Section 4-Q3 & $\begin{array}{l}\text { User interfaces and messages of e- } \\
\text { learning environment were clear and } \\
\text { understandable. }\end{array}$ & \\
\hline Section 4-Q4 & $\begin{array}{l}\text { User interfaces and messages of e- } \\
\text { learning environment were user- } \\
\text { friendly. }\end{array}$ & Clear \& Understandable \\
\hline Section 4-Q6 & $\begin{array}{l}\text { User interfaces and messages of e- } \\
\text { learning environment uses terms } \\
\text { familiar to me. }\end{array}$ & \\
\hline Section 4-Q7 & $\begin{array}{l}\text { It was hard to understand the user } \\
\text { interface of e-learning environment. }\end{array}$ & \\
\hline Section 4-Q8 & $\begin{array}{l}\text { I found e-learning environment easy to } \\
\text { use. }\end{array}$ & easy to use \\
\hline
\end{tabular}

This perception questionnaire was conducted at the end of the semester to see the perception of students to the tools that were used in the instruction (see Appendix N). 
Table 3-8: Sections and Number of Questions in Perception Questionnaire (Iş1k, 2009)

\begin{tabular}{lll}
\hline Subscales & Section & Number of Questions \\
\hline $\begin{array}{l}\text { Self-Reported Computer } \\
\text { Competency }\end{array}$ & Section 1 & 7 \\
Self-Reported E-learning & Section 2 & 4 \\
$\begin{array}{l}\text { Experience } \\
\text { Perceived effects on }\end{array}$ & Section 3 & \\
Students' Motivation & Section 3 & 9 \\
$\begin{array}{l}\text { Perceived Usefulness } \\
\text { Perceived Ease of Use }\end{array}$ & Section 4 & 10 \\
\hline TOTAL Questions & & 8 \\
\hline
\end{tabular}

\subsubsection{Researcher Diary}

The researcher diary contains the researcher's journal entries during the design and implementation of the new distance course. This source of data consists of many entries of the researcher about what is going on in the study. These notes were sometimes technical problems, sometimes students' responses, sometimes an alternative approach to a problem.

\subsection{Data Collection Procedures}

During the research, data were collected in two different semesters from different student groups. First data were collected from third year students in another university for needs analysis purposes in 2008-2009 Fall semester in BIO313 "Web Technologies" course. In this period researcher tried to determine problems of the students and instructor. In this semester, data were collected via 3 weeks of observations of the classroom and laboratory and 13 interviews with the students. These interviews were recorded with a digital voice recorder. These records were transcribed by the researcher and took 48 single-spaced pages of data. Also, observations were recorded with a digital voice recorder during the classroom and laboratory sessions of the course and researcher took observation notes with respect to the observation form. Researcher recorded the classroom and laboratory sessions 
to not to miss the events while he was taking notes. He observed 15 class-hours of course during the observation and recorded it (see Appendix D).

Second data collection procedure was initiated in 2009-2010 spring semester in new distance BIO106 "Web Design" course in first year students. Students who took new designed distance "web design" course participated to this study. In this study, multiple data collection instruments were employed in order to explore and understand the phenomenon that is studied in a more in-depth manner. During the course researcher had opportunity video recording the course. At the end of the semester researcher will collect data from students via interviews and questionnaires. These interviews were recorded with a digital voice recorder. These records were transcribed by the researcher and took 32 single-spaced pages of data. Perception questionnaires were conducted to the students in order to obtain their views on the effects of tools that were used in the course on perceived motivations on educational activities, perceived usefulness, perceived ease of use. Also, Web Based Instruction Attitudes Scale-WBI-AS were conducted to the students to learn efficiency of web based instruction and resistance to web based instruction.

Table 3-9: Data Collection Instruments and Procedure Indicating Related Research Question

\begin{tabular}{|c|c|c|}
\hline Research Questions & Instruments & Procedure \\
\hline $\begin{array}{l}\text { What are the problems } \\
\text { that students and the } \\
\text { instructor faced in an } \\
\text { existing F2F course? }\end{array}$ & $\begin{array}{l}\text { Students and Instructor } \\
\text { interviews in the first step } \\
\text { Course observations in } \\
\text { the first step }\end{array}$ & $\begin{array}{l}\text { Constant comparison } \\
\text { analysis of interview and } \\
\text { observation data in the } \\
\text { existing F2F course }\end{array}$ \\
\hline $\begin{array}{l}\text { What are the design } \\
\text { characteristics of new } \\
\text { distance "Web Design" } \\
\text { course to mitigate } \\
\text { problems identified for } \\
\text { the existing F2F course? }\end{array}$ & $\begin{array}{l}\text { Students and Instructor } \\
\text { interviews in the first step }\end{array}$ & $\begin{array}{l}\text { During the instructional } \\
\text { design process } \\
\text { characteristic of the } \\
\text { course formed based on } \\
\text { the results of the existing } \\
\text { course. }\end{array}$ \\
\hline
\end{tabular}


Table 3-9 (cont'd)

\begin{tabular}{|c|c|c|}
\hline Research Questions & Instruments & Procedure \\
\hline $\begin{array}{l}\text { What are the students' } \\
\text { perceptions about the } \\
\text { learning environment that } \\
\text { were used in new } \\
\text { distance "Web Design" } \\
\text { course? }\end{array}$ & $\begin{array}{l}\text { Students' Perceptions } \\
\text { Questionnaire }\end{array}$ & $\begin{array}{l}\text { The questionnaire, which } \\
\text { includes questions about } \\
\text { "Perceived effects on } \\
\text { Students' Motivation", } \\
\text { "Perceived Usefulness" } \\
\text { and "Perceived Ease of } \\
\text { Use", distributed to the } \\
\text { students at the end of the } \\
\text { semester. }\end{array}$ \\
\hline $\begin{array}{l}\text { What are the } \\
\text { accomplishments of the } \\
\text { new distance "Web } \\
\text { Design" course? } \\
\text { What aspects of the new } \\
\text { distance "Web Design" } \\
\text { course need to be } \\
\text { improved or changed? }\end{array}$ & $\begin{array}{l}\text { All data collection } \\
\text { instruments }\end{array}$ & $\begin{array}{l}\text { At the end of the semester, } \\
\text { researcher overviewed the } \\
\text { results of the whole } \\
\text { instruments and process } \\
\text { to gather information } \\
\text { about necessary } \\
\text { improvements in the new } \\
\text { web design course }\end{array}$ \\
\hline
\end{tabular}

Before the data collection process, participants sign a consent form about the voluntary participation and the use of data collected in this research. This consent form was approved by the Middle East Technical University, Human Researches \& Ethics Committee. All digital voice and video records, transcripts and any other documents will be stored at least one year from the end of the study.

\subsection{Data Analysis Procedures}

\subsubsection{Qualitative Data Analysis with Constant Comparison}

Related to the analysis of qualitative data we have several opportunities like content analysis, or constant comparison. In this research, researcher decided to analyze data with constant comparison data analysis technique (Charmaz, 2006, Strauss \& Strauss, 2008, Glaser \& Strauss, 2008). In this technique, research starts with the data and then with respect to the collected data concepts and categories were developed, rather than starting with an existing theory to check whether it is compatible with this existing 
theory. During the analysis, researcher needed to go back and forth between the data and the abstractions as the categories emerged. With this approach, it is possible to define codes, identify categories, connecting these categories, and decide on a central category or categories to explain related research questions.

In constant comparison researcher respected that each case has its unique structure and in this unique structure it may have its unique needs. Actually, in this analysis technique the purpose is to get deep information gathering in your data (Straus \& Corbin, 1998). Therefore, your codes and categories "grounded" in the data, and with this analysis you can pick them up. The important thing about this is that it provides a better explanation than using an existing theory borrowed "off-the-shelf", because it fits the situation that actually works in practice (Straus \& Corbin, 1998).

As it was stated above, this analysis is based on grounded theory, and this theory depends on the studies of Glassier and Straus. They first propose this approach in 1967 , and it was consists of four stages of data analysis. These are comparing incidents applicable to each category, integrating categories and their properties, delimiting the theory, and writing the theory (Glasser \& Strauss, 1967). However, in this version of data analysis approach is too systematic and prescribed. Researchers needed much more flexible approach to analyze data, so they revised grounded theory in 1990. In this revised edition it emphases the use of data analysis step of open, axial, selective coding get deeper understanding of the data by reviewing it several times, with several purposes, and with several questions in mind. In this study, researcher employed constant comparison method of grounded theory for the data analysis of the interview and observation records in three basic steps (Straus \& Corbin, 1998):

- Open Coding: Forms initial categories from the data that is collected from participants.

- Axial Coding: Select an open coding category, position it at the center of the process being explained, and relates to other categories

- Selective Coding: Write a theory from the interrelationship of categories in axial coding. 


\subsubsection{Open Coding}

Coding is the process of segmenting and labeling text to form descriptions and broad themes in the data. Although there are no set guidelines for coding data, some general guidelines exist. Agar (1980) suggests that

“...read the transcripts in their entity several times. Immerse yourself in the details, trying to sense of the interview as a whole before breaking it into parts...".

Within the framework of Strauss and Corbin (1998) presented the first step is open coding. This initial step is an analytic process of discovering concepts. In this process, concepts are identified and their properties dimensions are discovered in data. In order to achieve this, data are broken down into discrete parts, closely examined, and compared for similarities and differences. Events happenings objects and actions/interactions that are found to be conceptually similar in nature or related in meaning are grouped under more abstract concepts named as categories.

In order to determine categories firstly we should start with conceptualizing. Concepts are labeled phenomenon. They are an abstract representation of an event, object that a researcher identifies as being significant in the data. Group similar events, happenings, and objects under a common heading or classification. Actually, conceptualizing is an art and involve some creativity, but it is an art that can be learnt. Data are broken into discrete incidents, ideas, events, and acts and are given a name that represents or stands for these (the name might be given by the analysts or taken from the words of respondents- "in vivo codes"). With this way row data turn to a more understandable abstract form.

After conceptualizing, there are some concepts now. We try to have a greater analysis of what the concepts stand for or mean. Just naming objects do not always explain what is going on in complete sense. Therefore, more detailed and discriminative analysis is needed. Strauss and Corbin named this process as microanalysis. Our aim was to have a greater analysis of what the concepts stand for or mean. We want to 
discern the range of potential meanings contained within the words and develop them more fully in terms of their properties and dimensions. Questions like "What this word seem to mean or what could it mean?" can be asked by the analyzer. In order to guarantee very careful examination of the data, statement-by-statement analysis preferred. "Statement-by-statement" analysis aimed to have a greater analysis of what the concepts stand for or mean (see Appendix G).

\subsubsection{Axial Coding}

The purpose of axial coding is to begin the process of reassembling data that were fractured during open coding. In axial coding, categories are related to their subcategories to form more precise and complete explanation of phenomena. Axial coding requires that the analyst have some categories, but often a sense of how categories relate begins to emerge during open coding.

Now we have concepts, but some of them are interrelated and certain concepts can be grouped under more abstract and higher order concepts. There might be dozens of concepts and the researcher should think about what these objects share in common and come up with the grouped concepts. Grouping concepts into categories is important because it enables analyst to reduce the number of units with which he/she is working.

Categories is divided into subcategories which answers questions about phenomena such as when, where, why, who, how and what consequences, so they give the concept greater explanatory power

These two coding strategy (namely open and axial coding) will clarify the data and interpretations of relationships of the categories and sub-categories can be seen. Open and Axial coding cannot be seen as sequential stages, because while researcher working on coding relations between categories and sub-categories emerged. With those interpretations researcher can reach some conclusions when no new category or sub-category emerged. At that time, it can be concluded that the category is saturated. 
Now it is time to write a relational statement to explain relationships, the researcher links categories with sub-categories.

\title{
3.8.1.3 Selective Coding
}

The aim of this step is to systematically relating the core category with the other categories. Strauss and Corbin (1990)

\author{
“...The process of selecting the core category, systematically relating \\ it to other categories, validating those relationships, and filling in \\ categories that need further refinement and development..."(p.116)
}

Categories are organized around a central explanatory category. It represents main theme of the research. Central category (Strauss \& Corbin, 1990)

- must be central

- must appear frequently in the data

- must explain categories in a logical and consistent manner

- must be described as much abstract as can be.

\subsubsection{Quantitative Data Analysis}

For the triangulation purposes, qualitative results were supported and extended with the quantitative findings. Perception and attitude questionnaires administered to the students during the second data collection step of the study. The collected data of these paper based questionnaires were entered to SPSS 15 (Statistical Package for Social Science). Descriptive information like frequencies, percentages, means and standard deviations of the two questionnaires were calculated in SPSS. One-way Anova were conducted to compare factors of the WBI-AS (resistance and effectiveness) and variables of demographic questionnaire. Also, for the perception questionnaire Oneway Anova was conducted to compare perceived motivation, perceived ease of use and perceived usefulness factors with variables of the demographic variables. The significance level for one-way Anova was accepted as .05. 


\subsection{Implementation of the Study}

In this part of the study, research processes will be explained with respect to proactive action procedure from beginning to the end in a detailed manner. In this methodological perspective what were done during the research process will be explained to clarify research process because of evolving nature of the action research. When new data generated, new meanings and additional lines of inquiry were regularly suggested, and this situation necessitate more clarification of the research process (Davis, 2004).

\subsubsection{List Problems}

Informing about the research context is one of the important things that should be considered in action research, because the aim of the action research is problem solving that we have suffered. Therefore, determination of the problems in the research context would contribute to specifying right solutions to the problems and result in solving predetermined problems more. In order to achieve this, students' and instructor's views were collected via interviews and researcher observe the course in three weeks to see the problems in school setting. Those data would be very helpful in determining problems in the existing F2F course. With respect to these problems, researcher could determine solutions as the hopes of the participants.

Before analyzing the observations and interviews, researcher made literature review to name problems properly. Other studies gave idea about the general problems of vocational education. Then, all the interviews records and observation notes were transcribed with Express Dictate software. Then it was exported to Nvivo 8 qualitative data analysis software (see Figure 3-4). Express dictate helped researcher to transcribe voice records with its combined simple interface of voice player and a simple word processing opportunities. After transcription process, researcher edited each transcript of the participant in MS Word 2010 to made them into the same format to analyze comfortably. Those 48 page long formatted transcribes embedded to Nvivo 8 , and it was considerably easy to code the whole long observations and interviews documents. This software provided selecting meaningful chunks of text and named it as a code, and it is easy to modify codes. 
In Nvivo 8 researcher read those transcripts several times to explore and understand the content. As a part of constant comparison data analysis technique, qualitative data were analyzed statement-by-statement with open, axial, and selective coding processes. Early version of a statement-by-statement analysis can be seen in Appendix G. Each statement tried to be named with initial codes (see Figure 3-4). These codes named in Nvivo 8 as free nodes. In the remaining section, the results of the coding process will be explained in detail.

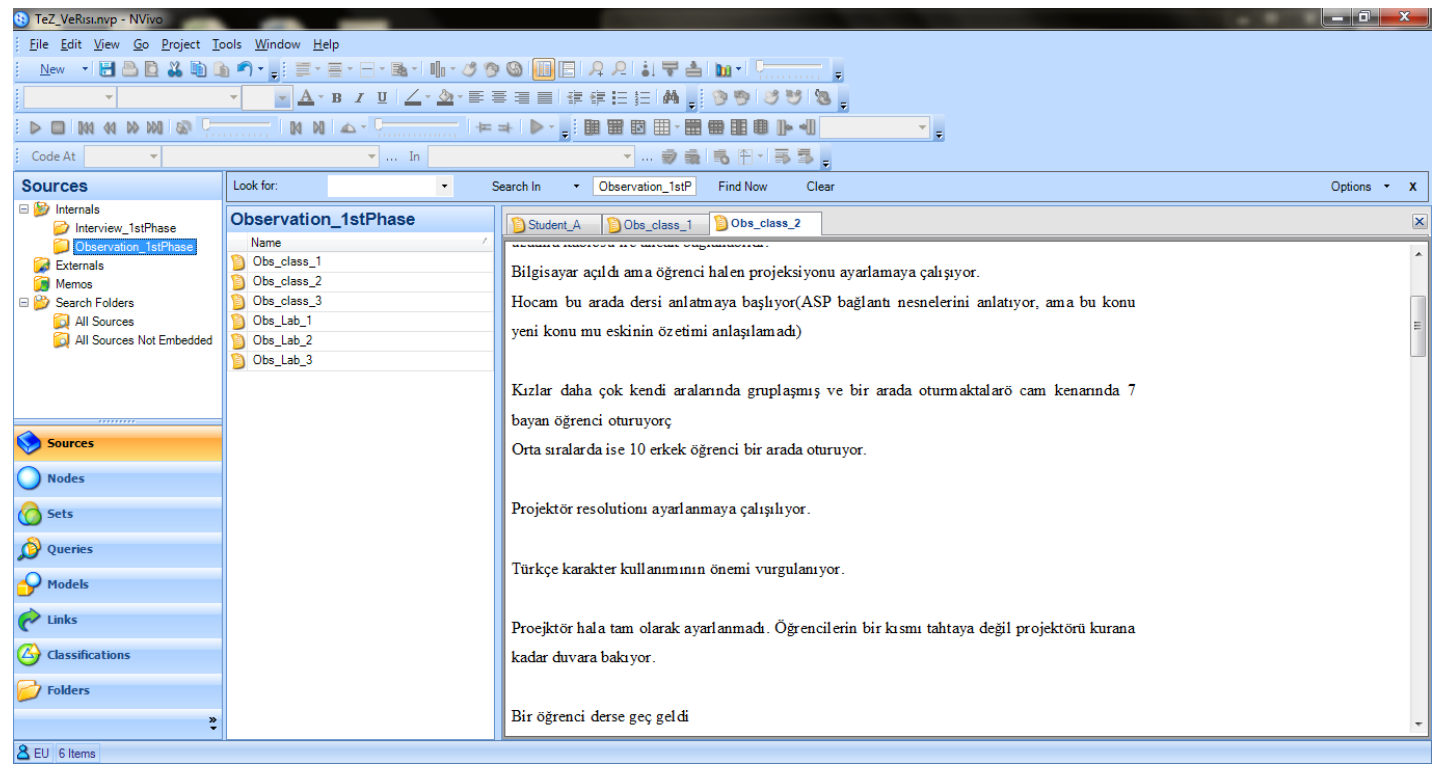

Figure 3-4: Transcribed data in Nvivo 8

\subsubsection{Open Coding}

Open coding is breaking down the data into manageable categories. The categories of this step is a little bit tentative, the purpose is to name each statement of the observation or interview records. Statement-by-statement analysis were done in this step to create open coding categories in order to determine instructional problems in Web Technologies course (see Figure 3-5). Sample open coding procedure and codes can be seen in the below. 


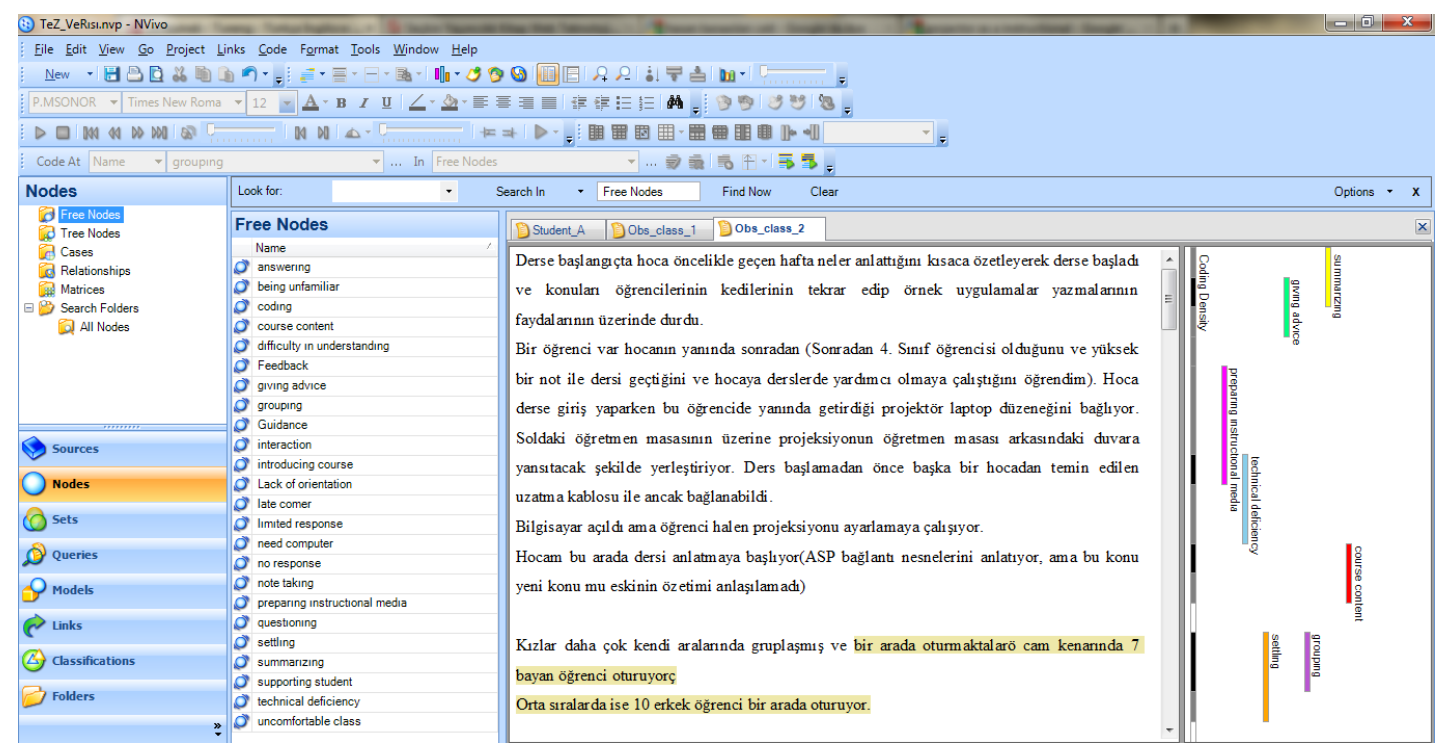

Figure 3-5: Statement-by-statement analysis in open coding with Nvivo 8

In statement-by-statement analysis, researcher read the transcripts several times and tried to name each statement to a code. Researcher started open coding with the interview transcripts, and there were hundreds of codes emerged. Here is an example of open coding process.

I had a computer but do not have an internet connection. I went to Internet [Access to Internet] and also I get things like lecture VCDs, I got it from my friends... yes yes with visual and sound explanations [Visual support material] In the web pages there were many different technologies used [Need up-to-date content], and many people use editors in fact and they are doing visually[WYSIWYG type of tool]. I mean many people do not use codes [WYSIWYG type of tool].

Apart from existing codes that was emerged in the interviews, some more codes emerged during the coding process of observation notes. Some codes that were not related to our research questions were excluded at this point of the study. After several revision processes the number of codes drop down to 129 codes in open coding (see Appendix H). 


\subsubsection{Axial Coding}

In this step, the aim of the researcher is to make connections between categories on open coding. As it was stated in the data analysis section of the study, those codes analyzed by constant comparison technique to compare interpretations in different levels. Like comparing data with data, code with code, code with data, or data with code to create broader categories that covers and explain many of codes.

In this analysis step, the purpose is to decrease the complexity of data with combining related codes to make it more abstract, understandable, and manageable. Major categories that were emerged from the different data collection instruments. Major categories and their properties will be seen in Appendix I. In fact open and axial coding are not sequential stages, in the coding process of this study researcher needed to consider open and axial coding rules collectively to make final decisions.

In this coding step, researcher reconsidered data, codes and categories to determine central categories with respect to the existing literature. With this long revision process, literature review about the issues of TVET before the study begin, and peer discussion processes codes obtained from open coding decreased. Those central categories facilitate our understanding about the existing situation of the course.

\subsubsection{Selective Coding}

Selective coding procedure is to decide on the core category or categories by integrating and refining categories from the data. The theory about the problems of the existing F2F course hidden in the data gathered via the observation and interviews. In this coding step, researcher reconsidered the categories and data to facilitate our understanding about the existing situation of the course.

\subsubsection{Try a New Practice}

One of the aim of this study is to design a new course to remediate the predetermined problems of the traditional $\mathrm{F} 2 \mathrm{~F}$ course in a vocational higher education institution. 
Those problems guided researcher to create a framework for the solution. Although in the research context it is not possible to deal with the structural problems of the existing course, researcher prefers to reduce or eliminate other problems with a new instructional design. In order to achieve this, problems and proposed solutions were listed that should be considered in the new design. With this new ID of the course, students to become fluent in web design with its different elements like language syntax, graphic production, media development, publishing, and webpage design.

The instructional design process provides a framework for thoroughly planning, developing, and adapting instruction, based on learner needs and content requirements. Especially in distance education, it is very essential for a course, because the instructor and students may share limited common background and typically have minimal face-to-face contact.

During the instructional design process researcher followed Morisson, Ross, and Kemps instructional design model to organize data collection, data analysis, and interpretation process. This model was selected because it represents better solutions to the real-life instructional design processes, and learner centered approach to the design (Akbulut, 2007; Hanley, 2009). Also, its cyclic structure made revision process easy and immediate. That is important in this research because during the course we will have some unexpected situations, and it can be handled only by fast responses.

Moreover, conventional instructional design approach considers instruction from the perspective of the content rather than from the perspective of the learner and context, but this model propose a different view to ID. Morrison, Ross and Kemp present the key elements of instructional design process as four fundamental components; learners or trainees, objectives, instructional strategies, and evaluation procedures, which form the framework for instructional planning. Instructional design process will be explained in detail in the Appendix J. It is worth to note that this instructional design process is not a one-time development process. During the delivery of the course, there were many changes and developments occur to make it better. 


\subsubsection{Collecting Data}

After designing the new distance course, it was implemented in 2009-2010 spring semester as a BIO106 "Web Design" course in first year students. Students who took new designed distance "web design" course participated to this study.

Data were collected in the new design of the course. The main source of data was researchers diaries and interviews. Researcher interviewed with 6 students, to provide a deeper understanding about the new distance web design course.

Moreover, at the end of the semester two questionnaires were conducted. One of them was attitude questionnaires were administered to the students who take this course in order to get their attitudes towards web-based instruction (see Appendix M). Moreover, demographic information questionnaire was integrated to this existing questionnaire by the researcher in order to specify demographic information of the students. Apart from this questionnaire, to get students' perceptions about the new learning environment that were used in web-based instruction another questionnaire were conducted (see Appendix N).

\subsubsection{Check What the Data Mean}

In this part of the study, the researcher evaluated the data collected from the new design of the course, and the results helped us decisions on whether this new distance course needs some more modifications or not. In the data collection step both quantitative and qualitative data were collected for the triangulation purposes. Qualitative results were supported and extended with the quantitative findings to get in-depth information about positive or negative effects of the new design on the course.

As it was stated above, two types of data collected during the course. In order to obtain their attitude on the web-based instruction Web-based instruction attitude scale (consisting of two factor named as "Efficiency of web based instruction" and "Resistance to web based instruction") were conducted at the end of the semester. Apart from that, students' perceptions towards the new learning environment that 
were used in the new course were asked with a questionnaire, and it was used to learn participants computer competency, e-learning experience, perceived effects on students' motivation, perceived usefulness, and perceived ease of use. Those questionnaires data were entered to SPSS 15 software to make analysis. Descriptive analysis, t-test and ANOVA analysis were conducted and findings were reported. These findings were supported with the qualitative results.

To see students views, problems they faced, and recommendations on the new distance "web design" course researcher interviewed with six students. Similar to the "List Problems" phase of the study, interviews were recorded woith a sound recorder and transcribed with Express Dictate. After transcription process, researcher edited each transcript of the participant in MS Word 2010 to make them into the same format to analyze comfortably. These 32 page long interviews were exported to NVivo 8 for data analysis. Researcher analyzed the qualitative data with constant comparison data analysis technique. This data analysis is a little bit heuristic ways of doing this and in the remaining section this process will be explained.

\subsubsection{Open Coding}

Those transcripts were imported to a new Nvivo 8 file. Researcher read those transcripts several times to explore and understands the content. As a part of constant comparison, qualitative data were and analyzed statement-by-statement. Each statement tried to be named with some codes. Those codes named in Nvivo 8 as free nodes. Those free nodes are a little bit tentative at the beginning of the analysis and covers some more additional topics out of the scope of this project. Those unrelated codes were eliminated during open coding process, because our aim is to see the achievements and problems of the new distance course. With this respect statementby-statement analysis were done by reading the transcripts several times repeatedly for each of the research question (see Appendix P; Appendix Q).

\subsubsection{Axial Coding}

In the qualitative data analysis of the new practice, the second step was axial coding to make connections between codes to create broader categories. In order to achieve as compatible with the constant comparison technique researcher compared data with 
data, code with code, data with code. This needs to be work on the data for a long time without splitting attention. However, naming the codes to create broader categories was not easy for the researcher, because researcher could make connections between codes but he faced with the problem to find the correct term to cover those codes. For that reason during this analysis step, researcher decided to read some more research papers on the literature contrary to some key figures of the grounded theory like Charmaz (2006). The reason of that approach based on the view that concepts should be generated from empirical data rather than from existing literature. On the contrary to this view, some key figures like Glaser thought that researcher could be informed from the existing literature to some extent before generating the theory. In this study, my understanding is that there is a fine line between avoiding literature review before study and drowning in the literature during the theory generation process (Lillemor \& Hallberg, 2010). In this part of the study, researcher preferred to go back to literature to clearly state and determine categories in the axial coding. After this literature review, peer discussions, and long coding processes codes obtained from the open coding reduced to determined central categories.

\subsubsection{Selective Coding}

This is the last step of the coding process. In this step, researcher decided on the core category of the study. Actually, all those categories are important to understand the problems of the new distance course design. In selective coding researcher explain central categories as a framework to explain problems.

\subsubsection{Alternate Ways to Behave and Fine Tuning}

Different from the traditional ways of doing educational researches, in action research researcher need to carry out to answers "How do I improve what I am doing?" (Whitehead, 1993). This type of problem-solving approach encouraged researcher to develop his own solutions to the problems of TVET in my case. Action research has allowed researcher to investigate existing situation of the traditional course in the vocational school, and then reflect on an alternative ways of course design. Instructional design process for distance education is a never-ending process, because each year students and course contents needs improvements, modifications. This study is a good example of this design, development, implementation, evaluation, and 
revision processes of a distance course design process in a vocational higher education institution.

Actually, this step of the study ran concurrently with the data analysis of the new distant "Web design" course. Moreover, as a characteristic of the action research, there were many modifications done during the course to minimize problems that researcher and instructor faced.

\subsection{Trustworthiness of the Study}

In interpretivist methodology, researchers try to understand social context, culture of the sample. Researchers try to understand each individual's interpretation, because ontologically multiple constructed realities exist. Therefore, it can be said that qualitative researchers might be highly subjective, and biased. It cannot be separated from time and context. In order to objectively analyze in positivist epistemology investigator and investigated objects are assumed to be independent entities and investigator should collect and comment data without influencing it.

Those fundamental differences in research methods ontology and epistemology have detrimental effect on views of validity and reliability issues in research, because qualitative research's ontology and epistemology is different from quantitative research. According to qualitative researcher, validity and reliability is not the primary concern and these are not validated as same as the qualitative research approaches. In fact, validity and reliability cannot be addressees in the same way of positivist point of view. Many qualitative researcher prefer to use different terminology about validity and reliability issue against quantitative paradigm. Many research studies exist on how qualitative researcher deal with this issue. In this study special attention were given to the trustworthiness of the study in the data collection and analysis process.

\subsubsection{Triangulation}

According to Le Compte and Goetz (1982) internal validity is the degree to which scientific observations and measurements reflect reality. In order to clarify meaning of the phenomenon data were collected with multiple procedures (Stake, 1994). Researcher tries to use using multiple data sources, such as interviews, observations, 
and questionnaire in this research. In the first step, data collected with observation of the course sessions (in three week site visits), and recorded interviews with students (with 13 students) during the semester. In the second step of the study, researcher collected data through recorded interviews (with 6 students), researcher diaries and notes during the study, perception and attitude questionnaires of students'. As many perceptions as provided on the phenomenon to contribute to the clarification of meaning

\subsubsection{Peer debriefing}

The proactive action research process with an instructional design is not a one-manshow. The view of a single person may cause biases, and to eliminate this researcher shared all research process with peers in every step of the study. As it was emphasized by Erlandson et al. (1993) peer debriefing is valuable in helping the inquirer deal with the process. The colleagues of the researcher listened to him to give alternative views and explanations that reveals many different ideas for the development of the research. One of those peers is not from the field of instructional technology but she has valuable qualitative data analysis background. The other one has been teaching many online courses and had familiarity towards concepts and processes.

\subsubsection{Inter-coding}

Related to trustworthiness issue inter-coder checking procedure were conducted in two data analysis step with two qualitative research expert independently. One of the procedures in this technique is that each expert analyzed a part of the data individually (Gall, Gall \& Borg, 2003).

In order to increase the understanding of the procedure for the inter-coder, researcher followed a set of procedure. Firstly, before analyzing the data, they were informed about purposes of the study, research questions, and the procedure that were used in the analysis. Secondly, researcher and inter-coders works on a part of the data to reach a common view about the coding process. Thirdly, inter-coder and researcher analyzed one interview by themselves on their own pace. Fourthly, the researcher and the inter-coders compared and discussed on the agreement level of the data. Intercoder agreement on independently coded data was $81 \%$ for the first coder, $84 \%$ for 
the second coder in the first data analysis step. In qualitative studies, these agreement levels seems to be acceptable range similar to other studies that procedure conducted (Borko, Livingston, McCaleb \& Mauro, 1988). Same procedure was repeated for the second data collection steps with the same coders. For the data collected from the second part of the study, inter-coder agreement on independently coded data was $82 \%$ for the first coder, $80 \%$ for the second coder.

\subsubsection{Audit Trial}

In order to increase dependability and confirmatibility of the study audit trials were conducted (Erlandson et. al, 1993). An auditor who was experienced in qualitative research contributed to this part of the study. This procedure was conducted during the maturation of the study to provide feedback about the each chapter of the study. Transcribed data, questionnaires, data analysis results and the whole document were provided to him/her. After the full paper completed, the auditor provided feedback for the whole document. With the help of those recommendations researcher made necessary changes on the document.

\subsubsection{Prolonged Engagement}

As a requirement of action research, researcher should have close relationships between participants and instructor. He had made three visit during the semester and one of them is with the instructor of the course. Moreover, he was always get in touch with the students and technical staff in the vocational higher education institution. By this way he has direct access to data, this is very important to gain insight to trustworthiness of a naturalistic study. This situation helps researcher to see the reality more accurately and closely (Le Compte \& Goetz, 1982). However, being extra exposure to the research context may have disadvantages for the researcher to cause biases. In order to overcome bias, Erickson (1973) highlighted attention to "dual identity as an insider and outsider" (cited in Le Compte \& Goetz, 1982).

\subsubsection{Context, Participant, and Researcher Definition}

Although the aim of this study is not to generalize its findings, its context, participants and researcher role were clearly define for transferability of the study (Le Compte \& 
Goetz, 1982). It can be contribute to some more studies in similar context and reveal similar results.

Le Compte and Goetz (1982) suggested that all data should be recorded, in order to prevent the validity problem. The researcher recorded all session with a sound recorder device. In this way, he did not want to miss any details in data because he had a chance to listen interviews, observations repeatedly. Also, computer-based transcriptions were performed for all interviews and observations.

\subsection{Limitations of the Study}

There are some limitations in this study. Some of them were because of the nature of the action research, or qualitative research, some of them were not controlled by the researcher. Sometimes research context did not let control over some situations.

First, this study has limited generalizability due to its context dependent structure. In the first step, 40 third year students from the vocational higher education institution participated to this study. In the second step of the study, 32 first year students from the same vocational higher education institution participated. Moreover, in the first step interviewees were selected with convenience sampling, this situation decreases the generalizability of the findings of the study. For that reason, this study cannot be generalizable for all educational settings. In fact the aim of this study is not to generalize findings. The purpose is to design a course compatible with the existing facilities of the vocational school and needs of the students in that school.

Second limitation of this study is novelty effect. According to Clark (1983), the most challenging thing in the media research studies is this novelty effect. This project did not aim short term technology integration, students had opportunity to use every tool on the whole semester. Moreover, some instructional materials and tools are still available. Therefore, this situation may decrease the effect the novelty in this research context.

Third limitation of the study was based on the nature of the research methodology itself. Action research process cause researcher to have multiple roles in the research 
process as a teaching assistant to instructional designer. Researcher as a Ph.D.. candidate performed data collection and analysis procedure alone, but with the guidance of advisors, research committee members, and colleagues. Researcher gave special attention to eliminate the effects of this trustworthiness issue (expert opinion, peer review, data triangulation etc.)

\subsection{Summary of the Chapter}

In this study researcher decided to proactive action research to solve the existing problems of a F2F course with a new instructional design. In order to achieve this data were collected in two different semesters. In the first semester, researcher observed and interviewed in an existing F2F course to determine problems and needs. With respect to the findings of this initial step, researcher and his advisor designed a new distance course with many instructional supports.

In the second semester, data were collected with interviews, attitude and perception questionnaires. Students' attitude were asked with a questionnaire consisting of 26 items Web Based Instruction Attitudes Scale. This questionnaire composed of two factors namely "effectiveness of WBI" and "resistance to WBI". The other questionnaire was used to learn students' perceptions about the tools that were used in the learning environment. This distance course contained many new instructional tools and students' perceptions would be beneficial for future studies. For that reason, at the end of the semester students were asked to fill another questionnaire consists of three factors namely "perceived effect of students motivation to the new learning environment", "perceived usefulness of the new learning environment", and "perceived ease of use of the new learning environment".

In addition to these, data analysis procedure of the study was explained for both quantitative and qualitative part of the study. In this study, our aim was to explain how to analyze and use quantitative findings to support qualitative findings. In the analysis of the qualitative data, constant comparison method was used to get detail information from the data. 
In the implementation of the study section, researcher wanted to explain proactive action research process systematically to clarify research process. In action research processes will be more important than the product. After that, trustworthiness and limitation of the study was told in the last section of the method. 


\title{
CHAPTER 4
}

\begin{abstract}
RESULTS
"Adding wings to caterpillars does not create butterflies. It creates awkward and dysfunctional caterpillars. Butterflies are created through transformation"

Stephanie Marshall
\end{abstract}

The purpose of this section is to report the findings of this study. All results will be presented in seven sections parallel with the research questions of the study: problems of an existing F2F course, solutions produced in response to identified problems, students attitude towards WBI, students perceptions about learning environment, accomplishments of the new design, and critical elements of new distance course needed to be improved. At the end of this chapter, summary of the results can be seen.

\subsection{Problems of Traditional F2F Course}

The aim of this study is to create a new course with respect to the needs of vocational higher education institution and students. In order to achieve this, first we should understand existing situation of a course in this school as much as possible. In order to highlight problems that students and instructor faced in F2F course, researcher interviewed with students and instructor. Moreover, researcher observed the course to take field notes. Rather than using available results of the literature, researcher wanted to learn current situation of the real context of the study. Collected data were analyzed with constant comparison data analysis technique to be more informed about context rather than borrowing information from the existing studies. Moreover, this data analysis technique resulted in deeper understanding of the context than the other qualitative data analysis techniques. 
After open, axial coding process of the data, researcher reconsidered data, codes and categories to determine central categories with respect to the existing literature. In this long revision and analysis process of the first part of the study, literature review about the problems of TVET, and peer discussions about the existing data guides researcher to conclude coding. In this coding process, 129 codes obtained in the open coding. Finally, those codes decreased to two central categories emerged in the end with 6 sub-categories after coding process. These are:

- Instructional Problems

- Interaction

○ Motivation

○ Support material

○ Up-to-date content

○ Instructional activity

- Intervening Conditions

○ Technologic

○ Non-technologic

Those central categories facilitate our understanding about the existing situation of the course.

In the remaining section, each component of the problems of the existing F2F course in a vocational higher education institution will be explained in detail.

\subsubsection{Instructional Problems}

It is possible separately consider each of the categories of the instructional problems, but this may restrict our understanding of the importance of the problem. Each category that will be explained in this section is interconnected with each other, and in general perspective this interconnected structure affect the instructional environment. For instance, increased interaction may increase students' motivation. On the other hand, it was affected limitations of the instructional activity. 


\subsubsection{Interaction}

Interaction is a superficial form of communication extended with both verbal and nonverbal communication to exchanging ideas, feelings, thoughts, knowledge and getting feedback. Interaction is a complementary factor to increase knowledge sharing in a course. Within this context, researcher determines problems in student-instructor and student-student interaction.

\subsection{Student-Instructor Interaction}

During the classroom and the laboratory sessions of the course, students had limited interaction with instructor. Both in and out of the classroom, student-instructor interaction is influenced by the teaching perspective of the instructor. Instructor used direct instruction during the course, and students had limited participation and contribution. Only a group of students asked their questions during the course, and the remaining has problems to participate the course. Student L stated, "Some of our friends dominated the course and they are asking questions that I want to ask." [I-1]. In addition, this situation was noted during the observation by the researcher.

Up to that time (Almost one hour after the class started) only three students asked question...After writing every code line instructor turn to students and ask whether they have questions or not? Students get bored with the codes they are just writing codes to their notebook.

During the class, instructor considered the first shout-out response to the question as an answer. That is the reason for only a few students responded to the questions and this situation caused lack of knowledge sharing and interaction. In contrast, more student-centered approaches like giving adequate time during activities for students to think about concepts, receive feedback, and/or participate in discussions that may guide the direction of the lesson. Student $\mathrm{C}$ expected to see "If I were the instructor of this course, I tried to achieve student's active involvement by doing different things. I want to behave like an advisor to guide students ' with different questions. " [I-2]. 
Instructor highlighted that issue by saying:

I am trying to increase their participation to the course by asking challenging questions. However, if you do not take response to your questions, you may forgot and continue to the lesson without considering students'involvement to the lesson.[I-3]

In fact, supporting communication between the instructor and students in class are essential for the effective construction of student knowledge. This will increase curiosity and encouraging students to raise their own questions about the content or their claims about the discussion. In the observations, researcher noted, "Instructor tries to ask questions to take response from the students but only a few students responded with hoarse voice. That is the reason why students and instructor had limited communication “. Moreover, Student A stated his/her feeling by saying "We do not actively participate to the course as instructor XXX expected. He always asking questions about one-step further but only a few, sometimes nobody can answer it" [I4].

However, just writing codes on a computer and using a projector did not encourage students to generate and share their own ideas or guide them to improve their critical thinking skills. As it was stated by Student L, that makes easy to take note, and rote memorization.

Our instructor use different method writing codes on the computer and this makes note taking easy... Also, we can get codes from the computer sometimes we do not need to take note and before the exam we can practice easier...[I-5]

Many students tried to take note, rather than participating the course. Instructor as an only source of knowledge what was written on the board is more important than participation to the course. 
Although in-class interaction between student and instructor is limited, students had opportunity to ask their questions to the instructor in an office hour each week. Instructor informed researcher about that opportunity.

Only some of the students come to my room for asking questions... Most of them have problems in coding what I had written on the board, sometimes they forgot punctuation, and sometimes they may have problems in their computers...[I-6]

Instructor tried to support his/her student out of the classroom but Student C stated, "We cannot reach to instructor via e-mail, but we can find him at his office..." [I-7]. Instructor did not prefer to use electronic communication tools for interaction but students expect to be in a communication both in the classroom and outside the school.

\subsection{Student-Student Interaction}

The other problem related to interaction was limited student-student interaction. Limited interaction among students was related to more lecture-focused structure of the course. Students did not have an idea about they need to communicate with each other, or share their ideas with each other for effectively constructing their knowledge. Related to this issue Student F stated about his/her course preparation style "Before the exam, three of my friend come together, we live close to each other, and study over the example codes..." [I-8].

On the contrary to the existing structure of the course, students wanted to work together on a project to share their ideas. Students should have opportunity to work in pairs and small groups and use multiple modes of communication. Student E stated that:

In this kind of a course, I will give group project to work together, because I believe that students can compensate their missing parts. 
Working together and discuss about what they know or not will increase their understanding about that topic.[I-9]

On the other hand, Student F stated, "I do not prefer to ask my question to my friend, because the real source about this is our instructor, and the right information can only be learned from him... " [I-10].

In fact, students were not accustomed to actively using student-student interaction effectively.

\subsubsection{Motivation}

Motivation is considered as a term to define endeavoring to achieve academic and personal goals in a course. In our case for the traditional F2F course, students had low level of motivation. Some of them related to their limited intrinsic motivation, some of them related to the problems in their extrinsic motivations.

\subsection{Intrinsic Motivation}

Students were not motivated to the course. Although in interviews, some of them stated that they were motivated because of the instructor, only a few students participated to the course actively. Most students just taking note, moreover some of them just sit and neither participating to the course, nor taking notes. Student B stated, "During the course just taking notes bored me and I do not take note, I want to write code on the computer in the lab but I cannot..." [I-11].

Moreover, they were not well informed about the course at the beginning of the semester. This situation limited their expectations and the aim of the course could not be understand by some of the students, so this makes lower motivation on students. About this issue, Student F stated that: 
At the beginning of the semester we were not informed about what we can do at the end of the semester, also now I cannot clearly say that how can I use this, or to which extend it would benefit me in the future...[I-12]

Integrating some more motivational elements to the laboratory activity might have positive impact on students' motivation. Actually, the aim of vocational education is improving hands-on skills of the students rather than traditional education opportunities. The problem of the laboratory sessions of the course related to its follow-up structure of the classroom session of the course without any hands-on activity. This situation decreased students' motivation. Student H stated that he/she wanted to write codes in the laboratory by saying "In the class and lab we are writing codes on our notebooks... we cannot try it in the lab that makes me bored..." [I-13].

Also, Student D stated that:

I learn many things in the class, but when it comes to coding outside of class, I stucked on what I want to code or how these codes would be beneficial for me in what kind of projects. That is the reason why I do not want to try a new code outside the class...[I-14]

In fact some of the students did not have any Internet access or computer access, this situation also restrict their motivation to the course. Student $\mathrm{H}$ stated his/her thoughts on the effects of physical and computer, Internet access problems by saying:

At the beginning of the course, I was not motivated to the course. That is somehow related to physical infrastructure problems that we have. First of all, I could not have a computer and I am studying on one of my friends computer and it is not effective... [I-15] 
Also, as it was stated above, some students dominates the course and other students feel desperate to compete with them. In this situation rather than study more, they postponed their expectancy from the course to the incoming years. This situation resulted in lower motivation to the course. Student $\mathrm{H}$ expressed his feeling "We are coming from different backgrounds, some of my friends know coding but up-to this year I have no desire to learn coding... “ [I-16].

\subsection{Extrinsic Motivation}

This is a motivation to achieve personal goals like grade and graduation. Although some of the students caring about the grade, some of them had different plans. Student I stated his/her thoughts by saying "In fact, I am planning to fail in this course this semester because I do not have a computer, in the summer I will work and save some money to buy a computer to study on it..." [I-17].

Apart from students' different plans of students, some students expected to get homework and projects would be beneficial for their extrinsic motivation. Student $\mathrm{L}$ stated, "In this course we did not do any homework, if something force us to study we may study more." [I-18].

In addition, Student A thought, "Groups project like a final exam force us to study over in practical manner. Because we somehow know codes but we do not have chance to apply them in a real project. " [I-19].

Related to this issue instructor stated, "In the past I have tried to give assignments to practice at home but students are not motivated to do those kind of activities, only a few of them deal with it..." [I-20].

In addition to these kind of personal problems, students were not motivated because of the general problems in vocational education system, they know that only a few of them will be a teacher. In general, $4 \%$ of the graduates of Faculty of Technical Education can be a teacher in Ministry of Education (Kayır \& Kılıç, 2008). Student K expressed his/her thoughts on this issue with saying, "Now I am learning this but I 
am not sure I will be a teacher because KPSS will be an obstacle in front of us...In the future I am not sure I will teach what I have learnt this year... " [I-21].

\subsubsection{Support Material}

In traditional courses, traditional materials such as textbooks, and other print materials are widely used by learners and instructors. However, in this case instructor did not prefer to force students to a textbook, because of the limited economic income of the students. Related to this instructor stated that:

Some of the students do not have any money to pay their fare to come to school, if I offer a course book this will cause economic problems among them. Also some of them can get it some of them cannot... [I-

In addition, vocational higher education institution was not in the main campus of the university. The main library was in the city center and this faculty located in another county. There was a small library but this cannot be enough for the students' needs. Instructor claimed, “...All the related information can be found on Internet... I do not want to limit sources with only a book or course note.... " [I-23].

Support materials will be used to promote efficiency of education by improving the quality of teaching and learning. Incorporating these materials to present, support and reinforce teaching may improve the quality of instruction. This will help instructor to create interesting and compelling platform to teach. In fact, students expected to reach this kind of support materials in the course. Student F stated, “...Me and some of my friends find some videos on internet to support our learning... " [I-24].

In addition, students wanted to obtain written codes on the computer to review it again. However, if written codes were distributed, instructor thought that they did not take note or listen the course. Different from the instructor's point of view, Student L expected that: 
If we had chance to integrate a course web site that is full of instructor notes, additional information, exam dates etc., it would be very beneficial for us. It would be great that we can find everything in the same address, by this way we do not need to spend hours to find a video, or document... [I-25]

\subsubsection{Up-to-date Content}

The aim of vocational education is somehow related to the needs of the society and market. Course contents, scopes is getting change more quickly than ever before because of the developing technologies. In vocational education instructor should consider the needs of the market. However, in this traditional course, rather than the needs of the students and market, existing capabilities of the school influenced the instructor's decisions. In many studies that was conducted in vocational education system of Turkey, students thought that curriculum partially or completely insufficient. Student H thought, "I am not sure whether I will teach what I have learnt this year when I was a teacher..." [I-26].

In our context, obtaining licensed software is another important problem, this situation restricted students and instructor with respect to integration of new content. They were only using notepad for coding HTML and ASP codes rather than using visual editors. Students wanted to have a WYSIWYG type of visual coding environments. Student $\mathrm{G}$ reported this issue as:

Coding on the notepad is boring and time consuming. Even if I wrote a small mistake, it takes too much time to find my mistake. In the 2year vocational school, I took a similar course and we have used an editor for all these coding... Rather than study over the same content, I prefer to learn extended and new versions....[I-27] 
In those faculties, there are many web related courses and in our case web technologies course content did not meet the needs of the students. Student D stated, "In vocational high school, I have learnt web technologies before, so I am accustomed to many thing in this year..." [I-28].

That means almost five years ago that student had taken a similar course, and today in this course he/she was familiar with the content. However, in this field, technological development does not allow static course contents. Instructor stated that he tried to renew course year-by-year. In order to achieve this purpose he stated "Each year I was making a small survey about the course and the way I instructed, but last year I cannot do it because of lack of time... " [I-29].

\subsubsection{Instructional Activity}

Although the aim of vocational schools to educate students who have hands-on experience apart from theoretical knowledge, teacher was the main source of knowledge in this course. It is highly teacher oriented and did not have any engagement. Student $\mathrm{F}$ highlighted this issue in the following comment:

During the course, I am using instructor's example as a source, but sometimes I tried to listen and take note during the course... It would be better if we had chance to write codes on the computer and see the outputs, but the computers in the lab do not have related tools, even some of them do not have a mouse...[I-30]

Teacher mainly dominates the course from beginning to the end. Sometimes he tried to ask questions to the students, but only a few students respond to these questions. He tried to guide students by creating discussion environment. However, these attempts rejected by students because they are only concentrated on note taking that was written on the board, or on the projector. Related to this issue Student G stated that: 
In order to memorize codes that were written on the board I was taking notes but sometimes I have missed the questions of the instructor. In fact, ST A and the group of ST F always asking questions and answering the instructors question...[I-31]

The other important problem of lack of instructional activity directed students to rote memorization rather than deeper understanding on codes and processes. Student B expressed his/her comments on this issue as:

Our instructor use a different method, rather than using the whiteboard he uses projector to show the code writing process. This is an important opportunity for us but if we had the chance, I want to write the code in the laboratory to practice more...[I-32]

Moreover, instructor did not have any teaching assistant for that reason he could not give homework. He expressed this current situation as "Last year I was giving assignments to the students... but this year because of my loaded schedule this semester I cannot give assignments... ” [I-33].

Students expect to see variety of different instructional activities in this traditional course. Related to this Student G stated that:

In fact, we can see the codes on the projector, but If we can write the code ourselves it would be better. In the two-year vocational program, I had taken the same course and someone wrote the code with the projector, and also we wrote the code in our computer. Also, instructor gave homework to practice more...[I-34] 
Also, Student H stated that:

If I were the instructor of this course, I will reorganize the course based on projects. Students supposed to prepare a project websites, and present them in the classroom to share their experiences like mistakes, problems they have faced. Other students may give feedback to the projects, or they can say heyy!! This kind of things can be prepared or if I were him, I could add something else to this project. However, this kind of structure needs flexibility. Time and content should be flexible...[I-35]

Student K expected to see:

May be we can redesign the schedule from simple to complex projects. At the beginning of the semester students can prepare a simple web page and when the time passes this simple web site will be developed and getting complex with the new things that can be seen in the course...[I-36]

\subsubsection{Intervening Conditions}

This category is an umbrella category that covers technological and non-technological problems that were observed by the researcher and were reported by the students.

\subsubsection{Technologic Problems}

Technology has potential fundamentally change on how we instruct. Emerging technologies are changing how students communicate and learn, how they approach learning, and how they process information. However, there is a misunderstanding that we put computers in every classroom and we will revolutionize teaching. That is a big lie, because equipment and hardware malfunctions can be a great detriment to the effectiveness of the course.

Even in our case on F2F traditional course technologic problems had directly limit the way of instruction. Both instructor and students suffer from those problems. Those 
problems observed by the researcher and stated by the students. Student L stated that problem

We have technologic problems. We have it because also in the lab two students stay in front of a computer. Two students sharing. Usually even these computers do not work. We cannot use them. The working ones have different problems, they are not connected to internet, there is no program installed on them. Or I cannot coincide them....$-[\mathrm{I}-37]$

Technical problems also affect students in the computer laboratory and in the classroom. Especially, hardware problems were observed in the course. In the observation notes researcher reported that problems:

The number of computers in the laboratory was not sufficient to practice what was written on the board.

Even instructor did not have opportunity to write codes on the computer and show the output. An external projector was used to do this but it took too much time to set it up.

During the observation, each week instructor should deal with the cable problems, and connection of the projector. A student assistant helped instructor during the lesson. Student assistant is fourth year student who takes high grade in this course and he/she voluntarily helped the instructor. However, this student was not an expert and before the course, he tried to find projector and its power cable.

Moreover, there was not a technologic support service in the school, instructor and student assistant tried to solve those problems. That is because of the faculty building is not in the central campus and they should deal with their own problems like maintenance, and infrastructure problems. 
The effect of technologic problems could be obviously seen especially in the laboratory session of the course. Although this course had hands-on experience part, during the laboratory sessions computer laboratory used as a traditional classroom. Instructor wrote codes and reflected with the projector to show the output. Related to this issue Student C stated, "If we had chance to use lab, it would be better to write and try codes on the computer. That would be more effective..." [I-38].

Students could not find computers to work on because none of them has internet connection. Even some of the computers did not have a mouse. Only some basic programs installed on the computer laboratories because the lack of licensed software. This issue highlighted by Students B. He expected to increase his hands-on experience in the course and stated that:

Our instructor use a different method, rather than using the whiteboard he uses projector to show the code writing process. This is an important opportunity for us but if we had the chance, I want to write the code in the laboratory to practice more...[I-39]

The main reason for the technological problems was based on the problems of the technological support service of the school. Although computers have related hardware to connect those computers to the network, lack of staff cause maintenance problems in the laboratory or classroom setting. Related to this issue instructor stated, "Even we do not have an assistant or personnel to maintain computers, you have to deal with all the technologic problems..." [I-40].

Inside the school, students and instructor deal with those problems, but outside the school students have other problems about internet connection. Student I stated, "I have a PC, but do not have an Internet connection for that reason to reach something else about this course I have to go to my friends' house or to an internet café... " [I41]. 


\subsubsection{Non-Technologic Problems}

TVET is still facing a number of serious issues like lacking of resources, and facilities. Lack of sufficient and properly equipped learning spaces and facilities caused problems in the courses that are given in these institutions.

The structure of the building is not suitable for a vocational education institution. Especially, computer laboratory needs modification. Apart from technological problems of the laboratory, location of the computers and sitting plan of the students were also problematic (see Figure 4-1). In the observations researcher noted, "The computer laboratory used as a traditional classroom, most of the students sits in the center of the laboratory to take note.", and "Only a few students have laptop and he tried to write codes to his computer. “"

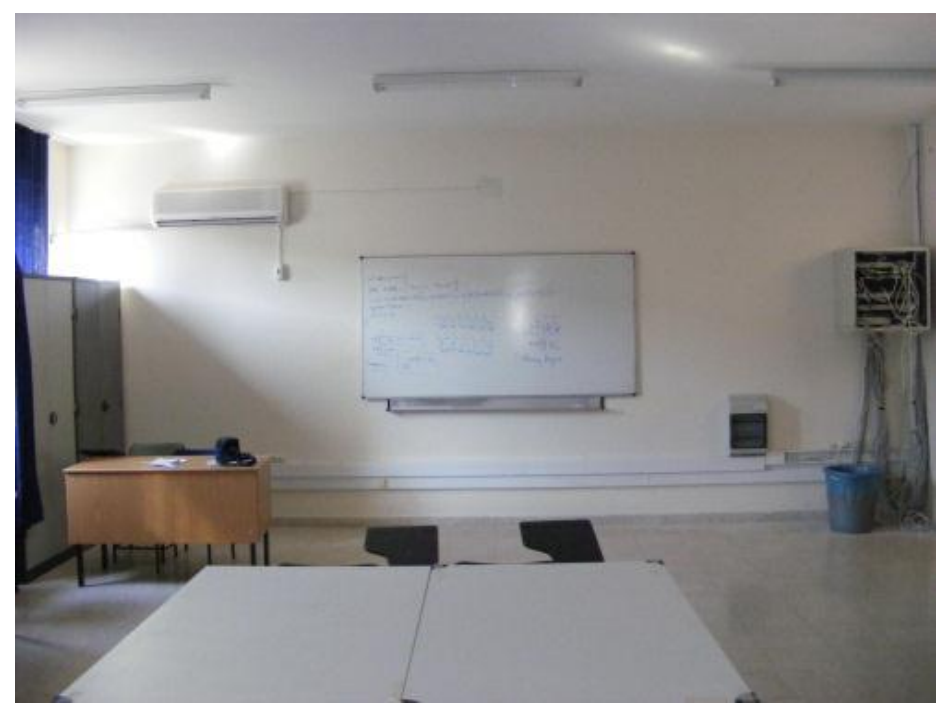

Figure 4-1 (a) : View of the Computer Laboratory 


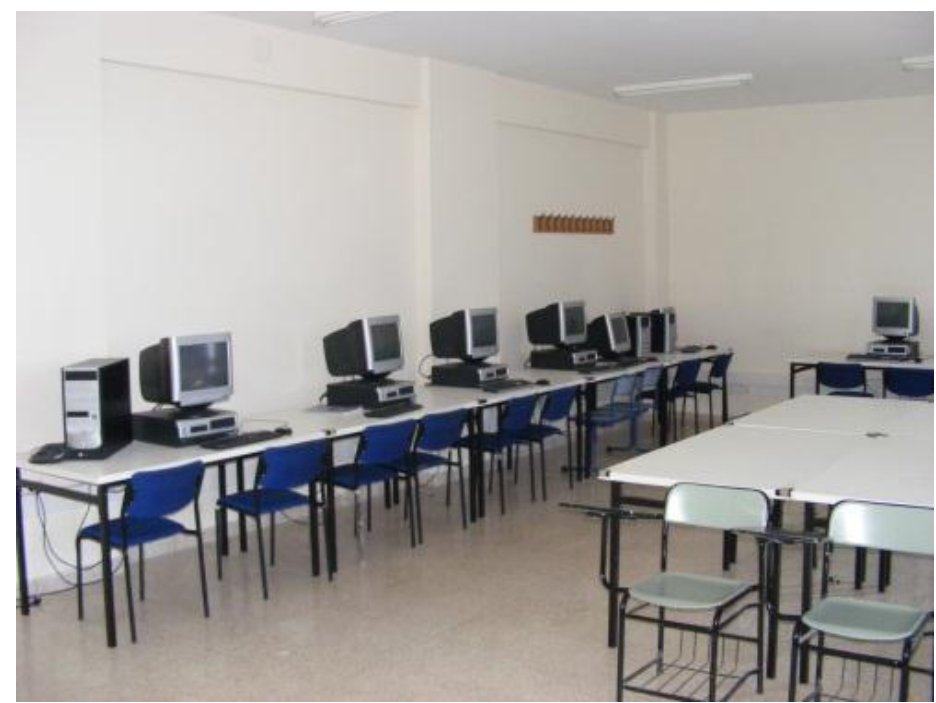

Figure 4-2 (b): View of the Computer Laboratory

The other important non-technologic, structural problem was weather conditions of the city that vocational school is located. This institution had a new building there is no central heating system or any other climate control system. The researcher observed and interviewed with students in winter. Although the weather was $5-8{ }^{\circ} \mathrm{C}$, because of the humidity students participated the course with coats and scarfs.

Moreover, the transportation system from city center to university building was not a well-organized and good working system. During the observation process researcher, also have to wait for an hour to come to school. Also in the observations, researcher noted that almost most of the students come to the course late. These late comers distract instructor and students.

Different from the general structure of the school there were some problems related to the general problems of higher education. Some students stated that their unwillingness to the computer education department in faculty of vocational education. One of the students expressed his feeling with saying "I am not the man of this department, I like reading books, poems. I do not feel myself as a computer expert." [I-42]. 


\subsection{Design Characteristics for the New Course}

In order to find solutions to a problem situation, first we should clearly define the problem. In a school setting, sometimes courses do not have perfect structure without any problem. For instance, some classes may have well-planned structure, and some others were not. In the remaining section researcher tried to address the main problems of the existing course to produce solutions. Then, proposed solutions will be presented.

As a result of the coding process, central categories with sub-categories were generated by integrating and refining categories from the data. This process resulted in determining existing problems of the "Web Technologies" course that is hidden in the data gathered via the observation and interviews. This is a good way to see the main problems of the exiting course and to determine a framework for the solution. As it was stated above, during the coding process, central categories are "instructional problems", and "intervening conditions", because it is frequently seen in the data and abstract.

Interaction, motivation, support material, up-to-date content, instructional activity, technical and non-technical problems are always important concept for all educational environment, but in our case those are the most problematic concepts that an instructor have to deal with them to provide better learning opportunities.

Researcher site visits and interviews gave many clues about this issue of the existing F2Fcourse in the first step of the study. Students' neither have a syllabus like course information document, nor have sufficient information about the content or sequence. They did not know what would be the topic in the next lesson, and did not have clear information about the course at the beginning of the semester. He said "At the beginning of the semester I am not motivated enough. I did not know what this course was about..." [I-43].

In the remaining section, pre-determined problems and ways to overcome those problems will be explained (see Table 4-1). Those solutions were determined with the findings of the existing literature and discussion with the field experts. 
Table 4-1 : Summary of the Findings and Proposed Solution's

\section{Central Determined- Proposed Solutions to Solve Problems \\ Category Problems}

\begin{tabular}{ll}
\hline Instructional Interaction & $\begin{array}{l}\text { More interaction via online forum, chat, e- } \\
\text { mail } \\
\text { Problems }\end{array}$ \\
& Online announcements \\
& Online assignments \\
& Online instructor and teaching assistant \\
& support \\
& $\begin{array}{l}\text { Instructor participation to online } \\
\text { environment }\end{array}$
\end{tabular}

Adequate and timely feedback

\begin{tabular}{|c|c|}
\hline \multirow[t]{7}{*}{ Motivation } & Instructor from METU as a field expert \\
\hline & Flexibility with online learning environment \\
\hline & Predetermined course schedule \\
\hline & $\begin{array}{l}\text { Maintain active student participation to } \\
\text { discussions }\end{array}$ \\
\hline & $\begin{array}{l}\text { Maintain active student participation to } \\
\text { assignments, and projects }\end{array}$ \\
\hline & Reflective feedback to assignments \\
\hline & $\begin{array}{l}\text { Student centered engaging, practical } \\
\text { activities }\end{array}$ \\
\hline \multirow[t]{3}{*}{ Support Material } & $\begin{array}{l}\text { Creating new course materials parallel with } \\
\text { the new content }\end{array}$ \\
\hline & $\begin{array}{l}\text { Deliver online, and printable course } \\
\text { materials like presentations, course hand- } \\
\text { outs, coding examples, sample activities }\end{array}$ \\
\hline & Guidelines and relevant resources \\
\hline
\end{tabular}


Table 4-1 (cont'd)

\section{Central Determined- Proposed Solutions to Solve Problems Category Problems}

\begin{tabular}{ll}
\hline $\begin{array}{l}\text { Instructional Content } \\
\text { Problems }\end{array}$ & $\begin{array}{l}\text { Changing course content with considering } \\
\text { new trends, technologies, tools, editors } \\
\text { Consider software licensing cost } \\
\text { More technical content }\end{array}$ \\
\cline { 2 - 3 } & Online assignment \\
Activity & Demonstration of real life examples \\
& Practical new activity design for each week \\
& Project - Based approaches
\end{tabular}

\begin{tabular}{lll}
\hline Intervening & Technologic & $\begin{array}{l}\text { Creating alternative plans in the case of } \\
\text { emergency that can be seen during the } \\
\text { course }\end{array}$
\end{tabular}

Supporting students' needs about the editor

Creating printable documents

\begin{tabular}{ll}
\hline Non-Technologic & $\begin{array}{l}\text { Instructor will encourage students about } \\
\text { the future expectations }\end{array}$ \\
& $\begin{array}{l}\text { The use of online environment for dealing } \\
\text { with the transportation and weather } \\
\text { problems }\end{array}$
\end{tabular}

In this course in vocational higher education, students expected better instructional opportunities in their courses with less intervening conditions. Instructor should be cautious about interaction, motivation, support material, up-to-date content, and instructional activity problems to create a better instructional environment. Moreover, technologic and non-technologic problems should always be considered, and tried to be eliminated or minimized in the learning environment. 
When researcher asked questions about the expectations of students, almost every student stated instructional problems of the course. For that reason, rather than making modifications of the course, it would be better completely change the course. In addition, the instructor stated, "If I had opportunity to deal with the instruction process and sufficient facilities, I wanted to change the course..." [I-44]. Although vocational higher education has problems interaction, motivation, support material, up-to-date content, instructional activity, technical and non-technical problems, our considerations to solve those problems is a new course design from beginning to the end. With respect to the related literature, researcher's discussions with his peers, meetings with researcher's advisor guide him to find solutions to the problems. Aforementioned problems have direct effects into the classroom and somehow new course design can be used as a cure for solving some of these problems. During the design of the new course, those predetermined problems tried to be handled (see Figure 4-2).

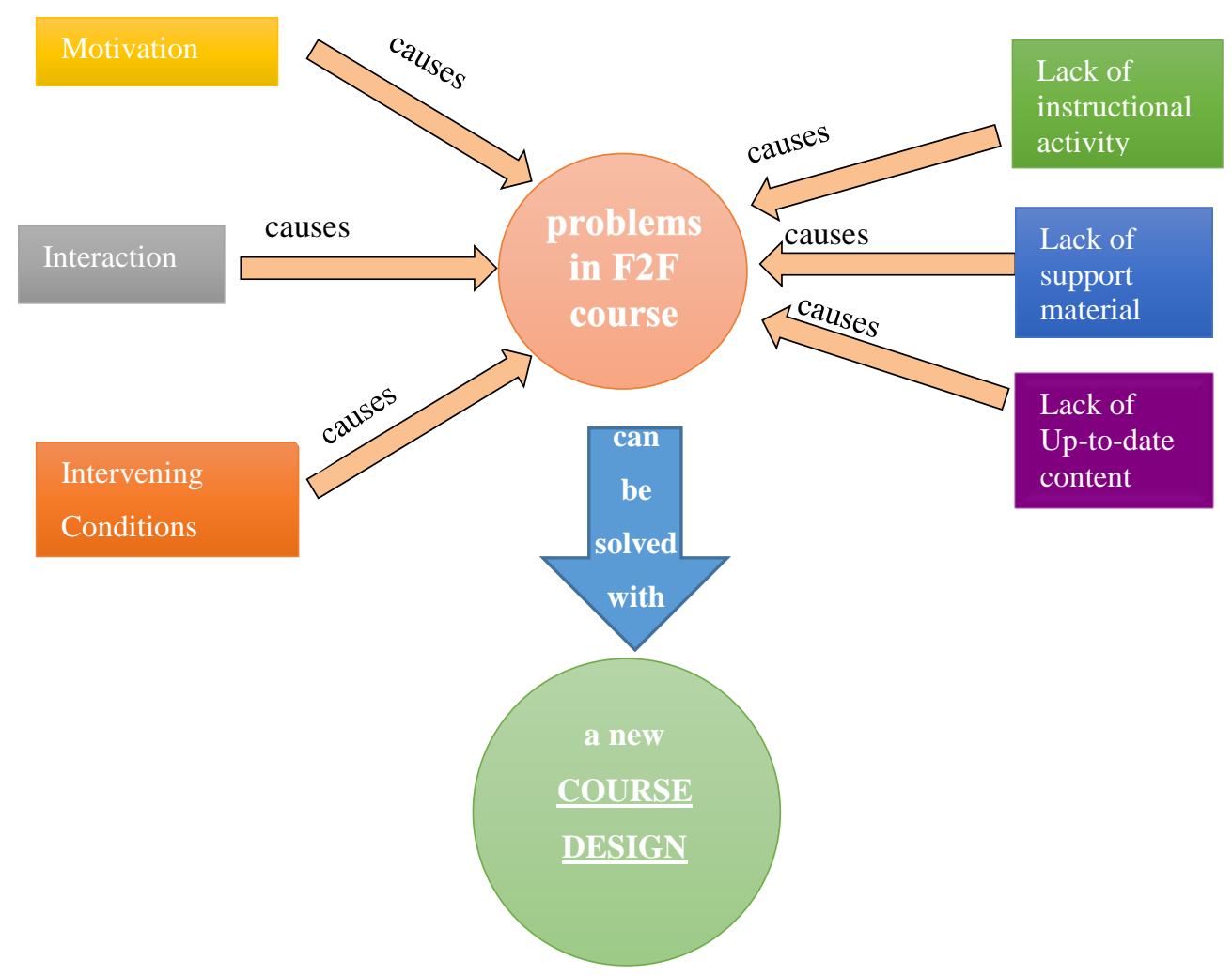

Figure 4-3 : Proposed Solution to Minimize Existing Problems 
In order to eliminate the problems of the existing F2F course in vocational higher education and to reach desired course level, we should be cautious about instructional design of the courses by considering interaction, motivation, support material, up-todate content, instructional activity, technical and non-technical problems. Researcher decided to work on a new instructional design as a solution to the problems of the existing F2F course. In this new course design process, researcher concentrated on those problems as much as possible.

In the design of the course researcher did not want to just presenting the same F2F content with converting them to electronic files to present them in the distance environment. Actually, conventional instructional design approach considers instruction from the perspective of the content rather than from the perspective of the learner and context. On the contrary, Morrison, Ross and Kemp's ID model presents the key elements of instructional design process as learners or trainees, objectives, instructional strategies, and evaluation procedures, which form the framework for instructional planning. For that reason, in the design process, Morisson, Ross, and Kemp's ID model was used as a framework. This process will be explained in the Appendix $\mathbf{J}$ in detail.

There is a fact that, in this research context it is not possible to deal with the intervening conditions of the existing course, researcher prefers to deal with the instructional problems. With this new ID of a web design course, the purpose of the course was to help students to become fluent in web design with its different elements like language syntax, graphic production, media development and publishing and webpage design.

\subsection{Students' Attitude towards WBI}

A new course was designed and given from one university to the other, and data were collected in the new design of the course at the end of the semester. Attitude questionnaires were administered to the students who take this course in order to obtain their views on the web-based instruction (WBI-AS). Moreover, demographic information questions were integrated to the existing the questionnaire by the researcher in order to specify demographic information of the students. 
Researcher's diaries and interviews supported abovementioned quantitative data collection procedure. Researcher interviewed with 6 students, to provide a deeper understanding about the new distance web design course. In this section for the triangulation purposes, quantitative results will be supported and extended with the qualitative findings.

\subsubsection{Descriptive Results}

As shown in Table 4-2, 32 students participated to the new distance course. 10 $(31.3 \%)$ of the students were female, $22(69.7 \%)$ of them were male. This unequal distribution of gender is very common in vocational schools.

Table 4-2 Descriptive Results (Gender)

\begin{tabular}{llrr}
\hline & & Frequency & Percent \\
\hline \multirow{2}{*}{ Valid } & Male & 22 & 69.7 \\
& Female & 10 & 31.3 \\
\hline \multirow{2}{*}{ Total } & & 32 & 100.0 \\
\hline
\end{tabular}

$20(62.5 \%)$ students connected to internet from internet cafes, $9(28.1 \%)$ of them at their home, $3(9.4 \%)$ of them were connected to internet at their school (see Table 4-3).

Table 4-3 Descriptive Results (Internet Connection)

\begin{tabular}{llrr}
\hline & & Frequency & Percent \\
\hline \multirow{4}{*}{ Valid } & At home & 9 & 28.1 \\
& At School & 3 & 9.4 \\
& At Café & 20 & 62.5 \\
& & & \\
\hline Total & & 32 & 100.0 \\
\hline
\end{tabular}


As seen in Table 4-4, 20 (62.5\%) of the students were at the age of 19-20 (18.8\%) of them were at the age of 21-22, 4 (12.5\%) of them were over 23 years old, and $2(6.3 \%)$ of them were under 18 years old.

Table 4-4 Descriptive Results (Age)

\begin{tabular}{llrr}
\hline & & Frequency & Percent \\
\hline \multirow{4}{*}{ Valid } & Under 18 & 2 & 6.3 \\
& $19-20$ & 20 & 62.5 \\
& $21-22$ & 6 & 18.8 \\
& 23 and above & 4 & 12.5 \\
\hline Total & & & \\
\hline
\end{tabular}

When we looked at the high school graduation of the students, $18(56.3 \%)$ of them were graduated from vocational high schools, 5 (15.6\%) of them from Anatolian high schools, and 4 (12.5\%) of them from high schools (see Table 4-5).

Table 4-5 Descriptive Results (High School Graduation)

\begin{tabular}{llrr}
\hline & Frequency & Percent \\
\hline \multirow{4}{*}{ Valid } & 4 & 12.5 \\
& High School & 5 & 15.6 \\
& Anatolian High School & 18 & 56.3 \\
& Vocational High School & 2 & 6.3 \\
& Other & 29 & 90.6 \\
& Total & 3 & 9.4 \\
\hline Missing & System & 32 & 100.0 \\
\hline Total & & & \\
\hline
\end{tabular}


As shown in Table 4-6, 11 (34.4\%) students have less than 750 TL income, 13 (40.6\%) students had between 750-1500 TL, and only 4 (12.5\%) of them had an income over 1500 TL.

Table 4-6 Descriptive Results (Monthly Income)

\begin{tabular}{llrr}
\hline & & Frequency & Percent \\
\hline \multirow{4}{*}{ Valid } & $0-750 \mathrm{TL}$ & 11 & 34.4 \\
& $750-1500 \mathrm{TL}$ & 13 & 40.6 \\
& $1500-2250 \mathrm{TL}$ & 4 & 12.5 \\
& Total & 27 & 84.4 \\
Missing & System & 4 & 12.5 \\
\hline Total & & 32 & 100.0 \\
\hline
\end{tabular}

When we looked at the computer experience of the students, they stated that 12 $(37.5 \%)$ of them had more than 4 year experience, 8 (25\%) of them had 2-4 year of experience, 3 (9.4\%) of them had 1-2 year experience, $6(18.8 \%)$ of them has less than one year of computer experience (see Table 4-7).

Table 4-7 Descriptive Results (Computer Experience)

\begin{tabular}{|c|c|c|c|}
\hline & & Frequency & Percent \\
\hline \multirow{5}{*}{ Valid } & $0-1$ year & 6 & 18.8 \\
\hline & 1-2 year & 3 & 9.4 \\
\hline & 2-4 year & 8 & 25.0 \\
\hline & More than 4 years & 12 & 37.5 \\
\hline & Total & 29 & 90.6 \\
\hline Missing & System & 3 & 9.4 \\
\hline Total & & 32 & 100.0 \\
\hline
\end{tabular}


As shown in Table 4-8, 10 (31.3\%) students did not have computers in their homes, but 19 (59.4\%) students have computers at home. Although this department is a computer education department, almost one third of the students did not have a computer, although most courses needed to have computer based activities.

Table 4-8 Descriptive Results (Computer Access At Home)

\begin{tabular}{llrr}
\hline & & Frequency & Percent \\
\hline \multirow{4}{*}{ Valid } & Yes & 19 & 59.4 \\
& No & 10 & 31.3 \\
& Total & 29 & 90.6 \\
\hline Missing & System & 3 & 9.4 \\
\hline Total & & 32 & 100.0 \\
\hline
\end{tabular}

As can be seen in Table 4-9, 17 (53.1\%) students used computer less than two hour in a day, $10(31.3 \%)$ of them used 2-4 hours, 1(3.1\%) of them 4-6 hours, and $1(3.1 \%)$ of them use computer more than 6 hours in a day.

Table 4-9 Descriptive Results (Daily Computer Usage)

\begin{tabular}{llrr}
\hline & & Frequency & Percent \\
\hline & Less than 2 hours & 17 & 53.1 \\
& 2-4 hours & 10 & 31.3 \\
Valid & 4-6 hours & 1 & 3.1 \\
& More than 6 hours & 1 & 3.1 \\
& Total & 29 & 90.6 \\
\hline Missing & System & 3 & 9.4 \\
\hline Total & & 32 & 100.0 \\
\hline
\end{tabular}


$16(50 \%)$ students have no internet connections in their homes, and $13(40.6 \%)$ of them have internet connections in their homes (see Table 4-10).

Table 4-10 Descriptive Results (Household Internet)

\begin{tabular}{llrr}
\hline & & Frequency & Percent \\
\hline \multirow{4}{*}{ Valid } & No & 16 & 50.0 \\
& Yes & 13 & 40.6 \\
& Total & 29 & 90.6 \\
\hline Missing & System & 3 & 9.4 \\
\hline Total & & 32 & 100.0 \\
\hline
\end{tabular}

Parallel with the daily computer usage, $19(59.4 \%)$ students were connected to internet less than two hours a day, $8(25 \%)$ of them connected to $2-4$ hours in a day, 1 (3.1\%)student connected to internet 2-4 hours, and only $1(3.1 \%)$ student connected to internet more than 6 hours (see Table 4-11).

Table 4-11 Descriptive Results (Daily Internet Usage)

\begin{tabular}{llrr}
\hline & & Frequency & Percent \\
\hline \multirow{4}{*}{ Valid } & Less than 2 hours & 19 & 59.4 \\
& 2-4 hours & 8 & 25.0 \\
& 4-6 hours & 1 & 3.1 \\
& More than 6 hours & 1 & 3.1 \\
& Total & 29 & 90.6 \\
\hline Missing & System & 3 & 9.4 \\
\hline Total & & 32 & 100.0 \\
\hline
\end{tabular}




\subsubsection{Overall Attitude towards WBI}

As it was mentioned in the method section of the study, this attitude questionnaire is consisting of two different factors. One of them is effectiveness of the WBI, the other is resistance to WBI. 26 questions were asked to the students to see their attitude towards WBI. The scale of this questionnaire was ranging from "totally agree" to "totally disagree". When we looked at the total mean score of the questionnaire $(M=3.19)$, it is between neutral and I agree. That means in general, students did not have negative attitudes towards WBI. When we looked at students attitude towards effectiveness of the WBI $(M=3.26)$, it is between neutral and agree, and a bit higher than general attitude towards WBI. The mean score of the resistance to the WBI is lower than the others $(M=2.88)$, and it is between disagree and neutral.

Table 4-12 Descriptive Statistics of Attitude Constructs

\begin{tabular}{|c|c|c|c|}
\hline & $\mathbf{N}$ & Mean & $\begin{array}{c}\text { Std. } \\
\text { Deviation }\end{array}$ \\
\hline Effectiveness & 32 & 3.26 & 1.02 \\
\hline Resistance & 32 & 2.88 & .64 \\
\hline Overall Attitude & 32 & 3.19 & .84 \\
\hline
\end{tabular}

Totally, 26 questions were asked to see students attitude towards WBI and 17 of them was related to effectiveness of WBI, 9 of them was related to resistance to WBI. In this part of the study, item based frequencies, mean scores and standard deviations will be presented.

\subsubsection{Effectiveness of WBI}

As it is shown in the Table 4-13, WBI improve my sense of responsibility ( $M=3.62$, $S D=1.36$ ) is seen as the most agreed effectiveness of WBI. Related to sense of responsibility perspective, Student 2-A stated that: 
In this kind of course, most of the responsibility is on the students. If a student wants to learn something more, he should spend more time on this. Just sitting and taking note is not possible...[I-45]

Moreover, students thought that widespreading WBI is beneficial for the society $(M=3.57, S D=1.38)$, and WBI will be indispensable in the future $(M=3.53, S D=1.29)$. Some students thought that the use of WBI would be beneficial for the society, and Students 2-C stated that:

This course was a good beginning for us, I have never been a part of this kind of a course, but probably in the future we will be familiar with it...[I-46]

On the other hand, they gradually less in favor of WBI is effective as traditional education $(M=2.93, S D=1.41)$. Especially, technical problems limit the effectiveness of the course and some of the students were distracted from those problems and related to this issue Student 2-F stated that:

Rather than participating this kind of a course, I would prefer F2F courses because I cannot be adapted to this system, using web site for everything we need, moreover I want to be in front of the instructor during the course, rather than far away... [I-47]

In the remaining section, item based mean scores and students' response rates to the effectiveness of WBI will be listed. 
Table 4-13 Statistics about Effectiveness of WBI

\begin{tabular}{|c|c|c|c|c|c|c|c|c|c|c|c|c|}
\hline & \multicolumn{2}{|c|}{ TD } & \multicolumn{2}{|c|}{ D } & \multicolumn{2}{|c|}{$\mathbf{N}$} & \multicolumn{2}{|c|}{$\mathbf{A}$} & \multicolumn{2}{|c|}{ TA } & \multirow[t]{2}{*}{$\mathbf{M}$} & \multirow[t]{2}{*}{ St. Dev. } \\
\hline & $\mathbf{N}$ & $\%$ & $\mathbf{N}$ & $\%$ & $\mathbf{N}$ & $\%$ & $\mathbf{N}$ & $\%$ & $\mathbf{N}$ & $\%$ & & \\
\hline $\begin{array}{l}\text { WBI-AS Q1: WBI } \\
\text { improve my sense of } \\
\text { responsibility }\end{array}$ & 4 & 12.5 & 3 & 9.4 & 4 & 12.5 & 11 & 34.4 & 10 & 31.3 & 3.62 & 1.36 \\
\hline $\begin{array}{l}\text { WBI-AS Q2: I } \\
\text { recommend WBI to my } \\
\text { friends }\end{array}$ & 5 & 15.6 & 4 & 12.5 & 6 & 18.8 & 8 & 25 & 9 & 28.1 & 3.37 & 1.43 \\
\hline $\begin{array}{l}\text { WBI-AS Q4: WBI should } \\
\text { be applied in higher } \\
\text { education }\end{array}$ & 6 & 18.8 & 6 & 18.8 & 7 & 21.9 & 9 & 28.1 & 4 & 12.5 & 2.96 & 1.33 \\
\hline $\begin{array}{l}\text { WBI-AS Q5: I can } \\
\text { communicate with } \\
\text { instructors in WBI }\end{array}$ & 2 & 6.3 & 7 & 21.9 & 7 & 21.9 & 14 & 43.8 & 2 & 6.3 & 3.22 & 1.06 \\
\hline $\begin{array}{l}\text { WBI-AS Q6: WBI is an } \\
\text { alternative solution to } \\
\text { education }\end{array}$ & 5 & 15.6 & 3 & 9.4 & 5 & 15.6 & 13 & 40.6 & 6 & 18.8 & 3.37 & 1.33 \\
\hline $\begin{array}{l}\text { WBI-AS Q8: } \\
\text { Widespreading WBI is } \\
\text { beneficial for the society }\end{array}$ & 3 & 9.4 & 6 & 18.8 & 3 & 9.4 & 9 & 28.1 & 11 & 34.4 & 3.57 & 1.38 \\
\hline
\end{tabular}


Table 4-13 (cont'd)

\begin{tabular}{|c|c|c|c|c|c|c|c|c|c|c|c|c|}
\hline & \multicolumn{2}{|c|}{ TD } & \multicolumn{2}{|c|}{ D } & \multicolumn{2}{|r|}{$\mathbf{N}$} & \multicolumn{2}{|c|}{$\mathbf{A}$} & \multicolumn{2}{|c|}{ TA } & \multirow[t]{2}{*}{$\mathbf{M}$} & \multirow[t]{2}{*}{ St. Dev. } \\
\hline & $\mathbf{N}$ & $\%$ & $\mathbf{N}$ & $\%$ & $\mathbf{N}$ & $\%$ & $\mathbf{N}$ & $\%$ & $\mathbf{N}$ & $\%$ & & \\
\hline $\begin{array}{l}\text { WBI-AS Q10: WBI gives } \\
\text { me opportunity to self- } \\
\text { paced learning }\end{array}$ & 4 & 12.5 & 9 & 28.1 & 5 & 15.6 & 8 & 25 & 6 & 18.8 & 3.09 & 1.35 \\
\hline $\begin{array}{l}\text { WBI-AS Q11: WBI } \\
\text { encourages me to research }\end{array}$ & 4 & 12.5 & 4 & 12.5 & 3 & 9.4 & 14 & 43.8 & 7 & 21.9 & 3.50 & 1.31 \\
\hline $\begin{array}{l}\text { WBI-AS Q12: Sufficient } \\
\text { guidance service is given } \\
\text { in WBI }\end{array}$ & 4 & 12.5 & 7 & 21.9 & 7 & 21.9 & 9 & 28.1 & 5 & 15.6 & 3.12 & 1.28 \\
\hline $\begin{array}{l}\text { WBI-AS Q15: WBI } \\
\text { improves my self- } \\
\text { confidence }\end{array}$ & 4 & 12.5 & 3 & 9.4 & 9 & 28.1 & 10 & 31.3 & 6 & 18.8 & 3.34 & 1.26 \\
\hline $\begin{array}{l}\text { WBI-AS Q16: I can } \\
\text { express my feeling freely } \\
\text { in WBI }\end{array}$ & 3 & 9.4 & 8 & 25 & 6 & 18.8 & 10 & 31.3 & 5 & 15.6 & 3.18 & 1.25 \\
\hline $\begin{array}{l}\text { WBI-AS Q17: WBI } \\
\text { encourages university- } \\
\text { industry cooperation }\end{array}$ & 3 & 9.4 & 7 & 21.9 & 9 & 28.1 & 6 & 18.8 & 7 & 21.9 & 3.21 & 1.28 \\
\hline
\end{tabular}


Table 4-13 (cont'd)

\begin{tabular}{|c|c|c|c|c|c|c|c|c|c|c|c|c|}
\hline & \multicolumn{2}{|c|}{ TD } & \multicolumn{2}{|c|}{ D } & \multicolumn{2}{|r|}{$\mathbf{N}$} & \multicolumn{2}{|c|}{$\mathbf{A}$} & \multicolumn{2}{|c|}{ TA } & \multirow[t]{2}{*}{$\mathbf{M}$} & \multirow[t]{2}{*}{ St. Dev } \\
\hline & $\mathbf{N}$ & $\%$ & $\mathbf{N}$ & $\%$ & $\mathbf{N}$ & $\%$ & $\mathbf{N}$ & $\%$ & $\mathbf{N}$ & $\%$ & & \\
\hline $\begin{array}{l}\text { WBI-AS Q19: WBI } \\
\text { ensure life-long learning }\end{array}$ & 8 & 25 & 1 & 3.1 & 8 & 25 & 9 & 28.1 & 6 & 18.8 & 3.12 & 1.45 \\
\hline $\begin{array}{l}\text { WBI-AS Q21: WBI is } \\
\text { effective as traditional } \\
\text { education }\end{array}$ & 7 & 21.9 & 6 & 18.8 & 6 & 18.8 & 8 & 25 & 5 & 15.6 & 2.93 & 1.41 \\
\hline $\begin{array}{l}\text { WBI-AS Q22: I trust on } \\
\text { WBI }\end{array}$ & 6 & 18.8 & 5 & 15.6 & 6 & 18.8 & 10 & 31.3 & 5 & 15.6 & 3.09 & 1.37 \\
\hline $\begin{array}{l}\text { WBI-AS Q24: I can take } \\
\text { sufficient feedback in } \\
\text { WBI }\end{array}$ & 2 & 6.3 & 5 & 15.6 & 15 & 46.8 & 6 & 18.8 & 4 & 12.5 & 3.16 & 1.04 \\
\hline $\begin{array}{l}\text { WBI-AS Q26: WBI will } \\
\text { be indispensable in the } \\
\text { future }\end{array}$ & 3 & 9.4 & 4 & 12.5 & 7 & 21.9 & 9 & 28.1 & 9 & 28.1 & 3.53 & 1.29 \\
\hline
\end{tabular}




\subsubsection{Resistance to WBI}

The other factor that was assessed in this attitude questionnaire is resistance to WBI. The most highlighted resistance is about "the problems in WBI makes me angry" $(M=3.65, S D=1.45)$, because this distance course highly technology oriented and technological problems caused students to resist on WBI. Student 2-D stated that:

We have faced many problems during the video conferencing. While we tried to connect, we have to wait for a while, and even we have connected, sometimes we had sound problems ...[I-48]

Moreover, none of the students were totally agree about "WBI is a waste of time" $(M=2.34, S D=.90)$. That was very important that none of the participants of this study thought that WBI is useless. Student 2-B stated that:

Although this is an initial attempt in this kind of studies, we have learnt many things about how to use internet as a technology for educational purposes...[I-49]

In the remaining section, item based mean scores and students' response rates to the resistance of WBI will be listed in Table 4-14. 
Table 4-14 Statistics about Resistance to WBI

\begin{tabular}{|c|c|c|c|c|c|c|c|c|c|c|c|c|}
\hline & \multicolumn{2}{|c|}{ TD } & \multicolumn{2}{|c|}{$\mathbf{D}$} & \multicolumn{2}{|c|}{$\mathbf{N}$} & \multicolumn{2}{|c|}{$\mathbf{A}$} & \multicolumn{2}{|c|}{ TA } & \multirow[t]{2}{*}{$\mathbf{M}$} & \multirow[t]{2}{*}{ St. Dev. } \\
\hline & $\mathbf{N}$ & $\%$ & $\mathbf{N}$ & $\%$ & $\mathbf{N}$ & $\%$ & $\mathbf{N}$ & $\%$ & $\mathbf{N}$ & $\%$ & & \\
\hline WBI-AS Q3: The problems in WBI makes me angry & 5 & 15.6 & 3 & 9.4 & 1 & 3.1 & 12 & 37.5 & 11 & 34.4 & 3.65 & 1.45 \\
\hline WBI-AS Q7: I quickly forget what I have learnt in WBI & 8 & 25 & 6 & 18.8 & 8 & 25 & 7 & 21.9 & 3 & 9.4 & 2.71 & 1.32 \\
\hline WBI-AS Q9: WBI effects teamwork in a negative manner & 8 & 25 & 7 & 21.9 & 10 & 31.3 & 5 & 15.6 & 2 & 6.3 & 2.56 & 1.21 \\
\hline WBI-AS Q13: WBI weaken my social side & 3 & 9.4 & 13 & 40.6 & 9 & 28.1 & 4 & 12.5 & 3 & 9.4 & 2.71 & 1.11 \\
\hline WBI-AS Q14: Because of WBI I cannot spare time for myself & 4 & 12.5 & 12 & 37.5 & 7 & 21.9 & 7 & 21.9 & 2 & 6.3 & 2.71 & 1.14 \\
\hline WBI-AS Q18: I get bored while I am studying on web & 4 & 12.5 & 7 & 21.9 & 10 & 31.3 & 4 & 12.5 & 7 & 21.9 & 3.09 & 1.32 \\
\hline WBI-AS Q20: I think WBI is boring & 6 & 18.8 & 9 & 28.1 & 3 & 9.4 & 9 & 28.1 & 5 & 15.6 & 2.93 & 1.41 \\
\hline WBI-AS Q23: WBI is a waste of time & 6 & 18.8 & 12 & 37.5 & 11 & 34.4 & 3 & 9.4 & 0 & 0 & 2.34 & .90 \\
\hline WBI-AS Q25: I do not feel myself belong to the university & 3 & 9.4 & 7 & 21.9 & 9 & 28.1 & 6 & 18.8 & 7 & 21.9 & 3.21 & 1.28 \\
\hline
\end{tabular}




\subsubsection{Comparisons with Some Demographic Data}

\subsubsection{Gender Difference on Students' Attitude towards WBI}

Actually, there is no significant difference between male and female students to effectiveness of WBI, resistance to WBI, and overall attitude. However, male students view on effectiveness of WBI is higher than the female student's. In addition to that, female students' resistance to WBI is higher than the male student's (see Table 4-15).

Table 4-15 Mean Scores of Attitudes towards WBI with Respect to Gender

\begin{tabular}{llrrr}
\hline & Sex & \multicolumn{1}{c}{ N } & Mean & $\begin{array}{c}\text { Std. } \\
\text { Deviation }\end{array}$ \\
\hline Effectiveness & Male & 18 & 3,53 & 1,03 \\
& Female & 10 & 2,71 & 1,02 \\
Resistance & Male & 18 & 2,72 &, 71 \\
Overall Attitude & Female & 10 & 3,13 &, 53 \\
& Male & 18 & 3,43 &, 88 \\
& Female & 10 & 2,75 &, 77 \\
\hline
\end{tabular}

\subsubsection{Computer Experience on Students' Attitude towards WBI}

One-way analysis of variance (ANOVA) was conducted to compare computer experience on effectiveness of WBI in 0-1 year, 1-2 year, 2-4 year, and 4 or more year. The ANOVA results indicated that there was a significant effect of computer experience on effectiveness of WBI at the $p<.05$ level for the four conditions $[F(3,25)=4.29, p=0.14]$. Since overall $F$ test was found significant, post-hoc comparison was performed to determine which institutes have significant mean difference. In this point, since Levene's Test of Equality of Error Variance was found insignificant indicating equal variances among the groups, therefore Tukey procedure was preferred for post hoc comparison. Post hoc comparisons using the Tukey HSD test indicated that the mean score for 0-1 year computer experience $(M=2.12, S D=$ $0.60)$ was significantly different from 1-2 year computer experience $(M=3.05, S D=$ 
1.02), 2-4 year computer experience $(M=3.75, S D=.87)$, and 4 or more year computer experience $(M=3.56, S D=1.04)$. However, 1-2 year computer experience $(M=3.05, S D=1.02)$ did not significantly differ from $0-1(M=2.12, S D=0.60), 2-4$ $(M=3.75, S D=.87)$, and 4 or more year computer experience $(M=3.56, S D=1.04)$. Taken together, these results suggest that long computer experience effect on effectiveness of WBI (see Table 4-16).

Table 4-16 Post-hoc Results, Mean and Standard Deviation Scores for Effectiveness of WBI

\begin{tabular}{llccccc}
\hline & M & SD & $\mathbf{1}$ & $\mathbf{2}$ & $\mathbf{3}$ & $\mathbf{4}$ \\
\hline 1. 0-1 years & 2.12 & .60 & -- & NS & $*$ & $*$ \\
2. 1-2 years & 3.05 & 1.02 & & -- & NS & NS \\
3. 2-4 years & 3.75 & .87 & & & -- & NS \\
4. More than 4 years & 3.56 & 1.04 & & & & -- \\
\hline
\end{tabular}

* The mean difference is significant at the 0.05 level.

$\mathrm{NS}=$ non-significant

One-way analysis of variance (ANOVA) was conducted to compare computer experience on students' overall attitude towards WBI in 0-1 year, 1-2 year, 2-4 year, and 4 or more year. The ANOVA results indicated that there was a significant effect of computer experience on effectiveness of WBI at the $p<.05$ level for the four conditions $[F(3,25)=3.63, p=0.27]$. Since overall $F$ test was found significant, post hoc comparison was performed to determine which institutes have significant mean difference. In this point, since Levene's Test of Equality of Error Variance was found insignificant indicating equal variances among the groups, therefore Tukey procedure was preferred for post hoc comparison. Post hoc comparisons using the Tukey HSD test indicated that the mean score for 0-1 year computer experience $(M=2.29, S D=$ .45) was significantly different than 1-2 year computer experience $(M=3.16, S D=$ .76), 2-4 year computer experience $(M=3.54, S D=.75)$, and 4 or more year computer experience $(M=3.45, S D=.90)$. However, $1-2$ year computer experience $(M=3.16$, 
$S D=.76)$ did not significantly differ from $0-1(M=2.29, S D=.45), 2-4(M=3.54$, $S D=.75)$, and 4 or more year computer experience $(M=3.45, S D=.90)$. Taken together, these results suggest that long computer experience has effects on students' attitude towards WBI (see Table 4-17).

Table 4-17 Post-hoc Results, Mean and Standard Deviation Scores for Students' Overall Attitude towards WBI

\begin{tabular}{lcccccc}
\hline & M & SD & $\mathbf{1}$ & $\mathbf{2}$ & $\mathbf{3}$ & $\mathbf{4}$ \\
\hline 1. 0-1 years & 2.29 & .45 & -- & NS & $*$ & $*$ \\
2. 1-2 years & 3.16 & .76 & & -- & NS & NS \\
3. 2-4 years & 3.54 & .75 & & & -- & NS \\
4. More than 4 years & 3.45 & .90 & & & & -- \\
\hline
\end{tabular}

* The mean difference is significant at the 0.05 level.

$\mathrm{NS}=$ non-significant

One of the experienced students, who voluntarily helped researcher during the study Student 2-B stated that:

I have been dealing with computer for a long time but even for me it is complicated to use this system, getting familiar with them took some time. Especially in video conferencing being far away and tried to communicate with instructor was a different experience for me ... [I-50]

\subsubsection{High School Graduation on Students'Attitude towards WBI}

One-way analysis of variance (ANOVA) was conducted to compare high school graduation on effectiveness of WBI (see Table 4-18). The ANOVA results indicated that there was a significant effect of high school graduation on effectiveness of WBI at the $p<.05$ level for the four conditions $[F(3,25)=7.61, p=0.01]$. Since overall $F$ test was found significant, post hoc comparison was performed to determine which institutes have significant mean difference. In this point, since Levene's Test of Equality of Error Variance was found insignificant indicating equal variances among 
the groups, therefore Tukey procedure was preferred for post hoc comparison. Posthoc comparisons using the Tukey HSD test indicated that the mean score for students who have graduated from high schools $(M=1.81, S D=0.53)$ was significantly different than students who have graduated from vocational high schools $(M=3.63$, $S D=.90)$, and graduates of other schools $(M=4.41, S D=.58)$.

Table 4-18 Post-hoc Results, Mean and Standard Deviation Scores for Effectiveness of WBI

\begin{tabular}{lcccccc}
\hline & M & SD & 1 & 2 & 3 & $\mathbf{4}$ \\
\hline 1. High School & 1.81 & .53 & -- & NS & $*$ & $*$ \\
2. Anatolian High School & 2.64 & .66 & & -- & NS & NS \\
3. Vocational High School & 3.63 & .90 & & & -- & NS \\
4. Other & 4.41 & .58 & & & & -- \\
\hline
\end{tabular}

* The mean difference is significant at the 0.05 level.

$\mathrm{NS}=$ non-significant

One-way analysis of variance (ANOVA) was conducted to compare high school graduation on students' overall attitude towards WBI (see Table 4-19). The ANOVA results indicated that there was a significant effect of high school graduation on students' attitude towards WBI at the $\mathrm{p}<.05$ level for the four conditions $[F(3,25)=6.38, p=0.02]$. Since overall $F$ test was found significant, post hoc comparison was performed to determine which institutes have significant mean difference.

In this point, since Levene's Test of Equality of Error Variance was found insignificant indicating equal variances among the groups, therefore Tukey procedure was preferred for post hoc comparison. Post hoc comparisons using the Tukey HSD test indicated that the mean score for high school graduate students $(\mathrm{M}=2.15, \mathrm{SD}=$ 0.49) was significantly different than vocational high school graduate students $(\mathrm{M}=$ $3.51, \mathrm{SD}=.77)$, and graduates of other schools $(\mathrm{M}=4.06, \mathrm{SD}=.65)$. 
Table 4-19 Post-hoc Results, Mean and Standard Deviation Scores for Students' Overall Attitude towards WBI

\begin{tabular}{lcccccc}
\hline & M & SD & 1 & 2 & 3 & $\mathbf{4}$ \\
\hline 1. High School & 2.15 & .49 & -- & NS & $*$ & $*$ \\
2. Anatolian High School & 2.60 & .46 & & -- & NS & NS \\
3. Vocational High School & 3.51 & .77 & & & -- & NS \\
4. Other & 4.06 & .65 & & & & -- \\
\hline
\end{tabular}

* The mean difference is significant at the 0.05 level.

$\mathrm{NS}=$ non-significant

In the field notes, researcher highlights this issue that students who have graduated from High School have adaptation problems to this new way of instruction. Researcher noted that:

Some students who were mainly graduated from high school were have problems in using web site and CMC tool, they were always asking questions about how to reach and how to connect even how to install

\subsubsection{Household Internet Connection on Students' Attitude towards WBI}

As can be seen in the Table 4-20, the average effectiveness of WBI score of students who have no internet connection is 2.89 with a standard deviation of 1.15 and that of students who have internet connection is 3.73 with a standard deviation of .76 . To determine the possible effect of household internet belonging on students' attitude towards effectiveness of WBI, independent t-tests were run. There was a significant difference in the students' attitude towards effectiveness of WBI, students who have internet connection or not: $\mathrm{T}(26.07)=-2.33, \mathrm{p}=.027$. 
Table 4-20 T-test Results for Household Internet Belonging on Students' View on Effectiveness of WBI

\begin{tabular}{llrrrrrr}
\hline & Household & & & & & & \\
& Internet & N & Mean & St. Dev. & T & Df & Sig \\
\hline Effectiveness & Yes & 16 & 2.89 & 1.15 & & 26.07 & .027 \\
& No & 13 & 3.73 & .76 & & & \\
\hline
\end{tabular}

As can be seen in the Table 4-21, the average score of students' overall attitude towards WBI score of students who have no internet connection is 2.9 with a standard deviation of 0.9 and that of students who have internet connection is 3.58 with a standard deviation of .70. To determine the possible effect of household internet belonging on students' attitude towards WBI, independent t-tests were run. There was a significant difference in the students' attitude towards WBI, students who have internet connection or not: $\mathrm{T}(27)=-2.22, \mathrm{p}=.035$.

Table 4-21 T-test Results for Household Internet Belonging on Students' Overall Attitude towards WBI

\begin{tabular}{lrrrrrrrr}
\hline & \multicolumn{2}{c}{$\begin{array}{c}\text { Household } \\
\text { Internet }\end{array}$} & N & Mean & St. Dev. & T & Df & Sig \\
\hline $\begin{array}{l}\text { Overall } \\
\text { Attitude }\end{array}$ & Yes & & 16 & 2.9 & .90 & & & \\
& No & 13 & 3.58 & .70 & & & \\
\hline
\end{tabular}

Internet connection that is available in the house or in the dormitories significantly affected the students view on WBI. Related to this issue Student 2-F stated that: 
"The most important problem that I faced in this course was all the documents were on the web, everything is online, even the courses. However, I lived in the dorm and there is no internet connection. For that reson, I have to go to internet café and spend my hours there...Moreover, there is no program installed that we use and I cannot practice..." $[\mathrm{I}-51]$

\subsection{Students' Perceptions about Learning Environment of the New Course}

Students' perceptions about learning environment of the new course were assessed with a questionnaire consists of:

- Self-Reported Computer Competency

- Self-Reported E-learning Experience

- Perceived Effects on Students' Motivation

- Perceived Usefulness

- Perceived Ease of Use

This questionnaire is a modified version of a TAM. In this questionnaire, perceived usefulness and perceived ease of use are important factors for this study. Perceived usefulness is an important concept that influence students' intention to use the technology. The other construct perceived ease of use structured the use of the system free of effort. Those two construct will show us students are willing to adopt applications of e-learning environment. To improve the TAM's predictive value for the this distance course, additional constructs, Computer Self-Efficacy, E-learning Experience, and Perceived Effects on Students' Motivation was included in the model. The results of this study show that TAM can be used to explain the students acceptance of e-learning Technology

\subsubsection{Students' Computer Competency}

As a part of the perception questionnaire, researcher asked the students' self-reported computer competency level (see Table 4-22). Students' competencies about web browser, search engine, e-mail, online forums and blogs, online chat applications, Word, Excel, PowerPoint, and e-learning application were asked in this part of the 
questionnaire. $13(40.6 \%)$ students reported their competencies on web browser as intermediate, and $9(28.1 \%)$ of them reported as an expert. The strange data is $2(6.3 \%)$ students stated that they are not using web browser, and $8(25 \%)$ of them stated themselves as a beginner in a computer education department.

Students' competency on search engine was gradually better than web browser. The number of expert students on search engine was 11 (34.4\%). $16(50 \%)$ of them were intermediate, $5(15.6 \%)$ of them were beginner. Similarly, $13(40.6 \%)$ students define their e-mail competency as expert. 15 (46.9\%) students stated that they were intermediate, $4(12.5 \%)$ of them were beginner. With respect to competencies on forums and blogs, $4(12.5 \%)$ students express themselves as an expert, 10 (31.3\%) of them as an intermediate, $14(43.8 \%)$ of them as beginner, $4(12.5 \%)$ of them stated that they were not used forums and blogs. Students define their competencies on chat applications were lower than that. None of the students reported their chat application competency as an expert. $12(30.5 \%)$ of them were intermediate, $13(40.6 \%)$ of them were beginner chat application users, and 7 (21.9\%) of them were not using those kind of applications.

According to participants answers on their self-reported computer competency was moderate with respect to MS Office applications. 12 (37.5\%) students were expert MS Word users, $16(50 \%)$ of the students were intermediate, $4(12.5 \%)$ of them were beginner MS Word users. The MS Excel results are a little bit worse than word. 6 $(18.8 \%)$ students were expert users, $14(43.8 \%)$ of them were intermediate users, 6 $(18.8 \%)$ of them were beginner users, and $6(18.8 \%)$ of them were not used. $9(28.1 \%)$ students express their PowerPoint competency as expert, 15 (46.9\%) of them were intermediate, $8(25 \%)$ of them were beginner. However, students self-reported elearning application competency was very low. Only $1(3.1 \%)$ of them define himself/herself as an expert, 1(3.1\%) of them as an intermediate user, $6(18.8 \%)$ of them as a beginner, $24(75 \%)$ of them as a not used before the course.

Those results represented that students have medium computer competency level as we expected. This situation somehow related to students' background knowledge, somehow socio-economic status that effect internet connection. Student 2-E stated that: 
Some of our friends even do not have a computer, for that reason only way to connect to the course site was using computer laboratory of the school...I think as a first distance course experience we need more time to adapt this system...[I-52]

Table 4-22 Statistics of Students' Self-Reported Computer Competencies

\begin{tabular}{|c|c|c|c|c|c|c|c|c|}
\hline & \multicolumn{2}{|c|}{ Not Used } & \multicolumn{2}{|c|}{ Beginner } & \multicolumn{2}{|c|}{ Intermediate } & \multicolumn{2}{|c|}{ Expert } \\
\hline & $\mathbf{N}$ & $\%$ & $\mathbf{N}$ & $\%$ & $\mathbf{N}$ & $\%$ & $\mathbf{N}$ & $\%$ \\
\hline Web Browsers & 2 & 6.3 & 8 & 25 & 13 & 40.6 & 9 & 28.1 \\
\hline Search Engines & 0 & 0 & 5 & 15.6 & 16 & 50 & 11 & 34.4 \\
\hline E-mail & 0 & 0 & 4 & 12.5 & 15 & 46.9 & 13 & 40.6 \\
\hline Online Forums \& Blogs & 4 & 12.5 & 14 & 43.8 & 10 & 31.3 & 4 & 12.5 \\
\hline Online Chat Applications & 7 & 21.9 & 13 & 40.6 & 12 & 30.5 & 0 & 0 \\
\hline Microsoft Word Application & 0 & 0 & 4 & 12.5 & 16 & 50 & 12 & 37.5 \\
\hline Microsoft Excel Application & 6 & 18.8 & 6 & 18.8 & 14 & 43.8 & 6 & 18.8 \\
\hline $\begin{array}{l}\text { Microsoft PowerPoint } \\
\text { Application }\end{array}$ & 0 & 0 & 8 & 25 & 15 & 46.9 & 9 & 28.1 \\
\hline E-Learning Applications & 24 & 75 & 6 & 18.8 & 1 & 3.1 & 1 & 3.1 \\
\hline
\end{tabular}




\subsubsection{Self-Reported E-Learning Background}

As a second part of the perception questionnaire students' self-reported e-learning background were asked in 4 questions. The results revealed that students have limited or no e-learning background. For instance, only $6(18.8 \%)$ students stated that they had taken web-supported or online course before. Only $1(3.1 \%)$ student stated that he/she had a distance course experience before that course. Interestingly more than a half of the students stated that they have never used internet for their courses before. Similar to the distance course experience results, only one student stated his/her elearning/sharing portal experience.

These results showed that students have low-level e-learning experience. For that reason, adapting to this new environment and changing habits needs time for students. Student 2-B stated about that:

I have taken a distance course in the two-year program, but it is not that complicated system. Only we can reach some pdf files, but in that course it was over my expectation, even I do not think that I can effectively use everything in the course...[I-53]

Table 4-23 Statistics of Students' Self-Reported E-Learning Background

\begin{tabular}{|c|c|c|c|c|}
\hline & \multicolumn{2}{|c|}{ Yes } & \multicolumn{2}{|c|}{ No } \\
\hline & $\mathbf{N}$ & $\%$ & $\mathbf{N}$ & $\%$ \\
\hline $\begin{array}{l}\text { Have you ever taken any web-supported or online course } \\
\text { before this semester? }\end{array}$ & 6 & 18.8 & 26 & 81.3 \\
\hline $\begin{array}{l}\text { Have you ever taken any distance learning application in } \\
\text { your courses before this semester? }\end{array}$ & 1 & 3.1 & 31 & 96.9 \\
\hline $\begin{array}{l}\text { Have you ever used Internet for your course studies } \\
\text { before this semester? }\end{array}$ & 17 & 53.1 & 15 & 46.9 \\
\hline $\begin{array}{l}\text { Have you ever used any e-learning/sharing portal } \\
\text { application in your courses until now? }\end{array}$ & 1 & 3.1 & 31 & 96.9 \\
\hline
\end{tabular}




\subsubsection{Students' Perceptions about Learning Environment}

The remaining section of the questionnaire is to see the effects of the use of tools in distance "web design" course with respect to students' perceived motivation, perceived usefulness, and perceived ease of use (see Table 4-24). 27 questions were asked ranging from "Strongly Agree" to "Strongly Disagree" to see the students' perceptions with respect to these 3 factors, namely "Perceived Effects on Motivation", "Perceived Usefulness", "Perceived Ease of Use".

When we looked at the perceived effects on motivation (M=3.15), it is between neutral and agree. Mean score of perceived usefulness' is 3.23. It is a bit higher than perceived effects on motivation, and it is between neutral and agree in the scale. The mean score of perceived ease of use is 2.97 . It is a little bit lower than 3 , that means it is in the range of neutral an disagree. The overall perception mean is 3.11 .

Table 4-24 Descriptive Statistics of Perception Constructs

\begin{tabular}{lccr}
\hline & N & M & Std. Dev. \\
\hline Perceived Effects on Motivation & 32 & 3.15 & .96 \\
Perceived Usefulness & 32 & 3.23 & .97 \\
Perceived Ease of Use & 32 & 2.97 & .73 \\
\hline Overall Perception & 32 & 3.11 & .84 \\
\hline
\end{tabular}

\subsubsection{Perceived Effects of Motivation}

9 questions were asked to the students to see the effects of students' perceptions about the tools that were used in the distance course on their motivation. The sub-factors of this construct are interest/enjoyment, perceived competence, willingness, and participation. 
As it can be seen in the Table 4-25, all sub-factors' mean score is over three. That means students agreed on learning environment had positive effect on motivation. Especially, "interest \& enjoyment" $(M=3.21)$ and "willingness" $(M=3.20)$ of the learning environment seems to have more positive effects on students' motivation. Although mean scores of "Perceived Competence" $(M=3.06)$ and "Participation" $(M=3.09)$ mean scores were over three, these were lower than the other two one.

Table 4-25 Mean Scores, and Standard Deviations of Sub-factors of Perceived Effects of Motivation

\begin{tabular}{lrrr}
\hline & N & M & Std. Dev. \\
\hline Interest \& Enjoyment & 32 & 3.21 & 1.06 \\
Perceived Competence & 32 & 3.06 & 1.04 \\
Willingness & 32 & 3.20 & 1.03 \\
Participation & 32 & 3.09 & 1.04 \\
Overall Perceived Effects of & 32 & 3.15 & .96 \\
Motivation & & & \\
\hline
\end{tabular}

\subsection{Interest \& Enjoyment}

Three questions were asked to understand the effects of interest and enjoyment of the learning environment on students' motivation. Students were not agreed on learning environment made educational activities enjoyable $(M=2.93)$. Related to the interest of students on educational activities $(M=3.22)$, students' responses revealed that they were between neutral and agree. 
Table 4-26 Frequencies, Mean Scores, and Standard Deviations for "Interest \& Enjoyment"

\begin{tabular}{|c|c|c|c|c|c|c|c|c|c|c|c|c|}
\hline & \multicolumn{2}{|c|}{ SD } & \multicolumn{2}{|r|}{ D } & \multicolumn{2}{|c|}{$\mathbf{N}$} & \multicolumn{2}{|c|}{$\mathbf{A}$} & \multicolumn{2}{|c|}{$\mathbf{S A}$} & \multirow[t]{2}{*}{$\mathbf{M}$} & \multirow{2}{*}{$\begin{array}{c}\text { St. } \\
\text { Dev. }\end{array}$} \\
\hline & $\mathbf{N}$ & $\%$ & $\mathbf{N}$ & $\%$ & $\mathbf{N}$ & $\%$ & $\mathbf{N}$ & $\%$ & $\mathbf{N}$ & $\%$ & & \\
\hline $\begin{array}{l}\text { Section 3-Q4 } \\
\ldots \text { increased } \\
\text { my interest on } \\
\text { our } \\
\text { educational } \\
\text { activities. }\end{array}$ & 3 & 9.4 & 6 & 18.8 & 6 & 18.8 & 15 & 46.9 & 2 & 6.3 & 3.22 & 1.12 \\
\hline $\begin{array}{l}\text { Section 3-Q6 } \\
\text {... made our } \\
\text { educational } \\
\text { activities } \\
\text { enjoyable. }\end{array}$ & 5 & 15.6 & 8 & 25.0 & 7 & 21.9 & 8 & 25.0 & 4 & 12.5 & 2.93 & 1.29 \\
\hline $\begin{array}{l}\text { Section 3-Q19 } \\
\text {... made our } \\
\text { educational } \\
\text { activities } \\
\text { boring. }\end{array}$ & 2 & 6.3 & 8 & 25.0 & 4 & 12.5 & 9 & 28.1 & 9 & 28.1 & 3.46 & 1.31 \\
\hline
\end{tabular}

Note: Question 3.19 were reversely coded

Student 2-C stated that:

In each time, I visited the web site I could see new materials for us, course video, pdffiles, sample video activity. Course web site was the most important tool that I have used in the course, especially every new video covers a new topic was beneficial... [I-54]

\subsection{Perceived Competence}

Perceived competence is a term to identify students' own thoughts about their ability in a specific area. That is important concept that represents high perceived competence 
will be the reason to enjoy the activities they are involved in. In this questionnaire one question were asked to assess that. The mean score of this question was 3.06, and it was between neutral and agree. That means most of the students were not strongly agreed on they were capable of using tools in the learning environment (see Table 427).

Table 4-27 Frequencies, Mean Scores, and Standard Deviations for "Perceived Competence"

\begin{tabular}{|c|c|c|c|c|c|c|c|c|c|c|c|c|}
\hline & \multicolumn{3}{|c|}{ SD } & D & \multicolumn{2}{|c|}{$\mathbf{N}$} & \multicolumn{2}{|l|}{$\mathbf{A}$} & \multicolumn{2}{|l|}{ SA } & \multirow[t]{2}{*}{$\mathbf{M}$} & \multirow[t]{2}{*}{$\begin{array}{c}\text { St. } \\
\text { Dev. }\end{array}$} \\
\hline & $\mathbf{N}$ & $\%$ & $\mathbf{N}$ & $\%$ & $\mathbf{N}$ & $\%$ & $\mathbf{N}$ & $\%$ & $\mathbf{N}$ & $\%$ & & \\
\hline $\begin{array}{l}\text { Section 3-Q16 } \\
\text {... increased my } \\
\text { satisfaction } \\
\text { about our } \\
\text { educational } \\
\text { activities. }\end{array}$ & 2 & 6.3 & 8 & 25.0 & 10 & 31.3 & 10 & 31.3 & 2 & 6.3 & 3.06 & 1.04 \\
\hline
\end{tabular}

\subsection{Willingness}

Three questions were asked to investigate this factor. Question 7 and 18 were asked to see the effects of this learning environment on students' willingness (see Table 428). The mean score was over three and that means students did not have negative perceptions about the effect of learning environment on their willingness. Related to the motivation question that was asked in the question 11, it was a bit lower than three $(M=2.93)$. 
Table 4-28 Frequencies, Mean Scores, and Standard Deviations for "Willingness"

\begin{tabular}{|c|c|c|c|c|c|c|c|c|c|c|c|c|}
\hline & \multicolumn{2}{|c|}{ SD } & \multicolumn{2}{|c|}{ D } & \multicolumn{2}{|c|}{$\mathbf{N}$} & \multicolumn{2}{|c|}{$\mathbf{A}$} & \multicolumn{2}{|c|}{$\mathbf{S A}$} & \multirow[t]{2}{*}{$\mathbf{M}$} & \multirow{2}{*}{$\begin{array}{l}\text { St. } \\
\text { Dev. }\end{array}$} \\
\hline & $\mathbf{N}$ & $\%$ & $\mathbf{N}$ & $\%$ & $\mathbf{N}$ & $\%$ & $\mathbf{N}$ & $\%$ & $\mathbf{N}$ & $\%$ & & \\
\hline $\begin{array}{l}\text { Section 3-Q7 } \\
\text {... decreased } \\
\text { my } \\
\text { willingness to } \\
\text { work on our } \\
\text { educational } \\
\text { activities. }\end{array}$ & 2 & 6.3 & 8 & 25.0 & 10 & 31.3 & 10 & 31.3 & 2 & 6.3 & 3.40 & 1.21 \\
\hline $\begin{array}{l}\text { Section 3-Q11 } \\
\ldots \text { increased } \\
\text { my } \\
\text { motivation } \\
\text { towards our } \\
\text { educational } \\
\text { activities. }\end{array}$ & 6 & 18.8 & 5 & 15.6 & 7 & 21.9 & 13 & 40.6 & 1 & 3.1 & 2.93 & 1.21 \\
\hline $\begin{array}{l}\text { Section 3-Q18 } \\
\text {... increased } \\
\text { willingness to } \\
\text { work on our } \\
\text { educational } \\
\text { activities. }\end{array}$ & 3 & 9.4 & 6 & 18.8 & 6 & 18.8 & 13 & 40.6 & 4 & 12.5 & 3.28 & 1.19 \\
\hline
\end{tabular}

Note: Question 3.07 were reversely coded

Student 2-C stated express his/her willingness to use learning environment with saying:

In traditional courses I sometimes suffer from my embarresement, I had questions but I cannot asked them and waiting to someone else to ask. But use of chat tool.. It is different, I can meet with the instructor unexpectedly, and I can freely talk with him... [I-55] 


\subsection{Participation}

Students' perceptions about the participation in learning environment also important factor that contributes to the motivation (see Table 4-29). The more positive perception on participation in learning environment will cause increased motivation. In order to see students' view on this factor, two questions were asked. In the third question students view on participation were asked $(M=3.03)$, and in the twelfth question students time spent on the learning environment were asked $(M=3.15)$.

Table 4-29 Frequencies, Mean Scores, and Standard Deviations for "Participation"

\begin{tabular}{|c|c|c|c|c|c|c|c|c|c|c|c|c|}
\hline & \multicolumn{3}{|c|}{ SD } & D & \multicolumn{2}{|c|}{$\mathbf{N}$} & \multicolumn{2}{|l|}{$\mathbf{A}$} & \multicolumn{2}{|c|}{$\mathbf{S A}$} & \multirow[t]{2}{*}{$\mathbf{M}$} & \multirow[t]{2}{*}{$\begin{array}{c}\text { St. } \\
\text { Dev. }\end{array}$} \\
\hline & $\mathbf{N}$ & $\%$ & $\mathbf{N}$ & $\%$ & $\mathbf{N}$ & $\%$ & $\mathbf{N}$ & $\%$ & $\mathbf{N}$ & $\%$ & & \\
\hline $\begin{array}{l}\text { Section 3-Q3 ... } \\
\text { increased my } \\
\text { participation to } \\
\text { our educational } \\
\text { activities. }\end{array}$ & 3 & 9.4 & 8 & 25.0 & 7 & 21.9 & 13 & 40.6 & 1 & 3.1 & 3.03 & 1.09 \\
\hline $\begin{array}{l}\text { Section } 3-\mathrm{Q} 12 \\
\ldots \text { increased my } \\
\text { study time on } \\
\text { our educational } \\
\text { activities. }\end{array}$ & 3 & 9.4 & 9 & 28.1 & 4 & 12.5 & 12 & 37.5 & 4 & 12.5 & 3.15 & 1.24 \\
\hline
\end{tabular}

Student 2-B stated that:

I have used communicator to talk with the instructor and you (teaching assitant) but most of my friends have problems to install it in their computers...[I-56] 


\subsubsection{Perceived Usefulness}

Students' perceptions about the usefulness of the learning environment were asked with 10 questions. Usefulness is an important concept to represent learning environment's effect on students' performance on educational activities. It was investigated with 6 sub-factors namely: Work More Quickly, Job Performance, Increase Productivity, Effectiveness, Makes Job Easier, and Useful.

As it can be seen in the Table 4-30, all sub-factors' mean score is over three except "Makes Job Easier" factor $(M=2.74)$. That means students agreed on learning environment had positive effect on usefulness.

Table 4-30 Mean Scores and Standard Deviation of Sub-factors of Perceived Usefulness

\begin{tabular}{|c|c|c|c|}
\hline & $\mathbf{N}$ & Mean & $\begin{array}{c}\text { Std. } \\
\text { Deviation }\end{array}$ \\
\hline Work More Quickly & 32 & 3.04 & 1.06 \\
\hline Job Performance & 32 & 3.32 & 1.04 \\
\hline Increase Productivity & 32 & 3.21 & 1.23 \\
\hline Effectiveness & 32 & 3.56 & 1.24 \\
\hline Makes Job Easier & 32 & 2.74 & 1.01 \\
\hline Useful & 32 & 3.35 & 1.08 \\
\hline Overall Perceived Usefulness & 32 & 3.23 & .97 \\
\hline
\end{tabular}

\subsection{Work More Quickly}

Work more quickly is one of the sub-factors of perceived usefulness. It supports learning environment as a time-consuming thing, or time saving opportunity for students. Two questions were asked to the students (see Table 4-31). For question one, none of the students strongly agreed on it enables them to achieve educational 
activities faster. For question fifteen, the mean score was 3.4, that means they do not agreed on learning environment was the reason for decrease in their work speed.

Table 4-31 Frequencies, Mean Scores, and Standard Deviations for "Work More Quickly"

\begin{tabular}{|c|c|c|c|c|c|c|c|c|c|c|c|c|}
\hline & \multicolumn{2}{|c|}{ SD } & \multicolumn{2}{|c|}{ D } & \multicolumn{2}{|c|}{$\mathbf{N}$} & \multicolumn{2}{|l|}{$\mathbf{A}$} & \multicolumn{2}{|c|}{$\mathbf{S A}$} & \multirow[t]{2}{*}{$\mathbf{M}$} & \multirow[t]{2}{*}{$\begin{array}{c}\text { St. } \\
\text { Dev. }\end{array}$} \\
\hline & $\mathbf{N}$ & $\%$ & $\mathbf{N}$ & $\%$ & $\mathbf{N}$ & $\%$ & $\mathbf{N}$ & $\%$ & $\mathbf{N}$ & $\%$ & & \\
\hline $\begin{array}{l}\text { Section 3-Q1 } \\
\text {... enabled us } \\
\text { to accomplish } \\
\text { educational } \\
\text { activities more } \\
\text { quickly. }\end{array}$ & 7 & 21.9 & 6 & 18.8 & 9 & 28.1 & 10 & 31.3 & 0 & 0 & 2.68 & 1.14 \\
\hline $\begin{array}{l}\text { Section 3- } \\
\text { Q15... } \\
\text { decreased my } \\
\text { work speed in } \\
\text { our } \\
\text { educational } \\
\text { activities. }\end{array}$ & 3 & 9.4 & 4 & 12.5 & 8 & 25.0 & 11 & 34.4 & 6 & 18.8 & 3.40 & 1.21 \\
\hline
\end{tabular}

Note: Question 3.15 were reversely coded

\subsection{Job Performance}

Although it is a term that is widely used in business, in this context it is used as a term to define how well a student performs in educational activities. Two questions were asked to clarify this sub-factor of usefulness, and the mean scores of two of them were over 3 (see Table 4-32). That means, most of the students were neutral or agreed on learning environment had positive effect on job performance. 
Table 4-32 Frequencies, Mean Scores, and Standard Deviations for "Job

Performance"

\begin{tabular}{|c|c|c|c|c|c|c|c|c|c|c|c|c|}
\hline & \multicolumn{2}{|c|}{ SD } & \multicolumn{2}{|c|}{ D } & \multicolumn{2}{|c|}{$\mathbf{N}$} & \multicolumn{2}{|l|}{$\mathbf{A}$} & \multicolumn{2}{|c|}{$\mathbf{S A}$} & \multirow[t]{2}{*}{$\mathbf{M}$} & \multirow{2}{*}{$\begin{array}{c}\text { St. } \\
\text { Dev. }\end{array}$} \\
\hline & $\mathbf{N}$ & $\%$ & $\mathbf{N}$ & $\%$ & $\mathbf{N}$ & $\%$ & $\mathbf{N}$ & $\%$ & $\mathbf{N}$ & $\%$ & & \\
\hline $\begin{array}{l}\text { Section 3-Q2... } \\
\text { improved my } \\
\text { performance in } \\
\text { our educational } \\
\text { activities. }\end{array}$ & 3 & 9.4 & 6 & 18.8 & 8 & 25.0 & 13 & 40.6 & 2 & 6.3 & 3.15 & 1.11 \\
\hline $\begin{array}{l}\text { Section 3- } \\
\text { Q14... has } \\
\text { decreased my } \\
\text { performance in } \\
\text { our educational } \\
\text { activities. }\end{array}$ & 3 & 9.4 & 5 & 15.6 & 5 & 15.6 & 11 & 34.4 & 8 & 25.0 & 3.50 & 1.29 \\
\hline
\end{tabular}

Note: Question 3.14 were reversely coded

\subsection{Productivity}

Productivity is a measure that support efficiency of a student based on outputs. Increased productivity increases the usability of the learning environment. With this respect one question were asked to the students, and its $M=3.21$ (see Table 4-33). 
Table 4-33 Frequencies, Mean Score, and Standard Deviation for "Productivity"

\begin{tabular}{|c|c|c|c|c|c|c|c|c|c|c|c|c|}
\hline & \multicolumn{2}{|c|}{ SD } & \multicolumn{2}{|r|}{ D } & \multicolumn{2}{|c|}{$\mathbf{N}$} & \multicolumn{2}{|l|}{$\mathbf{A}$} & \multicolumn{2}{|l|}{$\mathbf{S A}$} & \multirow[t]{2}{*}{$\mathbf{M}$} & \multirow{2}{*}{$\begin{array}{c}\text { St. } \\
\text { Dev. }\end{array}$} \\
\hline & $\mathbf{N}$ & $\%$ & $\mathbf{N}$ & $\%$ & $\mathbf{N}$ & $\%$ & $\mathbf{N}$ & $\%$ & $\mathbf{N}$ & $\%$ & & \\
\hline $\begin{array}{l}\text { Section 3-Q5 ... } \\
\text { increased my } \\
\text { productivity in } \\
\text { our educational } \\
\text { activities. }\end{array}$ & 4 & 12.5 & 6 & 18.8 & 4 & 12.5 & 15 & 46.9 & 3 & 6.3 & 3.21 & 1.23 \\
\hline
\end{tabular}

\subsection{Effectiveness}

Effectiveness is a factor that represents learning environments' ability to cause someone else to learn. One question were asked and more than half of the students stated that learning environment increased their effectiveness in their educational activities $(M=3.56)$ (see Table 4-34).

Table 4-34 Frequencies, Mean Score, and Standard Deviation for "Effectiveness"

\begin{tabular}{|c|c|c|c|c|c|c|c|c|c|c|c|c|}
\hline & \multicolumn{2}{|c|}{ SD } & \multicolumn{2}{|r|}{ D } & \multicolumn{2}{|c|}{$\mathbf{N}$} & \multicolumn{2}{|l|}{$\mathbf{A}$} & \multicolumn{2}{|l|}{$\mathbf{S A}$} & \multirow[t]{2}{*}{$\mathbf{M}$} & \multirow{2}{*}{$\begin{array}{l}\text { St. } \\
\text { Dev. }\end{array}$} \\
\hline & $\mathbf{N}$ & $\%$ & $\mathbf{N}$ & $\%$ & $\mathbf{N}$ & $\%$ & $\mathbf{N}$ & $\%$ & $\mathbf{N}$ & $\%$ & & \\
\hline $\begin{array}{l}\text { Section 3-Q8... } \\
\text { enhanced my } \\
\text { effectiveness in } \\
\text { our educational } \\
\text { activities. }\end{array}$ & 4 & 12.5 & 6 & 18.8 & 4 & 12.5 & 15 & 46.9 & 3 & 6.3 & 3.56 & 1.24 \\
\hline
\end{tabular}

Note: Question 3.08 were reversely coded 


\subsection{Makes Job Easier}

Learning environments in distance education sometimes causes confusions on students mind. The reason of this situation would be complex learning environment, and this will be result in longer task accomplishment time. In our case, students did not think that learning environment makes educational activities easier $(M=2.74)$. Moreover, none of the students expressed that they were strongly agreed on learning environment makes job easier for them (see Table 4-35).

Table 4-35 Frequencies, Mean Score, and Standard Deviation for "Makes Job Easier"

\begin{tabular}{|c|c|c|c|c|c|c|c|c|c|c|c|c|}
\hline & \multicolumn{3}{|c|}{ SD } & D & \multicolumn{2}{|l|}{$\mathbf{N}$} & \multicolumn{2}{|l|}{$\mathbf{A}$} & \multicolumn{2}{|l|}{$\mathbf{S A}$} & \multirow[t]{2}{*}{$\mathbf{M}$} & \multirow[t]{2}{*}{$\begin{array}{l}\text { St. } \\
\text { Dev. }\end{array}$} \\
\hline & $\mathbf{N}$ & $\%$ & $\mathbf{N}$ & $\%$ & $\mathbf{N}$ & $\%$ & $\mathbf{N}$ & $\%$ & $\mathbf{N}$ & $\%$ & & \\
\hline $\begin{array}{l}\text { Section 3-Q9... } \\
\text { made it easier } \\
\text { to study on our } \\
\text { educational } \\
\text { activities. }\end{array}$ & 4 & 12.5 & 9 & 28.1 & 10 & 31.3 & 9 & 28.1 & 0 & 0 & 2.74 & 1.01 \\
\hline
\end{tabular}

Student 2-F stated that:

The most challenging problem that I faced in this course was all documents were on the internet. Everything needs internet connection, even the course itself is internet dependent. However, I live in a dorm and there is no internet connection. For that reason, I have to go to Internet Café and spend my hours there in the close and crowded 
environment. Moreover, there is no software installed that we use, I cannot do any practice... [I-57]

\subsection{Useful}

Three questions were asked to investigate useful sub-factor of perceived usefulness (see Table 4-36). First question was about usefulness to access learning environment $(M=3.46)$. The other one is usefulness to work on educational activities $(M=3.34)$. The last one is about whether learning environment is useful educational activities, or $\operatorname{not}(\mathrm{M}=3.25)$.

Table 4-36 Frequencies, Mean Score, and Standard Deviation for "Useful"

\begin{tabular}{|c|c|c|c|c|c|c|c|c|c|c|c|c|}
\hline & \multicolumn{3}{|c|}{ SD } & D & \multicolumn{2}{|c|}{$\mathbf{N}$} & \multicolumn{2}{|l|}{$\mathbf{A}$} & \multicolumn{2}{|c|}{$\mathbf{S A}$} & \multirow[t]{2}{*}{$\mathbf{M}$} & \multirow{2}{*}{$\begin{array}{l}\text { St. } \\
\text { Dev. }\end{array}$} \\
\hline & $\mathbf{N}$ & $\%$ & $\mathbf{N}$ & $\%$ & $\mathbf{N}$ & $\%$ & $\mathbf{N}$ & $\%$ & $\mathbf{N}$ & $\%$ & & \\
\hline $\begin{array}{l}\text { Section 3- } \\
\text { Q10... was } \\
\text { beneficial to } \\
\text { access } \\
\text { educational } \\
\text { activities }\end{array}$ & 2 & 6.3 & 8 & 25 & 4 & 12.5 & 9 & 28.1 & 9 & 28.1 & 3.46 & 1.31 \\
\hline $\begin{array}{l}\text { Section 3- } \\
\text { Q13... } \\
\text { improved our } \\
\text { opportunity to } \\
\text { work on our } \\
\text { educational } \\
\text { activities. }\end{array}$ & 2 & 6.3 & 7 & 21.9 & 5 & 15.6 & 14 & 43.8 & 4 & 12.5 & 3.34 & 1.15 \\
\hline $\begin{array}{l}\text { Section 3- } \\
\text { Q17... was } \\
\text { useful in our } \\
\text { educational } \\
\text { activities. }\end{array}$ & 4 & 12.5 & 6 & 18.8 & 2 & 6.3 & 18 & 56.3 & 2 & 6.3 & 3.25 & 1.21 \\
\hline
\end{tabular}




\subsubsection{Perceived Ease of Use}

Students' perceptions about the ease of use of the learning environment were asked with 8 questions. Ease of use is an important concept to represent learning environment is easy to understand and operate. It was investigated with 4 sub-factors namely: easy to learn, easy to ese, easy to become skillful, and clear \& understandable.

As it can be seen in the Table 4-37, all sub-factors' mean score were lower than perceived usefulness. That means students were not agreed on learning environment is easy to use. Overall perceived ease of use were lower than three $(M=2.97)$, that is between neutral and disagree.

Table 4-37 Mean Scores and Standard Deviation of Sub-factors of Perceived Ease of Use

\begin{tabular}{lrrr}
\hline & N & Mean & $\begin{array}{c}\text { Std. } \\
\text { Deviation }\end{array}$ \\
\hline Easy to Learn & 32 & 2.90 & 1.09 \\
Easy to Use & 32 & 3.12 & 1.12 \\
Easy to Become Skillful & 32 & 3.03 & .96 \\
Clear \& Understandable & 32 & 2.95 & .75 \\
\hline Overall Perceived Ease of Use & 32 & 2.97 & .73 \\
\hline
\end{tabular}

\subsection{Easy to Learn}

Being easy to learn for educational context is very important to represent its ease of use. However, in the study students neither agree nor disagree about the learning environment is easy to learn. The two questions, S4-Q1 $(M=3.06)$, and S4-Q5 $(M=2.75)$ were close to the neutral in the scale (see Table 4-38). 
Table 4-38 Frequencies, Mean Score, and Standard Deviation for "Easy to Learn"

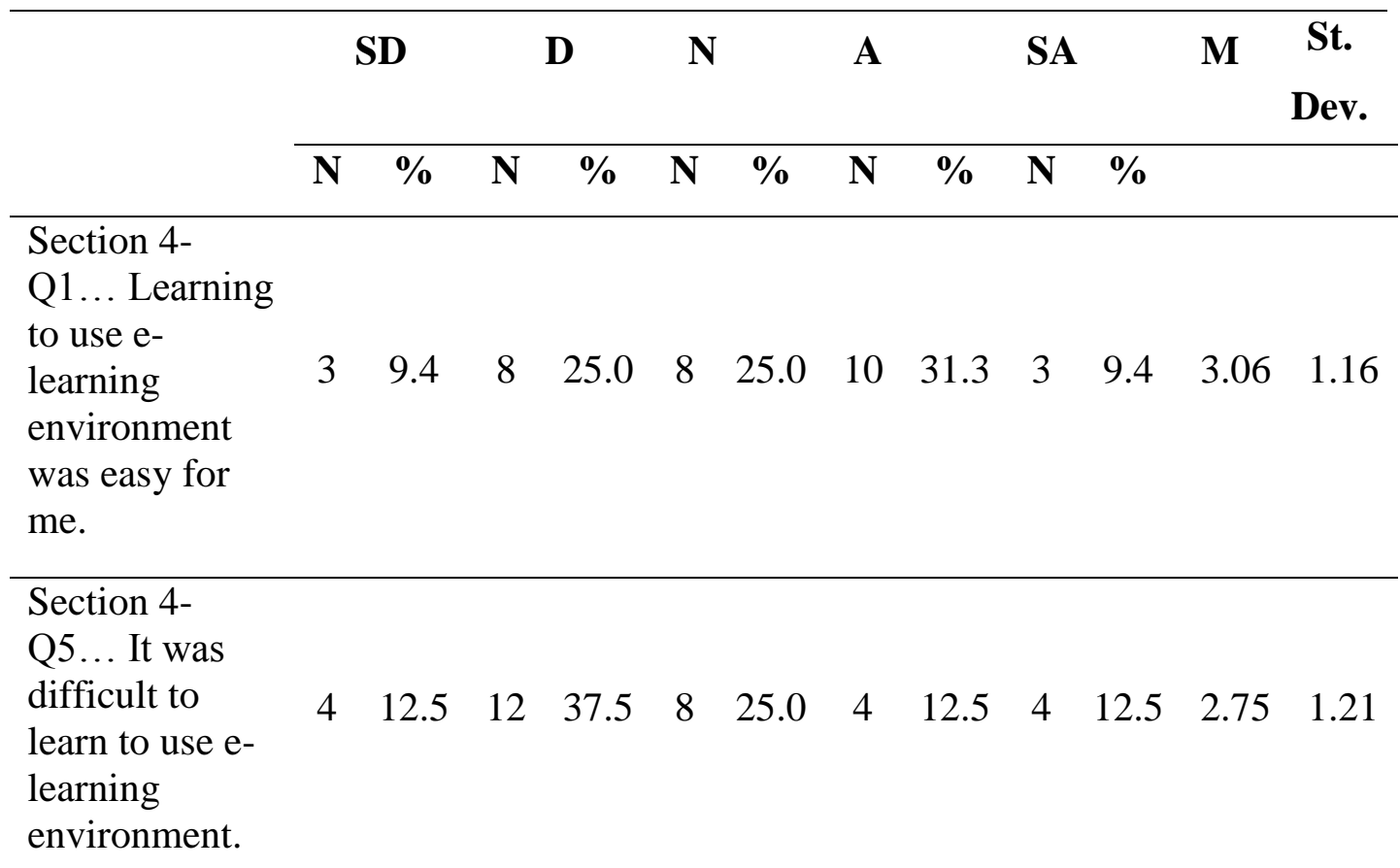

Note: Question 4.05 were reversely coded

\subsection{Easy to Use}

The only question used to investigate this factor was question 4.08. As can be seen in Table 4-39, while the percentage of strongly agree was only 6.3 , and the mean was 3.12. That is a bit higher tan easy to learn sub-factor.

Table 4-39 Frequencies, Mean Score, and Standard Deviation for "Easy to Use"

\begin{tabular}{|c|c|c|c|c|c|c|c|c|c|c|c|c|}
\hline & \multicolumn{2}{|c|}{ SD } & \multicolumn{2}{|r|}{ D } & \multicolumn{2}{|c|}{$\mathbf{N}$} & \multicolumn{2}{|c|}{$\mathbf{A}$} & \multicolumn{2}{|c|}{$\mathbf{S A}$} & \multirow[t]{2}{*}{$\mathbf{M}$} & \multirow{2}{*}{$\begin{array}{c}\text { St. } \\
\text { Dev. }\end{array}$} \\
\hline & $\mathbf{N}$ & $\%$ & $\mathbf{N}$ & $\%$ & $\mathbf{N}$ & $\%$ & $\mathbf{N}$ & $\%$ & $\mathbf{N}$ & $\%$ & & \\
\hline $\begin{array}{l}\text { Section 4-Q8 } \\
\text {...I found e- } \\
\text { learning } \\
\text { environment } \\
\text { easy to use. }\end{array}$ & 4 & 12.5 & 4 & 12.5 & 10 & 31.3 & 12 & 37.5 & 2 & 6.3 & 3.12 & 1.12 \\
\hline
\end{tabular}




\subsection{Easy to Become Skillful}

This factor is close to the easy to learn factor, and two students responded that they were strongly disagree about this learning environment was easy to become skillful, but only one student stated that he/she was strongly agree about this learning environment was easy to become skillful (see Table 4-40). That is why the mean score was 3.03 .

Table 4-40 Frequencies, Mean Score, and Standard Deviation for "Easy to Become Skillful"

\begin{tabular}{|c|c|c|c|c|c|c|c|c|c|c|c|c|}
\hline & \multicolumn{3}{|c|}{ SD } & D & \multicolumn{2}{|l|}{$\mathbf{N}$} & \multicolumn{2}{|l|}{$\mathbf{A}$} & \multicolumn{2}{|l|}{$\mathbf{S A}$} & \multirow[t]{2}{*}{$\mathbf{M}$} & \multirow[t]{2}{*}{$\begin{array}{r}\text { St. } \\
\text { Dev. }\end{array}$} \\
\hline & $\mathbf{N}$ & $\%$ & $\mathbf{N}$ & $\%$ & $\mathbf{N}$ & $\%$ & $\mathbf{N}$ & $\%$ & $\mathbf{N}$ & $\%$ & & \\
\hline $\begin{array}{l}\text { Section } 4-\mathrm{Q} 2 \ldots \\
\text { It was easy to } \\
\text { become skillful } \\
\text { at using e- } \\
\text { learning } \\
\text { environment. }\end{array}$ & 2 & 6.3 & 7 & 21.9 & 12 & 37.5 & 10 & 31.3 & 1 & 3.1 & 3.03 & .96 \\
\hline
\end{tabular}

\subsection{Clear \& Understandable}

"Clear \& Understandable" is the last sub-factor that is related to "Ease of use". Four questions were asked to be informed about this factor. Related to user interface and messages clear and understandable only one student express he/she strongly agreed on this item. Similarly, Related to user interface and messages user friendly, none of the students strongly agreed on this item. The other two items namely "User interfaces and messages of e-learning environment uses terms familiar to me", and "It was hard to understand the user interface of e-learning environment" had a mean score higher than three, gradually higher than the other two questions (see Table 4-41). 
Table 4-41 Frequencies, Mean Score, and Standard Deviation for "Clear \& Understandable"

\begin{tabular}{|c|c|c|c|c|c|c|c|c|c|c|c|c|}
\hline & \multicolumn{2}{|c|}{ SD } & \multicolumn{2}{|c|}{ D } & \multicolumn{2}{|c|}{$\mathbf{N}$} & \multicolumn{2}{|l|}{$\mathbf{A}$} & \multicolumn{2}{|c|}{$\mathbf{S A}$} & \multirow[t]{2}{*}{$\mathbf{M}$} & \multirow{2}{*}{$\begin{array}{c}\text { St. } \\
\text { Dev. }\end{array}$} \\
\hline & $\mathbf{N}$ & $\%$ & $\mathbf{N}$ & $\%$ & $\mathbf{N}$ & $\%$ & $\mathbf{N}$ & $\%$ & $\mathbf{N}$ & $\%$ & & \\
\hline $\begin{array}{l}\text { Section 4- } \\
\text { Q3... User } \\
\text { interfaces and } \\
\text { messages of e- } \\
\text { learning } \\
\text { environment } \\
\text { were clear and } \\
\text { understandable. }\end{array}$ & 3 & 9.4 & 13 & 40.6 & 7 & 21.9 & 8 & 25.0 & 1 & 3.1 & 2,71 & 1.05 \\
\hline
\end{tabular}

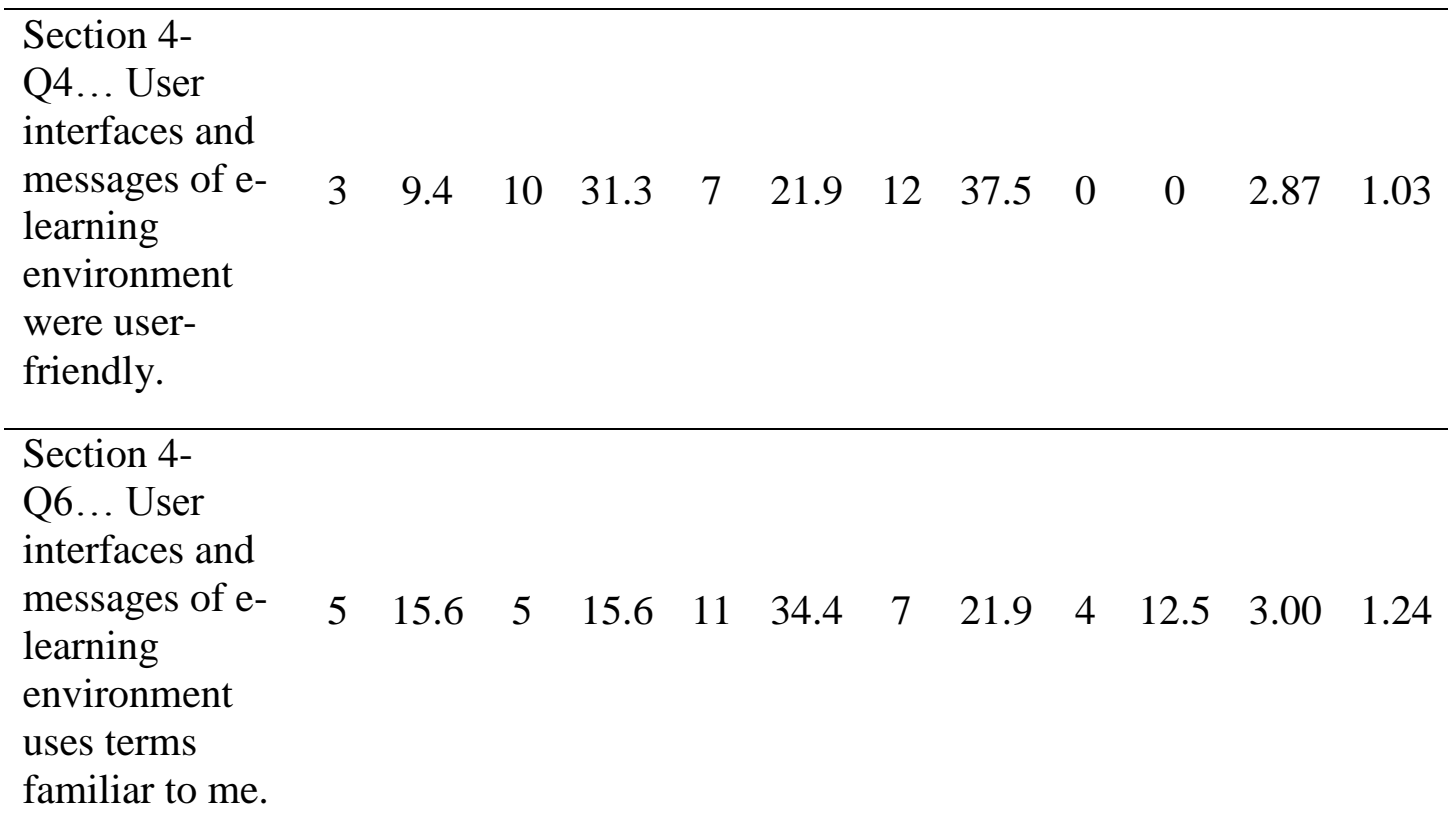

Section 4-

Q7... It was

hard to

$\begin{array}{lllllllllllll}\text { understand the } & 3 & 9.4 & 8 & 25.0 & 5 & 15.6 & 11 & 34.4 & 5 & 15.6 & 3.2 & 1.24\end{array}$ user interface

of e-learning

environment.

Note: Question 4.07 were reversely coded 


\subsection{Accomplishments of the New Design}

One of the aims of this study is to represent the achievements of the new design with respect to the needs of vocational higher education. From what aspects, this new course works well, and meets the students' needs. In order to see the accomplishments of the study, researcher interviewed with students and supported them with his field notes. Rather than using available results of the literature, researcher wanted to learn current situation of the real context of the study. Collected data were analyzed with constant comparison data analysis technique to be more informed about context rather than borrowing information from the existing studies. Moreover, this data analysis technique resulted in deeper understanding of the context than the other qualitative data analysis techniques.

During the coding process of the data, researcher reconsidered data, codes and categories to determine central categories with respect to the existing literature. In this long revision and analysis process on the second part of the study, literature review distance course experiences in TVET, and peer discussions about the existing data guides researcher to conclude coding. In this coding process, 46 codes obtained in the open coding. Finally, those codes decreased to two central categories emerged in the end with 5 sub-categories after coding process. These are:

- Instructional accomplishments

○ Experienced Instructor

○ Learning opportunities

○ Students' Future Expectations

- Technical Accomplishments

○ Software Support

- Applicability of a Distance Vocational Course

In addition to the interview results, as a type of learning outcome mean score of grades will be used to represent achievements. According to Rovai (2002), learning outcomes were used as an indicator of the success of distance education programs. The average academic achievement of new distant web design course was 66.01 out of 100 . This 
result revealed that the students who took that course had moderate achievement level in this new context, although the structure of the course was new and not easy to adapt.

In this study, with instructional developments and changes, the aim is to overcome some of the problems that we had determined before to create an effective distance course. However, in our case, this new design and our efforts provide a progress addressing some of the problems. Especially instructional problems of an existing course somehow eliminated. Effectiveness of a course especially in a distance vocational course should be evaluated in its own context. In Figure 4-4, you can see the tentative accomplishments of the new course.

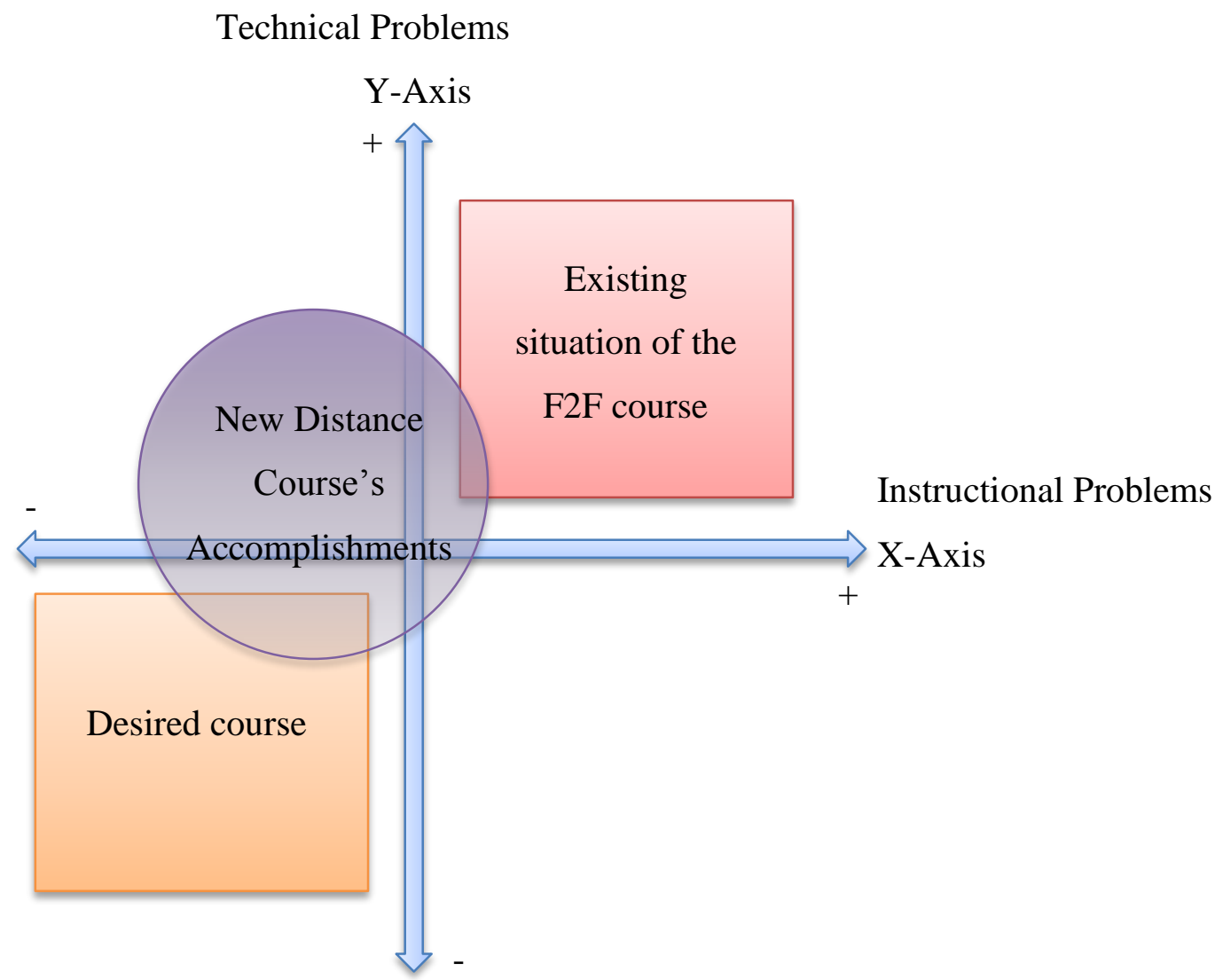

Figure 4-4 : Tentative Accomplishments of the Study 
Those central categories facilitate our understanding about the existing situation of the new distance course. In the remaining section, each component of the accomplishments of the distance course in a vocational higher education institution will be explained in detail.

\subsubsection{Instructional Accomplishment}

Effective distance education programs begin with careful planning and a focused understanding of course requirements and student needs. Appropriate technology with appropriate instructional support needs to work over the design, because in distance course context an entirely new set of variables enters the complex equation. Therefore, you need to know the accomplishments and the problems of the course. Although we cannot reach the desired level in the new course, we could produce solutions to some predetermined problems to create a better course. Especially with the new course materials, content, way of instruction reveals positive results in students' view. Student 2-A expresses one of the achievements of the course with saying:

Although this is an initial attempt, we have learnt many things about how to use internet as a technology for educational purposes... [I-58]

\subsubsection{Experienced Instructor}

The success of any distance education trials highly dependent on the instructor's experience in the distance context. Different form the F2F courses, instructor's responsibility includes assembling course content, continuously support students via CMS, should have an understanding of student needs, create solutions to the changing situations, and technological know-how. Moreover, instructing over a video conferencing system needs experience, patience, and great effort. Student 2-E stated that:

The instructor showed us the interesting uses of the web design. He explained from beginning to the end to design a web site. At the end of each week it turned to be a working web site with some additional things... [I-59] 
In the interactive part of the course with videoconferencing and other CMC tools, instructor should prepare learners for an active experience. Related to this Student 2C stated that:

In traditional courses I sometimes suffer from my embarrassment, I had questions but I cannot asked them and waiting to someone else to ask. But use of chat tool.. It is different, I can meet with the instructor unexpectedly, and I can freely talk with him...[I-60]

\subsubsection{Learning Opportunities}

In the traditional F2F courses in this vocational education institution, instructor highly dependent on direct instruction and instructor was the source of information. In this course, different needs and scenarios were considered and materials were developed in order to compensate those issues. Both inside and outside the classroom students have chance to reach course related documents.

For instance, video records of the course decided to publish over the CMS during the course because of the connection problems that was encountered in the course. In addition to video records of the course, parallel with the course content each week we added new video-based examples. Related to this Student 2-D stated that:

Video records of the course that we could receive over the web site was very useful to me because of the connection problems sometimes we could miss some parts of the course. However, video records compensate this problem to some extend...[I-61] 


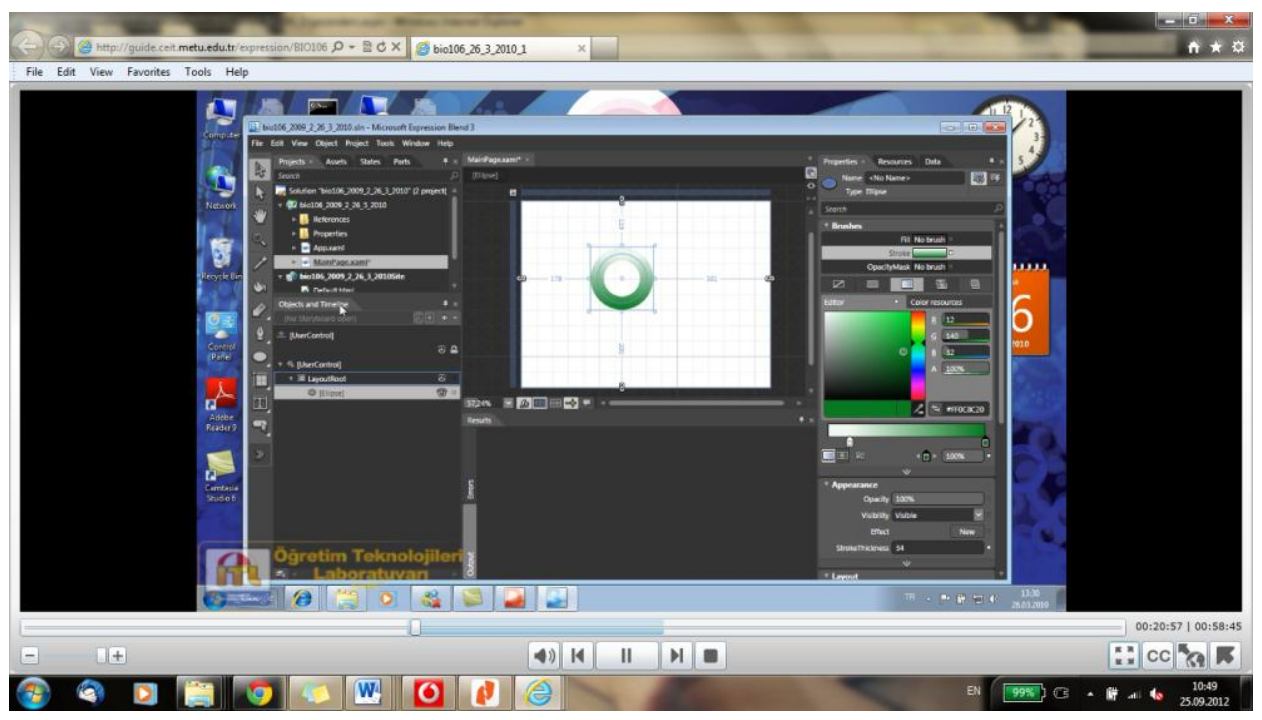

Figure 4-5: Sample Visual Material in the Course Web Site

In the course web site, students were supported with some additional materials. Especially, course content were presented with presentations of the course, sample course activities, and some other electronic resources. During the course students wants in addition to those electronic support materials, they need printable materials because some of them did not have internet connection and printable pdf documents were added. Student 2-F also supports these materials that were presented on the CMS by saying:

The PDF documents were the most important facility of the course. I have used very often because in the dorm I do not have an internet opportunity. I can print some of them and study over them, especially before the exam...[I-62]

\subsubsection{Students' Future Expectations}

Distance education offers freedom from place and time constraints, improved delivery of multimedia, and personalized learning, but these are not always achievable. Students thought that in their school this kind of technology enhanced learning opportunities could not be achievable because of lack of staff, support, lack of software, improper use of emerging or existing technologies etc. When the time passes 
and the observed problems getting less, their thoughts are turn to be neutral. Students 2-A's expectancy from other courses increased and stated that:

I cannot recommend any additional thing for this course. I have never got this kind of technological, or course related support. But you have increased our expectations from other courses. We saw that technology use or supporting with additional materials is possible...[I-63]

Also, some of them thought that this would be and hoped to be a beginning for this kind of courses in their schools, and Student 2-C expressed his/her future expectancy with:

This course was a good beginning for us, I have never been a part of this kind of a course but probably in the future we will be familiar with it, because now we know this kind of material support with technological things can be achievable. [I-64]

\subsubsection{Technical Accomplishments}

Distance course was highly dependent on technological capabilities of the vocational education institution but we tried to determine the use of instructional technologies with considering these capabilities of the school. Nonetheless, we had to face with unexpected problems during the actual study.

\subsubsection{Software Problems}

This course is a tool dependent course to create unique web pages, however our web design tool Expression Studio did not work any of the computer because of the lack of licensed software issues. In order to solve this problem, instructor added students to the Dreamspark (A Microsoft program to support technical education by providing access to Microsoft software for learning, teaching and research purposes), and they can reach any of the Microsoft software's without any payment during their higher education. 
Student 2-B expressed one of the problems that he/she faced during the course by saying:

At the beginning of the semester, you gave us a program (communicator) but we could not install it to our computers. After that you have send us Windows XP serials to install licensed ones to get updates without problem. Then we could install it to our computers...[I-65]

\subsubsection{Applicability of a Distance Vocational Course}

In recent years, distance education has increasingly become one of the most popular ways of instruction in vocational education, in Turkey. There has been many vocational higher education programs emerged that instruct student at a distance, with e-learning opportunities. However, one of the main problems of distance education is adapting the textbook information to html. In this study, in order to overcome this, we have created a unique course from beginning to the end. The existing F2F course in this vocational institution was highly instructor centered and needed to be supported instructionally and technologically. We have decided on solutions and create a unique, technologically and instructionally improved course. However, in the existing structure of the course students did not expected to give this course, they did not believe that this could be achievable. Related to this Student 2-F expressed that:

At the beginning of the course, I was not motivated because I did not believe that this kind of course could be done in our school. Nevertheless, today it is done, we had finalized with the exam. Although we had problems in the internet connection and video conferencing...[I-66]

Although using many different new technologies, many new different materials caused some confusion on students, now they are familiar with those new concepts and materials. Related to this opportunities, Student 2-A highlighted that:

I think receiving a course over internet... Just itself is new and unusual for me. I have never had an experience like this. We used many different things in the same course. Now I know that this can be done in our 
school. Although we had problems, now I know that something like this can be done in our school with limited resources. I need to participate more courses like that with technology support over internet. [I-67]

Not only technologically new opportunities provided to the students, but also instructional capabilities were increased in the new design of the course with new materials, activities, content etc. This achievement also respected by Student 2-A with these words:

Within the existing structure of our school we could receive this course. Now other students want to get the course notes, documents from me...[I-68]

\subsection{Critical Elements of New Distance Course Needed to be Improved}

In this study, a new distance course were designed, developed and evaluated. With respect to the evaluation results, the purpose was to determine from which aspects this course seems to be beneficial or problematic. In this part of the study, critical or problematic elements of the course tried to be determined by interviews and it was supported with the field notes. Rather than using available results of the literature, researcher wanted to learn current situation of the real context of the study. Collected data were analyzed with constant comparison data analysis technique to be more informed about context rather than borrowing information from the existing studies. Moreover, this data analysis technique resulted in deeper understanding of the context than the other qualitative data analysis techniques.

During the coding process of the data, researcher reconsidered data, codes and categories to determine central categories with respect to the existing literature. In this long revision and analysis process of the real implementation of the course, researcher preferred to go back to literature to clearly state and determine categories in the axial coding. After this literature review, peer discussions, and long coding processes 86 codes obtained from the open coding reduced to two central categories with 5 subcategories. 
- Course Delivery Problems

- Interaction

- Institutional Barriers

- Technical Problems

- On-demand Support

- Student Readiness

- Social Economic Status

○ Skills and Experiences

○ Beliefs

In the remaining section, each of the central categories and their sub-categories were explained and supported with quotations.

\subsubsection{Course Delivery Problems}

There is a room for improvement in even the most carefully developed distance course. Although in Open University, Europe's largest group of instructional designers and technologists were employed to create better courses, they have gradually change and modify their courses (Hawkridge, 2002). That means revision is essential in ID process. Knowing the problematic and missing points will guide designers to create better courses.

\subsubsection{Interaction}

With the new design of the course, not all problems of the existing course could be solved, but we became closer to the desired level of the course. Actually, there is a continuing debate on the effect of technological advances. Many people thought that these new technological improvements would provide solutions to many educational problems. However, sometimes technology comes with its unique problems like in this case. For instance, interaction was reported as a problem in the F2F course, it has still seemed to be a problem.

In flexible learning environments like this new course, learners do not confine within the walls of a classroom where the book and the teacher are seen as the main sources of information. With the integration of CMC tools (a variety of interactive sessions 
utilizing a range of technologies such as video conferences, Internet, e-mail, chat, forum etc.) in the learning setting, we expected students to become active members learning experience.

\section{Student-Student Interaction}

In school setting, interpersonal relationships are an important concern to facilitate learning environment. Especially, learner-learner interaction associates collaboration between learners and need to be supported with two-way communication technologies. In this study, students at a distance tried to be supported with both synchronous and asynchronous two-way communication technologies to increase interactivity. However, students had problems in using those tools. As it was highlighted by Student 2-B:

I have used communicator to talk with the instructor and you (teaching assistant), but most of my friends have problems installing it on their computers...[I-69]

\section{Student-Instructor Interaction}

In distance education, one of the important problems is the guidance. Distance education support students to work independently on their instructional activities, but students concerns about feeling alone during course need to be eliminated. In this case, some of the students could not be adapted to the new learning opportunities and they did not use CMC tools as we expected. Student 2-E expressed his thoughts about their adaptation problems with saying:

One of my concerns about this course was... I cannot communicate with the instructor as I want, I want to knock his door and talk with him but in this course I need to install a program and if he was there I can ask my questions... [I-70]

In addition to that, students prefer F2F communication with the instructor. Student 2F expressed his/her concerns with saying:

Rather than participating this kind of a course, I would prefer $F 2 F$ courses because I cannot be adapted to this system, using web site for 
everything we need, moreover I want to be in front of the instructor during the course, rather than far away... [I-71]

Moreover, in this classroom sessions of the course technical problems caused weak interaction between student and instructor. Especially at the beginning of the semester, in the field notes researcher emphasize this issue by reporting:

During the course today, there were audio related problems in some parts of the video conference. Sometimes interaction with the instructor and students were problematic. Apart from that, in the classroom there were only one microphone and only one student could respond to the questions...

\subsubsection{Institutional Barriers}

During the analysis of the data, researcher decided to combine some categories in institutional barriers. According to the researcher, institutional barriers are obstacles caused by the organization that makes difficult students access to all resources or achieving their learning goals. In this case, the institution may not be aware of the barriers presented here. Nonetheless, it is important to consider these potential barriers, categorized under technical problems and on-demand support.

\subsection{Technical Problems}

This course was supported with many technologic and instructional materials to support distributed learning, but sometimes technology cannot respond to our expectations. Sometimes technology comes with its unique problems, in that case you need to have an alternative plan. Although new alternative approaches were integrated to the course with additional materials and opportunities, technologic problems seemed to continue to distract student in the course.

The most important problems that we have faced in this course was connection problems that we suffer from especially at the beginning of the semester. Later we 
had only experiences some connection loss. Related to this issue Student 2-D stated that:

We have faced many problems during the video conferencing. While we tried to connect, we have to wait for a while, and even we have connected, sometimes we had sound problems ...[I-72]

Moreover, sometimes limitations of the technologic capabilities of the vocational higher education institution were perceived as connection problems. In the remaining example, for instance, the problem in the projector caused problems in visual quality of the display, but Student 2-D thought that:

Because of connection problems sometimes we could not read the projector. For that reason, we needed to sit to the front, sometime on a chair...[I-73]

\subsection{On-Demand Support}

Generally, instructors' demand support from the institution during the delivery of a distance course. However, in our case instructor and the researcher worked hard to compensate some technical issues that students' faced, and tried to deal with the problems in the delivery of the course.

Especially students required to be supported to use instructional tools designed to support educational activities. In fact, distance learning requires students to work independently and to use instructional tools, technologies to fulfill course requirements. However, in this course students need support and guidance to use those technologies both in the school and outside the school. Existing technical knowledge and experience of the students required technical support service when it was demanded.

In the school, technical support barriers to learning caused limits or no access to classrooms, laboratories and resources. For instance, computer laboratory equipped with new computers, but installing related programs took long time before the laboratory session of the course. Some of the students' did not have a computer and 
they needed to use this laboratory to made hands-on practice. They should install programs themselves. That is somehow related to limited or no support service exists in this school. Related to this issue Student 2-E stated that:

At the beginning of the semester, we had problems to connect to Ankara, when we had problems, some of my friends working on this, and sometimes they tried to reach XXX (an instructor) to help them. [I74]

Network security and restrictions caused some problems in using Communicator. In the first week of the course, students cannot login to the server and researcher noted that situation in his field notes:

We had problems in using Communicator in our initial trials of the course tools. I cannot share my desktop with my sound at the same time. After some time we discovered that we had problems about restrictions in the firewall of the school. We need to contact with the network security services but it took long time to reach him and fixing this issue...

Apart from school access to the course related technologies, some more problems observed prevent students' access. For instance, because of lack of licensed software in students' computers, they could not get essential updates to install MS Expression. About this issue Student 2-C stated, "At the beginning of the semester we cannot install software until you gave us a licensed Windows XP." [I-75].

In addition to that, after overcome this issue some of the students could not install communication tool. Although installation process were explained step by step, some of them had problems. Student 2-F highlighted this issue with saying:

I could never install MSN like program. I have tried several times to one of my friends computer but I could not. When I asked to my friend he showed me a word document, but after one or two trials I did not deal with it [I-76] 


\subsubsection{Students' Readiness}

Moreover, in this technology integrated learning environments, students' adaptation takes time. That means early use of an innovation is too slow. Continuous feedbacks from students and academic staffs should be taken into consideration, and by this way better improvements can be done. As it was cited by Davis, Bangozzi, and Warshaw (1989), Swanson stated that the technology acceptance had been one of the most challenging problems in the information systems. This technology acceptance decision were effected some important concepts like students' socio economic status, skills and experiences, and students' beliefs.

\subsubsection{Students'Socio Economic Status}

The improved access and availability of technology has enabled more students to participated and benefited from the learning process. However, in our case most of the students had low-level income and they had problems to reach technological resources. One of the most challenging thing that was observed in this course was highlighted by Student 2-F

The most challenging problem that I faced in this course was all documents were on the internet. Everything needs internet connection, even the course itself is internet dependent. However, I live in a dorm and there is no internet connection. For that reason, I have to go to Internet Café and spend my hours there in the close and crowded environment. Moreover, there is no software installed that we use, I cannot do any practice... [I-77]

Similarly, Student 2-E expressed this issue:

Some of my friends even do not have a computer, for that reason we need to use course web site in the computer lab of the school in a limited time...[I-78] 


\subsubsection{Students' Skills and Experiences}

The nature of the distance learning needs students to take their own responsibility in managing their own learning. Different from the traditional approaches in education, distance learners must have increased self-regulation and they should have more computer competency skills than students in F2F learning environments. Student 2-A expressed his/her thoughts with saying:

In this kind of a course, most of the responsibility is on the student. If a student wants to learn something more, he should spend more time to work on this. Just sitting and taking note is not possible in this type of education. We are accustomed to get traditional courses just sit and listen, and before the exam study and pass. It was different in this course, we should do homework, project and exam, study on many videos, documents, website...[I-79]

In the field notes of the researcher, he pointed out an issue students existing computing skills caused problems in the course. In the field notes he recorded that:

Some students who were mainly graduated from high school have problems in using website and CMC tools. They were always asking questions about how to reach, how to connect. Some students who were mainly graduated from high school were have problems in using web site and CMC tool, they were always asking questions about how to reach and how to connect even how to install ...

Even only one of the students had a distance course experience, and in the interview Student 2-B admitted that:

I had taken a distance course in a two-year program, but it was not that complicated system. Only we could reach PDF files, but in that course it was over my expectations. Even I do not think that I can effectively use everything in the course web site... [I-80] 


\subsubsection{Students' Beliefs}

Some of the students did not believe the effectiveness of a distance course, because traditionally they are familiar with them, and they were underestimate their capacity and technologic infrastructure. Student 2-D stated that:

\section{At the beginning of the semester I was not very motivated because Ifelt that this will be a trial of a system and with our existing capacity in the faculty this would be like an adventure...[I-81]}

Distance education can be as effective as traditional face-to-face education when the methods and techniques were used properly through the technological aids. However, combination of the all technologies in a course caused confusions in students' minds. Student 2-B expressed that:
I have been dealing with computer for a long time but even for me using this complicated system, getting familiar with them took some time, especially video conferencing with the instructor is a different experience for me because I did not think that this would be done in our school [I-82]

\subsection{Summary of the Chapter}

The results of the study were presented parallel with the research questions. The problems of the existing F2F course were identified and alternative strategies were decided. In order to create a better learning environment to remediate the problems of the existing course, researcher and his advisor decided to design a new course from instructional materials, to learning environment. In order to see the effectiveness of the new distance course the results of both quantitative and qualitative data were presented in this section. Quantitative results were supported with the interview quotations and field notes of the researcher.

As a result of all these collected data, the new distance course remediated some of the problems of the course in the vocational higher education institution. That means the 
new course achieved an important improvement in the course. Nonetheless, accomplishments and pitfalls of the new design should be critically investigated critically. 


\section{CHAPTER 5}

\section{DISCUSSION AND CONCLUSION}

"The wisdom of a technology is framed by the wisdom of the user and developer of this technology"

M. Yaşar Özden

The purpose of this study is to contribute to the design, development, and evaluation of a distance course for vocational higher education, because vocational education needs to be supported both instructionally and technologically. In line with this purpose, the findings of the study were discussed parallel with the data collection process in three sections. In the first section, investigated problems of an existing F2F course were discussed. In the second section, new course and its design characteristics were discussed with explaining decision making processes. In the third section, students' attitudes towards the WBI, students' perception on the new learning environment, and accomplishments and problems of the new course to see its advantages and disadvantages were discussed. This chapter examines the findings of this study with interpretation of the results, which discuss these findings in the light of previous researches, and the chapter concludes with implications for further practice making suggestions for future research.

\subsection{Major Findings \& Discussion}

The purpose of this study is to contribute to the development of a distance course design for vocational higher education. With this purpose in mind, proactive action research was conducted to solve the problems of an existing course with the new design. As discussed above, action research focused on change, which was compatible with the purpose of research. It entails improvement by understanding the existing situation of the F2F course. 
In this initial step of the study, the existing situation of the F2F course that was given in the vocational higher education institution was observed and interviewed with the students. The researcher specifically wanted to work on vocational education because of the existing problems of the courses in these institutions. There are many research studies representing instructional and technical problems of courses in vocational education (Unesco, 2003; Buğday, 2007; Şahin \& Fındık, 2008).

When the researcher look at the definition of the vocational education, each of them represents different aspects of vocational education. Throughout different periods of the development of the vocational education, various terms have been used to describe different elements and perspectives of the field. These are now conceived, and named as Technical Vocational Education and Training (TVET), Apprenticeship Training, Vocational Education, Technical Education, Technical-Vocational Education (TVE), Occupational Education (OE), Vocational Education and Training (VET), Career and Technical Education (CTE), Workforce Education (WE), Workplace Education (WPE). Each of the vocational education terms highlights different aspects. For instance, while "Vocational Education and Training" covers the life-long-learning view of the vocational education from staff training to software certificate programs or "vocational education" is training and educating students for giving especially technical skills to bring skills of a specific occupation or vocation. Every country defines vocational education from their own perspectives and needs. For example, in Turkey, according to Alkan, Doğan, and Sezgin (1996), vocational education is an educational process to give job related information, skills, work habits to the learner, and increase learners abilities in different ways. Vocational education defined as a way to provide job related necessary skills to the intermediate staff or blue collars. This definition to vocational education is limited to workplace needs and should be modified with the realities of the new world view. It is an outdated definition refers to the industrial age, not to the information age.

In the $21^{\text {st }}$ century technical and vocational education and training definition should be an integral part of general education, prepare students for occupational fields for 
effective participation in the world of business, cover an aspect of lifelong learning, and prepare students' as a responsible citizenship (Unesco \& Ilo, 2002).

According to the Carl D. Perkins "Technical and Education Improvement Act of 1996" (Perkins Act) defined vocational education as "Career and Technical (Vocational) Education”. This definition covers

\begin{abstract}
"organized educational activities that offer a sequence of courses that provides individuals with coherent and rigorous content aligned with challenging academic standards and relevant technical knowledge and skills needed to prepare for further education and careers in current or emerging professions, and should include competency-based applied learning that contributes to the academic knowledge, higherorder reasoning and problem-solving skills, work attitudes, general employability skills, technical skills, and occupation specific skills, and knowledge of all aspects of an industry, including entrepreneurship, of an individual." (U.S.Department of Education, 2006, p.4-5).
\end{abstract}

In fact, vocational education should have a dynamic structure to satisfy the needs of the developing technologies, production methods and business life (İssever et al., 2005). This is because the needs of the information age are different from those of the industrial age. Globalization and information age highlight the needs of corporations and employers. Today employees are expected to not only job related skills, but also $21^{\text {st }}$ century learning skills, which are good problem solving skills, collaboration skills, communication skills with each other, and ability to express their feelings. If we consider educated people as a product, then we should change our process to reach this desired product. In order to accomplish this, we need to modify current instructional theory (Reigeluth, 1999). In Turkey, the main problem of TVET is staff and resource problems. Resources are not only related to physical infrastructure, or hardware, but also how these resources are effectively used to facilitate learning opportunities. Educational resources and approaches need revision for the requirements of the $21^{\text {st }}$ century learning skills. As stated above the aim of this study is to change the way of instruction to satisfy the needs of the information age in 
vocational education institution. In order to achieve this, an existing course was selected as a target to make modifications to create better teaching and learning experience.

\subsubsection{Problems of the Existing Course}

In this research, our purpose is to design, develop, and evaluate a course for a vocational higher education institution. The initial step of the instructional design process always starts with the analysis. Analyzing learner characteristics and what is going on in the context is very important to make inferences. Many studies revealed that in vocational schools content is outdated and courses were based on rote memorization and direct instruction. This is a contradictory situation to the foundational purposes of faculty of technical education. A technical teacher should know theory as well as an engineer and should have job related hands-on skills as well as a workman (Y1lmaz et. al., 2004). However, the existing structure of courses are not in line with the foundational purposes of these schools.

For this study, data were collected in two different semesters. In the first semester, an existing course was investigated to see the problems and the needs. In order to get detailed understanding of the existing course, data were collected with observations and interviews throughout several site visits. The findings of the first research question namely "What are the problems that students and the instructor faced in an existing F2F course?" reveal that in the existing course the problems were categorized as follow:

- Instructional Problems

- Interaction

- Motivation

○ Support material

○ Up-to-date content

- Instructional activity

- Intervening Conditions

- Technologic

○ Non-technologic 
In the upcoming section, each category will be discussed with the support of the existing literature. Most of these problems originated from the instructional structure of the course, thus an alternative approach was proposed in this study through the redesign of the course to cope with these problems.

\subsubsection{Instructional Problems}

Şahin and Findik (2008) define the problems of the vocational education in four main areas. These were vocational guidance, curricular problems, coordination with related sectors, and physical and technological problems. In critical reviews of TVET systems different countries have identified their unique problems. However, specifically developing countries such as India, Malaysia, Nigeria, and Turkey share similar problems in vocational education (Unesco, 2003, Buğday, 2007; Şahin \& Findık, 2008; Malkan, 2009; Okobia, 2011).For example, in these countries the curricula is based on a "teacher oriented" approach, and do not show any flexibility with different teaching approach to achieve stronger training support. Teaching methods used in these countries are incompatible with students' learning styles and the need of the $21 \mathrm{st}$ century. In order to meet those needs, students should have higher-order thinking skills like problem-framing and problem-solving, communication skills and teamwork, analyzing information, critical thinking and reasoning (Unesco, 2002). Unfortunately, instructional structure of the courses do not meet these needs, moreover mainly direct instruction, rote memorization, and insufficient hands-on experience resulted in decrease in student satisfaction from the instruction in vocational schools. The rapid change in individual and social needs call for continuous regeneration of vocational programs (Gelişli, 2009).

\subsection{Interaction}

Interaction is a superficial form of communication extended with both verbal and nonverbal communication to exchange ideas, feelings, thoughts, knowledge in education, and it is a good way to get feedback. Interaction is a complementary factor to increase knowledge sharing in a course. Within this research context in a F2F course, the researcher determines problems in student-instructor and student-student interaction. A study that was conducted in Turkey revealed that students expect fast feedback, fast answers about course context, and effective guidance of facilitator, broad content, 
more social interaction and communication opportunities (Y1ldiz et al., 2007). At this point social aspect of learning seems to be highlighted with this research in vocational education.

Although it was an old vocational education theory (dating back to 1920's), Prosser's vocational education theory highlighted the social aspects of vocational education. As Wonacott (2003) cited, Prosser offered: "Vocational education will be socially efficient in proportion as in its methods of instruction and its personal relations with learners it takes into consideration the particular characteristics of any particular group which it serves."(p. 9).

Contrary to Prosser's theory, we still have problems in interaction in vocational courses. In a study that was conducted in a faculty of technical education Akpinar and Özer (2004) represented the communication level between students and instructors in that vocational institution which was not considered to be enough by the students. In another study, in order to see students' view on an accounting course, data were collected from 951 students (Hatunoğlu, 2006). The results of this study indicated that more than a half $(53.2 \%)$ of the students thought that they could not be communicate effectively with the course instructor. In the same study, it was investigated the extent to which e-mail was used as a communication tool between student and instructor. Only $13.9 \%$ of the students stated that they were using e-mail to communicate with the instructor very often. $40.6 \%$ stated that they were using very rarely, but the most important result exhibited that $45.5 \%$ of students never use e-mail as a communication tool with the instructor. The results clearly represent that there are communication and interaction problems in both F2F and computer supported communication in vocational education.

Similarly, ISTE (2012) determines the standards for teaching, and learning in the digital age with NETS (The National Educational Technology Standards) for students. According to this organization, communication and collaboration is one of the key standards in education. Similarly, Akpınar and Özer (2004) investigated the instructors' view on quality issues on education in a faculty of technical education. 
One of the important issues that was reported in this study was lack of teamwork in courses.

\subsection{Motivation}

Presser's theory of vocational education is thought to be old, but it is still commonly used in modern vocational educational theory definitions. Prosser offers 16 key approaches to create an effective vocational education. As was cited by Wonacott (2003), Prosser offered in his fourth theory that "Vocational education will be effective in proportion as it enables each individual to capitalize his interests, aptitudes and intrinsic intelligence to the highest possible degree"(p. 8). Motivation was highlighted in those days, and seems to be still an important problem in existing courses. Motivational problems were based on external and internal factors.

In that study, it was evident that students are not motivated to the course. In the interviews, a question was directly asking their motivation. In their responses, some of them stated that they were motivated to the course and they liked their instructor. However, their responses to the other questions and observations revealed that they were not motivated to the course. Only a few students participated in the course actively. In order to increase their participation integrating some more motivational elements to the laboratory activity will have positive impact on students' motivation. However, because of the existing structure of the course, instructor could not achieve this. For instance, this course requires students to practice more on the computer but students' access and familiarity with technology is another concern in this case. It would be difficult to provide instruction when students did not have computer access. As Keleşoğlu and Aksoy (2006) stated that Faculty of Technical Education students' thought that the reason of their low achievement in their courses is based on the instructor and facility problems of their schools. As Hatunoğlu (2006) stated that although they have computer access in their schools, $59.8 \%$ of them stated that those computers could not be used effectively in their courses as expected.

As for the external factors, students are not motivated because of the general problems in vocational education system. They are aware that only a few of the graduates of this institution will be able to work as a teacher. In general, $4 \%$ of the graduates of Faculty 
of Technical Education can be a teacher in Ministry of Education (Kayır \& Kilıç, 2008; Eşme, 2007). This low level of opportunity to be a teacher decreases their motivation towards their courses in their schools (Beşoluk \& Horzum, 2011). According to Akpınar \& Özer (2004), 54.6\% of the students choose their existing vocational higher education departments six th or higher ranking in university entrance exam. That was somehow related to their concerns or the future benefits or drawbacks of these departments in their future career.

\subsection{Support Material}

In this existing F2F course, students expected to have more access to support material to be informed from a variety of resources. Although in this traditional perspective, instruction expected to be based on printed materials like textbooks. Since instructor considered the economic income of the students, and he/she did not offer a textbook. Lack of additional resources considered to be problem in the course.

In fact, Akpınar \& Özer (2004) determined the use of instructional materials in a faculty of technical education as low. That means the use of supportive instructional materials is still an important concern in other cases. The absence or low level of use of instructional materials directly affect the quality of instruction in these institutions. In the case of vocational education, Alkan et al. (1996) stated that the use of printed materials to support the course would be beneficial to create effective instruction in vocational education.

Korkmaz \& Tunç (2010) indicate that, the main reason of students' low access to and use of instructional materials are due to lack of sufficient hardware. The existing instructional capacity of the schools needed to be reconsidered. Moreover, in these institutions there is a lack of instructor. The number of students per each academic staff in Faculty of Technical Education is 33.6, and in technical vocational schools of higher education is 68.07 (ÖSYM, 2007). By contrast, in the engineering faculties the number of students per each academic staff is 17.1 (Şahin \& Findik, 2008). This situation resulted in problems in the quality of instruction in those institutions. Thus, students' expectations from the instructor could not be met. According to the survey 
results of Kayır and K1lıç (2008), only $30.1 \%$ of students think that instructors have sufficient professional knowledge and skills as a field expert and instructor.

\subsection{Up-to-date Content}

One of the most important problems in vocational education is keeping content up to date. The most obvious debates about vocational education curricula are focused on how output skills of students need to be changed and how to incorporate them into the curriculum.

According to Ogawa and Tansel (2005) less than half of employed vocational high school graduates use their skills that they have learnt in their schools. That is market needs were not taken into account while developing the curricula. Similarly, in the present study, the existing course content did not respond to the realities of the market. Moreover, the graduates of these institutions do not transfer their abilities and skills from their academic lives to their business life (Buğday, 2007). 58.1\% of instructors in vocational schools state that the curriculum partially or completely insufficient (Kayır \& Kılıç, 2008)

For instance, according to Tucker et. al (2003) vast majority of career opportunities in the $21^{\text {st }}$ century are in the field of computer technologies. In those vocational schools, there are many web related courses, in our case web technologies course content did not meet the needs of the students. For instance, according to Mahiroğlu (1996), in faculty of technical education $49 \%$ of the students expressed that content was insufficient. Since than, still students are not satisfied with the content. Moreover, the curriculum of the courses is far behind the existing technologies and does not meet the need of the workplace (Develioğlu, 2008). Therefore, when the students are graduated, they do not transfer enough abilities and skills from their academic lives to their jobs.

\subsection{Instructional Activity}

Instructional activity is one of the key concept for the success of a course, to gain and maintain students' curiosity, attention to achieve deeper understanding of the content. Although Prosser's theory has a behaviorist orientation compatible with trend of that 
period, it highlights the importance of hands-on experience. Today it is compatible with the learning-by-doing approach to instructional activities. As cited by Wonacott (2003), Prosser pointed out that “. .. vocational training will be effective in proportion as the specific training for forming right habits of doing and thinking are repeated to the point that these habits become fixed to the degree necessary for gainful employment ... "(p. 9).

That represents the importance of hands-on experience in vocational education. Intended learning opportunities cannot be easily adapted to the traditional curriculum in vocational education (Barnett \& Ryan, 2005). In a study that was conducted by Hatunoğlu (2006), $85.2 \%$ of the students stated that courses were theoratic. Moreover, $80.7 \%$ of the students stated that there were limited hands-on experiences in vocational education. In a traditional vocational course, laboratory sessions of courses are very crucial to developing their experiences. However, because of aforementioned and herein below mentioned reasons (instructional and technical related problems) it is not possible to integrate relevant instructional activities. The study of Mahiroğlu (1996) supports this issue and highlighted that $79 \%$ of students expressed that laboratory activities did not sufficiently satisfy their needs.

\subsubsection{Intervening Conditions}

Some contextual and general problems limit the quality of instruction. These conditions were named as intervening conditions that has effected the course. According to the Prosser's theory of vocational education cited by Wonacott (2003) "Effective vocational training can only be given where the training jobs are carried on in the same way with the same operations, the same tools and the same machines as in the occupation itself." (p.8). That represents the technical and physical needs of vocational education. In fact, vocational education is a more expensive way to educate students than general higher education. Its technical, hardware, physical needs required to spend more money on an activity. For instance, students should have access to relevant resources to practice on the relevant skills. In addition, with the developing technologies all these hardware needs to be renewed to satisfy emerging technologies that needed to be adapt to. 
In our case, the number of computers in the computer laboratory was not sufficient to practice the tasks what was written on the board. Even the instructor did not have the opportunity to write codes on the computer and show the output. An external projector should be used to do this but it took too much time to set it up. A student assistant helped the instructor during the lesson. Student assistant who is fourth year volunteer student who previously scored high in this course helps the instructor.

\subsubsection{Decision-Making Process of the New Course Design}

Before the delivery of the new course in the second semester, a new distance course was designed with the new characteristics to mitigate some of the predetermined problems of the existing course. In this new structure, an instructor from Ankara gave the course via smart class to this vocational institution located in another city. This course was also supported with the ITL Learning Gateway content management system with new content, course materials, communication opportunities, and instructional activities. In the new course, proposed considerations to mitigate predetermined problems were tried to be integrated into the new design as much as possible.

In order to solve aforementioned issues in the existing F2F course, researcher should decide on some design characteristics with the help of the existing literature, observations, and students' interviews. In this regard, the detailed ID process will be discussed further in Appendix $\mathbf{J}$, but in this section the decision making process of proposed solutions and the outcome of the new design will be discussed

During the instructional design process, it would be better not to start with a particular theory. The main focus of the ID'ers is the problem and its context. After informed about the nature of the instructional problem, it would be better to ask "What theory or models would be most appropriate to mitigate these problems?". In a similar vein, according to Klink, Boon, and Schlusmans (2007), in vocational higher education instructor initially should focus on the problems, and then pedagogical and technological solutions would be thought as a solutions to these problems. 


\subsubsection{New Content}

The main problem of the existing course was related to lack of considering the needs of the business life and $21^{\text {st }}$ century skills with the relevant technological and instructional opportunities. In this initial step, researcher attempted to decide on the content, because web technologies are rapidly developing and changing. In addition, students expected to learn up-to-date content for their future business life. This excitement to adapt new technologies as course content may sometimes result in a rush to introduce the latest technologies into the classroom without fully studying the need and future benefits or pitfalls of the technology. The decision process of selecting content for web design courses is more challenging than that of other courses. This process requires instructional designers to take into special consideration technology and content to be included in the course. For instance, designer should consider needs of the market and students, and as well as technological capacities of the school. The critical point is that ID'ers should not be in a rush to adapt the latest technologies without considering the abovementioned problems. That is why picture editing, animation creation, video editing, video embedding, and web page design were attempted to be integrated as a course content. Expression Studio were used as an editor that included all relevant tools from animation to web page design capabilities. Moreover, it is free of charge for the educational use, easily distributable, and downloadable for individual use.

\subsubsection{New Instructor \& New Medium Selection for the Delivery of the Course}

The second critical decision about the course was the way of instruction. It was decided to be given as a distance course, because instructor was in Ankara, students were in another city. Reaching a subject-matter expert is one of the most important problems of the vocational higher education. The number of students per each academic staff in Faculty of Technical Education is 33.6, and in technical vocational schools of higher education is 68.07 (ÖSYM, 2007). On the contrary, in the engineering faculties the number of students per each academic staff is 17.1 (Şahin \& Fındık, 2008).The survey results of Kayır and Kılıç (2008) reported that, $70 \%$ of students think that instructors have not sufficient professional knowledge and skills. An experienced instructor in web design courses and distance education from Ankara 
contribute to the study voluntarily. In our case, instructor experience was very important because of not only using specific hardware and software, but also he should know how to teach at a distance. It was required to have an understanding of pedagogical principles that are specific to the use of technology in a distance instructional setting.

This kind of distance course would be beneficial to represent that they will have opportunity to reach different instructor from one of the best universities of Turkey. Moreover, felling of ignorance, departed would be somehow eliminated. This will have positive effect on their future expectations and achievements, because as it was stated by Keleşoğlu \& Aksoy (2006) Faculty of Technical Education students' thought that the reason of their low achievement in their courses based on the instructor and facility related problems of their schools. With the wise integration of technologies like videoconferencing, ITL Learning Gateway Content Management System (CMS), and CMC (Computer Mediated Communication) hoped for a change in their ways of teaching on the contrary to traditional courses, and would be beneficial for their future expectations and vision to teaching and learning. All detailed explanation of the instructional design processes and tools can be seen in the Appendix $\mathbf{J}$.

In fact, DE has been used to successfully impart electronic circuit design skills to wooden seat design, etc.. Dhanarajan (2002) also noted that DE can be used for training workers in many fields ranging from farming to electronics, health to engineering, and animal husbandry to automobile engineering. In DE how you facilitate learning environment will specify the chance of success.

Online courses should not be limited with online resources and assignments in a university. The underlying reason of students' less preference might be related to the quality issues. Meta-analysis of comparisons of traditional and online learning showed that online learning modestly more effective than traditional face-to-face education (Means et al., 2010). Findings of this meta-analysis revealed that putting existing course to the online learning environment is not sufficient to create better learning opportunities. It needs to be supported and redesigned with the additional learning opportunities. In fact, students expect fast feedback, fast answers about course 
context, and effective guidance of facilitator, broad content, more social interaction and communication opportunities (Inal, Karakus, and Cagiltay, 2007). Especially many 2-year distance vocational higher education programs emerged in recent years, in Turkey. However, the main problem of distance education is that most of the course contents were based on electronically converted textbooks to HTML and PDF (Shi et al., 2003). Therefore, universities should improve the quality of online courses by considering students' expectations and rather than directly replacing F2F courses with online courses. They needed to be redesigned and supported with new instructional tools and facilities.

Moreover, the critical review presented that many studies about open and distance learning were mainly technology driven. This means that the researchers in general stuck on the technology use in the design and development of educational environments, without trying to develop and apply new theoretical models, pedagogical and instructional approaches. Even they use instructional design models as a way to integrate technology.

\subsubsection{New Instructional Design Process}

In this study, instructional design process was one of the most important decisionmaking steps. Morisson, Ross, and Kemp (2004) ID model was used as a framework during the course design process. In addition to that model, researcher and his advisors previous experiences guides the design process. During the design researcher did not stuck on the stages and the things that have to be done in these stages, with this instructional design model researcher could consider and knowledgeable about technology, content, students' needs, and instructional theories as a whole. There was always a balance between each of them. This knowledge is described as a combination of "technology", "pedagogy”, and "content knowledge" (TPACK) (Harris, Mishra \& Koehler, 2009; Mishra \& Koehler, 2006). These are the important concepts that teachers must master in order to use the technology effectively in their courses, and in the instructional design process (Doering, Veletsianos, Scharber, \& Miller, 2009; Polly, \& Mims, 2009). A high level of instructor technological-content-pedagogical knowledge may improve the success of the new design. This ID model contribute to 
the use of these different knowledge during the design process. Breaking out the ID processes into "content sequencing", "instructional strategies,", and "instructional delivery" gave freedom to the designer with the help of the instructional design. It is possible to design the content well, structure/re-arrange as needed for the pedagogical and technological needs of the distance course. It is obvious that poorly designed learning environments often result in unsuccessful or unsatisfactory educational experiences. Another reason to decide on this model was because of its wide application of technology enhanced learning environments, considered the perspective of the learner not only the content, and it is easy to revise.

Another consideration about the new course design was deciding on the desired learning outcomes of students have. After related literature review and collaborative work with a group of expert researcher decided to use ISTE-NETS for students and $21^{\text {st }}$ century students skills framework. ISTE (International Society for Technology in Education) determines the standards for teaching, and learning in the digital age with NETS (The National Educational Technology Standards) for students. Those standards includes following items (ISTE, 2007):

- Creativity and Innovation

- Communication and Collaboration

- Research and Information Fluency

- Critical Thinking, Problem Solving and Decision Making

- Digital Citizenship

- Technology Operations and Concepts

In a similar vein, $21^{\text {st }}$ century student skills were highlighted in many studies. This framework was described the skills, knowledge and expertise students must obtain to deal with the problems of the $21^{\text {st }}$ century (see Figure 5-1). This framework is a blend of content knowledge, specific skills, expertise and literacies. $21^{\text {st }}$ century skills implementation requires the development of core academic subject knowledge namely reading, writing, arithmetic. This knowledge should be covered with the life and career skills, learning and innovation skills, and information media, and technology skills. These are the skills that students needed to have in order to be successful in the $21^{\text {st }}$ century. 


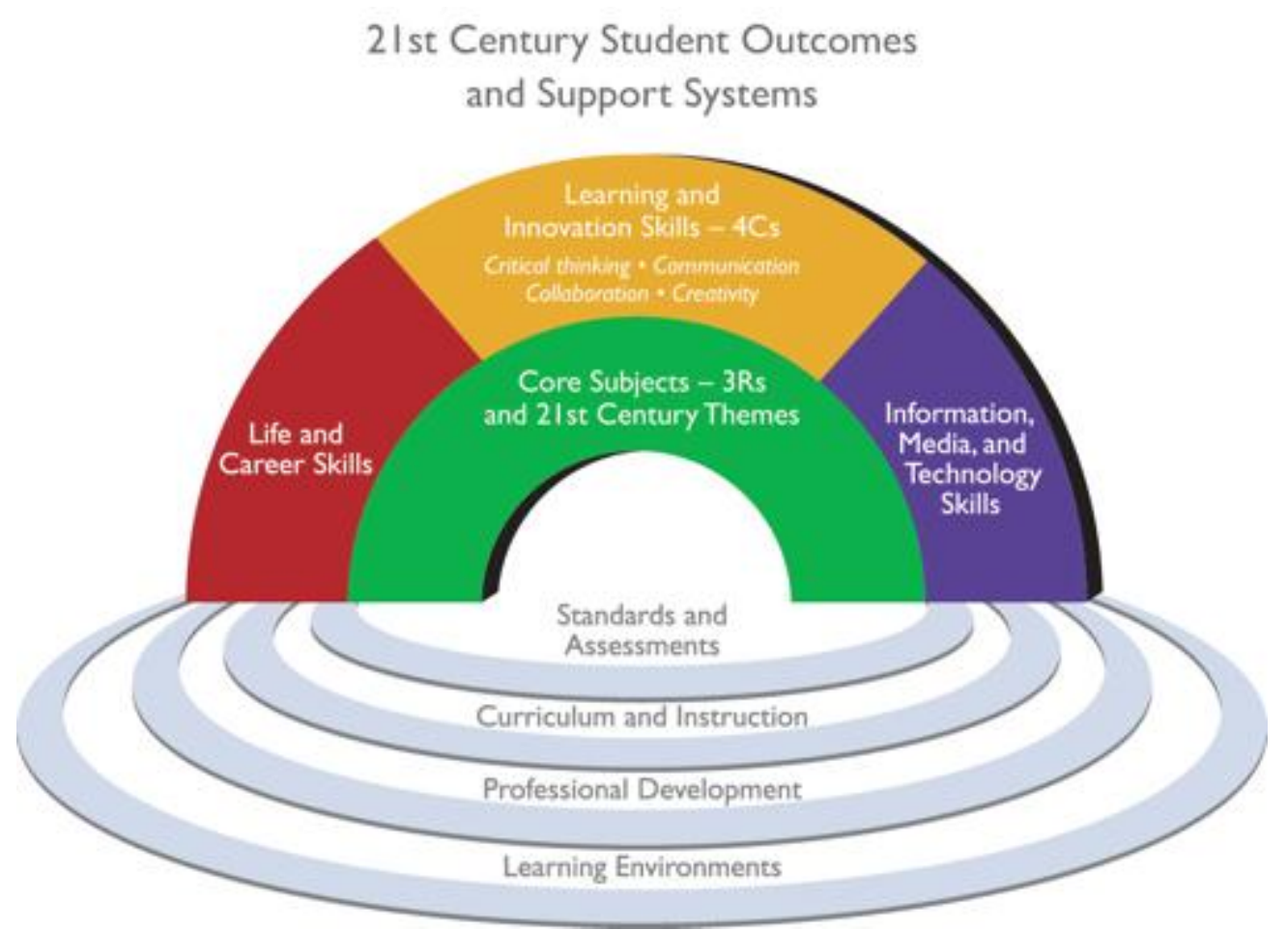

Figure 5-1: Framework for the $21^{\text {st }}$ century learning. (Adapted from Partnership for $21^{\text {st }}$ Century Skills, 2012)

After deciding on the content and delivery, researcher should decide on how technology facilitates learning to achieve this outcome. Jonassen (2000) define technology-based cognitive tools as mindtools and categorize those tools with respect to his view in three categories "learning about technology", "learning from technology", and "learning with technology". As a content of the course, technology was our topic and technology teaching was our aim. In addition to this use of technology, it is possible to use technology as a tool in web-based learning environment. However, when computers serve as cognitive tools, the most effective way to use computer is "learning with computer". By this way, computers can be used as a facilitator to think in meaningful ways and require using applications to represents what users or students know (Jonassen, 2000). That means technology planning should be an integral part of the ID process, because according to Gülbahar and Güven (2008) technology has a direct effect on instruction as a tool. To which extend we will have used technology in the new course was an important concern of the researcher 
during the instructional design process. The most significant reason of this concern is limited and unequal access to computers and the Internet, and being far away from the vocational institution for technical assistance.

In the Project Tomorrow 2010 Speak Up survey (2011) student surveys indicated that schools should include a socially-based, un-tethered and digitally-rich learning environment. This situation indicates online and blended learning, which would allow students to participate and communicate in an online environment, including social chat activities (Maher, 2009; Project Tomorrow, 2011). In the same line, Kozma (1994) pointed out that “... learning is an active, constructive, cognitive and social process by which the learner strategically manages available cognitive, social and physical resources to create new knowledge..."(p.8).

This reveals the social and human aspect of learning. That is the reason why DE is not an isolating experience for the learner. In fact, an effective DE experience should provide plenty of opportunity for human interactions based on the content of instruction. The Internet and related technologies provide a range of options for this purpose through what has come to be called CMC. CMC makes it easy to construct students' own understanding by collaborating each other. While designing and controlling online discussion teacher have to consider some important points. It was recommended that $\mathrm{CMC}$ moderators be prepared to act as assistant, consultant, coordinator, facilitator, goal setter, helper. In this context, teacher should not be the source of information; he/she should be the facilitator of the process by monitoring, bridging between the content-student, and increasing the interaction between studentstudent, student-content, student-teacher (Gunawardena \& MsIsaac, 2003).

Compatible with the Işık, Aşkun, and Özden's study (2010), which was used Microsoft SharePoint based e-learning sharing portal, he recommended integrating additional educational materials instant messaging software. That means interaction should be supported in the new course design with synchronous and asynchronous CMC tools. In the new distance course, it was decided to apply teleconferencing technologies, setting up a live broadcast for educational purposes, because each side is equipped with video conferencing system. However, the use of this expensive 
system never contributes to the courses as expected. In fact, in a study that presents the main use of smart classrooms show that projection, projection remote controller and internet connection was the mostly used technologies in smart classroom (Zhao, 2006). Moreover, in the same study $78 \%$ of the respondents believe that teaching with smart classroom technologies was better than teaching in traditional classroom environment.

As it was stated by McKamey (2008), students and faculty perceived that high level of satisfaction and high level of instructional effectiveness to the smart classrooms. Similarly, in a study that was conducted in Turkey students view smart classrooms as effective learning environment (Sevindik \& Gürol, 2009). In a similar study that was done on nursing students in Turkey lectures given through smart classroom significantly increase the student's achievement with respect to control group (Sevindik, 2007).

According to Langenberg and Spicer (2001), for a modern university network infrastructure, institutional information course management system, cooperative learning tools communications tools are needed. The capabilities of two modern university could be used as much as possible in this course. Moreover, Savery (2002) revealed that $59 \%$ of students expressed that technology on instruction enhance their learning. In fact, students have high expectations from the technology. For instance, in a study that was conducted in METU highlighted the students' future expectations. This study revealed that students expected to reach online lecture notes $(31.3 \%)$, easy communication with academic staff $(24.1 \%)$, video and audio recordings of the lessons (18.2\%) online elective courses (7.2\%), and training for instructors about technology use in courses $(5.1 \%)$.

In order to solve problems of an existing F2F course, some instructional strategies implemented to eliminate some. With the help of observations, students' expectations and related literature we determine some instructional strategies for the needs of a distant "web design" course. Instructors should follow strategies like peer-to-peer collaboration, instructor feedback, grader feedback, student-centered learning, authentic learning, critical thinking and project based learning. Those strategies 
should be supported with new content, material and web support with using computer mediated communications tools to eliminate some of the problems of the course. In this context, teacher is not the source of information; he/she is the facilitator of the process by monitoring, bridging between the content-student, and increasing the interaction between student-student, student-content, student-teacher (Gunawardena $\&$ McIsaac, 2003).

Aforementioned proposed strategies are mostly based on constructivist point of view. According to Mayer, in constructivist learning theory knowledge is constructed by the learner. Learner use both incoming information and prior knowledge from long term memory. When the goal is to encourage the learner to become cognitively involved in learning, instruction should be designed to help the reader to identify useful information, understand how that material fits together, and see how material relates to prior knowledge. In DE students are independent but not lonely during learning process. Students construct their knowledge with the help of the content, experiment sets, interaction between peers and tutors etc. Furthermore, individuals' expectations and diversity among learners should be taken into consideration because learners' experiences may range widely.

\subsubsection{Thoughts on the Design Characteristic of the New Course}

With the advent of developing technologies, it is possible to use different resources in the courses. Web-based technologies provide us to use wide variety of educational technologies to extend educational opportunities beyond the traditional classroom learning. Especially, with the web-based instruction learners have chance to reach educational resources anywhere, anytime rather than a place and time bound learning. As Lundt (2004) stated that with the emergence of the Internet, distance education and online instruction represent a new and effective way of learning replacing the traditional school system with a highly effective and efficient means of instruction.

In the second semester, data were collected to understand what the accomplishments of the new course were to remediate the existing problems of the F2F course, and what aspects of the new course needed to be modified. Field notes and interviews constituted the main data source about the new structure of the course. To support 
those qualitative findings, two questionnaires were conducted during this semester. "Web-Based Instruction Attitudes Scale" were conducted to see students' attitude toward web-based instruction. This scale is composed of two factors namely "effectiveness of web-based instruction" and "resistance to web-based instruction". In addition, students' perceptions about usability, ease of use, and perceived effects on motivation of the new learning environment were asked with a perception questionnaire based on "Technology Acceptance Model".

That is a fact that, knowing the effectiveness of WBI can contribute to the decision making process of the e-learning strategies (Lee, 2005). Designing a perfect distance course with web-based support cannot be possible in the first attempt, designers should always be in a struggle to increase the effectiveness of instruction.

Students' expectations towards WBI significantly affect learning outcomes (Alomyan \& Au, 2004). That is the reason why students' expectations and attitude should be considered to increase effectiveness of WBI. It is essential to identify the effectiveness and resistance of WBI to create a better learning environment. Students' attitudes towards these technologies, the reasons of avoidance and their reasons to use them provide us information to finding solutions to this resistance.

In this study students' attitude towards WBI were asked with a questionnaire. This questionnaire consist of two construct namely effectiveness of WBI and resistance to WBI. Overall, mean score of students attitude towards WBI was 3.19. It was a bit more than neutral, so students did not have negative attitude towards WBI. The mean score of effectiveness of WBI is a bit higher than 3 in a 5 level likert type of questionnaire. That means they were neither satisfied nor hesitate to take part in WBI. The mean score of students' resistance to WBI were evaluated lower than 3 . The reason of this situation will be explained in detail as below.

In addition to students' attitude towards WBI, researcher asked students' perceptions about the new learning environment. Technology Acceptance Model (TAM) theorized that actual technology use determined by the behavioral intention and that intention collectively related to perceived usefulness and perceived ease of use. In this 
study, a modified and extended version of TAM adapted to this study. The perceived effect of motivation about the learning environment was integrated to the TAM as an external factor.

Extensive literature exist on the application of TAM in the educational technology acceptance such as acceptance of CMS, collaboration tools, cellular phone, multimedia, and e-learning (Sivo \& Pan, 2005; Smith, 2006; Yang, 2007; Saadé, Nebebe \& Tan, 2007). In this study students were asked to respond their computer competency levels, e-learning experience, perceptions on the motivational aspect of the learning environment, usefulness of the learning environment, and ease of use of the learning environment.

The results of these quantitative data collected via attitude questionnaire revealed that overall attitude scores of students got from the questionnaire towards web-based instruction increased a little bit from beginning of the semester to the end. At the end of the delivery of the new distance course, students view on effectiveness of webbased instruction was between neutral and agree, and resistance of web-based instruction was between neutral and disagree. In addition, students' perceptions about new learning environment represented that their perceptions was over neutral. The reason of this existing situation was somehow related to the low computer competency level, limited Internet access at home, and limited computer ownership of the students.

In the new distance course, students' concerns about some aspects of the instructional and technical problems of the existing F2F course were mitigated. The accomplishments of the new design can be categorized in five main heading. These are "working with an experienced instructor", "extended learning opportunities", "increased future expectations of students", "fulfilled software requirements", and "applicability of a distance vocational course". On the other hand, in the new structure of the course, new problems emerged such as "course delivery problems" and "students' readiness", because sometimes technology use in education sometimes comes with its unique problems including the solutions. 
In this regard we should question the effectiveness of the new design. The effectiveness of WBI in a distance course depends on pedagogic effectiveness, technological effectiveness, institutional effectiveness, and course effectiveness (Burma, 2008). Related to course effectiveness, Shank (2003) reported that learning gains can be measurable by examination and test scores were the primary measure of effectiveness. The average grade of new distance web design course was 66.01 out of 100. This result revealed that the students who took that course had moderate achievement level in this new context. Although students had almost no prior elearning experience, limited computer and Internet access, students could get similar grades like previous F2F version of the course. According to Korkmaz and Tunç (2010), the main reason of students' low access and use of instructional materials thought as lack of sufficient hardware.

In order to understand the underlying reasons of limited effectiveness of the course, it is possible to look at the effectiveness of the technology that was used in the course. Especially, students' technology use, how they used, where they used, and to which extent they could reach them was important concerns in this study. Students ICT use is important issue that should be considered for the distance education projects because the attitudes and perceptions of the information age students are different from the learners of the past (Prensky, 2012). For example, $21^{\text {st }}$ century students are much more fluent with their use of technology and learn new applications very quickly. In order to extent their capacities with the technology, in this course it was expected to achieve "learning with the technology" (Jonassen, 2000). That means the use of technology as a tool for exploration, collaboration, and higher order thinking by the students. In this regard, it was expected that students participated to the course both inside and outside the school. Students access to the WBI tools at home and school reveled that the digital divide is an important issue to consider, because students from lower socio economic levels tend to have less access to technology outside of school, which limits their technology abilities in the classroom (Gündüz, 2010). In recent TÜİK (2012) report about the household ICT use of people in Turkey revealed that, computer and Internet access and household use of these technologies is not in the desired level. In this report, almost $51.3 \%$ of people in Turkey never used computer and internet before. Only, $31.8 \%$ of the people have Personal Computers 
in their homes. More than $50 \%$ of people do not have household internet access. Unfortunately, this number increases in Akdeniz region to 58.9\% which was important to note that because the new distance course were given to a university in that region. The reasons of this existing low internet access were asked to the respondents. Interestingly, almost $30 \%$ of them stated that they cannot get computer or other devices to access to internet because of expensive prices of them. Almost, $20 \%$ stated that internet access is expensive. In the January- March 2012 time period only $37.8 \%$ of the participants used Internet every day or once in a week. This number is lower in Akdeniz region, and it drops to $32.2 \%$.

In fact, during the design of the course, our attempt was to educate digital age learners with following the criteria's of the NETS for students, and $21^{\text {st }}$ century learning framework which defines what students should be accomplishing in the classroom with regards to technology. When computer experience of the students were highlighted, almost $20 \%$ of them has less than one year of computer experience. This situation revealed that in our case students were the digital immigrants. According to Prensky (2012), digital immigrants prefer traditional teaching methods rather than innovative ways of instruction.

Hudson (2011) pointed out that, $86 \%$ of students preferred to use technology outside the classroom. Students also indicated that the technology used in the classroom does not meet their expectations like the technology used at home, which can be personalized to the student's interests (Hudson, 2011; Project Tomorrow, 2012). That was compatible with our results. In our study, $20(62.5 \%)$ students connected to internet from internet cafes, $9(28.1 \%)$ of them at their home, $3(9.4 \%)$ of them were connected to internet at their school. Student's prefered to reach Internet outside the school, but not from their homes because of lack of access to the learning environment. Students did not have computers in their homes, only $59.4 \%$ of the students have computers at home. Although this department is a computer education department, almost one third of the students did not have a computer, although most courses needed to have computer based activities. Moreover, $50 \%$ of the students have no internet connections in their homes. 
It is obvious that this situation is an example of a digital divide related to the socioeconomic status of the child's family. When students' income was investigated, 75\% of the students has an income lower than $1500 \mathrm{TL}$. In that situation, the students from higher SES may have the higher the computer and internet adoption rate. Within the classroom, as we begin to use and rely upon ICT more and more, it is possible that the academic gap between the high SES and the low SES students will continue to widen. Moreover, this study revealed that students had almost no e-learning experience. For that reason, adapting to this new environment and changing habits needs time for students. As it was cited in a report of U.S Department of Education (2006), Perkins stated that effective technology integration could be provided if the technology is indeed available, if people are aware of it and if people are motivated.

Lack of appropriate hardware and software makes technology integration extremely difficult for instructional technologists. The classroom of vocational higher education institution suffer from limited computer access, limited internet connectivity, broken hardware, or outdated software. However, in vocational education developing and changing technologies should be followed closely, and this makes vocational education expensive (Develioğlu, 2012). In the same line, as highlighted by Barnett \& Ryan (2005), Australian Federal-State Ministerial Council on Employment, Education and Youth Affairs (MCEETYA) acknowledges that vocational education is more expensive than general education.

Obtaining and maintaining this up-to-date technological infrastructure is one of the important concerns of Turkish education system. Many studies highlight the information technology related problems (Göktaş, Yıldırım \& Yıldırım, 2009; Gülbahar \& Güven, 2008; Sadi et al., 2008). Unfortunately, these kind of technical and non-technical problems are encountered more in vocational higher education than general higher education. For instance, in the study of Kayır and Kılıç (2008) students and instructors from 20 vocational higher education institution participated in a study on the problems of vocational higher education. $78 \%$ of students stated that the physical structure of the schools are insufficient. Moreover, $72 \%$ of the students expressed that they could not use technological opportunities. Similarly, in another study, $25 \%$ of students in a faculty of technical education stated the lack of 
laboratories (Keleşoğlu \& Aksoy, 2006). The lack of related technological and physical needs resulted in limited use of technology in the courses.

\subsection{Recommendations for the Future Researches}

The needs of the information age are different from the needs of the industrial age. Globalization and information age highlight the needs of corporations and employers. Today, the expected profile of employees is being a good problem solvers, and team workers, communicating with other members of the firm well, and expressing their ideas freely. If we thought educated people as a product, we should change our process to reach desired product. In order to accomplish this, we need to modify current instructional theory (Reigeluth, 1999). According to Driscoll (2002), learning is a lifelong activity, and occurs intentionally in formal settings and incidentally through experience. According to Reigeluth(1999),

\footnotetext{
"... the increasing complexity of equipment, and current restructuring movement's emphasis on quality combine to require ever-increasing number of employees who can take initiative, think critically, and solve problems. To meet this need in industry and the need for life-long learners, we must focus on learning..."(p.18).
}

Moreover, this new approach will allow learners time to reach the learning goals in their own pace (Reigeluth, 1999). Today user-oriented ID may expand the potential of learners, so new theory need to meet the learner's needs of user-designer by creating flexible computer-based learning tools.

In user-centered ID processes, one of the critical decision is media and method selection with respect to contextual needs and students expectations. The influence of media was examined by reviewing many studies in many meta-analyses, and these analyses revealed similar learning benefits of F2F and technology enhanced learning environments, which means that no learning benefits may be gained by employing any specific medium to deliver instruction. In fact, Clark (1994) stated that 
instructional methods are the underlying common elements of all substitutable media and attributes of media.

In the new design of the course in the current study, researcher tried to find a middleway between technology and theory. During the instructional design process, constructivist ways of learning were employed to make extensive use of cooperative learning and to discover and comprehend difficult concepts more easily with extensive use of $\mathrm{CMC}$ technologies. Collaboration and cooperative inquiry have proved to be effective educational strategies, yet conventional methods often resulted in limited interactivity because of underestimation of social aspect of learning. In fact, social constructivism is a valuable approach to teaching-learning and it proposes that learning is a constructive and social process. Although in the web based learning environments we have limited opportunity to create and highlight social aspects of learning, it is possible to remediate this problem with CMC technologies (Özden, Gedik, and Kocaman-Karoğlu, 2012). With the impact of the Internet and communication technologies (ICT), there is a growing interest in CMC. Actually, computer and $\mathrm{CMC}$ tools are generally used to support individual learning, but it can also be used for a group of distance students. As it was cited by Romiszowski and Mason (2005), some research results show some gains of CMC such as more satisfaction with the web course, ability to study at one's own convenience, opportunity to gain experience about internet, faster assignment return, more immediate feedback, increased interaction with tutor and students, and extended learning experience beyond tutorials. With these improvements for technology integration in teaching/learning, there have been some changes in the responsibility of instructors. In line with these improvements, they are not the source of information anymore, instead, they turn to be "knowledgeable mentor" and "learning facilitator" (Langenberg \& Spicer, 2001). Actually, the only reason for this situation is not technology, but also changing teaching/leaning styles with the information age. Therefore, it is crucial for a university to be aware of what instructors do, use and think for their courses especially while integrating technology. Knowing the current situation, instructors' opinions and expectations is very important in terms of deciding on the future plans and strategies for improving learning opportunities. 
By considering students' and teacher's need during the design of a new course, everthing should completely be changed. Although students are willing to use those technologies, designers should overcome many important issues. One of these issues is social aspect of learning. These aspects and constructivism especially gain importance in distance courses. In fact, constructivism is not only a theory about teaching. It is a theory about knowledge and learning. In this study, it serves as the basis for many of the new approaches in education with respect to curriculum, instruction and assessment (Brooks \& Brooks, 1999). In the new design, students can develop new meaning and understanding in relation to their prior knowledge and experience. Learning results when students establish a connection between new information and prior understanding. Those strategies can be implemented in any instructional settings, especially in a distance course, e-learning applications, and web-based instruction. In fact, in web-based learning environment each student constructs his/her knowledge with the rich opportunity to communicate and collaborate with his or her peers and through in variety of ways (Özden, Gedik, and Kocaman-Karoğlu, 2012). While we are thinking about those strategies, we should concentrate on distance instructor, students, and their needs.

This study was conducted with limited resources and within time constrains. Thus, a longitudinal study could be carried out to analyze the developmental process of reflection further. This will provide more in-depth insight into reflection and its developmental process in further studies. Some recommendations are listed below for those who want to conduct a similar research:

- Action research is a good way to conduct this kind of studies because the main purpose of this study is to solve the problem in an educational setting. Although in some resources action research is named as a weak research methodology, its design-based structure and commitment to the research process will increase its effectiveness (Johnson \& Christensen, 2008).

In the nature of the action research, researcher should assume multiple roles and responsibilities. That is why, action researcher needs to be tolerant, 
ambitious for the evolving nature of the research and should have commitment to the change process to overcome unexpected things.

Moreover, writing action research dissertation needs time commitment to explain researcher decisions and underlying reasons for these decisions. It is important to record everything in the research process, even researcher's thoughts, feelings, and impressions. These would be beneficial in explaining the decision making process. There is a fact that this research process is a chronicle of the researcher decisions and the main focus is the process of what you did in the research rather than the results. According to Herr \& Anderson (2005), action research is "designing a plane while flying it" (p.69). Researcher performance swing the balance of the research, whether you can design a better plane as a pilot, or you may cause a plane crash.

- In this research process, researcher analyzes data by constant comparison data analysis technique to gain in depth understanding about the phenomenon. This analysis is framed by different authors and each of them proposed a unique way of doing the analysis (Charmaz, 2006, Corbin \& Strauss, 1998, Glaser \& Strauss, 2008). Data were analyzed with constantly comparing data with data, data with code, and code with code. Several times researcher needed to go back and forth in the data, codes, and categories by comparing them to create more abstract representations of the data. This process resulted in deeper thinking and understanding the data to make connections and abstractions. Although this research process is time consuming, it would be a good way to squeeze the data. It would be benefitial for the researchers to use this data analysis technique to get in-depth understanding about the instructional design process. Benefits and pitfalls of the new design can be detected better in qualitative studies with constant comparison data analysis.

- Design and delivery of a distance course from one university to the other needs to have a shared vision of all stakeholders including decision-makers, instructional designers, instructors, and support staff. Without this shared vision, it is not be possible to give a distance course. The main reason of this 
situation depends on the beurocracy. In Turkey, in order to deliver a distance course, especially to a different institution, needs to deal with many beurocratic issues. Apart from instructional problems, instructor have to struggle to solve beurocratic problems. Without a shared vision, it would be hard to overcome these beurocratic obstacles.

- A systemic plan should align with the shared vision to decide on ways of collaboration between counterparts of the distance course. Information and communication technology (ICT) and digital learning resource capacities can correspondingly be planned. Studies that were conducted in three different periods namely 1996, 1999, and 2008 revealed similar results on the problems of vocational higher education (Mahiroğlu, 1996; Bayulken \& Erturk, 1999; Şahin \& Findık, 2008). As time passes, there have been no changes in the problems of vocational higher education. These three studies revealed that physical and technical structure of the vocational institutions are viewed as one of the most important common problems.

- Educators, support staff, and decision-makers should be skilled even informed about the selection and effective use of appropriate ICT resources in a distance course. Although students had almost no prior e-learning experience, limited computer and Internet access, students could get similar grades to the previous F2F version of the course. According to Korkmaz and Tunç (2010), the main reason for students' low access and insufficient use of instructional materials is due to lack of sufficient hardware.

- Distance course design process needs to study more and time commitment to compensate limitatins of a distance course. Meta-analysis about comparisons of traditional and online learning showed that online learning modestly more effective than traditional face-to-face education (Means, Toyama, Murphy, Bakia, Jones, 2010). Findings of this meta-analysis revealed that putting existing course to the online learning environment is not sufficient to create better learning opportunities. Changing existing courses to a distance course 
needs to be supported with the additional learning opportunities and most of the time instructional designer should completely re-designed it.

During the instructional design process, it would be better not to start with a particular theory. Designer's main focus should be the problem and the context. After learning about the nature of the instructional problem, it would be better to ask "What theory or models would be most useful and appropriate to help address this problem?". In a similar vein, according to Klink, Boon, and Schlusmans (2007), in vocational higher education, instructor's initially should focus on the problem, and then they should propose pedagogical and technology related solutions.

This study aimed to provide information about every step of a distance course design process and how to set up technical infrastructure. It is obvious that in designing a course, the problems with respect to pedagogical and technological aspect of the distance course are more challenging than designing a F2F course.

- Both students and instructors should reach consistent and reliable assistance for maintaining, renewing, and using educational tools. In vocational education, developing and changing technologies should be followed closely to teach students up-to-date technologies. In addition to that, distance education needs some more technologies different from F2F courses. According to, Keleşoğlu \& Aksoy (2006), the students of Faculty of technical education thought that the reason for their low achievement in their courses are based on the instructor and facility problems of their schools. That means existing facilities could not be used as expected. Therefore, using distance education technologies in a vocational education needs new technologies, but how these technologies is used in these institutions necessitate to give consistent and reliable assistance.

- Students' skills, knowledge, and expectations should be located in the center of the distance course design process. Meaningful learning occurs both the 
trainers and the trainees need to be ready to learn (Özden, 2004). In the new structure of the course, new problems emerged such as "course delivery problems" and "students' readiness", because sometimes technology use in education sometimes comes with its unique problems including the solutions.

When computer experience of the students were highlighted, almost $20 \%$ of them has less than one year of computer experience. This situation revealed that in our case students were the digital immigrants. According to Prensky (2012), digital immigrants prefer traditional teaching methods rather than innovative ways of instruction. Students access to the WBI tools at home and school reveled that the digital divide is an important issue to consider, because students from lower socio economic levels tend to have less access to technology outside of school, which limits their technology abilities in the classroom (Gündüz, 2010).

- Students' should developed their skills compatiple with the ISTE NETS for students and $21^{\text {st }}$ century learning framework to take part on the information age. They should know how to reach and informed from the learning environment, including the ability to communicate using a variety of media and formats, access and exchange information in a variety of ways, collaborate and cooperate in a team etc. However, in a study that investigated the main use of smart classrooms showed that projection, remote controller and internet connection was the mostly used technologies in smart classroom (Zhao, 2006).

That means, students paradigm to technology use in education should be changed completely. Initially, they should have $21^{\text {st }}$ century learning skills. In the current study, their computer competency and internet access was problematic issue that should be considered in the future studies, because almost $20 \%$ of them has less than one year of computer experience. This situation revealed that in our case students were the digital immigrants. According to Prensky (2012), digital immigrants prefer traditional teaching methods rather than innovative ways of instruction. 
- Interaction should be improved with considering students' computer competency and e-learning experience. Students' limited existing knowledge, skills, and experience may result in low-level of interaction because of the limited use of the communication tools. Many research studies revealed that highly effective virtual teaching requires a highly interactive classroom (Friend \& Johnston, 2005; Cavanaugh, 2005; Zucker \& Kozma, 2003). In order to create constructivit distance learning environment, it should be designed to create rich opportunities for students to communicate and collaborate with their peers as well as a variety of resources.

In Turkey many study revealed that students have problems in interaction during their courses (Akpınar \& Özer, 2004; Hatunoğlu, 2006). However, in the Project Tomorrow 2010 Speak Up survey (2011). It was indicated that schools should be socially-based, un-tethered and digitally-rich learning environment. Although web environment thought to limit social aspect of learning, it can be argued that the use of CMC tools help diminishing this problem (Özden, Gedik, and Kocaman, 2012). This situation indicates online and blended learning, which would allow students to participate and communicate in an online environment, including social chat activities (Maher, 2009; Project Tomorrow, 2011).

- Using new interface may cause resistance for students to adapt the learning environment. Distance course instructors should plan at least one hour lecture to introduce the aim and the usage of the learning environment at the beginning of the semester. According to the seven principles of good teaching in webbased DE recommended the use of same general interface (like WebCT or in our case ITL Learning Gateway). This will increase students' familiarization to the interface for each course (Graham et al., 2001). Students do not have to deal with the adaptation to interface and directly they will contribute to the learning process and participate the course. Also, it is possible to integrate remote desktop technology to eliminate software and hardware related problems. By this was students could have equal access to the learning environment in the same interface (Tursak, 2007). 
- Not the technology but the instructor is the key point in a distance course. Teaching in a technologic environment faces instructors with a wide range of pedagogical, technological, and physical challenges. Unfortunately, most instructors are not trained to teach in tha kind of technologically enhanced learning environments. Moreover, from the constructivist perspective, the primary responsibility of the teacher is to create and maintain a collaborative problem-solving environment, where students are allowed to construct their own knowledge, and the teacher acts as a facilitator and guide. Doing all this with students who are far away necessitates to be informed about theoretical base of distance education and experienced in these learning environments. 


\section{REFERENCES}

Agar, M. (1980). The Professional Stranger: An Informal Introduction to Ethnography. New York: Academic Press, 1980.

Akbulut, Y. (2007). Implications of two well-known models for instructional designers in distance education. Dick-Carey versus Morrison-Ross-Kemp. Turkish Online Journal of Distance Education-TOJDE, 8 (2), 62-68.

Akçay, T. (2009). The effects of kid s programming language on problem solving skills of elementary school students in Turkey. Unpublished Ph.D. Thesis, Ankara: Middle East Technical University.

Akpinar, B., and Özer, B. (2004). The Assessment of the Teacher Professional Knowledge Lessons in the Technical Education Faculties According to Students' Point of View. Firat University Journal of Social Science, 14(2), 147-166.

Alkan, C., Doğan, H., Sezgin, İ.,(1996), Mesleki Teknik Eğitimin Esaslart. Ankara:Gazi Büro Kitabevi.

Allen, M., Bourhis, J., Burrell, N., \& Mabry, E. (2002). Comparing student satisfaction with distance education to traditional classrooms in higher education: a metaanalysis. The American Journal of Distance Education, 16(2), 83-97.

Allen, I.E. \& Seaman, J. (2003). Sizing the Opportunity: Online Education in the United States. Needham, MA: Sloan Consortium.

Allen, I.E. \& Seaman, J. (2004). Growing by degrees: Online Education in the United States. Needham, MA: Sloan Consortium.

Allen, I.E. \& Seaman, J. (2005). Growing by degrees: Online Education in the United States. Needham, MA: Sloan Consortium.

Allen, I.E. \& Seaman, J. (2006). Making the Grade: Online Education in the United States. Needham, MA: Sloan Consortium. 
Alomyan, H. and Au, W. (2004). Exploration of Instructional Strategies and Individual Difference within the Context of Web-based Learning. International Education Journal, 4(4), 86-91.

Angelides, P., Evangelou, M., and Leigh J. (2005). Implementing a Collaborative Model of Action Research for Teacher Development. Educational Action Research, 13 (2), 275-290.

Attwell, G. (2007). CDEFOP research resource base on ICTs and vocational education and training: An introduction and guide. CDEFOP: Germany.

Baran, B., Kılıç, E., Bakar, A. and Çağıltay, K. (2005). Turkish University Students: How Do They Use Technology and What Do They Think About Distance Education?, AECT Convention, October 2005, Orlando, Florida, USA.

Barlas, Z., Yilmaz, R., Uzun, H., and Findık, F. (2004). In order to Give Computer Aided Engineering Drawing Lesson Material Development, International Conference on VET Teacher Training, 22-23 January. Retrieved on December, 2010, from http://megep.meb.gov.tr.

Barnett, K and Ryan, R. (2005). Vocational education and training in Australian schools: Issues for practitioners. International Education Journal, 5(5), 89-104.

El-Mansour, B. (2011). Education in a technological world: communicating current and emerging research and technological efforts. Méndez-Vilas, (Ed.), Institutional Challenges Facing Online Education, Spain.

Bayülken, N. (1999). Üniversitelerde kalitenin stratejik yönetimi ve konu ile ilgili bir uygulama. Unpublished Mater Thesis, Çanakkale: Çanakkale Onsekiz Mart Üniversitesi.

Beaudin, B. P. (1999). Keeping online asynchronous discussions on topic. Journal of Asynchronous Learning Networks 3(2). Retrieved on March, 2010, from http://www.sloan-c.org/ publications/ jaln/v3n2/v3n2_beaudin.asp

Bertrand, M., \& Bouchard, S. (2008). Applying the Technology Acceptance Model to VR with people who are favorable to its use. Journal of CyberTherapy and Rehabilitation , 1(2), 200-210. 
Beşoluk, Ş., and Horzum, M.B. (2011). Öğretmen Adaylarının Meslek Bilgisi, Alan Bilgisi Dersleri ve Öğretmen Olma İsteğine İlişkin Görüşleri. Ankara Üniversitesi Eğitim Bilimleri Fakültesi Dergisi, 44(1), 17-49.

Bogdan, R. C., \& Biklen, S. K. (1998). Qualitative research for education: An introduction to theory and methods. Boston, MA: Allyn \& Bacon.

Borko, H., Livingston, C., McCaleb, J., and Mauro, L. (1988). Student teachers' planning and post-lesson reflections: Patterns and implications for teacher preparation. In J. Calderhead (Ed.), Teachers' professional learning. London: Falmer.

Branch, R. M. \& Gustafson, K. L. (2002). Revisioning model of instructional development. Educational communications and technology,18-22.

Brooks, J. G., \& Brooks, M. G. (1999). In Search of Understanding: The Case for Constructivist Classrooms. Alexandria, Virginia USA: ASCD - Association for Supervision and Curriculum Development.

Buchanan, E. (2002). Institutional and library services for distance education courses and programs. In Discenza, R., Howard, C., \& Schenk, K. (Eds.), The Design and Implementation of Effective Distance Learning Programs, 141-154. Hershey: Idea Group.

Buğday, H. (2007). The Political Implications of Vocational Education and Training Policy Of The European Union: A Case Study Of Svet Project. Unpublished Ph.D. Thesis, İstanbul: Marmara University.

Burma, Z. (2008). AB'ye Geçiş Sürecinde Meslek Elemanlarının Uzaktan Öğretim İle Eğitimi, Bilişim Teknolojileri Dergisi, 1(2), 15-20.

Çağiltay, K. (2001). Uzaktan Egitim: Basariya Giden Yol Teknolojide mi Yoksa Pedagojide mi?, Elektrik Muhendisleri Odasi Dergisi, 409-412.

Cavanaugh, C. (2005). Virtual Schooling: Effectiveness or Students and Implications for Teachers. Proceedings of Society for Information Technology and Teacher Education International Conference. Chesapeake, VA: AACE 
Chadwick, C (2002). Why Computers are Failing in the Education of our Children. Educational Technology, 35-40.

Chang, S., Chou, C., and Yang, J. (2010). The Literature Review of Technology Acceptance Model: A Study of the Bibliometric Distributions, PACIS 2010 Proceedings.

Charmaz, K. (2006). Constructing grounded theory: A practical guide through qualitative analysis. London: Sage.

Clark, R.E. (1983). Reconsidering research on learning from media. Review of Educational Research, 53(4), 445-459.

Clark, Richard E. (1994). Media will Never Influence Learning. Educational Technology Research and Development, 42(2), 21-29

Cresswell J. C. (2005). Educational research: planning, conducting, and evaluating quantitative and qualitative research. Upper Saddle River, N.J. Pearson/Merrill Prentice Hall.

Cuban, L., Kirkpatrick, H., and Peck, G. (2001). High Access and Low Use of Technologies in High School: explaining an apparent paradox. American Educational Research Journal. 38(4), 813-834.

Culp, K. M, Honey, M. \& Mandinach, E. (2005). A retrospective on twenty years of education technology policy, Journal of Educational Computing Research, 32(3), 279-307.

Davis, F. D. (1989). Perceived Usefulness, Perceived Ease of Use, and User Acceptance of Information Technology. MIS Quarterly, 3 (2), 319-339.

Davis, F. D., Bagozzi, R. P., and Warshaw, P. R. (1989), User acceptance of computer technology: A comparison of two theoretical models, Management Science, 35, 982-1003

Davis, J. M. (2004) Writing an action research thesis: One researcher's resolution of the problematic of form and process. In Erica, M., Susan, D. and John, K. (Eds.) Performing Educational Research: Theories, Methods and Practices, Post Pressed, Flaxton, Qld. 
Deci, E. L., \& Ryan, R. M. (1991). Intrinsic Motivation and Self-Determination in Human Behavior. In R. Steers, \& L. Porter, Motivation and Work Behavior (5th Edition ed., pp. 44-58). New York: McGraw-Hill, Inc.

Develioğlu, M. (2008). Mesleki Eğitimin Etkinleştirilmesinde Sivil Toplum Kuruluşlarinin Rolü: Ito Örneği. Retrieved from http://ismek.ibb.gov.tr/sempozyum/sunumlar/profdrmehmetdeveli.pdf

Dhanarajan G. (2002). Preface. In Mishra A. K. \& Bartram, J. (Eds.) Perspectives on Distance Education: Skills Development through Distance Education. Vancouver, Canada. Retrieved on October 28, 2011, from http://www.col.org/skills/ Skills_Development.pdf

Dishaw, M. T. and Strong, D. M. (1999). Extending the technology acceptance model with task-technology fit constructs. Information and Management, 36(1), 9-21.

Doering, A., Veletsianos, G., Scharber, C., \& Miller, C. (2009). Using the technological, pedagogical, and content knowledge framework to design online learning environments and professional development. Journal of Educational Computing Research, 41(3), 319-346.

Driscoll, M. P, Reiser, R. A., and Dempsey, J. A. (2002). Psychological Foundations of Instructional Design. Trends and issues in instructional design and technology. Upper Saddle River, New Jersey : Merrill/Prentice Hall.

Senem, Ş., E. (2006). Developing Reflective Teachers: A Study on Perception and Improvement of Reflection in re-Service Teacher Education. Unpublished Ph.D. Thesis. Ankara: Middle East Technical University.

Erdoğan, Y., Bayram, S. \& Deniz, L. (2007). Web tabanlı öğretim tutum ölçeği: Açıklayıcı ve doğrulayıcı faktör analizi çalışması. Uluslararası Insan Bilimleri Dergisi. 2(4), 1-14.

Erdoğan, Y., Bayram, S. \& Deniz, L. (2008). Factors that influence academic achievement and attitudes in web based education. International Journal of Instruction. 1(1), 31-48.

Erlandson, D., Harris, E., Skipper, B., and Allen S., (1993), Doing Naturalistic Inquiry: A Guide to Methods, Sage. 
Eşme, İ. (2007), Mesleki ve Teknik Eğitimin Bugünkü Durumu ve Sorunlar, T.C. YÖK Uluslararası Mesleki ve Teknik Ĕgitim Konferansı, Ankara.

Fraenkel, J. R., and Wallen N. E.(2000). How to design and evaluate research in education. The McGraw-Hill Companies, USA.

Fraenkel, J. R., \& Wallen, N.E. (2006). How to design and evaluate research in education. New York: McGraw-Hill.

Friend, B., \& Johnston, S. (2005). Florida Virtual School: A choice or all students. In Z. L. Berge \& T.Clark (Eds.), Virtual schools: Planning for success . New york: Teachers College Press

Gall, M. D., Gall, J. P., \& Borg, W. R. (2003). Educational Research: An Introduction (7th ed.). Pearson Education,Boston: Allyn \& Bacon, USA.

Garson, G. David. (2007). Scales and Standard Measures. Retrieved on August 24, 2010, from http://www2.chass.ncsu.edu/garson/pa765/standard.htm

Gefen, D. (2004). What makes an ERP implementation relationship worthwhile: linking trust mechanism and ERP usefulness. Journal of Management Information Systems, 21 (1), 263-288.

Gelişli, Y.,(2009),Vocational and Technical Education Faculty Students' Views Concerning Pedagogical Education, $12^{\text {th }}$ International Basoped Conference Inclusive Education in the Balkan Countries: Policy and Practices Proceeding, Ohrid.

Glaser, B., \& Strauss, A. (1967). The Discovery of grounded theory: Strategies for qualitative research. Chicago, IL: Aldine Atherton

Göktaş, Y., Yıldırım, S., and Yıldırım, Z. (2009). Main barriers and possible enablers of ICT integration into preservice teacher education programs. Journal of Educational Technology \& Society, 12 (1), 193-204.

Graham, C., K. Cagiltay, B.-R. Lim, J. Craner, and T. M. Duffy (2001). Seven Principles of Effective Teaching: A Practical Lens for Evaluating Online Courses. Technology Source, Retrieved April 2012 from: http://www.technologysource.org/article/274/ 
Gülbahar, Y. and Güven, İ. (2008). A survey on ICT usage and the perceptions of social studies teachers in Turkey. Educational Technology \& Society, 11 (3), 3751.

Gunawardena, C. N. \& McIsaac, M.S (2003). Distance Education. In Jonassen D. H. (Ed.). Handbook of Research for Educational Communications and Technology. NewYork: Macmillan. pp. 355-395.

Gündüz, H. B. (2010). Digital divide in Turkish primary schools: Sakarya sample. TOJET: The Turkish Online Journal of Educational Technology, 9(1), 43-53.

Gürüz K.,(2003), Higher Education in the World and in Türkiye, Retrieved on May 2009 from: http://www.yok.gov.tr

Gustafson, K. L. \& Branch R. M. (1997). Survey of Instructional Development Models. $3^{\text {rd }}$ ed. ERIC Clearinghouse on Information Technology mode, Syracuse, NY. (Skin over taxonomy and models)

Guthrie, R. \& Navaratte, C. (2002).Smart Classrooms: The Intersection of Technology and Pedagogy In Higher Education, Americas Conference on Information Systems (AMCIS) Proceedings.

Harris, J., Mishra, P., \& Koehler, M. (2009). Teacher's technological pedagogical content knowledge: Curriculum-based technology integration reframed. Journal of Research on Technology in Education, 41(4),393-416.

Hatunoğlu, Z. (2006). Muhasebe Eğitiminde Bilgi Teknolojisi Kullanımının Sunum Kalitesine Olan Etkilerinin Tespitine İlişkin Bir Araştırma, Vocational Education, 30 .

Kathryn H., and Gary L. A. (2005). The action research dissertation: A guide for students and faculty, US, Sage publication.

Hanley, M. (2009). Discovering instructional design: the Kemp Model. Retrieved on June 2009 from http://elearningcurve.blogspot.com/2009/06/discoveringinstructional-design-11.html

Harris, J., Mishra, P., \& Koehler, M. (2009). Teachers' technological pedagogical content knowledge and learning activity types: Curriculum-based technology 
integration reframed. Journal of Research on Technology in Education, 41(4), 393-416.

Hawkridge, D. (2002). Distance learning and instructional design in international settings. In R. A. Reiser \& J. V. Dempsey (Ed.), Trends and issues in instructional design and technology (pp. 183-193). Upper Saddle River, NJ: Merrill Prentice Hall.

Holmberg, B. (1989). Theory and practice of distance education. London and New York: Routledge.

Hudson, H. (2011). The Digital Divide. Instructor, 121(2), 46-50.

Inal, Y. Karakus, T. Cagiltay, K.(2007). Understanding Students' Readiness and Awareness about Distance Education for Enhancing The Quality, Association for Educational Communications and Technology Convention, 2007, October, 23-25 Anaheim, CA,

İşsever, C., Adak, M. A., Ünlü A., Fidan M., and Taş M. (2005). Mesleki ve Teknik Eğitimin Tarihçesi, Devlet Kitapları Müdürlügüü, Ankara.

ISTE. (2007). The ISTE NETS and Performance Indicators for students (NETS.S). Retrieved May 30, 2011, from: http://www.iste.org/Libraries/PDFs/NETS_for_Student_2007_EN.sflb.ashx

ISTE (2012). International Society for Technology in Education. Retrieved on 02 14, 2011, from: http://www.iste.org.

Iş1k, A. (2009). Perceptions of students and teachers about the use of e - learning / sharing portal in educational activities. Unpublished Master Thesis, Ankara: Middle East Technical University.

Iş1k, A., Aşkun, C. S., Özden, M. Y. (2010). Perceptions of Students and Teachers about the Use of E-Learning / Sharing Portal in Educational Activities. In D'Agustino S. (Ed.). Resistance and Access to Instructional Technologies: Assessing Future Trends in Education, IGI Press.

Jonassen, D. H. (2000). Computers as mindtools for schools: Engaging critical thinking. Upper Saddle River, NJ: Merrill/Prentice Hall. 
Johnson, B., \& Christensen, L. (2008). Educational research: Quantitative, qualitative, and mixed approaches. Thousand Oaks, CA: Sage Publications.

Karahanna, E. and Straub, D.W. (1999). The Psychological Origins of Perceived Usefulness and Easeof Use. Information and Management, 35(4), 237-250.

Kayır, Ö., and Kılıç, H., (2008), Mesleki Eğitim ve Teknik Eğitim Fakülteleri Araştırması, İTO Publications.

Keleşoğlu, Ö., and Aksoy, U. (2006). Öğrencilerin Teknik Eğitim Fakültelerinde verilern öğretime uyum sorunları: (F.Ü. Teknik Eğitim Fakültesi örneği). Firat University Journal of Social Science, 16(2), 147-157.

Kink, M., Boon, J., and Schlusmans, K. (2007). Competences and vocational higher education: Now and in future. European journal of vocational training, 40 (1).

King, W.R., \& He, J. (2006). A meta-analysis of the technology acceptance model. Information \& Managemement, 43, 740-755.

Koç, E., Yıldırım Z. \& Ozden, M.Y., (2006), Perceptions on Problem-Based Online Learning, Academic Exchange Quarterly, 10(3), 34-38.

Korkmaz, Ö., and Tunç, S. (2010). Mesleki-Teknik Eğitim Öğretmenlerinin Bilgisayar Ve İnternet Temelli Öğretim Materyallerinden Yararlanmaya İlişkin Görüşleri. Ahi Evran Üniversitesi Ĕgitim Fakültesi Dergisi, 11(3), 263-276.

Koufaris, M. (2003). Applying the Technology Acceptance Model and Flow Theory to Online Consumer Behaviour. Information Systems Research, 13 (2), 205-223.

Kozma, R. B. (1994). Will Media Influence Learning? Reframing the Debate. Educational Technology, Research and Development, 42(2), 7-19.

Langenberg, D. N, \& Spicer, D. Z (2001). The Modern Campus, New Direction for Higher Education, No. 115.

Laudon K. C. and Laudon J. P. (2003). Management Information Systems: new approaches to organization and technology (6th ed.). Prentice Hall.

Le Compte, M. D. and Goetz, J. P. (1982). Problems of reliability and validity in ethnographic research. Review of Educational Research, 52(1), 31-60. 
Lederer, A. L., Maupin, D. J., Sena, M. P., \& Zhuang, Y. (2000). The technology acceptance model and the world wild web. Decision Support Systems, 29 (3), 269282.

Lee, Kar-Tin (2005) E-Learning: The Quest for Effectiveness. Malaysia Online Journal of Instructional Technology, 2(2), 61-71.

Legris, P., Ingham, J. and Collerette, P. (2003). Why people use information technology? A critical review of technology acceptance model. Information \& Management, 40, 191-204.

Lillemor, R. and M., Hallberg (2010). Some thoughts about the literature review in grounded theory studies. International Journal of Qualitative Study Health Wellbeing, 5(3).

Lundt, J. C. (2004). Learning for ourselves: A new paradigm for education. The Futurist, 18-22.

Mahiroğlu, A. (1996), Teknik Eğitim Fakültesi Mezunlarının İzlenme Araştırması. Milli Eğitim Bakanlığı. Ankara: Milli Eğitim Basımevi.

Maher, D. (2009). The importance of elementary school students' social chat online: Reconceptualising the curriculum. Computers \& Education, 53(2), 511-516.

Marshall, C. and Rossman, G.B. (1999). Designing qualitative research. Thousand Oaks, CA: Sage.

Malkan, R. R. (2009). Post-Secondary Technical Vocational Education Training: a Qualitative Case Study of Industrial Training Institute (Iti) In Maharasthra State, India. Unpublished Ph.D. Thesis, Nebraska: University of Nebraska.

Mathieson, K. (1991). Predicting user intentions: Comparing the technology acceptance model with the theory of planned behavior. Information Systems Research, 2(3), 173-191.

Matthew K. O. Lee, Christy M. K. Cheung, and Zhaohui C. (2005). Acceptance of Internet-based learning medium: the role of extrinsic and intrinsic motivation. Information \& Management, 42:1095-1104 
McAuley, E., Duncan, T., and Tammen, V. V. (1989). Psychometric properties of the Intrinsic Motivation Inventory in a competitive sport setting: A confirmatory factor analysis. Research Quarterly for Exercise and Sport, 60, 48-58.

McCombs, B. (1986). The Instructional Systems Development (ISD) Model: A Review of those Factors Critical to its Successful Implementation, ECTJ, 34(2), 67-81.

McKamey, J. P. (2008). Smart Classroom Technology: Instructional Effectiveness and Faculty and Student Satisfaction. Unpublished Ph.D. thesis, Nova Southeastern University.

Mcniff, J. and Whitehead, J. (2005) Action Research for Teachers: A Practical Guide, David Fulton Publishers, London.

Means, B., Toyama, Y., Murphy, R., Bakia, M., Jones, K. (2010). Evaluation of evidence based practices in online learning: A meta-analysis and review of online learning studies. Washington DC, US Department of education.

Meyer, K. A. (2005). Critical decisions affecting the development of Western Governors University. Innovative Higher Education, 30(3), 177-194.

MEB (Ministry of Education) (2005). Ninth Fifth Year Development Plan. Retrieved January 5, 2006, from www.meb.gov.tr.

METU (2010), Smart Class, Retrieved March 2011, from http://www.it.ncc.metu.edu.tr/smartclass.php

Mishra, P. and Koehler, M. J. (2006). Technological pedagogical content knowledge: A new framework for teacher knowledge. Teachers College Record, 108(6), 1017-1054.

Molenda, M. and Sullivan, M. (2003). Issues \&Trends in Instructional Technology: Treading Water. Educational Media and Technology Yearbook 2003, Englewood, CO: Libraries Unlimited.

Moore, M.G. (2007). The Theory of Transactional Distance. In M.G.Moore (Ed.) The Handbook of Distance Education. Second Edition. Mahwah, N.J. Lawrence Erlbaum Associates. 89-108. 
Morrison, G. R., Ross, S.M., and Kemp, J. E. (2004). Designing Effective Instruction. Hoboken, NJ: John Wiley \& Sons, Inc.

Mümtaz, S. (2000). Factors affecting teachers' use of information and communications technology: a review of the literature. Technology, Pedagogy, and Education, $9(3), 319-342$.

Nachmias, R. (2002). A research framework for the study of a campus-wide Webbased academic instruction project. Internet and Higher Education. 5(3), 213 229.

NASA (2006). External Benchmarking Study of Advanced Technology Applications. Retrieved on January 5, 2008, from: http://learn.arc.nasa.gov/benchmark

Ndubisi, N. O., Gupta, O. K., and Ndubisi, G. C. (2005). The moguls' model of computing: Integrating the moderating impact of users' persona into the technology acceptance model. Journal of Global Information Technology Management, 8(1), 27-47.

Norton, R.D. (1999). The geography of the new economy. The Web Book of Regional Science. Retrieved on June, 12, 2009, from:

http://www.rri.wvu.edu/WebBook/Norton/contents.htm

O’Brein R.. (1998). An Overview of the Methodological Approach of Action Research, Retrieved on October 2009, from:

http://www.web.net/\%7Erobrien/papers/arfinal.doc

ODTÜ (2005). Orta Doğu Teknik Üniversitesi Stratejik Planı 2005 - 2010, Ankara, Mart 2005.

Ogawa, K. and A. Tansel.(2005). Transition from Education to Labor Market in Turkey. Journal of International Cooperation Studies, 12(3), 113-43.

Okobia E.O. (2011). Availability and Teachers' Use of Instructional Materials and Resources in the Implementation of Social Studies in Junior Secondary Schools in Edo State, Review of European Studies, 3(2).

ÖSYM (2007). 2006-2007 öğretim yılı yükseköğretim istatistikleri. Ankara: ÖSYM. 
ÖSYM (2011). 2010-2011 ögrretim yll yükseköğretim istatistikleri. Ankara: ÖSYM.

Öz, H. H.(2005). Synchronous Distance Interactive Classroom Conferencing , Teaching and Learning in Medicine, 17(3), 269 - 27.

Özden, M. Y. (2002). Ögretici tabanlı öğrenmeden Internet tabanlı çoklu ortam oluşturmacı yaklaşım uygulamalarına geçiş: Bir durum calışması, Biliş̧im Teknolojileri Işı̆̆ğnda Eğitim Konferansı ve Sergisi Bildiriler Kitabı. ODTÜ:Ankara. 44-50.

Özden, M. Y. (2004). Law of the minimum inlearning. Journal of Educational Technology \&Society, 7(3), 5-8.

Özden, M. Y. (2007). Use of Technology in Education? Integrating Technology into Curriculum: Blended Learning. Retrieved on November 2012, from https://www.facultyresourcecenter.com/curriculum/pfv.aspx?ID=6795

Özden, M. Y., Gedik, N., Kocaman-Karoğlu, N. (2012). A Web-based Training Experience in Turkey: A University-National Police Collaboration. Yang H. H. and Yuen, C. S. (Ed.). Handbook of Research on Practices and Outcomes in Virtual Worlds and Environments. Hershey, PA: IGI Global.

Özsoy, A. (2004). Modernization of Technical Training Faculties, Paper presented at The International Conference on VET Teacher Training, 22-23 January 2004. Retrieved in November, 2012, from http://megep.meb.gov.tr.

Özsoy, C. (2007). Türkiye'de Mesleki ve Teknik Eğitimin İktisadi Kalkinmadaki Yeri ve Önemi. Unpublished Ph.D. Thesis, Eskişehir: Anadolu Üniversitesi.

Özyılmaz, O. (2008). Bilgi Çağına Girerken Ülkemizde Mesleki Teknik Eğitim, Sorunlart ve Çözüm Önerileri, Retrieved on June 30 , 2008, from http://www.omerozyilmaz.com/

Partnership for $21^{\text {st }}$ Century Skills. (2012). The partnership for 21 st century skillsFramework for 21st century learning. Retrieved on November 30, 2012, from http://www.p21.org/overview.

Passerini, K. and Granger, M. J. (2000). A developmental model for distance learning using the Internet, Computers \& Education, 34, 1-15. 
Patton, M. Q. (1990). Qualitative Evaluation and Research Methods (2nd ed.). Newbury Park, CA: Sage Publications, Inc.

Patton, M.Q. (2002). Qualitative Research and Evaluation Methods. Thousand Oaks, CA: Sage Publications, Inc.

Peck, K. L., \& Dorricott, D. (1994). Why use technology?, Educational Leadership, 51(7), 11-14.

Perkins, C. (2006). U.S. Department of Education. Retrieved on January 21, 2009, from U.S. Department of Education: http://frwebgate.access.gpo.gov/cgi.

Perkins, D. (1985). The Fingertip Effect: How Information-Processing Technology Shapes Thinking. Educational Researcher. 14(7). 11-17.

Polly, D., \& Mims, C. (2009). Designing professional development to support teachers' TPACK and integration of Web 2.0 technologies. In Kidd and I. Chen (Eds.), Wired for learning: Web 2.0 guide for educators. Charlotte, NC: Information Age Publishing.

Prensky, M (2012). From Digital Natives to Digital Wisdom: Hopeful Essays for the $21^{\text {st }}$ Century Learning. Thousand Oaks, CA: Corwin.

Project Tomorrow. (2011). Mapping a personalized learning journey - K-12 students and parents connect the dots with digital learning, Retrieved on 25 November 2012, from

http://www.tomorrow.org/speakup/pdfs/SU11_PersonalizedLearning_Students.p df

Reigeluth, C. M. (1999). What is instructional design theory and how is it changing? In C. M. Reigeluth (Ed.), Instructional design theories and models: A new paradigm of instructional theory. Hillsdale, NJ: Lawrence Erlbaum Associates.

Reiser, R.A. (2002). A History of Instructional Design and Technology. Ch 3 in Trends and issues in instructional design and technology. In Reiser, R.A., \& Dempsey, J.A. (Eds.). Upper Saddle River, New Jersey : Merrill/Prentice Hall. 
Roblyer, M.D., Edwards, J. (2000). Integrating Educational Technology into Teaching, , 2nd edition, Prentice-Hall Inc.

Romiszowski, A. J., and Mason, R. (2005). Computer-mediated communication. In D. H. Jonassen (Ed.), Handbook of Research for Educational Communications and Technology. New York: Macmillian LIBRARY Reference USA.

Rovai, A. (April, 2002). Building sense of community at a distance.International Review of Research in Open and Distance Learning (IRRODL), 3, 1. Retrieved on April 13, 2008, from http://www.irrodl.org/content/v3.1/rovai.pdf

Saadé, G. R., Nebebe, F., \& Tan, W. (2007). Viability of the "Technology Acceptance Model" in multimedia learning environments: A comparative study. Interdisciplinary. Journal of Knowledge and Learning Objects, 3, 175-184. Retrieved on July, 11, 2010 from http://www.ijello.org/Volume3/IJKLOv3p175184Saade393.pdf

Sadi, S.,Şekerci, A. R., Kurban, B., Topu, F. B., Demirel, T., Tosun, C., Demirci, T. ve Göktaş, Y. (2008). Öğretmen eğitiminde teknolojinin etkin kullanımı: öğretim elemanları ve öğretmen adaylarn görüşleri. Bilişim Teknolojileri Dergisi, 1 (3), 43-49.

Şahin, İ. and Fındık, T. (2008). Türkiye'de Mesleki ve Teknik Eğitim: Mevcut Durum, Sorunlar ve Çözüm Önerileri, Türkiye Sosyal Araştırmalar Dergisi, 12 (3). s.6586

Savery (2002). Faculty and student perception of technology integration in teaching. The journal of interactive online learning, 1(2).

Schiffman, S. S. (1995). Instructional System Design: Five Views of the field. In G. J. Anglin (Ed.), Instructional Technology: Past, Present, and Future (2nd ed.), Englewood, CO, Libraries Unlimited.

Schmuck, R. A. (2006). Practical action research for change. Arlington Heights, IL : IRI/Skylight Training and Publishing.

Scurry, J. Couturier, L. Newman, F. (2004). The Future of Higher Education: Rhetoric, Reality, and the Risks of the Market. Jossey-Bass.

Sevindik, T. \& Gürol, M. (2009). The Effects of Smart Classrooms On The High Education Students' Attitudes, E-Journal of New World Sciences Academy, 4 (4). 
Sevindik, T. (2007). Future's learning environments in health education: The effects of smart classrooms on the academic achievements of the students at health college, Telematics and Informatics, 27 (2010) 314-322.

Shank, P. (2003). Showing the Value of e-Learning. Retrieved on May 2007, from: http://www.elearningguild.com/pdf/1/values_survey_results_-_final.pdf

Shi, M., \& Bichelmeyer, B. A. (2007). Teachers' experiences with computers: A comparative study. Educational Technology \& Society, 10 (2), 180-190.

Shi, Y., Xie, W., Xu, G., Xiang, P., \& Zhang, B. (2003). Project Smart Remote Classroom Providing Novel Real-Time Interactive Distance Learning Technologies.International Journal of Distance Education Technologies (IJDET), 1(3), 28-45.

Sink, D. L., (2002). ISD: Faster Better Easier, Performance Improvement Journal, 41(7), 16-21.

Sivo, S. and Pan, C. (2005). Undergraduate engineering and psychology students' use of a course management system: A factorial invariance study of user characteristics and attitudes. Journal of Technology Studies, 31(2), 94-103.

Smith, J. A. B. (2006). The effect of social presence on teacher technology acceptance, continuance intention, and performance in an online teacher professional development course. Unpublished Ph.D. Thesis, University of Central Florida, Orlando.

Stake, R. E. (1994). Case studies. In N. K. Denzin \& Y. S. Lincoln (Eds.), Handbook of qualitative research (pp. 236-247). Thousand Oaks, CA: Sage.

Strauss, A., Corbin, J. (1998). Grounded theory in practice, Thousand Oaks : Sage Publications.

Stringer, E. T. (2007). Action research (3rd edition). Thousand Oaks, CA: Sage Publications, Inc.

Sun, H., \& Zhang, P. (2006). The role of moderating factors in user technology acceptance. International Journal of Human-Computer Studies, 64(2), 53-78. 
Surry, D. W., \& Ely, D. P. (2001). Adoption, diffusion, implementation, and institutionalization of educational innovations. In R. Reiser \& J. V. Dempsey (Eds.), Trends \& Issues in Instructional Design and Technology, Upper Saddle River, NJ: Prentice-Hall.

Surry, D. W. and Land, S. M., 2000. Strategies for motivating higher education faculty to use technology. Innovations in Education and Training International, 37(2), 145153.

Tashakkori, A. \& Teddlie (1998). Mixed Methodology: Combining Qualitative and Quantitative Approaches. Thousand Oaks, CA. : Sage Publications.

TİSK (2005), Mesleki Eğitim Sistemimiz Ve İşletmelerdeki Beceri Eğitimi Sorunlar ve Çözüm Önerileri Raporu, TISK Yayınları, Ankara, 65.

Toral, S. L., Barrero, F. and Torres M. R. (2007). Analysis of utility and use of a webbased tool for digital signal processing teaching by means of a technological acceptance model, Computers \& Education, 49, 957-975.

Tucker, A., Deek, F., Jones, J., McCowan. D., Stephenson, C., and Verno, A. (2003). A Model Curriculum for K-12 Computer Science. Final Report of the ACM K-12 Task Force Curriculum Committee. Retrieved on March 20, 2010 from http://www.csta.acm.org/Curriculum/sub/CurrFiles/K-12ModelCurr2ndEd.pdf

Mishra, P., \& Koehler, M. J. (2006). Technological pedagogical content knowledge: A new framework for teacher knowledge. Teachers College Record. 108(6), 1017-1054.

Muhammet Turşak, (Y. Lisans, 2007). Perceptions of Students and Instructors About Using Remote Access Technology in Programming Language Courses: A Case Study. Unpublished Ph.D. thesis, Middle East Technical University, Ankara, Turkey.

Tüzün, H. (2004). Motivating Learners in Educational Computer Game. Unpublished Ph.D. thesis, Indiana University, Indiana, U.S..

TÜİK (2012). TÜIKK Hanehalkı Bilişim Teknolojileri Kullanım Araştırması, Retrieved on December, 2012, from: www.tuik.gov.tr. 
UNESCO (2002). Open and distance learning, Trends, policy and strategy considerations, Paris.

UNESCO \& ILO (2002). Technical and vocational education and training for the twenty-first century. Paris: UNESCO and ILO.

UNESCO (2003). The Use Of Icts In Technical And Vocational Education And Training. Moscow: UNESCO Institute for Information Technologies in Education.

UNESCO. (2000). Report of the Expert Meeting on Virtual Laboratories. Retrieved on January 5, 2006, from: http://www.collaborium.org/reports/vlfinal.pdf

U.S. Department of Education. (2006). Carl D. Perkins Act of 2006. Retrieved February 21, 2008, from U.S. Department of Education: http://frwebgate.access.gpo.gov/cgibin/getdoc.cgi?dbname=109_cong_bills\&docid=f:s250enr.txt.pdf

UZEM (2012). Uzaktan egitimle egitim veren meslek yuksekokullari, Retrieved on July, 3, 2012, from http://uzem.blogcu.com/turkiyede-uzaktan-egitim-verenmeslek-yuksekokullari/11724368

Venkatesh V., C. Speier, M.G. Morris (2003). User acceptance enablers in individual decision making about technology: toward an integrated model, Decision Sciences. 33(2), 297-316.

Venkatesh, V. and Davis, F.D. (2000). Extrinsic and intrinsic motivation to use computers in the work place. Journal of Applied Psychology, 22 (14), 1111-1132.

Venkatesh, V., Morris, M.G., Davis, G.B., \& Davis, F.D. (2003). User acceptance of information technology: toward a unified view. MIS Quaterly, 27 (3), 425-478.

Venkatesh V. and Bala, H. (2008). Technology Acceptance Model 3 and a Research Agenda on Interventions, Decision Sciences, 39 (2).

Whitehead, J. (1993) The Growth of Educational Knowledge, Bournemouth; Hyde. Retrieved on 1 March 2010

from: http://www.actionresearch.net/writings/jwgek93.htm 
Winter, M. (2006).Learning Management Systems for the Workplace. A Research Report.Core Education Ltd. Retrieved on 18 January 2009 from: http://www.tanz.ac.nz/pdf/LMS_Final.pdf

Wonacott, Michael E. (2003). History and Evolution of Vocational and CareerTechnical Education . Center on Education and Training Career and Vocational Education, College of Education, Ohio State University.

Yang, H. (2007). The effect of technology acceptance on undergraduate students' usage of WebCT as a collaborative tool. Unpublished Ph.D., University of Central Florida, Orlando.

Yıldırım, A. and Simsek, H. (2000). Sosyal bilimlerde nitel araştırma yöntemleri. Ankara: Seçkin.

Y1ldı, I., Karakus, T., Kursun, E., Uzun, E. and Karaaslan, H. (2007). Random Assigned Collaborative Working in A Distance Education Course: Experience And Recommendations Of Students, World Conference on Educational Multimedia, Hypermedia and Telecommunications (EDMEDIA) 2007.

Yılmaz, R., Findık, F., Ekiz, H. and Firat, S. (2004). Evaluation of the Technical Education Faculties Syllabus as to Development, International Conference on VET Teacher Training 2004 Proceeding. Retrieved on May 2006, from: http://megep.meb.gov.tr.

Yükseköğretim Kurulu. (2004). Türk Yükseköğreniminin Bugünkü Durumu.

Retrieved on January 5, 2006, from:

http://www.yok.gov.tr/egitim/raporlar/raporlar.htm.

Zane, B. and Collins, M.(1995). Computer-Mediated Communication and the Online Classroom in Distance Learning, Computer-Mediated Communication Magazine, 2(4).

Zemke, R. and Rossett, A. (2002). A Hard Look at ISD, Training, 39 (2), 27-34.

Zemsky, R., and Massy, W. F. (2004). Why the e-learning boom went bust. The Chronicle of Higher Education, 50(44), B.6-B8.

Zhao, J. (2006). Research University Faculty Perceptions of Smart Classroom Technologies, Unpublished Ph.D. Thesis, University of Arkansas. 
Zucker, A., \& Kozma, R. (2003).The virtual high school: Teaching generation V.. New york: TeachersCollege Press. 
APPENDICES

APPENDIX A

\section{INFORMED CONSENT FORM FOR INTERVIEW}

\section{Gönüllü Görüşme Katılım Formu}

Bu çalışma, ODTÜ Bilgisayar ve Öğretim Teknolojileri Eğitimi Bölümünde Prof. Dr. M. Yaşar Özden danışmanlığında, Araştırma Görevlisi Erman Uzun tarafından doktora tezi kapsamında XXX Üniversitesi, XXX Fakültesinde verilen BİO 313 kodlu “Web Teknolojileri” dersinin incelenip yeniden dizayn edilip etkililiğinin arttırılması amacıyla yürütülmektedir. Bu çalışma bilgisayar tabanlı mesleki ve teknik bir ders olan BİO 313 dersinde yaşanan problemlerin yerinde incelenip belirlenmesini, bu dersleri alan öğrencilerle ve dersi veren öğretim görevlisi ile ortak bir çalışma sonucunda bu problemlerin aşılmasını sağlayacak çözümlerin belirlenmesini ve belirlenen bu çözümlerin derse entegrasyonu sürecini içermektedir. Bu çalışmanın amacı bilgisayar tabanlı mesleki ve teknik bir ders olan BİO 313 dersinde öğrencilerin ve öğretim görevlilerinin yaşadığı problemleri ortaya koymak ve bu problemlerin çözümüne yönelik öneriler sunmaktır. Böylece birinci ağızdan mesleki eğitim sırasında sınıf ve bilgisayar laboratuvarı ortamlarındaki öğrencilerin yaşadığı sıkıntıları öğrenme olanağı oluşacaktır. Çünkü bu eğitsel süreç hatasız ve eksiksiz bir süreç olmayıp değişik nedenlerden ötürü öğrencilerin ve öğrencilerin sınıf ortamında ve laboratuvar ortamında sorunlarla karşılaşmaları mümkündür. $\mathrm{Bu}$ nedenle problemlerin belirlenmesi, bu problemlere neden olan etkilerin belirlenmesi ve ortaya koyulabilmesi büyük önem taşımaktadır. Bu kapsamda 2008-2009 güz yarıyılında BİO 313 dersini alan öğrenciler ile bir ihtiyaç analizi çalışması yapılacaktır. Bu dersi alan öğrenciler 
arasında gönüllü olan 15 kişi ile araştırmacı görüşmeler yapacak ve gerekli ihtiyaç analizini bu öğrenciler ile beraber çalışarak yapacaktır.

XXX Üniversitesi, XXX Fakültesinde verilen BIO 313 "Web Teknolojileri” dersinde yaşanan problemlerin çözümü için öğrenciler ve öğretim görevlisi ile ortak çalışmalar sonucu belirlenen iyileştirmelerin dersteki yansımalarını görebilmek amacı ile derse entegre edilen öğretim teknolojileri ve dersin tasarımı ile ilgili sorular sorulacaktır. $\mathrm{Bu}$ gözlem sonucunda elde edilecek veriler kesinlikle 3. kişilerle paylaşılmayacak ve sadece araştırmacılar tarafından tez ve bilimsel yayın amaçlı kullanılacaktır. Çalışma verisinin analizinden 1 sene sonra kayıtlar imha edilecektir. Ancak, uygulama sırasında sorulardan ya da herhangi başka bir nedenden ötürü kendinizi rahatsız hissederseniz cevaplama işini yarıda bırakıp çıkmakta serbestsiniz. $\mathrm{Bu}$ çalışmaya katıldığınız için şimdiden teşekkür ederiz. Çalışma hakkında daha fazla bilgi almak için Bilgisayar ve Öğretim Teknolojileri Eğitimi Bölümü araştırma görevlisi Erman UZUN (Oda: C105; Tel: 210 4183; E-posta: euzun@ @ metu.edu.tr) ile iletişim kurabilirsiniz.

Bu çalışmaya tamamen gönüllü olarak katılıyorum ve istediğim zaman yarıda kesip çıkabileceğimi biliyorum. Verdiğim bilgilerin bilimsel amaçlı yayımlarda kullanılmasını kabul ediyorum. (Formu doldurup imzaladıktan sonra uygulayıcıya geri veriniz).

İsim Soyad

Tarih

İmza

Alinan

Ders

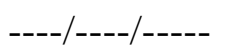




\section{APPENDIX B}

\section{INFORMED CONSENT FORM FOR OBSERVATION}

\section{Gönüllü Gözlem Katılım Formu}

Bu çalışma, ODTÜ Bilgisayar ve Öğretim Teknolojileri Eğitimi Bölümünde Prof. Dr. M. Yaşar Özden danışmanlığında Araştırma Görevlisi Erman Uzun tarafından doktora tezi kapsamında XXX Üniversitesi, XXX Fakültesinde verilen BİO 313 kodlu "Web Teknolojileri” dersinin incelenip yeniden dizayn edilip etkililiğinin arttırılması amacıyla yürütülmektedir. Çalışmanın bu aşamasında bir sene önce öğrenciler ve öğretim görevlisi ile ortak çalışmalarla belirlenen değişiklikler derse entegre edilecektir. Böylece bilgisayar tabanlı mesleki ve teknik bir ders olan BİO 313 dersinde öğrencilerin ve öğretim görevlilerinin yaşadığı problemlerin belirlenen iyileştirmeler ile ne derece çözülebildiğini görebilmektir. Böylece sınıf ve bilgisayar laboratuvarı ortamlarındaki bütün süreçler sistematik bir şekilde gözlemlenebilecektir. Çünkü bu eğitsel süreç hatasız ve eksiksiz bir süreç olmayıp değişik nedenlerden ötürü öğrencilerin ve öğrencilerin sınıf ortamında ve laboratuvar ortamında sorunlarla karşılaşmaları mümkündür. Bu kapsamda 2009-2010 güz yarıyılında BİO 313 dersinde önceki dönemde öğrenciler ve öğretim görevlisi ile ortak çalışmalar ile belirlenen çözümler derse entegre edilecektir. $\mathrm{Bu}$ entegrasyon sonunda dersler araştırmacı tarafından gözlemlenecek ve ne derecede sorunların çözümünü sağladığ belirlenecektir. Bu dersi alan öğrenciler araştırmacı tarafından haftada 3 saati teori ve 2 saati uygulamayı içeren BIO 313 dersinde gözlem çalışması yapılacak ve 3 hafta sürecektir. Gözlemler ve bunun sonucunda elde edilecek veriler sadece araştırmacı tarafından değerlendirilecektir, elde edilen bilgiler doktora tezi kapsamında ve bilimsel yayımlarda kullanılacaktır. 
XXX Üniversitesi, XXX Fakültesinde verilen BIO 313 "Web Teknolojileri” dersinde yaşanan problemlerin çözümü için öğrenciler ve öğretim görevlisi ile ortak çalışmalar sonucu belirlenen iyileştirmelerin dersteki yansımalarını görebilmek amacı ile 9 ders saati sınıf ortamında gözlem ve 6 ders saati bilgisayar laboratuvarında gözlem yapılacaktır. Bu gözlem sürecinde odaklanılacak noktalar: Dersin işlendiği fiziksel ve sosyal çevre, Sınıf içerisinde öğretim görevlisi ile öğrenci arasındaki etkileşim, Sınıf içi aktiviteler ve ödevler. Bu gözlem sonucunda elde edilecek veriler kesinlikle 3. kişilerle paylaşılmayacak ve sadece araştırmacılar tarafindan tez ve bilimsel yayın amaçlı kullanılacaktır. Çalışma verisinin analizinden 1 sene sonra kayıtlar imha edilecektir. Ancak, uygulama sırasında bir nedenden ötürü gözlemlenmekten dolayı kendinizi rahatsız hissederseniz araştırmacıya bu durumu belirtip gözlem sırasında göz ardı edilmesini isteyebilirsiniz. Böyle bir durumda uygulamayı yürüten kişi sizin sınıf içerisindeki aktivitelerinizi göz ardı ederek gözlem verisini şekillendirecektir. Bu çalışmaya katıldığınız için şimdiden teşekkür ederiz. Çalışma hakkında daha fazla bilgi almak için Bilgisayar ve Öğretim Teknolojileri Eğitimi Bölümü araştırma görevlisi Erman UZUN (Oda: C105; Tel: 210 4183; Eposta: euzun@metu.edu.tr) ile iletişim kurabilirsiniz.

Bu çalışmaya tamamen gönüllü olarak katılyyorum ve istediğim zaman yarıda kesip çıkabileceğimi biliyorum. Verdiğim bilgilerin bilimsel amaçlı yayımlarda kullanılmasını kabul ediyorum. (Formu doldurup imzaladıktan sonra uygulayıcıya geri veriniz).

İsim Soyad

Tarih

İmza

Alınan

Ders 


\section{APPENDIX C}

\section{OBSERVATION FORM}

Amaç:

Eğitsel süreç hatasız ve eksiksiz bir süreç olmayıp çeşitli nedenlerden ötürü öğrencilerin ve öğrencilerin sınıf ortamında ve laboratuvar ortamında sorunlarla karşılaşmaları mümkündür. Problemlerin ve bu problemlere neden olan etkilerin belirlenmesi öğretimde etkiliğin sağlanılabilmesi açısından büyük önem taşımaktadır. Bu nedenle, bu çalışmanın amacı XXX Üniversitesi, XXX Fakültesinde verilen BIO 313 kodlu Web Teknolojileri dersinde yaşanan problemleri (sıkıntıları) ortaya çıkarmaktır. Bu kapsamda haftada 3 saati sınıf ortamında gerçekleştirilen teori dersinden ve 2 saati bilgisayar laboratuvarında gerçekleştirilen uygulama dersinden oluşan BIO 313 “Web Teknolojileri” dersinde gözlem yapılacaktır. Bu gözlem ile sınıf ve bilgisayar laboratuvarı ortamlarındaki bütün süreçler sistematik bir şekilde gözlemlenebilecektir. Böylece bu ders sürecinde öğrencilerin ve dersi veren öğretmenin yaşadığı sıkıntılar ile ilgili önemli bilgiler elde edilebilecektir.

Araştırma Soruları:

- Öğrencilerin XXX Üniversitesi, XXX Fakültesinde verilen BIO 313 Web Teknolojileri dersinde yaşadıkları problemler nelerdir?

- XXX Üniversitesi, XXX Fakültesinde BIO 313 Web Teknolojileri dersini veren Öğretim Görevlisinin yaşadığı problemler nelerdir?

- XXX Üniversitesi, XXX Fakültesinde verilen BIO 313 Web Teknolojileri dersinde yaşanılan problemlerin nedenleri nelerdir?

- XXX Üniversitesi, XXX Fakültesinde verilen BIO 313 Web Teknolojileri dersinde Öğretim Görevlisi ve öğrenciler arasındaki nasıl bir etkileşim bulunmaktadır? 
- XXX Üniversitesi, XXX Fakültesinde verilen BIO 313 Web Teknolojileri dersinde Öğretim Görevlisi ve öğrenciler arasındaki etkileşim derste yaşanan problemleri ne şekilde etkilemektedir?

Veri Toplama:

XXX Üniversitesi, XXX Fakültesinde verilen BIO 313 Web Teknolojileri dersinde yaşanan sıkıntıları ve bu sıkıntıların altında yatan nedenleri ortaya koyabilmek amacı ile 9 ders saati sınıf ortamında gözlem ve 6 ders saati bilgisayar laboratuvarında gözlem yapılacaktır. Bu gözlem sürecinde odaklanılacak noktalar: Dersin işlendiği fiziksel ve sosyal çevre, Sınıf içerisinde öğretim görevlisi ile öğrenci arasındaki etkileşim, Sınıf içi aktiviteler ve ödevler.

$\mathrm{Bu}$ gözlem sürecinde gözlemci sınıfta ve bilgisayar laboratuvarında arkada bütün sınıfı görebileceği bir köşeye oturarak ortamı gözlemleyecek ve not alacaktır. Bunun haricinde sınıf içerisindeki etkileşimi ve diyalogları kaydetmek için bir ses kayıt cihazı kullanacaktır.

Fiziksel ortam (Sınıfın özellikleri ve durumu. Isı,sıcaklık, gürültü, oturma planı vs.)

Sosyal ortam (Öğrenci sayısı, öğretim görevlisi ve öğrencilerin tasviri)

Sınıf içi aktiviteler ve ödevler (Sınıf ve laboratuvardaki aktiviteler gözlemlenecek)

Sınıf içi etkileşim

Öğrenci öğretim görevlisi etkileşimi

Öğrencilerin öğretim görevlisine soruları

Öğretim görevlisinin sorulan sorulara verdiği cevaplar

Öğretim görevlisinin öğrencilere sorduğu sorular

Öğrencilerin öğretim görevlisinden gelen sorulara verdikleri cevaplar

Öğretim görevlisi-öğrencilerin genel dialogları

Öğrenci öğrenci etkileşimi

Kodlama sistemi (Sınıf ortamı) 
Ortam

Öğrenci sayısı ve öğrencilerin sınıf içerisindeki yerleşimleri

Sira sandalye ve bilgisayarların sinıf ve laboratuvar ortamındaki yerleşimleri

Sınıf içersindeki cihazların yerleşimi (Projektör, klima vs)

Sınıf içi aktiviteler ve ödevler

Derse başlangıç ve konuya giriş

Konunun anlatılması (Hangi metodlarla, ne tür aktivitelerle anlatılıyor)

Konu anlatımı sırasında öğrencilerin yaşadıkları problemler

Öğretim görevlisinin ders içerisindeki rolü

Öğrencilerin ders içerisindeki rolü

Öğrencilerin konu anlatımı sırasında sıkıntı yaşadıkları noktalar

Öğretim görevlisin bu sorunlara karşı yaklaşımı ve çözümleri

\section{Kodlama sistemi (Laboratuvar ortamı)}

Ortam

Öğrenci sayısı ve öğrencilerin sınıf içerisindeki yerleşimleri

Sira sandalye ve bilgisayarların sınıf ve laboratuvar ortamındaki yerleşimleri

Sınıf içersindeki cihazların yerleşimi (Projektör, klima vs)

Sınıf içi aktiviteler ve ödevler

Derse başlangıç ve uygulamaya (aktiviteye) giriş

Uygulama ile ilgili gerekli bilgilendirme

Uygulamanın yapılması (Hangi metodlarla, ne tür aktivitelerle anlat1liyor)

Uygulama sırasında öğrencilerin yaşadıkları problemler

Öğretim görevlisinin ders içerisindeki rolü

Öğrencilerin ders içerisindeki rolü

Öğrencilerin konu anlatımı sırasında sıkıntı yaşadıkları noktalar

Öğretim görevlisin bu sorunlara karşı yaklaşımı ve çözümleri 
Sınıf içi etkileşim

Ders içerisindeki tartışmalar

Ders içerisindeki aktiviteler ve bu aktivitelere katılım

Öğrenci-öğrenci Öğrenci-Öğretim görevlisi etkileşimi

Öğrencilerin ders içerisindeki soruları

Öğretim görevlisinin öğrencilerin sorularına yanıtları

Öğrencilerin öğretim görevlisinden gelen sorulara verdikleri cevaplar 


\section{APPENDIX D}

\section{OBSERVATION SAMPLE}

\begin{tabular}{|c|c|}
\hline Gözlem & Gözlen \\
\hline \multicolumn{2}{|l|}{ Gözlem Grubu: } \\
\hline Öğretmen: XXX & XXX \\
\hline \multicolumn{2}{|l|}{ Amaç } \\
\hline \multicolumn{2}{|c|}{$\begin{array}{l}\text { Bu çalışmanın amacı XXX Üniversitesi, XXX Fakültesinde verilen BIO } 313 \text { kodlu } \\
\text { Web Teknolojileri dersinde yaşanan problemleri (sıkıntıları) ortaya çıkarmaktır. Bu } \\
\text { kapsamda haftada } 3 \text { saati teori ve } 2 \text { saati uygulamayı içeren BIO } 313 \text { "Web } \\
\text { Teknolojileri" dersinde gözlem yapılacaktır. Bu dersin } 3 \text { saatlik teori kısmı sınıf } \\
\text { ortamında gerçekleştirilirken, } 2 \text { saatlik uygulama kısmı ise bilgisayar } \\
\text { laboratuvarında gerçekleştirilmektedir. } \\
\text { Bu gözlem ile sınıf ve bilgisayar laboratuvarı ortamlarındaki bütün süreçler } \\
\text { sistematik bir şekilde gözlemlenebilecektir. Böylece bu ders sürecinde öğrencilerin } \\
\text { ve dersi veren öğretmenin yaşadığı sıkıntılar ile ilgili önemli bilgiler elde } \\
\text { edilebilecektir, çünkü bu süreç hatasız ve eksiksiz bir süreç olmayıp değişik } \\
\text { nedenlerden ötürü öğrencilerin ve öğrencilerin sınıf ortamında ve laboratuvar } \\
\text { ortamında sorunlarla karşılaşmaları mümkündür.Bu nednele problemlerin } \\
\text { belirlenmesi ve bu problemlere neden olan etkilerin belirlenmesi ve ortaya } \\
\text { koyulabilmesi büyük önem taşımaktadır. }\end{array}$} \\
\hline \multicolumn{2}{|l|}{ Gözlem Soruları: } \\
\hline $\begin{array}{l}\text { Öğrencilerin XXX } \\
\text { Teknolojileri dersinc }\end{array}$ & $\begin{array}{l}\text { Fakültesinde verilen BIO } 313 \text { Web } \\
\text { plemler nelerdir? } \\
\text { BIO } 313 \text { Web Teknolojileri dersini } \\
\text { roblemler nelerdir? }\end{array}$ \\
\hline
\end{tabular}


- XXX Üniversitesi, XXX Fakültesinde verilen BIO 313 Web Teknolojileri dersinde yaşanılan problemlerin nedenleri nelerdir?

- XXX Üniversitesi, XXX Fakültesinde verilen BIO 313 Web Teknolojileri dersinde Öğretim Görevlisi ve öğrenciler arasındaki nasıl bir etkileşim bulunmaktadir?

- XXX Üniversitesi, XXX Fakültesinde verilen BIO 313 Web Teknolojileri dersinde Öğretim Görevlisi ve öğrenciler arasındaki etkileşim derste yaşanan problemleri ne şekilde etkilemektedir?

\section{Fiziksel Ortam:}

Gözlem sınıf ortamında gerçekleştirilmiştir. Sınıfta öğretmen masası 33 tane 2 şer kişilik sıra ve bir beyaz tahta bulunmaktadır. Öğrenci sıraları 4 erli sırlar ile fakat düzensiz bir şekilde sınıfın içerisine dağılmıştır. Tahta yeni olmasına karşın 1şıktan dolayı benim bulunduğum noktada okunamamaktadır.

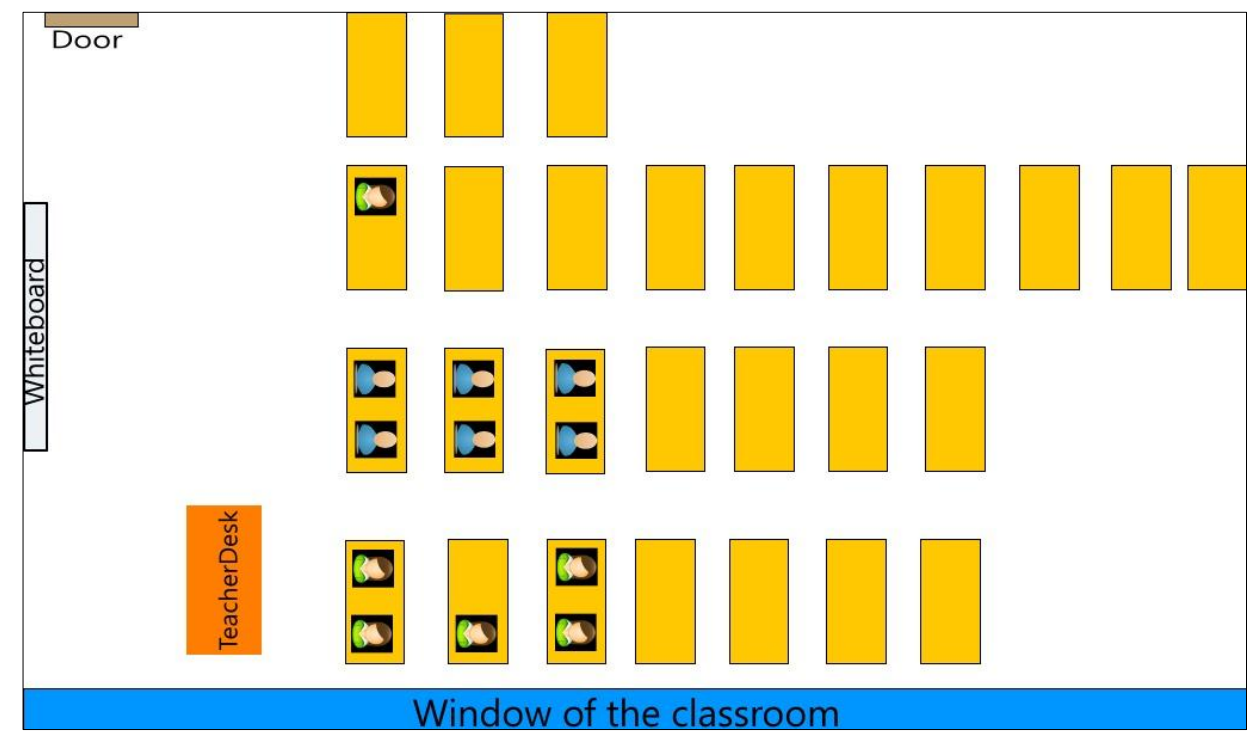

Ders ilk basladigindaki siniftaki yerlesim duzeni.

Tanımlayıcı Notlar:

Derse başlangıçta hoca öncelikle geçen hafta neler anlattı̆̆ını kısaca özetleyerek derse başladı ve konuları öğrencilerinin kedilerinin tekrar edip örnek uygulamalar yazmalarının faydalarının üzerinde durdu. 


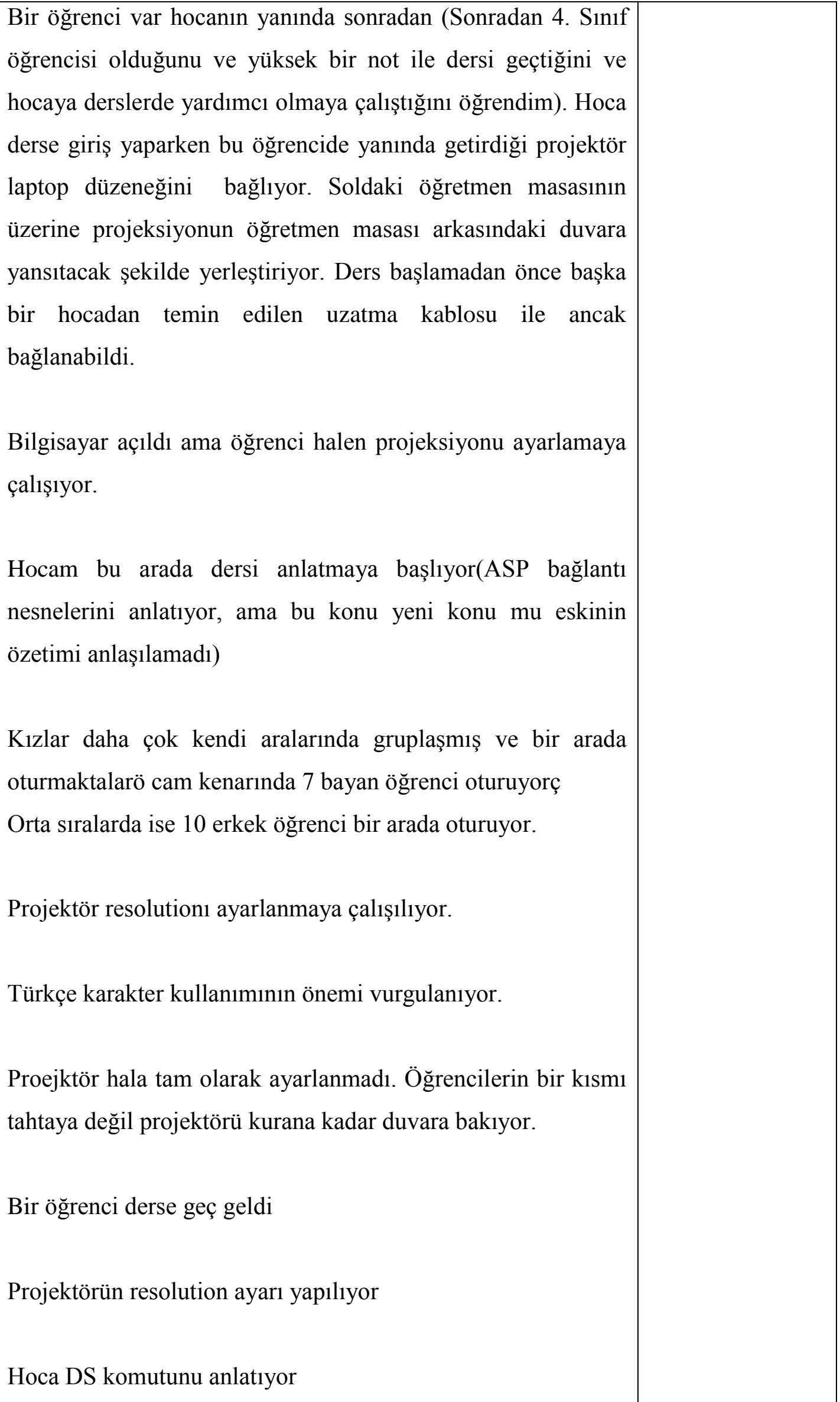


Anlatımında sürekli geçmiş konulara refer ediyor.

Doğrumu yazdım düyerek sürekli öğrencileri derse katmaya çalışıyor.

Geçmiş haftadan kalan DS komutu ile ilgili sorular geliyor.

Ds neyi işaret ediyor ve nesneye yönelik programlama anlatmadığı için sıkıntı yaşandığına değiniyor.

Hocanın tahtaya yazdığı kodu projektörü ve bilgisayarı ayarlayan öğrenci notepadde bilgisayarda yazmaya başladı.

Hoca bu arada listeleme işlemini anlatıyor.

SQL geçen haftalarda anlatılmış. Şu an SQL i ASP içerisinde kullanımı anlatılıyor.

Sql bağlantısını anlatıyor.

Bir öğrenci ofluyor ve kodu anlamaya çalışıyor arkadaşı ile kod ile ilgili birşeyler konuşuyor fakat not tutmuyor.

Ön sıralarda oturanlar not tutmaya çalışıyor deftere tahtadaki kodu yazmaya çalışıyorlar. Deftere not alıyorlar. Görüş alanındaki öğrencilerde spiral defterler var.

Yeni bir ögrenci daha geç geldi ve oturdu.

Hoca tahtada kod yazarak ilerliyor ve tahtaya yazılan kodlar öğretmen masasındaki öğrenci tarafından bilgisayarda yazılıp duvara yansit1liyor. $(15 ; 24)$ 
Cam kenarındaki öğrenciler üşüyor ve ortam gerçekten soğuk

Kimi öğrenciler deftere kimi öğrenciler kağıtlara not alırken kimileri not tutmuyor.

Bazı öğrencilerde fotokopiler var onlara not alıyorlar

Projektör görüntüsünü görebilmek için 1şıklar kapalı̈ fakat hava yağmurlu ve soğuk olduğu için ortam çok karanlık.

Bazı öğrenciler esniyor gözlerimi ovuşturuyor.

Ogretmen masasında bilgisayarın başında oturan öğrenciye meslek isimli tabloyu açmasını istiyor.

Fakat accesste sadece personel tablosu varmış

Hoca "Neyse" deyip o tablo üzerinde anlatmaya başlıyor.

$\mathrm{Bu}$ tablaya aslında Do while döngüsünü anlatırken ihtiyaö duydu

Döngüyü görsel bir şekilde anlatmaya çalışıyor.

Database de nereden nereye nasıl gideceğini anlatmaya çalışıyor.

İstediği tablo olmadığı için benzer bir tablo hayal etmelerini istiyor.

Meslek tablosunu gösteren bir tabloyu tahtaya çizdi 


Konuyu bu tablo üzerinden anlatmaya çalışıyor.
Hoca öğrencilere yeni durumlar hakkında sorular soruyor ve bu
durumda ne olacağını sorarak verilen cevaplara feedback
veriyor.
2 öğrenci daha geç geldi ve oturdular.
Öğrencilere kodun tableın neresinden veri çektiğini soruyor
fakat doğru cevap gelmiyor.
Hoca soruları ile öğrencileri doğru cavaba doğru
yönlendirmeye çalışıyor.
Geç gelen öğrenciler yoklama listesi aradılar ve öndeki bir
aarkadaşları onlara iletti
boşladılar.
Arada imza atmayanlarda olmuş onlar da imza kağıdını sordu.




\section{INTERVIEW PROTOCOL (FOR INSTRUCTOR)}

ŞUBE:

Gün ve Zaman:
Görüşülen:

Görüşmeci:

\section{Giriş:}

$\mathrm{Bu}$ görüşme için bana zaman ayırdığınız için çok teşekkür ederim. Ben bu çalışma kapsamında BİO 313 Web Teknolojileri dersinde yaşanan problemleri ortaya çıkarmak ve bu problemlerin çözümüne yönelik neler yapabileceğimizi belirlemeye yönelik bir çalışma yapıyorum. Bu nedenle bu işe yıllarını veren ve sürekli bu işin içinde bulunan biri olarak sizin deneyimleriniz ve bilgilerinizden faydalanmak istiyorum. Çünkü sizin bu bilgi ve birikimleriniz sorunların belirlenmesi ve çözüm önerilerinin ortaya koyulabilmesi için büyük önem taşımaktadır. Kişisel bilgileriniz ve cevaplarınız kesinlikle gizli tutulacak, sadece bu araştırma için kullanılacak ve araştırma sonunda toplu halde sunulacaktır. Hatta, görüşme sonunda istemediğiniz ve kayıttan çıkarılmasını istediğiniz kısımlar olursa bu kısımları silebiliriz. Araştırma sonuçlandığında dilerseniz size araştırmanın sonuçları hakkında bilgi verilebilecektir. Eğer sizin içinde sakıncası yoksa görüşmeyi ses kayıt cihazı ile kaydetmek istiyorum. Yapılacak olan görüşme hakkında sormak istediğiniz herhangi bir soru yok ise görüşmeye başlayabiliriz. Görüşme yaklaşık olarak 20-25 dakika sürecektir, eğer kendiniz hazır hissediyorsanız ilk soru ile başlayalım.

Sorular:

- Bana biraz kendinizden bahseder misiniz? XXX fakültesine öğretim görevlisi olarak gelene kadar nerelerde, ne tür eğitimler aldınız?

- Kaç senedir XXX fakültesinde ders vermektesiniz?

- Şu an XXX fakültesinde hangi dersleri veriyorsunuz? 
- BIO 313 web teknolojileri dersinde hangi kaynaklardan faydalanıyorsunuz? Kullandığınız kaynaklardan ders içerisinde ne sıklıkla faydalanıyorsunuz? (Ders kitabı, online materyaller vs)

- Derslerinizde teknoloji kullanıyor musunuz?

Sonda: Evet ise : Ne tür teknolojiler kullanıyorsunuz?

Hayır ise: Teknoloji kullanmama nedenlerinizden söz edebilir misiniz?

- $\mathrm{Bu}$ dersleri verirken karşılaştığınız fiziksel ve altyapı eksikliklerinden söz edebilir misiniz?

Sonda: Ne tür eksikleriniz var?

$\mathrm{Bu}$ eksiklikler derslerinizi nasıl ve ne ölçüde etkilemektedir?

- Sizin zevkle ders anlatmanızı sağlayacak bir ders ortamını tarif edermisiniz? Sonda: Sınıf ortamında neler olmalı sizce? (aktivite, öğrencilerin hazır bulunuşluluğu-katılımları, sınıfın fiziksel yapısı vs anlamında )

- Derslerinizde en çok sıkıntı çektiğiniz durumlar nelerdir? Başınızdan geçen bazı olaylardan bize birkaç örnek verebilir misiniz?

- Öğrencilerinizden dersin içeriği, sunuluşu ve değerlendirilmesi ile ilgili ne tür tepkiler geliyor?

Sonda: Bu tepkiler (olumlu ya da olumsuz) sizin derslerinizi planlamanızda ne derece etkili oluyor?

- Elinizde sınırsız bir yetki ve olanak olsa verdiğiniz mesleki eğitimin kalitesini daha iyi bir seviyeye taşımak için dersinizin içeriğinde ve sunuluşunda ne tür değişiklikler yapmayı isterdiniz?

- Siz derslerinizden daha iyi verim alabilmek ve bu gün derslerinizde gözlemlediğiniz problemleri çözmek adına herhangi bir teknolojinin çözüm sağlayacağını düşünüyor musunuz? Ne tür teknolojileri bu amaçla dersinize entegre etmek istersiniz?

- BİO 313 (Web Teknolojileri) dersinde yaşanan problemleri ortaya çıkarmak ve bu problemlerin çözümüne yönelik neler yapılabileceğine dair eklemek istediğiniz birşeyler var $\mathrm{m} 1$ ? 


\section{INTERVIEW PROTOCOL (FOR STUDENT)}

ŞUBE:

Gün ve Zaman:
Görüşülen:

Görüşmeci:

Giriş:

Öncelikle dersleriniz arasındaki bu yoğun periyotta bana zaman ayırdığınız için çok teşekkür ederim. Ben bu çalışmada aldığınız BİO 313 Web Teknolojileri dersinde yaşanan problemleri ortaya çıkarmak ve bu problemlerin çözümüne yönelik neler yapılabileceğini belirlemeye çalışıorum. Bu kapsamda XXX fakültesinde eğitim gören biri olarak sizin deneyimleriniz, gözlemleriniz ve bilgilerinizden faydalanmak istiyorum. Çünkü sizin aldığınız eğitim sürecindeki birikimleriniz sorunların belirlenmesi ve çözüm önerilerinin ortaya koyulabilmesi için büyük önem taşımaktadır. Öncelikle şunu özellikle belirtmek isterim ki bu görüşme sadece bu araştırma sürecinde araştırmacı tarafından incelenecektir, kimse ile paylaşılmayacaktır. $\mathrm{Bu}$ çalışma sonucunda oluşturulacak dokümanlarda isminiz dolaylı ya da doğrudan hiç bir şekilde geçmeyecektir. Hatta, görüşme sonunda istemediğiniz ve kayıttan çıkarılmasını istediğiniz kısımlar olursa bu kısımları silebiliriz. Ayrıca isminiz hiçbir yerde doğrudan ya da dolaylı olarak geçmeyecektir. Eğer sizin içinde sakıncası yoksa görüşmeyi ses kayıt cihazı ile kaydetmek istiyorum. Yapılacak olan görüşme hakkında sormak istediğiniz herhangi bir soru yok ise görüşmeye başlayabiliriz. Görüşme yaklaşık olarak 20-25 dakika sürecektir, eğer kendiniz hazır hissediyorsanız ilk soru ile başlayalım.

Sorular:

- Bana biraz kendinizden bahsedermisiniz? 
Sonda: Nerelerde eğitim aldın bu güne kadar? Kaç senedir teknik eğitim fakültesinde öğrencisiniz?

- Web Teknolojileri dersinde dönem başında seni en çok motive eden şey ne oldu? Sonda: Neden? Neden yoktu ders hakkında yeteri kadar bilgi sahibi değilmiydin?

- Web Teknolojileri dersine çalışırken hazırlanırken hangi kaynakları kullaniyorsun?

- Web Teknolojileri dersinde hoca ne tür materyaller, kaynakları kullanıyor? Sonda: Ders kitapları, Online materyaller.

- Derste kullanılan kaynaklara erişim olanağınız nasıl?

- Web teknolojileri dersinin içeriği ihtiyaç ve beklentilerini karşıladı mı? Sonda: Hayır ise Neden? Ne tür eksikleri vardı?

Evet ise Neden? Hangi açılardan tatmin oldun?

- Web Teknolojileri dersinin sınıf ve laboratuar da işlenişi, sunuluşu ve ders içi aktiviteleri senin ihtiyaç ve beklentilerini karşıladı mı?

Sonda: Hayır ise Neden? Ne tür eksikleri vardı?

Evet ise Neden? Hangi açılardan tatmin oldun?

- Bu güne kadar web teknolojileri dersinde sinifta ve laboratuar da verimli bir şekilde ders işlemenize engel olan şeyler nelerdir? Neden

Sonda: Teknik eksiklikler, bilgisayar sayısı, bilgiye erişim, ders saati vs.

- Eğitsel anlamda bana web teknolojileri dersi için kafandaki ideal sınıf ortamını ders içi etkinliklerini tarif edermisin?

Sonda: $\mathrm{Bu}$ sınıf yada laboratuar ortamında ne tür olanaklara sahip olmak isterdin?

- Siz derste gözlemlediğiniz sıkıntıları çözmek için dersinizde teknoloji entegrasyonunun ve öğretim teknolojilerinin kullanımının çözüm getireceğine inaniyormusunuz? Neden?

- Ellinizde sınırsız destek ve olanaklar olsa aldığınız eğitimin kalitesini artırmak için dersinize teknolojik destek anlamında neleri görmek isterdiniz? Sonda: web desteği, chat forum araçları vs.

- Peki bu teknloji entegrasyonunun dersinize ne gibi katkılar sağlayacağına inanıyorsunuz? 
- Web teknolojileri dersini iyileştirmek anlamında yaşanan problemler ve çözüm önerilerine yönelik eklemek istediğiniz birley var mı? 


\section{APPENDIX G}

\section{SAMPLE STATEMENT-BY-STAEMENT ANALYSIS}

\section{Sorularıma başlıyorum. Adin? Kayıtlara geçmesi için soruyorum.}

Adım ST A.

ST A. nerede lise eğitimini aldığını sorayım?

İlk başta ben Düzce'de. Düzce lisesinde düz lise eğitimi aldım. [Student's background]

\section{Fakülte kaçıncısı senen?}

Fakültede ikinci senem ben iki yıllıktan dikey geçişle geldim. [VE Experience]

Peki "Web Teknolojileri" derslerine dönecek olursak "Web Teknolojileri" derslerini dönem basında alırken seni bu derse karşı motive eden şey nedir?

Ben aslında "Web Teknolojileri" dersini iki yıllıkta aldım ama orda pek verimli olmadı [Dissatisfaction] dikey geçişe hazırlanma sürecim vardı bide son döneme denk geldiği için pek verimli alamadım tekrar alayım diye muafiyet yazmadım benimle gelen diğer iki arkadaş yazdı. [Self regulation] Daha iyi öğrenmek amacı ile eğer not sorun olmazsa benim için dedim derse girmem pek fazla anlamam dedim o yüzden muafiyeti yazmadım. Öğrenmek istiyorum. [Expectancy]

\section{Yani şey peki öğrenmek için seni bu derse en çok ne motive etti?}

Beni motive eden şey şimdi bilgisayar konusunda internet yazılımcılığı boğazıma bir şey takıldı çok önemli internet yazılımcılığı gerçekten çok önemli olduğu için yani gerekli [Intrinsic motivation] 
Derse dönem içerisinde çalışırken hazırlanırken hangi kaynakları kullanıordunuz?

Derse çalışırken öncelikle hocanın anlattıkları daha sonra internetten yararlanmaya çalışıyorum. [Online material]

\section{İnternetten yararlanıyorsun yani?}

Yaralanıyorum yani onunla ilgili hazır şeyler var komutlar onun üzerinde denemeler yapıyorum işte elimden geldiği kadar. [Limited instructor support] Hazır komutlar kopyala yapıştır. [Disorganized instructional material] Yani nedir neyi anlatmaya çalışıyor falan diye.

\section{Peki dersi anlatırken ne tür materyallerden kaynaklardan faydalanıyorsunuz?}

Sunu şeklinde, yani deneme yaptırıyor bir an önce oraya geçiriyor işte sizinde gördüğünüz gibi yansı ile anlatıyor göstererek değişik bir yöntem. Bilgisayarım var da internetim yok internete gidiyorum [Access to Internet] oradan şeyde aliyorum ondan sonra konu anlatım cd leri var arkadaşlardan alıyorum onlardan faydalanıyorum .....evet evet görsel olarak sesli anlatılıyor. [Visual support material] Web sayfalarında artık farklı teknolojiler kullanılıyor aslında [Need up-to-date content] yani çoğu insan yani şeylerde editörlerden yararlanıyor görsel olarak yapıyorlar yani [WYSIWYG type of tool]. Yani çoğu insan kullanmıyor kodları [WYSIWYG type of tool].

\section{Sence bu başarılı bir yol mudur? Yada faydasını gördün mü daha doğrusu?}

Faydasını gürdün mü derken aslında benim kişilik olarak bilgisayara karşı çok büyük bir şeyim var eksikliğim vardı yani ben ilgi duyamıyordum pek fazla bilgisayara yani bir türlü olmuyor [Motivation] yani daha çok ben mesela şiire kitap okumaya ben o yöne daha yani ben mesela bilgisayarcı olmak içimde yoktu [Problems of higher education system] ama bir şekilde oldu yani öğrenmeye çalışıyorum bakıyorum ediyorum ama elimden geldiği kadar etkili oluyor mu en etkili yolu denemeye çalışıyorum [Guidance] yani hani görsel olursa daha iyi öğrenirim gibi [Visual representations] yani ya da hocayı yeterli görmeyip yani hoca yeterli aslında da yeterli derken bazı eksiklikleri de olabilir ama ben elimden geldiği kadar farklı kaynakları da eğer şey yaparsam daha etkili olur diye yani en etkili yolu denemeye çalışıyorum [Lack of instructor support] 
Kendince bir çözüm bulmaya çalışıyorsun yani dersin içeriyi ile ilgili bir şey soracağım sana dersin içeriği senin ihtiyaçlarını beklentilerini karşılıyor mu? Yani. Karşılamıyor. [Content] 
APPENDIX H

\section{OPEN CODING RESULTS OF THE FIRST DATA COLLECTION}

Instructor control

Feedback

Asking question

Association with reallife

Assessment

Guidance

Instructional material

Ineffective technology use

Role of instructor

Motivation

Ineffective use of materials

Interaction

Inclass communication

Outclass communication

No groupwork

No cooperation

Grading policy

Limited question and answer

Limited discussion

Technological problems

Disorganized course content

Disorganized instructional material

Limited student skills

Classroom setting

Lab setting

Lack of verbal praise

Being shy

Fear of asking question

Based on individual communication

Low expectancy from the course
Intrinsic Motivation

Coding in notepad

Limited course involvement

Limited lab equipment

Students' existing knowledge

Lack of enthusiasm

Classroom size

Lack of project based

approaches

No opportunity to code in lab

No learning by doing

Mostly one-way communication

Split attention

Note-taking

Prejudice about programming

Limited participation to course activities

Limited interaction between

students

Interaction with instructor

Visual representations

Cold weather

Late comers

Physical structure of the school

No computer in class

Support materials

Transportation to school

Previous knowledge

Coordination with prerequisite

courses

No assignment

No future expectancy

Motivational support

Need lab activities 
High expectancy from the course

High expectancy from the instructor

Lack of recommended online materials

Lack of electronic sources

Lack of hardcopy support materials

Limited F2F discussion

Lack of lecture notes

No online communication

No e-mail support

Classroom infrastructure

Lab infrastructure

Limited instructor support

Limited instructor guidance

WYSIWYG type of tool

Content of the course

Physical problems

Climatization

Visual editor

Course structure

Student engagement

Classroom management

Teaching skill

Instructional Planning

Evaluation criteria

Course participation

Fear of programming

Need up-to-date content

Limited number of computer

Lack of software

Not informed about course content

Need modifications in content

Not informed about future benefits of the course

Content sequence

Visual materials support
Flexible curriculum

Project-based approaches

Lack of web support

Students PC belonging

Software support

Extra course material

Modifications in content

Real life examples

Instructor centered

Course material sharing

Number of computers

Limited use of computer labs

Absence of projectors

Grade as an aim

Group project

Personal project

Instructor student relation

Students' economic problems

Direct instruction

Lack of e-communication

Students' self-regulation

Rote memorization

General problems of vocational

higher education

General problems of higher

education

Content Scope

Video support

Need more resources

Access to internet

Instructors' high expectancy

Uncortable classroom

Unconfortable Lab

Need summarization

Domination of a few student

Limited student response

Extrinsic Motivation 


\section{APPENDIX I}

\section{AXIAL CODING FROM DIFFERENT INSTRUMENTS}

\begin{tabular}{|c|c|c|c|}
\hline Instrument & Classification & Properties & Example \\
\hline \multirow{4}{*}{ 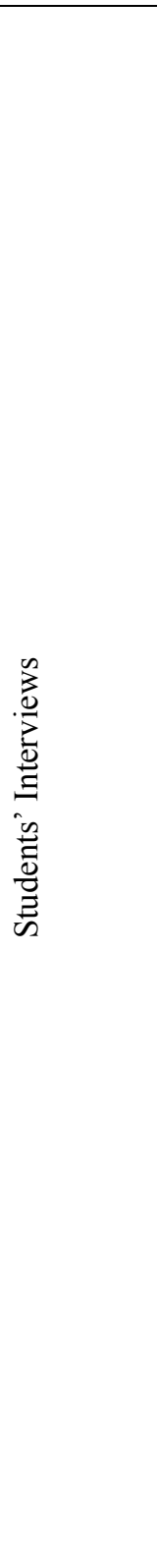 } & $\begin{array}{l}\text { Instructional } \\
\text { Activity }\end{array}$ & $\begin{array}{l}\text { They do not have } \\
\text { opportunity to apply } \\
\text { what they learn. } \\
\text { They do not have } \\
\text { opportunity to apply it } \\
\text { in a whole project. }\end{array}$ & $\begin{array}{l}\text { “...şoyle soyleyim bunu lab da işlemiş } \\
\text { olsaydık çok daha güzel olurdu çünkü } \\
\text { hocanın verdiği kodları biz de aynı anda } \\
\text { yazınca çok daha verimli olabilirdi } \\
\text { ama..." }\end{array}$ \\
\hline & $\begin{array}{l}\text { Intervening } \\
\text { Conditions }\end{array}$ & $\begin{array}{l}\text { Lack of lab facilities } \\
\text { Crowded classroom } \\
\text { Climatization problems } \\
\text { Transportation } \\
\text { problem }\end{array}$ & $\begin{array}{l}\text { "Resmiyette lab var görüyüyor } \\
\text { çünkü'...resmiyette var görünüyor ama } \\
\text { genelde lab da işlemediğimizden dolayı } \\
\text { salı günleri lab da işleyebiliyoruz } \\
\text { pazartesi günleri işleyemiyoruz." }\end{array}$ \\
\hline & $\begin{array}{l}\text { Support } \\
\text { Material }\end{array}$ & $\begin{array}{l}\text { There was no course } \\
\text { material. }\end{array}$ & $\begin{array}{l}\text { "Bunun için yine XX hocama danıştım. } \\
\text { Hocam kitap alsan olur falan dedi. } \\
\text { Aslında dersi iyi takip edersen yeterli dedi. } \\
\text { Ona şükür dedi:) dersini takip etmeye } \\
\text { çalışıyorum. Tam olarak takip } \\
\text { edebildiğim söylenemez çünkü aynı } \\
\text { zamanda başka bir dersi de alıyorum } \\
\text { zamanları çakışlyor. Yani ben girdiğimde } \\
\text { aslında dersin ortalarında veya } \\
\text { sonlarında oluyor.", }\end{array}$ \\
\hline & Motivational & $\begin{array}{l}\text { Students were not } \\
\text { motivated because of } \\
\text { the general problems } \\
\text { or personal reasons. }\end{array}$ & $\begin{array}{l}\text { "Sorun temelden kaynaklanıyor çünkü bu } \\
\text { bölümü açıçası pek sevdiğimi } \\
\text { söyleyemem. bilgisayar bölümünü. } \\
\text { özellikle teknik eğitim fakültesini. ilgim } \\
\text { farklı olduğu için. Isinamadım bu bölüme }\end{array}$ \\
\hline
\end{tabular}




\begin{tabular}{|c|c|c|}
\hline & & ama teknolojıyle içli dışlı olmak \\
\hline & & zorundayım. Cünkü gelişen bir \\
\hline & & dünyadayız. globalleşen bir dünyadayız. \\
\hline & & gerçekten buna ayak uydurmak \\
\hline & & zorundayı.bu derse motive olmak \\
\hline & & zorundayım çünkü ilerde mesleğim \\
\hline & & açısından bana baya bi faydası dokunacak \\
\hline & & anlatacağım şeyler bunlar" \\
\hline Interaction & Students were not & "yani biraz eleştiri gibi olacak diğer \\
\hline & voluntarily participate & hocalara karşı ama diğer hocalar pek \\
\hline & to the course. & hani hepsi değil pek şeyapmaz. Ŏgrenciyle \\
\hline & & tam sosyal bir iletişim kurmasını \\
\hline & & istemiyoruz sıradan arkadaş olalım değil. \\
\hline & & ama dersle ilgili birşeyle pek \\
\hline & & ilgilenmiyorlar." \\
\hline
\end{tabular}

\begin{tabular}{lll}
$\begin{array}{l}\text { Support } \\
\text { material }\end{array}$ & $\begin{array}{l}\text { Instructor did not offer } \\
\text { any additional } \\
\text { materials to the } \\
\text { students }\end{array}$ & $\begin{array}{l}\text { "...Bütün gerekli bilgiler internette var... } \\
\text { Ben örencileri tek bi rkitap yada ders } \\
\text { notlart ile sinırlamak istemiyorum...". }\end{array}$ \\
\hline Motivation & $\begin{array}{l}\text { Students were not } \\
\text { motivated to the course }\end{array}$ & $\begin{array}{l}\text { "Ogrencilerin derse olan ilgisini artirmak } \\
\text { icimden geleni yapiyorum ama } \\
\end{array}$ \\
& & onlardan talep gelmeyincede olmuyor"
\end{tabular}

\begin{tabular}{|c|c|c|}
\hline $\begin{array}{l}\text { Intervening } \\
\text { Conditions }\end{array}$ & $\begin{array}{l}\text { Both laboratory and } \\
\text { classroom is not } \\
\text { designed for } \\
\text { programming course. }\end{array}$ & $\begin{array}{l}\text { "Kodlari yazabilecekleri tek ortam } \\
\text { notepad, keske baska olanaklarimiz } \\
\text { olsa..." }\end{array}$ \\
\hline $\begin{array}{l}\text { Intervening } \\
\text { Conditions }\end{array}$ & $\begin{array}{l}\text { Instructor had too } \\
\text { many responsibilities } \\
\text { in the faculty. }\end{array}$ & $\begin{array}{l}\text { "Aslinda derslerimde her sene sonunda } \\
\text { ogrencilere bir form verip dersle ilgili } \\
\text { bilgi alirdim ama artik } 2 \text { senedir bunu da } \\
\text { yapamiyorum" }\end{array}$ \\
\hline Content & $\begin{array}{l}\text { Course content did not } \\
\text { attract students } \\
\text { attention }\end{array}$ & $\begin{array}{l}\text { "Bir ogrenci "biz bunu niye notepadde } \\
\text { yaziyoruz ki hocam? Neden gorsel } \\
\text { birseyler frontpage falan kullanmiyoruz" }\end{array}$ \\
\hline
\end{tabular}




\begin{tabular}{|c|c|c|c|}
\hline \multirow{4}{*}{ 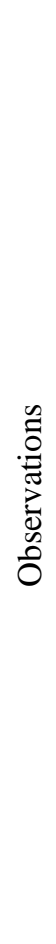 } & Motivation & $\begin{array}{l}\text { Students were not } \\
\text { motivated to the } \\
\text { course. }\end{array}$ & $\begin{array}{l}\text { "Ogrenciler genellikle derse gec } \\
\text { geliyorlar ve not tutmuyorlar." }\end{array}$ \\
\hline & $\begin{array}{l}\text { Intervening } \\
\text { Conditions }\end{array}$ & $\begin{array}{l}\text { Quality and quantity of } \\
\text { computer lab facilities } \\
\text { Crowded classroom } \\
\text { Climitaziation \& } \\
\text { Transportation }\end{array}$ & $\begin{array}{l}\text { "Ogrencilerin azimsanmayacak bir } \\
\text { miktari derse gec geliyorlar bu durum } \\
\text { dersin bolunmesine yol aciyor. Bunun } \\
\text { nedenini sordugumda otobus saatlerinin } \\
\text { cok belirsiz oldugunu belirttiler" }\end{array}$ \\
\hline & Interaction & $\begin{array}{l}\text { There was limited } \\
\text { interaction between } \\
\text { instructor and students }\end{array}$ & $\begin{array}{l}\text { "Dersi anlatirken hoca sirtini dondu ve } \\
\text { koddaki problem kendi kendine cozmeye } \\
\text { calisti" }\end{array}$ \\
\hline & $\begin{array}{l}\text { Instructional } \\
\text { Activity }\end{array}$ & $\begin{array}{l}\text { Course is highly } \\
\text { teacher oriented and do } \\
\text { not have any flexibility. }\end{array}$ & $\begin{array}{l}\text { "Hoca sadece soru cevap yontemi ile } \\
\text { ogrencileri derse katmaya calisiyor." }\end{array}$ \\
\hline
\end{tabular}




\section{APPENDIX J}

\section{INSTRUCTIONAL DESIGN PROCESS}

The instructional design process provides a framework for thoroughly planning, developing, and adapting instruction, based on learner needs and content requirements. Especially in distance education, it is essential for a course, because the instructor and students may share limited common background, and typically have minimal or no face-to-face contact.

During the instructional design process, researcher followed Morisson, Ross, and Kemps instructional design model to organize data collection, data analysis, and interpretation processes. This model was selected because of its wide application of technology enhanced learning environments, and it is flexibility to easy to revise. Moreover, conventional instructional design approaches considers instruction from the perspective of the content rather than from the perspective of the learner and context, but this model propose a different view to ID.

Morrison, Ross and Kemp present the key elements of instructional design process as four fundamental components; learners or trainees, objectives, instructional strategies, and evaluation procedures, which form the framework for instructional planning. Their complete instructional design plan includes nine elements. These are:

- Identify instructional problems and specify goals for designing an instructional program.

- Examine learner characteristics that will influence instructional decisions.

- Identify subject content; analyze task components related to stated goals and purposes. 
- Specify instructional objectives

- Sequence content within each instructional unit for logical learning.

- Design instructional strategies so that each learner can master the objectives.

- Plan the instructional message and delivery.

- Develop evaluation instruments to assess objectives.

- Select resources to support instruction and learning activities.

\section{Determination of Instructional Problems}

First step of instructional design process is to see the problems. If a designer cannot see the missing and problematic things in an educational setting, it is impossible to make any improvement. In this study, our context is vocational educational institution and those institutions have many problems. Those problems were listed below:

- Instructional Problems

○ Interaction

○ Motivation

○ Support material

○ Up-to-date content

○ Instructional activity

- Intervening Conditions

○ Technologic

○ Non-technologic

During the design of the study, researcher always considered those problems.

\section{Learner, Instructor \& Contextual Analysis}

\section{Learner Characteristic}

Different students have different ways of learning for that reason it is essential early in the planning process, to give attention to the characteristics, abilities and experiences of the learners both as a group, and as individuals. In order to understand 
better the distant learners and their needs, designers should consider their ages, cultural backgrounds, interests, and educational levels. Learner characteristic may have effect on instructional planning, for example, the choice of sequencing of objectives, the depth of treatment, and the variety of learning activities.

Although data were collected to be informed about the students, each year student profiles, their needs, skills, and their existing knowledge varies. That means, we could not get exact information about these students. However, general characteristics of students in the first step of the study and in the second step is expected to be similar.

The new course was implemented in the first-year students. Most of the students would be male, because of the general characteristic of vocational education system in Turkey. Their computer skills should be diverse because some of them would be graduated from high schools, some of them would be graduated from vocational high schools, computer related programs. Most of the students are not motivated to the course because they are not aware of what can be done with using tools. Students have diverse programming skills. Some of them are talented and experienced, but some of them are beginners. Their computer competency level would be diverse and needed to consider students who had limited knowledge.

\section{Context}

Context has important effects on instruction by inhibiting or facilitating instruction and learning. While conducting a contextual analysis, rich data are needed to be provided to the designer with an accurate picture of the instructional environment so interviews and observations were used to accomplish this.

Context was observed in the first step of the study by the researcher. Moreover, during the instructional design process researcher was informed about the recent resources of the school

In the first step, computer laboratory was composed of 15 computers, a portable projector and whiteboard. Most of them were working but included programs in the 
computers were limited with the basic tools. They were not located properly. Students should turn around to see the instructor or the board. When there was a lesson, students should sit different locations in the laboratory, because they were not dealing with the computers. They were dealing with the written codes on the board. Students have limited interaction with the instructor, and they did not have chance to try codes on a computer in the laboratory.
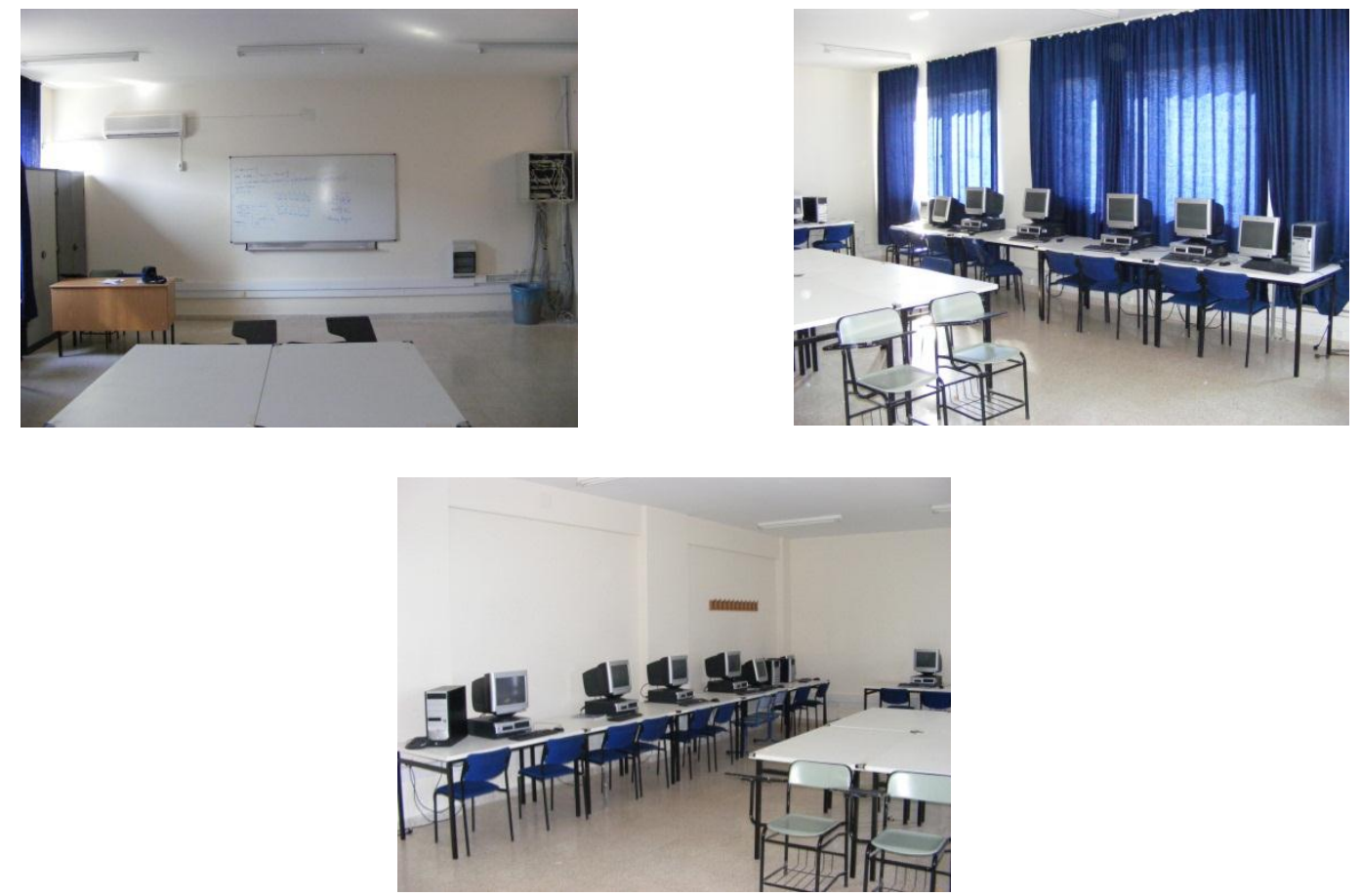

Figure 7-1: Existing structure of the computer laboratory

During the design of the course, researcher informed about the new laboratory facilities of the faculty. 20 new computer and new infrastructure were settled down in this new laboratories, and it was ready to use during the real implementation of the course. Moreover, in a conference room of the faculty a new video conferencing infrastructure were integrated. This would be a great opportunity for our new design. 
Classrooms are big enough to sit more than 50 students, but there is no climate control or central heating system in the classroom. This situation observed by the researcher in the first step of the study. In cold weather, it is impossible to sit in the classroom. In addition, there was no overhead projector and desktop computer on the teacher desk.

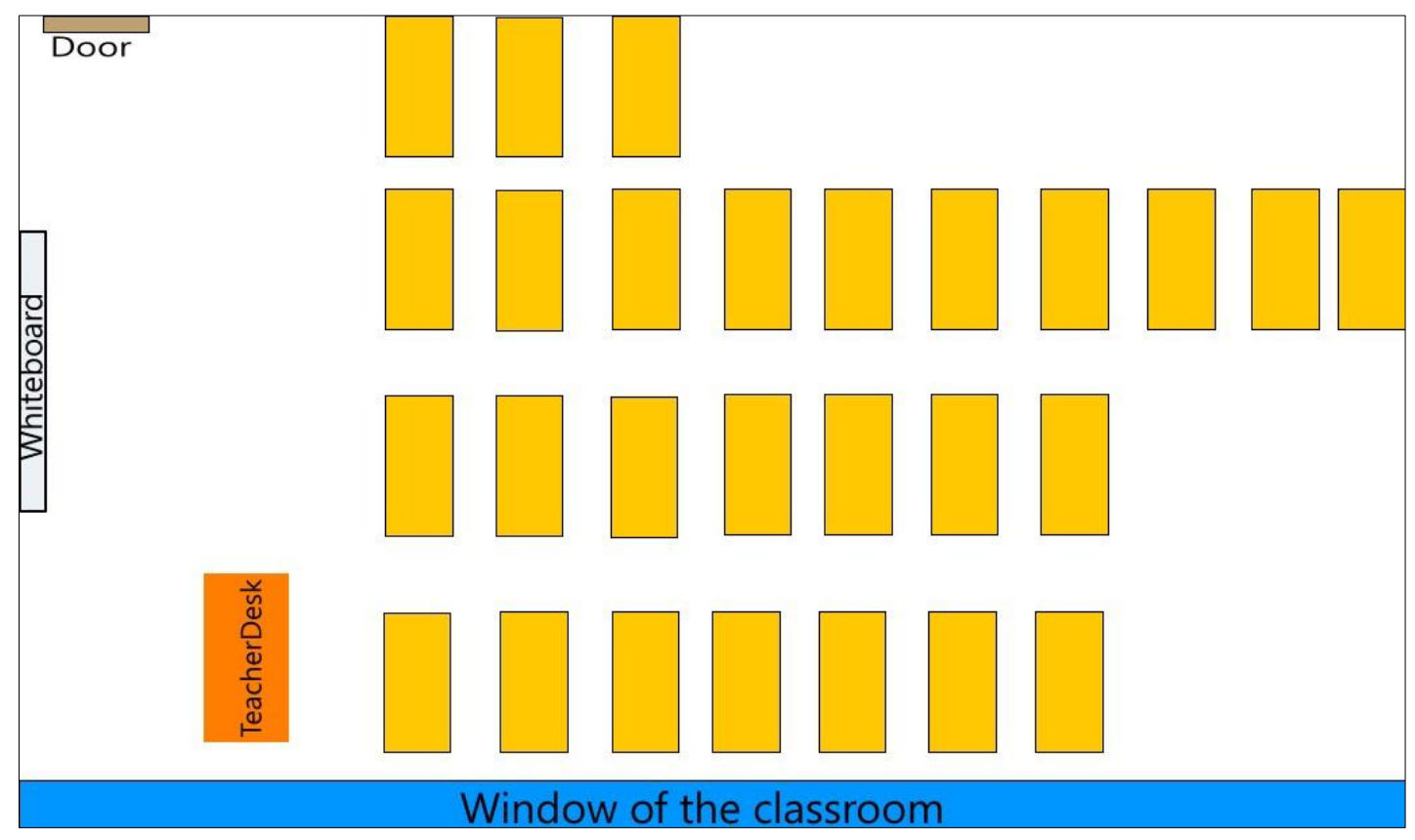

Figure 7-2: Sitting plan of the classroom

\section{Instructor}

He is professor in Computer Education and Instructional Technology Department in METU. He taught students in this study through his great experience and knowledge as an instructor in this study. He has great experience in instructional technology. Also, he was instructing Special Problems in Computer Education \& Instructional Technology, Web Design, Applications of Authoring Languages in Instructional 
Technology courses in each semester. He is the editor of many educational web sites. Some of them are

- http://guide.ceit.metu.edu.tr

- http://ideas.ceit.metu.edu.tr

- http://ideas.ceit.metu.edu.tr/BotebOnline

- http://itl.ceit.metu.edu.tr

- http://www.tbm.metu.edu.tr

- http://itl.ceit.metu.edu.tr/websearch/

- http://egm.ceit.metu.edu.tr

Moreover, he has valuable e-learning background and experience both as an expert and instructor. Each courses that is given by him has an e-learning support system called ITL Learning Gateway. This system gradually developed from 1999 and tested in many studies. Therefore, he knows how to manage and teach in technology enhaced learning environments.

\section{Task Analysis}

Instructional designer should thought over this step extensively, because this step is the collection of procedures for defining the content of an instructional unit. If designer cannot define content properly, other steps of the design most probably fail whatever instructional strategy you use, whatever instructional material you develop. Each step up to now depends on deciding on the right tasks.

Thanks to the information gathered from the first step of the study, researcher had more information about the needs of the students. Students expected to have more WYSIWYG type of content in their courses. Although some of them are satisfied with the existing content of the course, some of them wanted to be informed about new tools. 
In order to determine course content properly, researcher worked with his advisor as a subject matter expert. Advisor provides accurate, detailed information to use in developing the instructional unit. Moreover, he was still giving similar courses. For all these reasons, researcher decided to change the course content with the help of the advisor. They decided name this new course as a web design course. In the scope of this course, MS Expression Studio were used as a tool. This new tool enabled students to create designs for the desktop and the web. It was enriched with Silverlight and .NET's amazing possibilities. Moreover, MS Expression Studio could be distributed to every student and could be installed to the laboratory. Microsoft Dreamspark support students who were willing to develop programs over Microsoft programming environments. With the support of Dreamspark students can download many programs free of charge. That was the main reason on deciding the course content.

MS Expression Studio consists of 4 main component and planned to be covered in this course content. One of the components of the tool is Microsoft Expression Design, which is used as a graphics application. It helps you to create complex and attractive designs. Logos, advertisements, brochures and animation graphics can be easily created with using this software. In the context of this course, the purpose is to create related elements for a web page design and export it to your web page designs. For instance, students would learn to use Microsoft Expression Design by drawing and manipulating simple shapes to create logos. Students would also create user interface elements and animation graphics.

Moreover, Microsoft Expression Web makes it possible for designers to design websites that are highly interactive and dynamic. In this course, students could create a fluid designed website and add dynamic features to make it engaging to the users. By this was fundamental competency in using Expression Web for designing web pages, adding content and some functionalities into them with using JavaScript and CSS to those pages. Those are important skills to use Expression Web to design a website with enhanced functionality and usability. For individuals who need create media files that would be publishable on the web, Expression Encoder would be integrated to the course. With this tool, students would create media files and you can 
publish it in a web site. Therefore, web creation experience would be combined with media creation and publication.

In short, this course is thought as a complete guide to create web pages as a product with using MS Expression, starting with Design elements to create logos, animation graphics etc., and continues with Web to create interactive web sites with using CSS and JavaScript. At the end of the course students will be able to use Silverlight to add media components to their web pages.

\section{Instructional Objective}

Determining instructional objectives is a way of presenting the benefits of the instruction. It is important to planning instruction to evaluate student learning, defining instructional strategies to facilitate the learners. In addition, objectives may guide the learners with the aim of instruction. In brief, instructional objectives are essential to design; they define content, document the intended outcomes, and set standards for success.

Initial instructional objectives are:

1. Identify capabilities and limitations of contemporary and emerging technology resources and assess the potential of these systems and services to address personal, lifelong learning, and workplace needs.

2. Make informed choices among technology systems, resources, and services.

3. Demonstrate/advocate for legal and ethical behaviors regarding technology and information.

4. Use technology tools and resources for managing and communicating information.

5. Apply design and communication principles to Web projects.

6. Routinely and efficiently use online information resources to meet needs for collaboration, research, publication, communication, and productivity. 
7. Select and apply technology tools for research, information analysis, problem solving, and decision making.

8. Collaborate with peers and experts to compile, synthesize, produce, and disseminate information through Web technology.

9. Demonstrate team and leadership skills.

10. Explore careers in Web technologies.

\section{Content Sequencing}

Once task analysis were completed and the objectives were written, it would be benefitial to begin design instruction by determining the most appropriate sequence for presenting the information. The sequence of the content were decided with the help of advisor. The underlying reason of the sequence depends on somehow related to the literature, somehow the use of tools in web design projects. If you have an idea about the framework of a website, designer starts with the visual elements. Then those visual elements embedded to the website.

Table 7-1: Sequence of the content for the new design

\section{Week Topic}

1 - 2 Graphic Design (Expression Design)

3-4 Building Interactive Animations (Expression Blend)

5 Introduction to Hyper Text Markup Language 4 (HTML4)

6 Intermediate HTML (Expression WEB)

$7 \quad$ Midterm

8 JavaScript/JScript: Introduction to Scripting (Expression WEB)

9 Dynamic HTML: Cascading Style Sheets (CSS) (Expression WEB)

Table 7-1 (cont'd)

10-11 Multimedia: Audio, Video (Expression Encoder)

12 Silverlight

13 Project Discussion

14 Project Discussion 


\section{Instructional Strategy}

In order to solve aforementioned issues in F2F course, some instructional strategies implemented to eliminate some. With the help of observations, students' expectations and related literature, we determined some instructional strategies for the needs of a distance "web design" course.

First of all, this course decided to be given as a distance course, because instructor was in Ankara, students were in another city. While deciding on instructional strategies researcher and instructor consider this limitation, in addition to the predetermined problems.

In this context, instructor should not be the source of information; he/she should be the facilitator of the process by monitoring, bridging between the content-student, and facilitate the interaction between student-student, student-content, student-teacher (Gunawardena \& McIsaac, 2003). Therefore, interaction needs to be supported in the instructional strategy determination process.

Another consideration while deciding on instructional strategy is ISTE-NETS for students. ISTE (International Society for Technology in Education) determines the standards for teaching, and learning in the digital age with NETS (The National Educational Technology Standards) NETS for students. Those standards includes following items:

- Creativity and Innovation

- Communication and Collaboration

- Research and Information Fluency

- Critical Thinking, Problem Solving and Decision Making

- Digital Citizenship

- Technology Operations and Concepts

Those standarts represents the skills and knowledge that students represents to learn effectively. Moreover, as it was cited by the National Aenautics and Space Administration (NASA) (2006) learning technologies report, Trilling and Hood emphasis " $21^{\text {st }}$ Century, Knowledge Age skills". Those skills needed to be supported in the new design of the course. In this age mastering on reading, writing, and 
arithmetic (3Rs) do not meet the needs of the information age. " $21^{\text {st }}$ Century, Knowledge Age skills" should be empowered with 7Cs beyond 3Rs. Seven clusters of $21^{\text {st }}$ Century skills are:

- Critical Thinking-and-Doing

- Creativity

- Collaboration

- Cross-cultural Understanding

- Communication

- Computing

- Career and Learning Self-reliance

Table 7-2: Instructional Strategies

\begin{tabular}{ll}
\hline Strategy & Explanation \\
\hline Peer-to-Peer & Students will be encouraged to interact on a regular basis with \\
Collaboration & each other on the topics that will be discussed in the course. \\
Instructor & Much time will be spent supplying instructor feedback to both \\
Feedback & individual students and the class in general \\
Grader & Along with the instructor's feedback on content issues, a course \\
Feedback & grader will supply detailed critiques of each assignment. \\
Student- & Because of the range of student abilities and experiences, the \\
Centered & lectures were designed to support advanced, intermediate and \\
Learning & novice users. \\
Authentic & Students will be immersed in realistic situations in which they \\
Learning & will have to apply what they will learn to solve real-world \\
& problems and deal with authentic real-life situations. \\
Critical & Students will be challenged to form their own opinions \\
Thinking & concerning a range of topics that pertained to the use of the \\
& Internet.
\end{tabular}


With considering these theoretical knowledge that represents skills that students' needed to represent in information age, it was decided that instructors had to follow strategies like Peer-to-Peer Collaboration, Instructor Feedback, Grader Feedback, Student-Centered Learning, Authentic Learning, Critical Thinking and Project Based Learning (Özden, 2007). Those strategies were used in my advisor's undergraduate and graduate courses since 1999. In our case it is planned to be supported with new content, material and web support with using computer mediated communications tools to eliminate some of the problems of the course.

\section{Instructional Delivery}

Within the scope of this project, many improvements planned and applied during the research project with the help of students and the instructor. With ICT integration to the course, our purpose is to create a new online web design course, which includes a new instructional design and several e-learning tools to support the course. With this respect, our aim is to design a full online and distance course. Moreover, it was aimed to integrate e-learning support to the course and manage this environment during the course. In the design of the course, researcher and instructor decided to use two delivery methods. One of them is based on Microsoft Learning Gateway, the other is based on videoconferencing. Tools that were used in this research had been improved during the research process.

\section{Distance Web Design Course}

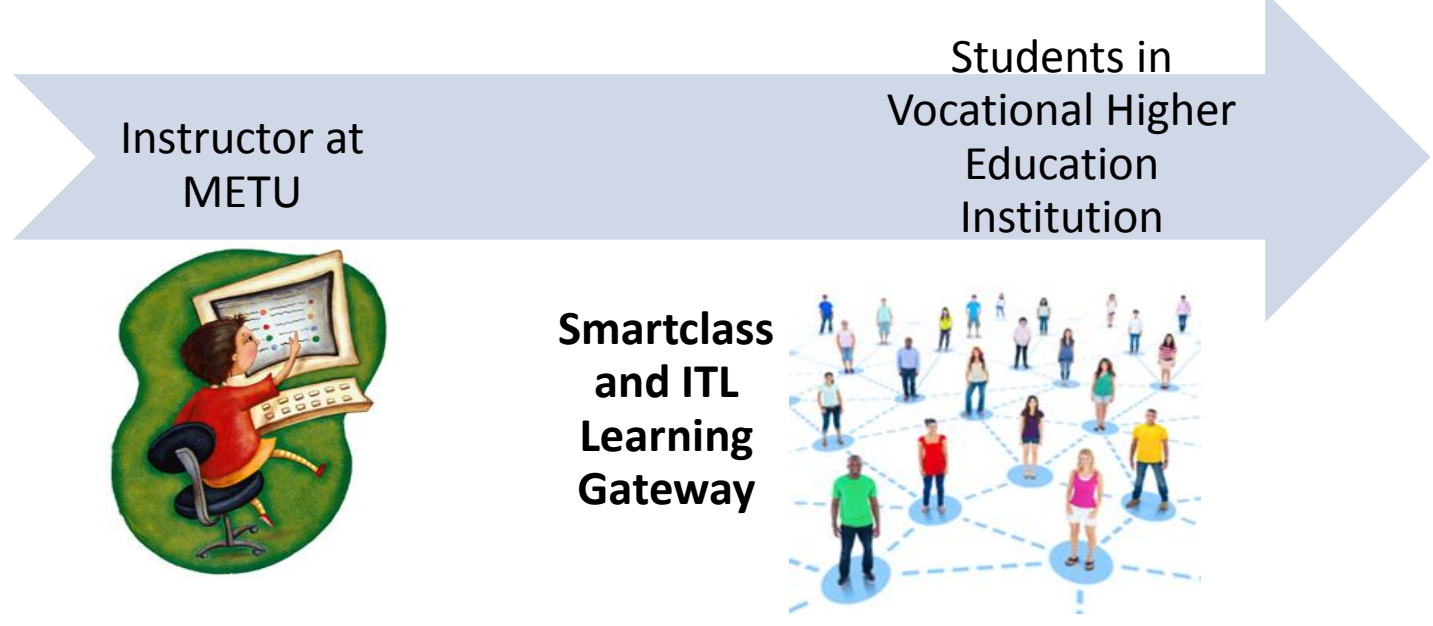

Figure 7-3: Instructional Delivery of the Course 


\section{ITL Learning Gateway}

Especially, emergence and advancement of the Information and Communication Technologies (ICT) made teaching activities more dependent on technology. There are many online learning environments based on different pedagogical philosophies, although they are presenting similar features such as (Winter, 2006):

- provide course materials,

- manage enrolment and registration,

- develop evaluation material such as quizzes, tests, or assignments,

- provide communication with instructor and other students online through an announcement section, discussion boards, e-mail, real-time chat sessions or "class rooms",

- take and save notes about a course,

- manage grades and provide the grades to the students,

- present important dates through a calendar tool,

- provide links to related web sites.

Generally, these environments are named as Content Management Systems (CMS). Using CMSs bring many advantages such as that they require the instructors' preparation for the course; the students can reach the information anytime and anywhere (Winter, 2006). In addition, CMSs make easy to contact with faculty and instructors who may be difficult to reached for help.

Microsoft Learning Gateway included a complete online education system that integrate many Microsoft services. Based on Microsoft Learning Gateway, preexisting online learning environment was developed by Prof. Dr. M. Yaşar Özden were used for this study. This system named as ITL (Instructional Technology Laboratory) Learning Gateway. This is a secure framework for combining e-Learning solutions in a secure online environment (Özden, Gedik, and Kocaman, 2012). With this environment, it would be strengthen communication between teachers and 
students, reduces administration, lets students collaborate and express themselves in new ways.

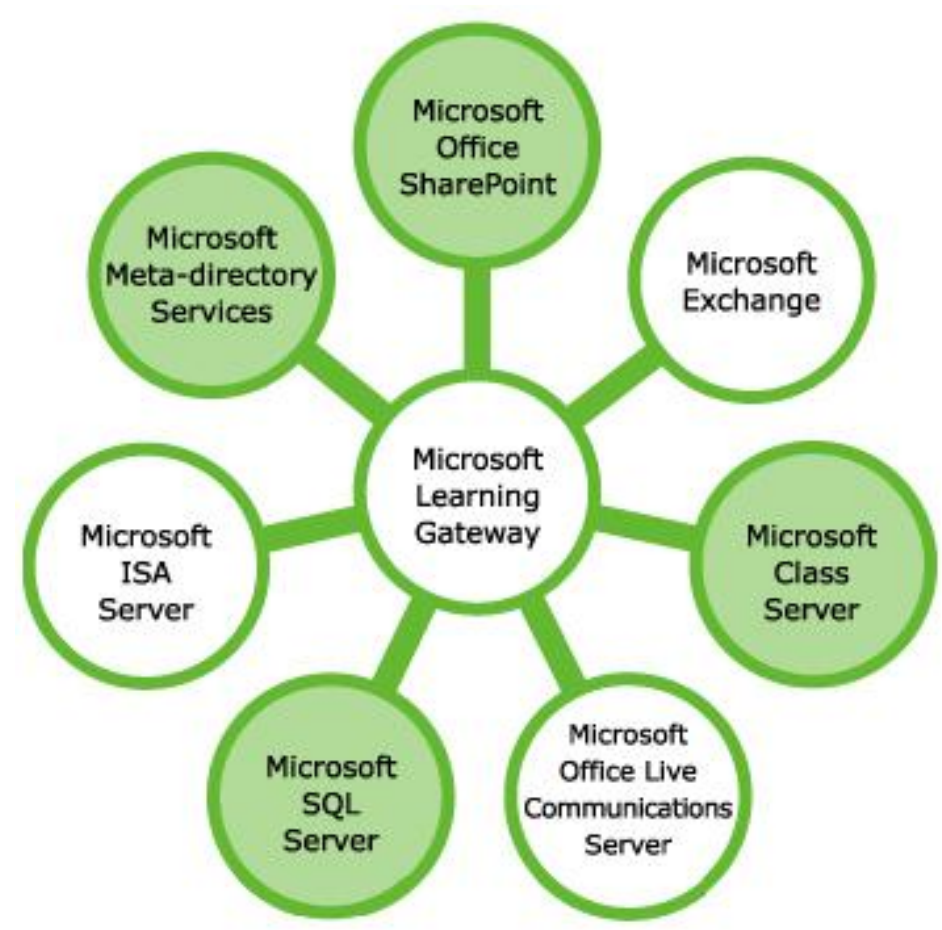

Figure 7-4: Components of Microsoft Learning Gateway (Özden, 2007)

\section{Content Management Systems (CMS)}

ITL CMS was developed in METU and used in undergraduate and graduate classes since 1998. It was gradually revised and improved during this period by taking users reactions into account (Özden, 2002). It is designed to deliver tools and services that enable schools to place students at the centre of the learning experience (Özden, 2007).

A password assigned to each student, to loged in the system. In order to enter the course website, unique username and passwords assigned to the students. Students must login to the course web site at the beginning of the semester. They supposed to 
change their predetermined passwords as soon as possible. Students had access to the site over:

- http://guide.ceit.metu.edu.tr

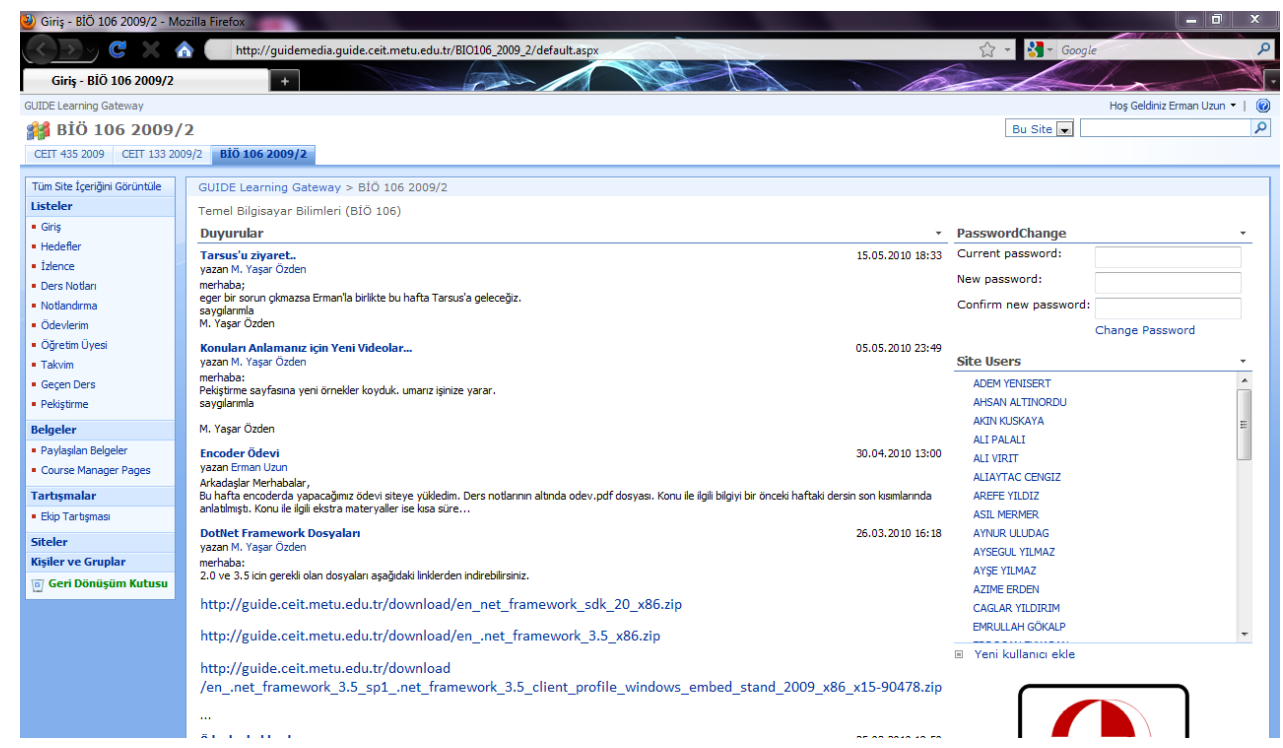

Figure 7-5: A screenshot from ITL Learning Gateway's Welcome Screen

The main categories of ITL Learning Gateway consist of 12 sections. Those sections were previously used, and tested in many researches (Işık, 2009; Gedik, 2010). The left menu contains:

- Introduction: This section includes some introductory information about the course, the aim and the scope of the course presented in this section.

- Objectives: Predetermined course objectives presented in this section.

- Syllabus: An electronic copy of the course syllabus with detailed explanation was presented in this section.

- Lecture notes: Students can reach instructors' presentations and related support materials. Those documents are dowloadable and preview available. 


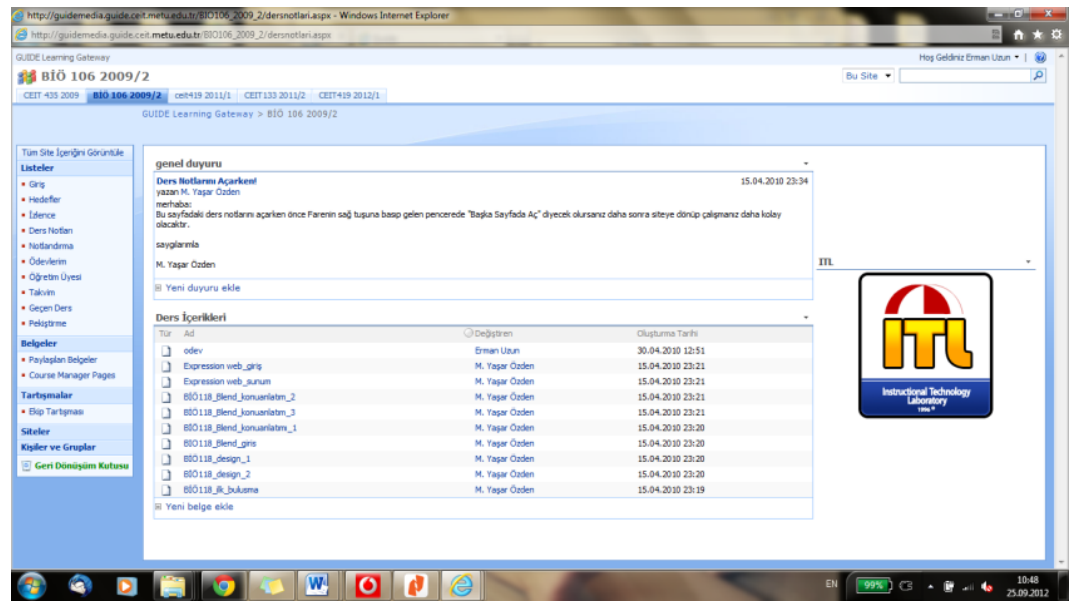

Figure 7-6: A screenshot from ITL Learning Gateway's Lecture Notes Section

- Gradings: Grading policy of the course presented in this section.

- Homeworks: Instructor can assign homeworks, reach finalized homeworks, and grade students' homeworks with relevant feedback in this section. Students can see the assignments, upload their assignments, and reach the grades and feedbacks of the finalized assignments.

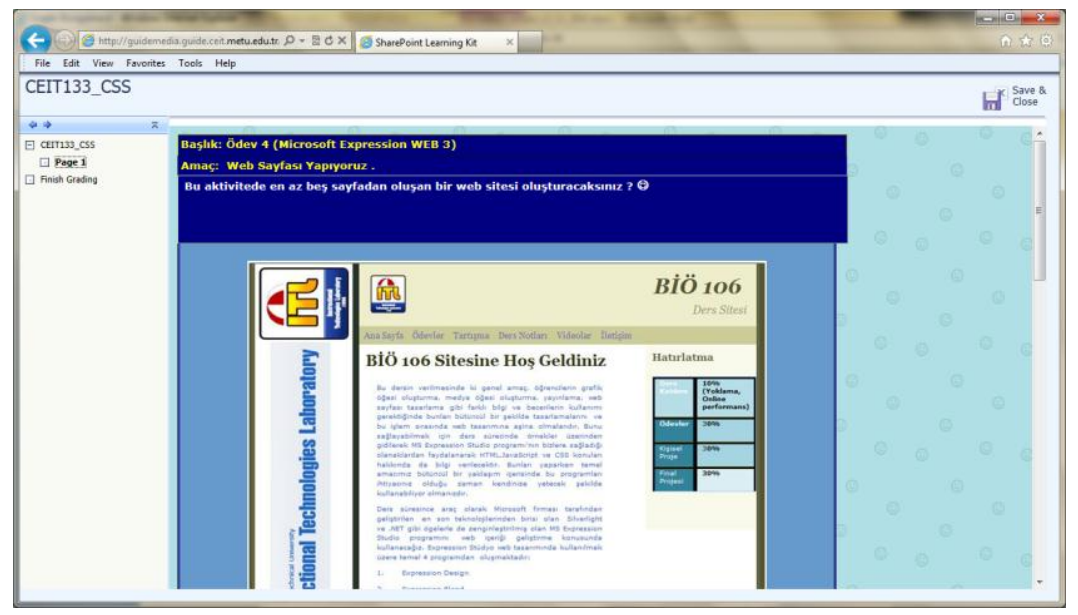

Figure 7-7: A screenshot from ITL Learning Gateway's Homework Upload Section 
- Instructor: Course instructor information can be seen in this section.

- Calender: In this section, students can set reminders, and can see the upcoming events whenever they logged on to the system on the right side of the main secreen.

- Previous courses: This section represents flexible structure of the course design. It was added to the CMS for this course, because of the emergent needs of the course to present video records of the course.

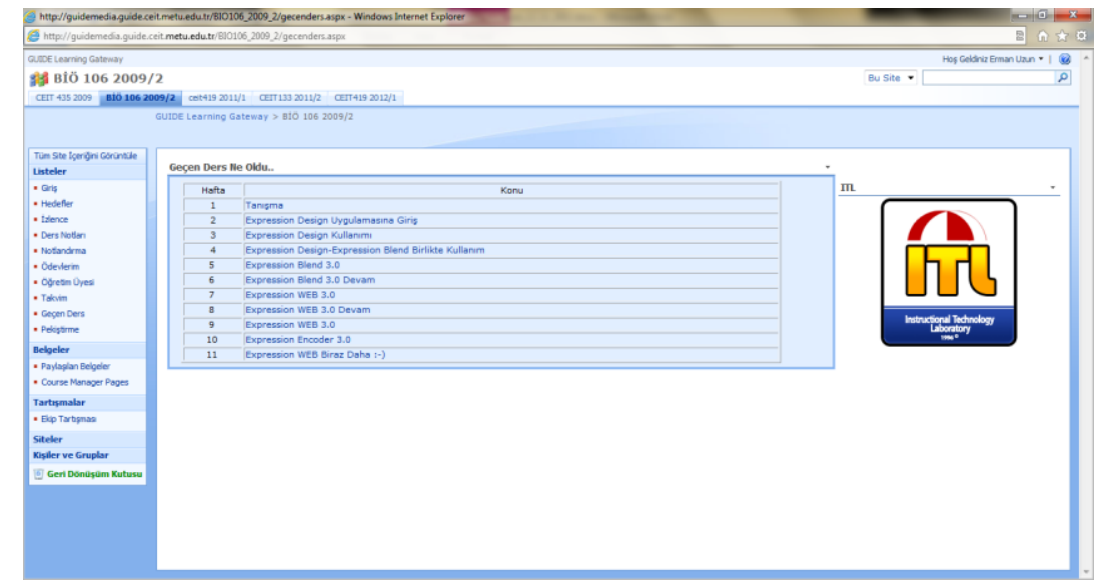

Figure 7-8: A screenshot from ITL Learning Gateway's Previous Courses Section

- Reinforcement: This section provides additional documents to support students during the course. Students can reach sample activity documents and video records of some sample exercises. 


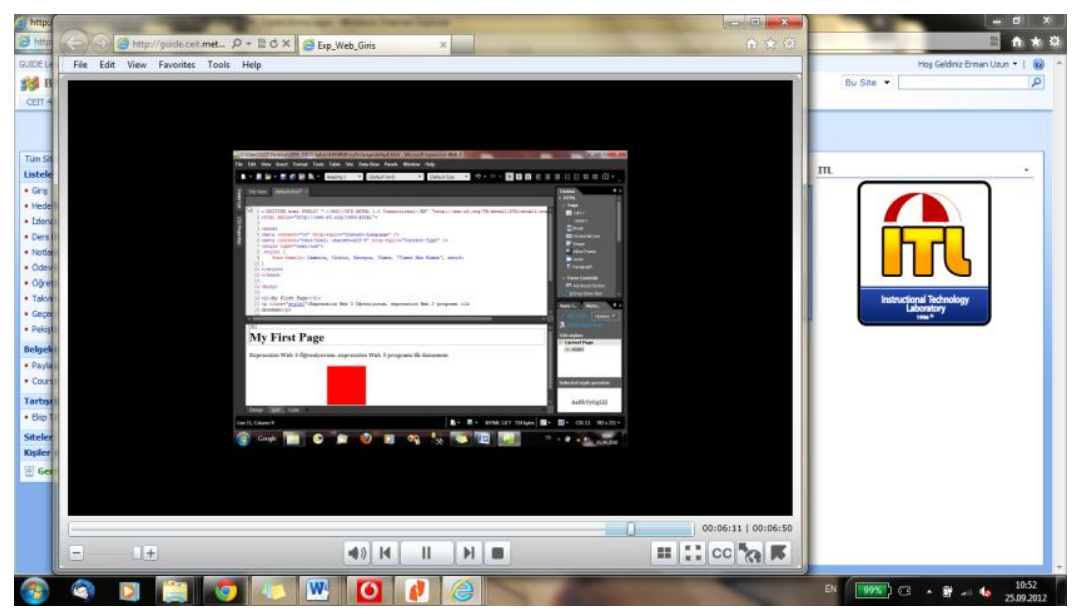

Figure 7-9: A screenshot from ITL Learning Gateway's Sample Video Support Material

- Discussion: The communication and collaboration tools were included in the main page. It was included document sharing and forum. In this online learning environment, administrator have opportunitiy assign user with different permissions.

- Shared Documents: Students and instructor can share some additional course related materials in this section.

\section{Computer Mediated Communication Tools}

Asynchronous online discussions were one of the basic collaboration tools provided by the forums in this study. ITL Learning Gateway provides access to a discussion board where class members can participate in discussion apart from course time. all the participants had access to the forum, the course instructor was the sole moderator of discussion sessions (see Figure 7-10). General course related topics and problems that students faced can be posted by students and wise answers, comments about those topics will enhance the quality of instruction. 


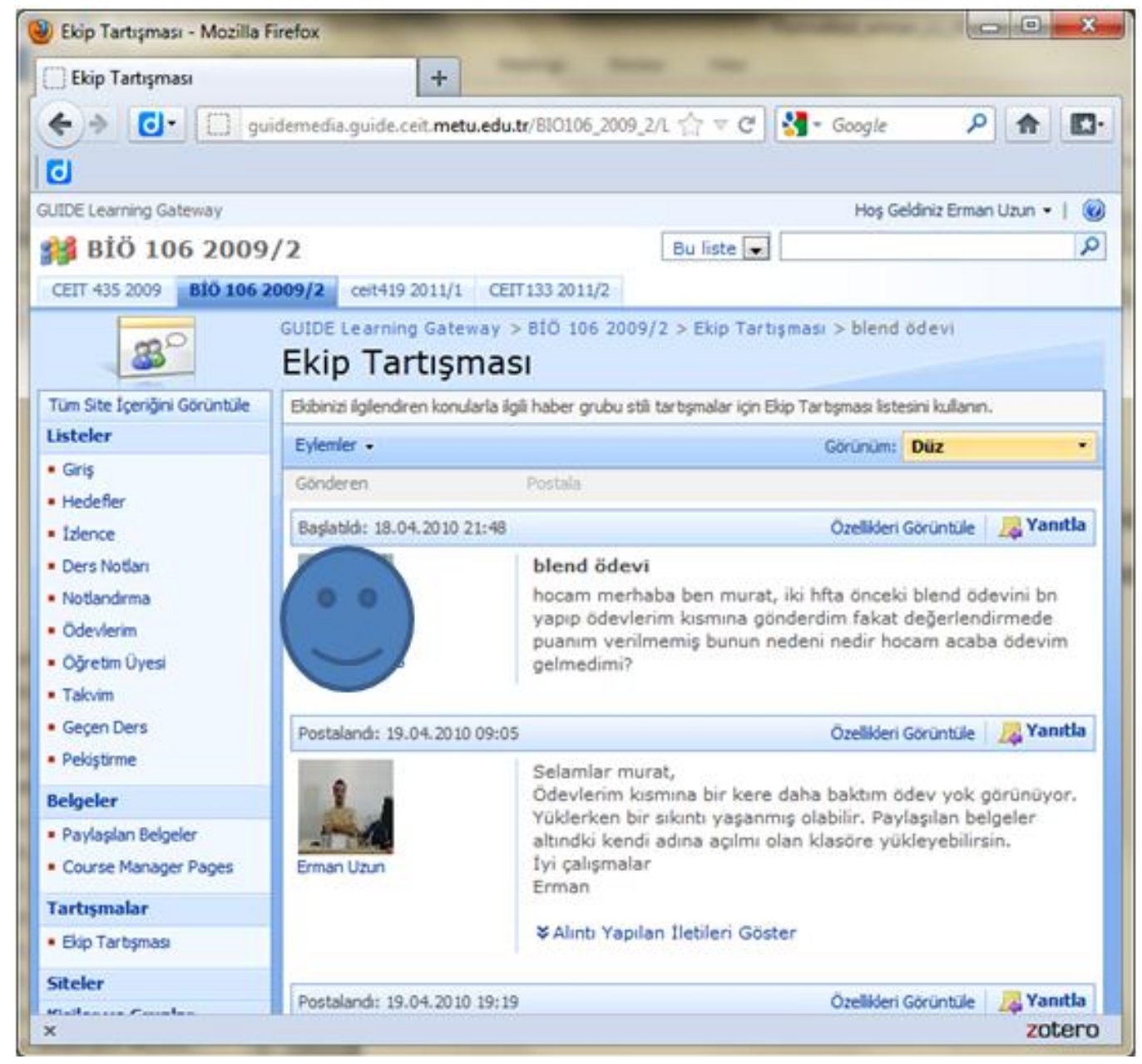

Figure 7-10: A screenshot from discussion board in ITL Learning Gateway

Moreover, it is possible to communicate with other students and instructor via chat tool that gives users a chance to communicate with others users synchronously. Communicator (A synchronous computer mediated communication tool) to ask something or to share students' experiences (see Figure 7-11). Laboratory activities will be given via LMS with some more documents that represent the activity and step by step explanation of the activity. Moreover, each weeks video records used as a benefitial resource. Lab assistant will support this assignment from Ankara with connecting students in the lab with video conferencing, desktop sharing and chatting. 


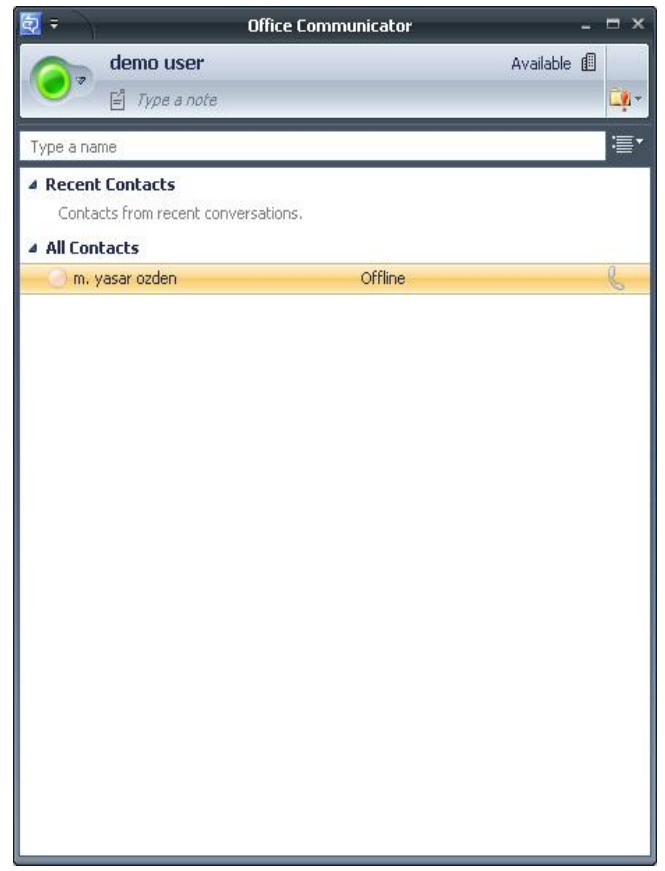

Figure 7-11: A screenshot from synchronous CMC tool in ITL Learning Gateway

Throughout the course, online discussions were a course requirement that was presented in the grading policy section. Student participation was expected during the course and their online contribution was graded as $10 \%$ of the overall course grade.

\section{Video Conferencing}

Interaction between learner-learner, learner-instructor and learner-content is necessary to consider in instructional design process and media has a critical role to exchange of information. Goodyear (2005) stated that one of the important things in the design of learning environments is the effective use of the communication capabilities of technologies that can connect learner in a meaningful way.

Compatible with the Iş1k (2009) study, he represented recommendations for the Microsoft Sharepoint based e-learning sharing portal similar to our CMS. He reported to integrate additional educational materials, instant messaging software. Compatible 
with his recommendation those were integrated to the new course structure. Moreover, he recommended that this system could be supported with teleconferencing technologies, or live broadcast for educational purposes to increase interaction.

As a synchronous instructional delivery environment, researcher and instructor preferred to use smart class and its video conferencing capabilities. In each side of the course there was video conferencing equipment. Subject matter expert lives in Ankara and his transportation to Vocational School was not possible in each week. Therefore, it is not feasible to do face-to-face instruction. For that reason, researcher and the instructor prefer to use smart class for instructional delivery.

First, researcher decided on what kind of structure should be used in the delivery of the course from one site of the course to the other site. The researcher tried to be informed about the capabilities of smartclass in each side. For the delivery side of the study, researcher should learn more about the capabilities and properties of the smartclass to record the course sessions and the delivery of the course. This system is very complicated and many times researcher and instructor worked on different alternative instructional delivery via smartclass. First, equipments of the smartclassroom were analyzed. Here are the main devices in the delivery site:

- Aethra (Video conferencing system)(see Figure 7-12).

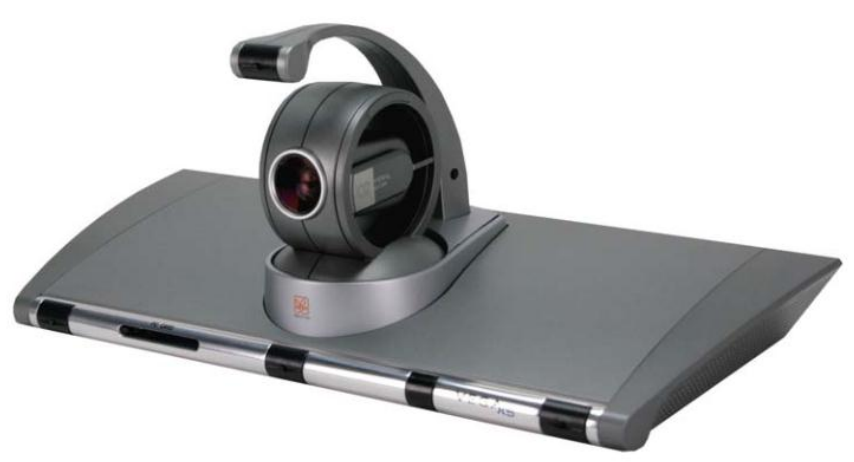

Figure 7-12: Aethra Video Conferencing Device 
- Canon Camera (RC Camera)

- 2 Projector in each side of the classroom

- 1 Video Camera

- 2 Laptop

- A control room (with sound and video mixer)

Each device connected to each other and researcher should be informed about the inputs and outputs of the devices in the smart class. Wiring diagram were prepared to learn what kind of sound and video could be obtained from which output.

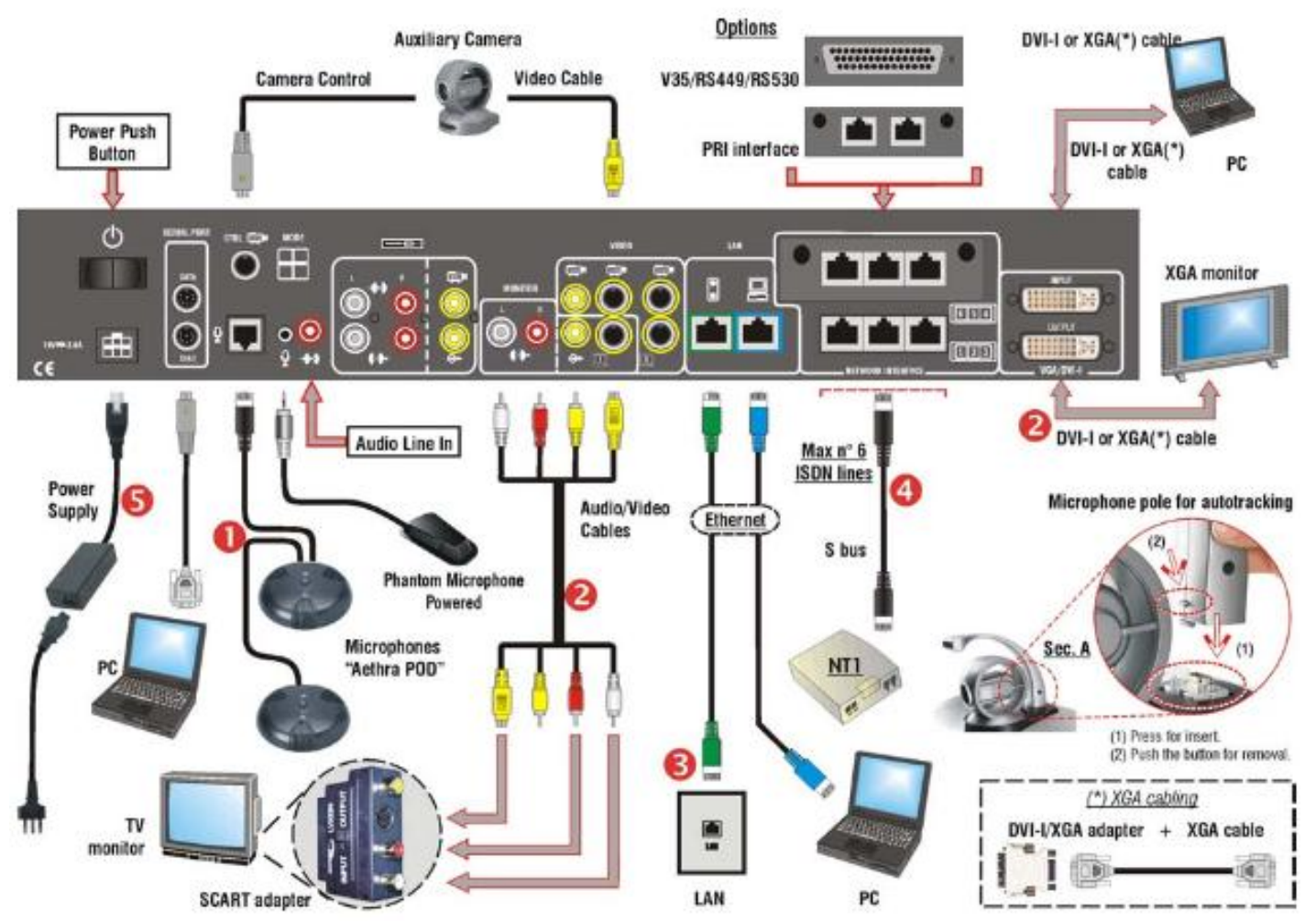

Figure 7-13: Aethra Video Conferencing Device Connection Diagram 
The existing capabilities of the smart class in vocational institution were analyzed and reported (see Figure 7-14). The smartclass in the receiver site of the course was less complicated, because it was just designed like a video conferencing system. It was used a conference hall. In this instructional delivery environment design, the differences of the technologic capabilities of the smart classes made this process more complicated. No major changes were made in the physical characteristic of the classroom in the video conferencing system integration (see Figure 7-15).

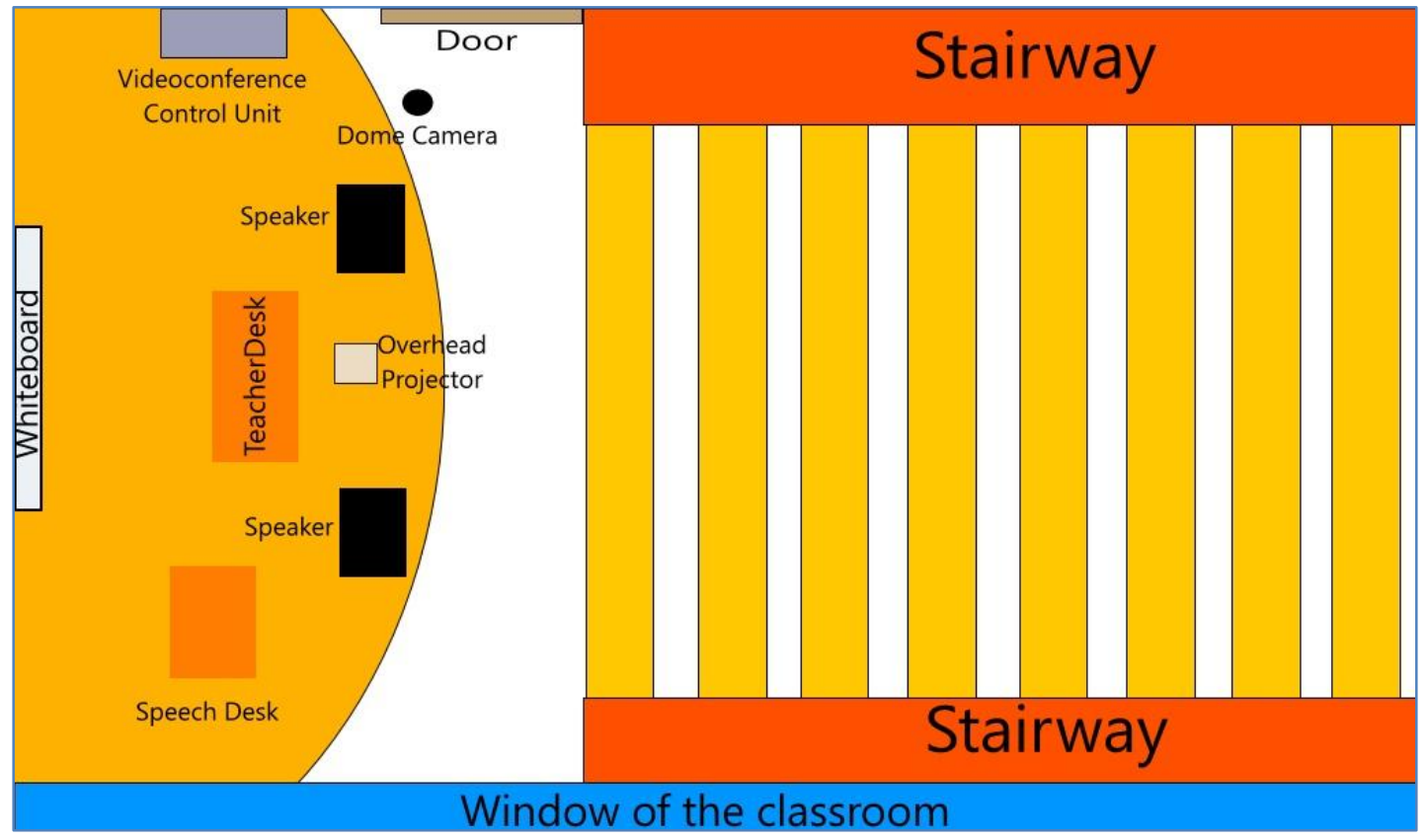

Figure 7-14: Physical Structure of the Smart Class in Vocational Higher Education Institution 


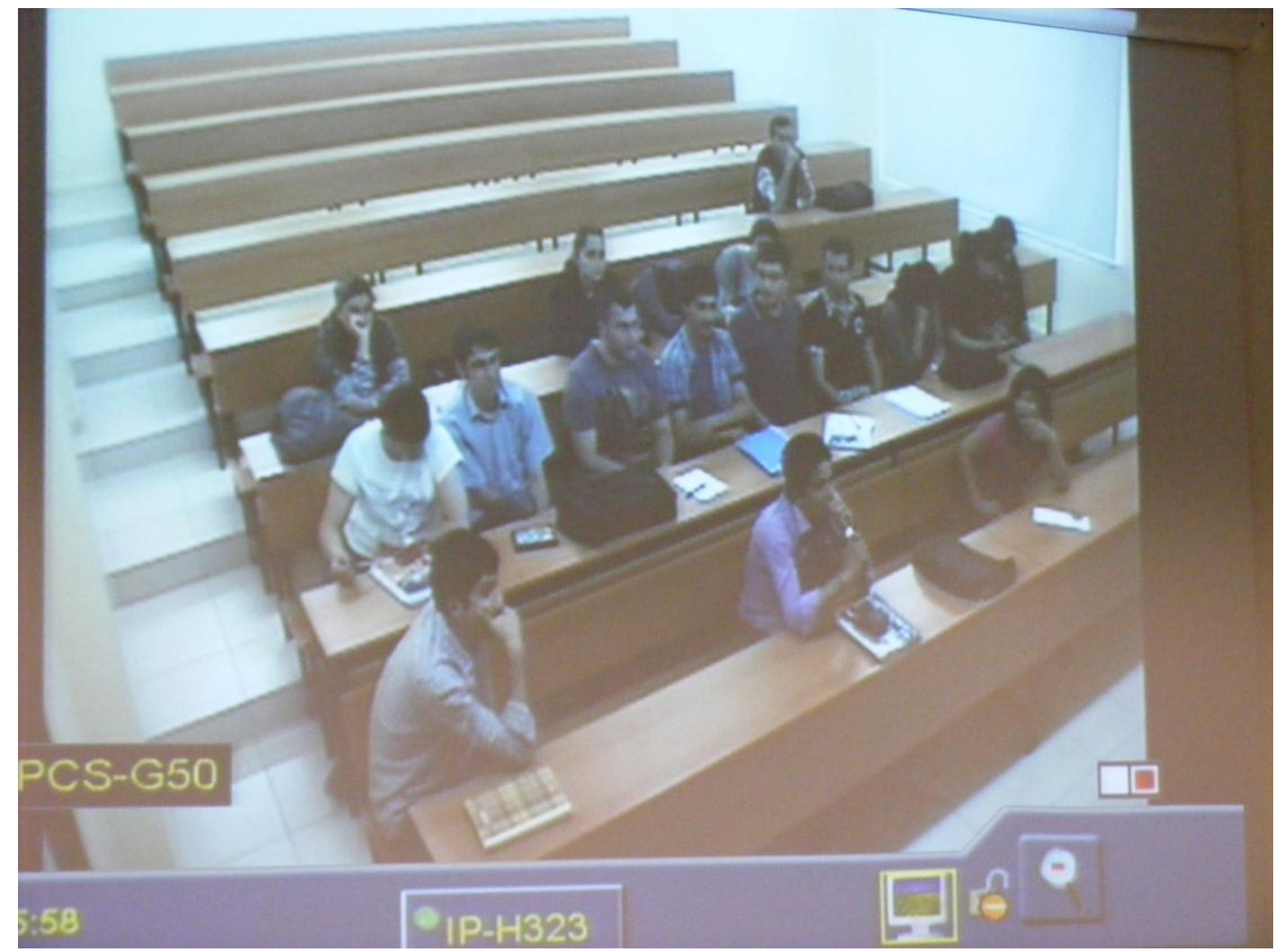

Figure 7-15: Preview from the video conferencing session of the course

With all aforementioned information, researcher and instructor worked on alternative ways of the course delivery and records. Several trials about the delivery structure were made with the smart class in Continuing Education Center in METU and personal computers. Finally, we could send different outputs to the other site from two cameras and the instructor computer in the smart class with changing it during the course. In order to eliminate static view angle, during the course researcher sometimes change the camara angles and computer. Also, course sessions were recorded to another computer in the case of emergency at the beginning of the course, but later it was published over the web site. 


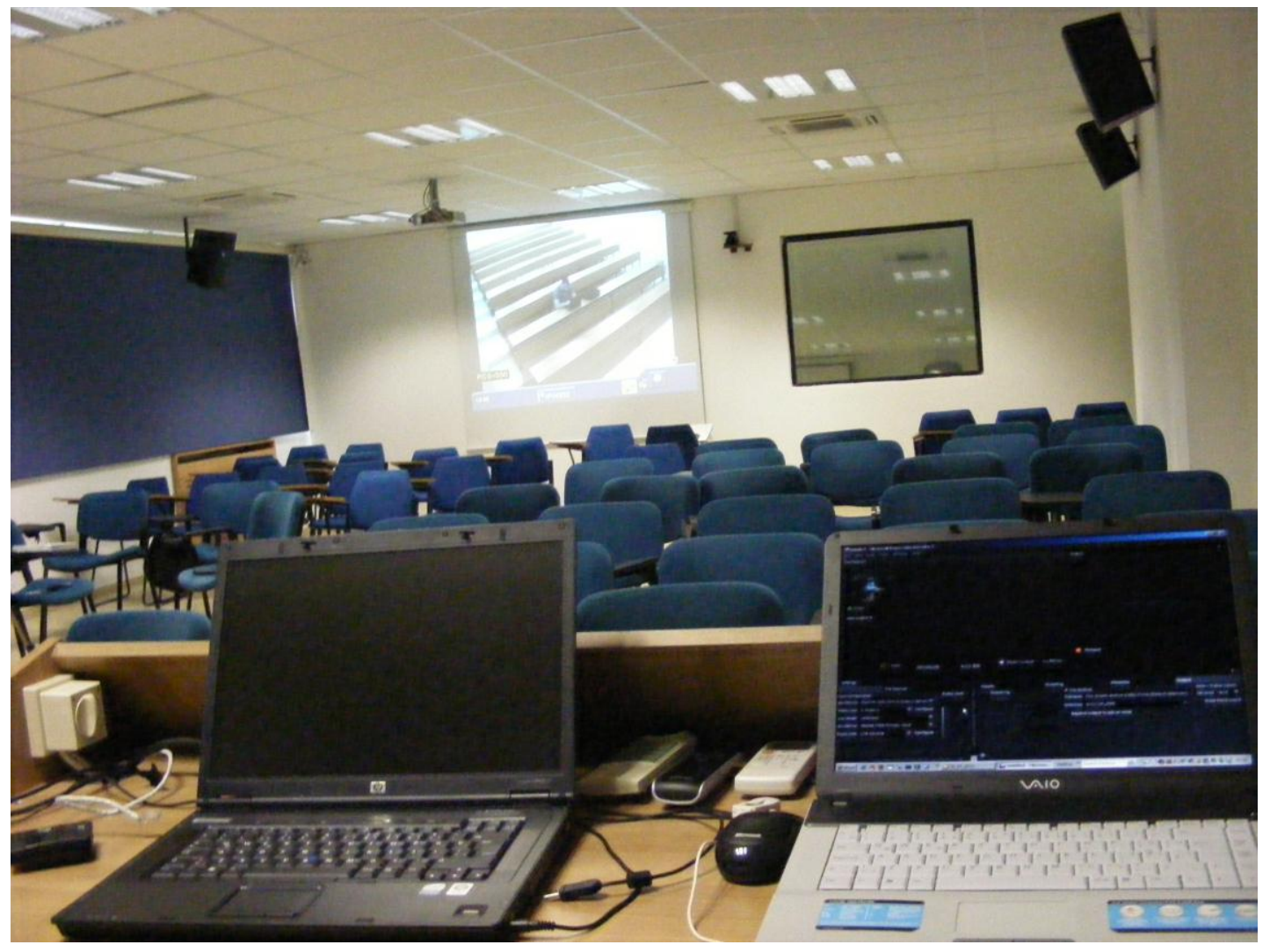

Figure 7-16: Instructor view in the smart class

\section{Evaluation}

Finally the evaluation instruments were developed to measure the degree to which learners have acquired the knowledge, can perform the skills, and exhibit changes in attitudes as required by the objectives. Evaluation is used for the purposes of making judgments about whether the objectives of the course accomplished or not.

Related to evaluation of the instruction, researcher prefered to use both summative and formative evaluation methods.

- Five assignment were given during the semester - $25 \%$ (That covers each topic that was seen in the course content)

- Personal Project - \%25 (One Personal project were given as a term project), 
- Final Exam - \%40 (Objective based evaluations were done with the exam at the end of the semester to test students),

- Online Participation - \%10 (In order to improve students participation)

As it can be seen on the table above the average academic achievement of new distance web design course was 66,01 out of 100 . This result revealed that the students who took that course had moderate achievement level in this new context. 


\section{APPENDIX K}

\section{COURSE SYLLABUS}

Elektronik ve Bilgisayar Eğitimi Bölümü Bilgisayar Eğitimi Bölümü Temel Bilgisayar Bilimleri (BİÖ 106)

Ders web sayfası: guide.ceit.metu.edu.tr => BİÖ106

Asistan :Ar. Gör. Erman Uzun

euzun@metu.edu.tr

\section{Giriş:}

$\mathrm{Bu}$ ders genel olarak web programlama ve mantığını kavramak üzerine yoğunlaşmaktadır. Bu ders öğrencilere profesyonel bir web sayfasını oluşturabilecek ve yayınlayabilmeleri amacı ile temel bilgi ve uygulama konularını sunmak için tasarlanmıştır. Öğrenciler HTML(Hyper Text Markup Language), CSS (Cascading Style Sheet) ve javascript gibi kodlama dillerini kullanarak web programlama mantığını anlamaya ve uygulamaya çalışacaklar. Bunlara ek olarak, öğrenciler MS Expression Studio ortamını kullanarak yalnızca basit web sayfaları yapmakla kalmayacak, aynı zamanda ihtiyaca uygun web uygulamalarını tasarlayıp hayata geçirebilecek becerilere sahip olacaklardır.

Günümüzde web ve web tabanlı uygulamalar hızla gelişmekte ve eğitim alanında da öğrencilere büyük firsatlar sunmaktadır. Video konferanslar, WWW, e-posta, forumlar, anlık mesajlaşma, ve ftp gibi birçok uygulama eğitimde de yaygın olarak kullanım alanı bulabilmektedir. Bu nedenle bu ders, internet ortamının öğrencilerin 
bilgiyi oluşturmada, kullanmada ve birbirleriyle paylaşmada aktif olarak nasıl kullanacağının kavranması üzerinde yoğunlaşacaktır. Dersin bir başka amacı ise, öğretim materyali, iletişim aracı ve bilgi kaynağı olarak internet ve web tabanlı uygulamaların sınıf ortamında kullanımını ön plana çıkmaktır. Bu ders kapsamında sadece web programlama ile ilgili temel bilgiler verilmek ile kalınmayacak aynı zamanda da ders içerisinde web teknolojileri aktif olarak kullanılacaktır. Ders, ODTÜ - Bilgisayar ve Öğretim Teknolojileri Bölümünde bulunan akıllı sınıf üzerinden Tarsus Teknik Eğitim Fakültesinde bulunan sizlere video konferans olanakları kullanılarak gerçekleştirilecek ve dönem içerisinde sizden gelen istekler ve talepler doğrultusunda sürekli gözden geçirilecek ve yeniden düzenlenecektir.

\section{Amaçlar:}

$\mathrm{Bu}$ dersin verilmesinde ki genel amaç, öğrencilerin grafik öğesi oluşturma, medya öğesi oluşturma, yayınlama, web sayfası tasarlama gibi farklı bilgi ve becerilerin kullanımı gerektiğinde bunları bütüncül bir şekilde tasarlamalarını ve bu işlem sırasında web tasarımına aşina olmalarıdır. Bunu sağlayabilmek için ders sürecinde örnekler üzerinden gidilerek MS Expression Studio programı'nın bizlere sağladığı olanaklardan faydalanarak HTML, JavaScript ve CSS konuları hakkında da bilgi verilecektir. Bunları yaparken temel amacımız bütüncül bir yaklaşım içerisinde bu programları ihtiyacınız olduğu zaman kendinize yetecek şekilde kullanabiliyor olmanizdir.

Ders süresince araç olarak Microsoft firması tarafından geliştirilen en son teknolojilerinden birisi olan Silverlight ve .NET gibi ögelerle de zenginleştirilmiş olan MS Expression Studio programını web içeriği geliştirme konusunda kullanacağız. Expression Stüdyo web tasarımında kullanılmak üzere temel 4 programdan oluşmaktadır;

1. Expression Design

2. Expression Blend

3. Expression Web

4. Expression Encoder

Bir web sayfasında grafik öğelerinin önemi şüphesiz ki çok yüksektir. Görsel öğelerin varlığı web sayfasını daha etkili kılmaktadır. Logolar, resimler ve amaca uygun 
şekiller web metaryalimizin etkinliğini arttıracaktır. İşte bu noktada, Expression Design aracını kullanarak etkili görseller ve grafikler tasarlayabilirsiniz. Logolar, reklamlar, broşürler ve animasyonlarda kullanılacak grafikler bu araç vasıtası ile kolaylıkla tasarlanıp kullanılabilir. Bu dersin amaçlarından birisi de oluşturacağımız web sayfası için gerekli olan görselleri yaratmaktır. Bu amaç için "Expression Design" aracından yararlanacağız.

Ayrıca, web sayfalarınızda kullanabileceğiniz animasyon ve interaktif öğeleri MS Expression Blend programını kullanarak üretebiliriz. Bu doğrultuda gerekli olan animasyonların oluşturulması sırasında Expression Blend programının çalışma ortamı ve çeşitli araçlarının kullanımını ele alacağız.

Bu noktada web sayfası tasarlamanın temel ögesi olan HTML'den de bahsedeceğiz ve bu işaretleme dilinin bilinmesinin sayfa tasarımındaki vazgeçilmezliği ve gerekliliği konusunda örnekler ile çalışacağız. Ardından web sayfalarımızın tasarımında ve etkileşimli hale getirilmesinde MS Expression Web programından yararlanacağız. MS Expression web çalışma ortamını kullanarak sayfalarımızı dinamik ve etkileşimli hale getirmeyi öğreneceğiz. JavaScript ve CSS mantığını kullanarak kolay ve etkili web tasarımları oluşturma, daha önce hazırladığımız grafik, animasyon ve medya dosyalarını sayfalarımıza ekleme bu süreçte ele alacağımız konular arasında yer alacaktır.

Son olarak, öğretim sürecinde en etkili materyallerden birisi olan video dosyalarının nasıl işleneceğini ve sayfamıza uygun hale getirileceğini öğreneceğiz. Bunun için MS Expression Encoder programının çalışma ortamını ve önemli araçlarını video dosyalarımızı düzenlemede ve yayınlamada nasıl kullanabileceğimizi tartışacağız.

\section{Genel Hedefler ve Kazanımlar:}

Öğrencilerin bu dersin sonunda aşağıda ki kazanımları edinmeleri hedeflenmektedir;

1. Eğitimde internet ortamının ve web tabanlı eğitimin önemini kavrama.

2. Ders sürecinde, ödev ve projelerde gerekli bilgiye ulaşmaya ihtiyaç duyma.

3. Bu süreçte geçerli ve güvenilir bilgilere ulaşma.

4. Ulaştı̆̆ bilgiyi seçme, düzenleme ve kullanma. 
5. Proje ve haftalık ödevlerin yapılması sırasında karşılaştığı problemleri çözme.

6. Ulaştığı bilgileri, karşılaştığı problemleri arkadaşları, öğretim üyeleri ile uygun ortamlarda paylaşma.

7. Web sayfası tasarlamada gerekli olan araçları tanıma ve onları kullanma.

8. Bir web sayfasını oluşturan öğeleri ve bu öğelerin kullanım amaçlarını kavrama.

9. İhtiyaca yönelik bir web sayfası tasarlama ve bu sayfayı yayınlama.

10. Tasarlanan web sayfasinın ihtiyaca uygunluğunu kontrol etme değerlendirmelerde bulunma.

11. Projelerde var olan kaynakları etkili ve verimli kullanma.

12. Projelerde ve ödevlerde ahlaki ve etik kuralları uygulama.

Table 7-3: Instructional strategies that were used in the course

\section{Öğretim Açılama}

\section{Stratejileri}

İş birliği ile Öğrenciler derste işlenen temel konular hakkında birbirleriyle öğrenme: $\quad$ etkileşim haline geçmeye teşvik edilecek ve öğrenci grupları oluşturularak öğrencilerin öğrenme sürecinde birbirleriyle etkileşmelerine olanak sağlanacaktır.

Öğretim Üyesi Öğretim Üyesi öğrencilere gerek ders içerisinde yapılan geri dönütü : $\quad$ aktivitelerle ilgili gerekse ders dışı verilen aktivitelerle ilgili geri dönüt ve bilgilendirmelerde bulunacaktır.

Öğrenci Öğgrenci ihtiyaçlarının giderilmesi adına oluşturmacı bir yaklaşımla merkezli öğrencilerin aktif olarak derse katılmaları ve kendi ihtiyaç ve öğrenme : $\quad$ seviyelerine uygun şekilde bir öğrenim süreci geçirmeleri amaçlanmaktadır. 
Table 7-3: (cont'd)

\begin{tabular}{ll}
\hline $\begin{array}{l}\text { Öğretim } \\
\text { Stratejileri }\end{array}$ & Açılama \\
\hline Gerçek Hayat & Öğrencilere gerçek hayatta karşllaşılan problemler ve çözüm \\
Problemlerinden & yollarıyla alakalı örnekler verilerek ve bunların öğrenciler \\
öğrenme : & tarafından çözümlenmeleri ve değerlendirilmeleri istenilerek \\
& öğrencilerin öğrendiklerini gerçek hayata uygulamaları \\
& sağlanılacaktır. \\
& Öğrencilerden öğrendikleri konular hakkındaki düşünceleri \\
Eleştirel & sorgulanacak ve böylelikle öğrencilerin dersin hedefleri \\
& doğrultusunda konuyu daha derin kavramaları sağlanacaktır. \\
Proje & Öğrencilerden amaca uygun bir web tabanlı proje geliştirmeleri \\
öğrenme : & istenilerek öğrencilerin öğrendiklerini uygulama becerileri \\
& geliştirilecektir. Böylelikle öğrenciler bildiklerini uygulama firsatı \\
& elde ederken aynı zamanda eksiklerini de görebileceklerdir.
\end{tabular}

Table 7-4: Course Content

\section{Hafta Konu}

1 - 2 Grafik tasarımı (MS Expression Design)

3-4 Interaktif animasyonlar tasarlama (MS Expression Blend)

5 HTML'e giriş (HTML4)

6 HTML'in MS Expression WEB' de kullanımı (MS Expression WEB)

7 Ara Sinav

8 JavaScript/Jscript (Expression WEB)

9 Dinamik HTML: Cascading Style Sheets (CSS) (MS Expression WEB)

10-11 Multimedia: Audio, Video (MS Expression Encoder)

12 Silverlight

13 Proje Toplantısı

14 Proje Toplantısı 


\section{Puanlama:}

Ders Katılımı

$10 \%$ (Yoklama, Online

performans)

Ödevler

$25 \%$

Kişisel Proje

$25 \%$

Final Sinavı

$40 \%$

\section{Ödevler:}

Öğrenciler ITL Learning Gateway (guidemedia.guide.ceit.metu.edu.tr $=>$ BIO106) üzerinde o haftanın konusuyla alakalı verilen ödevleri istedikleri yerde ve zamanda belirtilen tarih ve zaman aralıklarında yapmakla görevlidirler. Belirlenen süreyi aşan ödevlerde süreyi aşan her gün için \% 10 puan kırılacaktır. Her öğrenci ödevin yapılması ve kontrolünden kendisi sorumludur. Öğrencilerden tüm ödevleri yapmaları beklenmektedir.

\section{Yoklama:}

Her öğrencinin belirlenen miktarda derse devam etmesi zorunludur. Sınıf içi derslerin haricinde ITL Learning Gateway üzerinde yayınlanan ders materyallerine ve ödevlere vakit ayrılması gerekmektedir. Bunlar:

- Derse gelmeden önce ITL learning Gateway üzerinde bulunan ders materyallerinin incelenmesi ve tekrarı.

- Verilen ödevlerin zamanında ve örneklerdeki gibi tamamlanması ve sisteme yüklenmesi.

- Akıllı sınıftaki ve ITL Learning Gateway üzerinde sağlanacak olan online tartışmalara katılım. (Sınıf-içi ve sınıf dıșı aktivitelrede aktif katılım gerekmektedir. Bu katılımlar ayrıca puanlandırılacaktır)

Bütün bunların gerçekleştirilebilmesi için zamanın iyi programlanması ve ders ile ilgili yoğunluğa bağlı olarak zamanın iyi değerlendirmesi gerekmektedir. 


\section{Tartışma Ortamı kullanımı:}

ITL Learning Gateway ders saati dişında da iletişim içerisinde olabilmek ve etkileşimi sürdürebilmek adına Tartışma Ortamı aracını da içermektedir. Tartışma Ortamı arayüzü öğrencilerin yaşadıkları sıkıntıları, buldukları ilginç bilgileri, kafalarına takılan noktaları sorabilmeleri adına oluşturulmuş bir araçtır. Buraya öğretim elemanları da öğrenciler de mesaj atıp cevap yazabilirler. Öğrencilerin Tartışma ortamı sayfalarını sürekli ziyaret etmeleri ve soru sorup cevap yazmaları beklenmektedir.

\section{Intihal ve Aşırma:}

Ödevlerde ya da projelerde karşılaşılacak kopya, intihal ve diğer akademik dürüstlüğe yakışmayan davranışlar kesinlikle göz ardı edilmeyecektir. Bu tür davranışlar sergileyenler ilgili ödevden " 0 " alacaklardır. Bu durumun tekrar etmesi durumunda ise ders tekrarı söz konusu olacaktır.

\section{Kaynaklar:}

http://expression.microsoft.com/

http://daron.yondem.com/tr/formatpage.aspx?path=liste.format.html\#Expression http://www.ew-resource.co.uk/ 


\section{INFORMED CONSENT FORM FOR NEW DESIGN}

Bu çalışma, ODTÜ Bilgisayar ve Öğretim Teknolojileri Eğitimi Bölümünde Prof. Dr. M. Yaşar Özden danışmanlığında, Araştırma Görevlisi Erman Uzun tarafından doktora tezi kapsamında yapılmaktadır. Çalışmadaki amacımız ön çalışmaları ve planlanmış yapılmış olan yeni bir çevrimiçi dersi hayata geçirmektir. Bu kapsamda BİO 106 kodlu "Temel Bilgisayar Bilimleri” dersi yeniden dizayn edilip, akıllı sınıf aracılığı ile uzaktan verilerek daha önce mesleki ve teknik eğitim sürecinde karşılaşılan bazı sıkıntıların çözümü amaçlanmaktadır.

Araştırma süreci bilgisayar tabanlı mesleki ve teknik derslerde yaşanan problemlerin yerinde incelenip belirlenmesini, bu dersleri alan öğrencilerle ve dersi veren öğretim görevlisi ile ortak bir çalışma sonucunda bu problemlerin aşılmasını sağlayacak çözümlerin belirlenmesini ve belirlenen bu çözümlerin derse entegrasyonu sürecini içermektedir. Bu kapsamda şu anda daha önceden topladığımız veriler doğrultusunda tasarlanmış olan bu çevrimiçi dersin verilmesi ve bu dönem süreç içerisinde iyileştirilmesi planlanmaktadır. Çünkü eğitsel süreç hatasız ve eksiksiz bir süreç olmayıp değişik nedenlerden ötürü öğrencilerin ve öğrencilerin sınıf ortamında ve laboratuvar ortamında sorunlarla karşılaşmaları mümkündür. Bu nedenle problemlerin ve bu problemlere neden olan etkilerin belirlenmesi, ortaya koyulabilmesi büyük önem taşımaktadır.

XXX Üniversitesi, XXX Fakültesinde verilen BIO 106 “Temel Bilgisayar Bilimleri” dersinde yaşanan problemlerin çözümü için öğrenciler ve öğretim görevlisi ile ortak çalışmalar sonucu süreç içerisinde derste bazı değişiklikler yapılacaktır. Sizlerinde katkısı ile bu yeni tasarlanmış ders sırasında yaşadığınız sıkıntıları çözmeye 
çalışacağız. Bu kapsamda bu dönem derste gözlemler yapılacak ve anketler uygulanacaktır. Ayrıca çevrimiçi dersi desteklemek amacı ile kullanılacak olan ITL Learning Gateway'deki kayıtlar araştırma sürecinde kullanılacaktır.

Bu ders sürecinde anket, gözlem, çevrimiçi aktivitelerden toplanacak veriler kesinlikle 3. kişilerle paylaşılmayacak ve sadece araştırmacılar tarafından tez ve bilimsel yayın amaçlı kullanılacak. Ancak, çalışma ile ilgili veri toplama süreçlerinde herhangi bir nedenden ötürü kendinizi rahatsız hissederseniz bunu araştırmacıya bildirebilir ve veri toplama sürecinden çıkabilirsiniz.Bu çalışmaya katıldığınız için şimdiden teşekkür ederiz. Çalışma hakkında daha fazla bilgi almak için Bilgisayar ve Öğretim Teknolojileri Eğitimi Bölümü araştırma görevlisi Erman UZUN (Oda: Z-12; Tel: 0312-210 4183; E-posta: euzun@ metu.edu.tr) ile iletişim kurabilirsiniz.

Bu çalışmaya tamamen gönüllü olarak katılyyorum ve istediğim zaman yarıda kesip çıkabileceğimi biliyorum. Verdiğim bilgilerin bilimsel amaçlı yayımlarda kullanılmasinı kabul ediyorum.

(Formu doldurup imzaladıktan sonra uygulayıc1ya geri veriniz).

İsim Soyad

Tarih $----/----/ 2010$
İmza Alınan Ders

BİÖ 106 - Temel Bilgisayar Bilimleri 


\section{WEB BASED INSTRUCTION ATTITUDES SCALE-(WBI-AS)}

\section{Değerli Öğrenciler;}

$\mathrm{Bu}$ anket "Web Tabanlı Eğitim" e karşı tutumlarınızı dönem başında belirlemek amacı ile hazırlanmıştır. Buradan elde edilecek veriler sadece araştırmacının doktora tez çalışması kapsamında kullanılacaktır. $\mathrm{Bu}$ amacın gerçekleştirilmesinde sizin görüşlerinizin önemi büyüktür.

Katkılarınız için şimdiden teşekkür ederim.

Ar. Gör. Erman UZUN

euzun@metu.edu.tr

0-312-210 3682

\section{DEMOGRAFÍK BILLGILER ANKETİ}

1. Cinsiyetiniz?
( ) Bay
( ) Bayan

2. İnternete en çok nereden bağlanıyorsunuz?
( ) Evden
( ) İşyerinden
( ) Okuldan
( ) İnternet Cafeden

3. Yaşınız?
( ) 18 ve alt1
( ) $19-20$
( ) $21-22$
( ) 23 ve üzeri

4. Mezun olduğunuz lise türü?
( ) Düz Lise
( ) Anadolu Lisesi
( ) Meslek Lisesi
( ) Diğer:

5. Ailenizin aylık toplam geliri?
( ) 0-750 TL
( ) $750-1500 \mathrm{TL}$ 

( ) $1500-2250 \mathrm{TL}$
( ) 2250 TL ve üzeri

6. Ne kadar zamandır bilgisayar kullanıyorsunuz?
( ) 0-1 yil ( ) 1- 2 yil
( ) 2-4 Yil
( ) 4 Yildan fazla

7. Evde yada yaşadığınız yerde bilgisayarınız var mı?

( ) Evet ( ) Hayır

8. Günlük ortalama bilgisayar kullanma süreniz?
( ) 2 saat ve altı
( ) 2 -4 saat
( ) 4-6 saat
( )6 saat ve üzeri

9. Evde yada yaşadı ğınız yerde internetiniz var mı?

( ) Evet ( ) Hayır

10. Günlük ortalama interneti kullanma süreniz?
( ) 2 saat ve alt1
( ) 2 -4 saat
( ) 4-6 saat
( )6 saat ve üzeri 


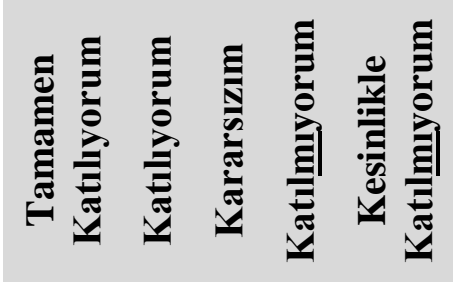

1. WTÖ ${ }^{1}$ sorumluluk duygusunu geliştirmektedir.

( ) ( ) ( ) ( ) ( )

2. WTÖ'i arkadaşlarıma tavsiye ediyorum.

$(\mathrm{)}(\mathrm{)})(\mathrm{)}(\mathrm{)}$

WTÖ'de ortaya çıkan teknik sorunlar beni

3. sinirlendiriyor.

( ) ( ) ( ) ( ) ( )

4. Yükseköğretimde WTÖ uygulamalarına geçilmelidir. ( ) ( ) ( ) ( ) ( )

5. WTÖ'de öğretim elemanlarıyla iletişim kurabiliyorum. ( ) ( ) ( ) ( ) ( )

6. WTÖ, eğitim sorununa alternatif bir çözümdür. $\quad($ ) ( ) ( ) ( ) ( )

7. WTÖ'de öğrendiğim bir konuyu çabuk unutuyorum. ( ) ( ) ( ) ( ) ( )

8. WTÖ'in yaygınlaşması toplum için yararlıdır. $\quad$ ( ) ( ) ( ) ( ) ( )

WTÖ takım çalışmasını olumsuz yönde

9. etkilemektedir.

( ) ( ) ( ) ( ) ( )

10. WTÖ kendi hızıma uygun öğrenme firsatı sağlıyor. $\quad$ ( ) ( ) ( ) ( ) ( )

11. WTÖ beni araştırmaya teşvik ediyor. $\quad($ ) ( ) ( ) ( ) ( )

12. WTÖ'de yeterli rehberlik hizmeti verilebilmektedir. ( ) ( ) ( ) ( ) ( )

13. WTÖ sosyal yönümü zayıflatıyor.

( ) ( ) ( ) ( ) ( )

14. WTO yüzünden kendime yeterli zaman WTÖ yüzünden

( ) ( ) ( ) ( ) ( )

15. WTÖ kendime olan özgüvenimi arttırıyor.

( ) $($ ) $($ ) ( ) ( )

16. WTÖ'de düşüncelerimi özgürce ifade edebiliyorum. ( ) ( ) ( ) ( ) ( )

17. WTÖ üniversite-sanayi işbirliğini teşvik etmektedir. ( ) ( ) ( ) ( ) ( )

18. Web üzerinden ders çalışırken sıkılıyorum. $\quad$ ( ) ( ) ( ) ( ) ( )

19. WTÖ yaşamboyu öğrenmeyi sağlar.

$(\mathrm{)})(\mathrm{)})(\mathrm{)})$

20. WTÖ'in sıkıcı olduğunu düşünüyorum.

$($ ) $($ ) $($ ) $($ ) ( )

21. WTÖ klasik eğitim kadar etkilidir.

$(\mathrm{)})(\mathrm{)})(\mathrm{)})$

22. Aldığım WTÖ'e güveniyorum.

$($ ) $($ ) ( ) ( ) ( )

23. WTÖ zaman kaybıdır.

$(\mathrm{)})(\mathrm{)})(\mathrm{)})$

24. WTÖ'de yeterli geribildirim alabiliyorum.

$($ ) $($ ) $($ ) ( ) ( )

25. Kendimi okuduğum üniversiteye ait hissetmiyorum.

$($ ) $($ ) $($ ) ( ) ( )

26. WTÖ önümüzdeki yıllarda kaçınılmaz olacaktır.

$($ ) $($ ) $($ ) ( ) ( )

${ }^{1}$ WTÖ: Web Tabanlı Öğretim 


\title{
APPENDIX N
}

\section{STUDENTS' PERCEPTION TOWARDS NEW LEARNING ENVIRONMENT SCALE}

\author{
Akıllı Sınıf Üzerinden Verilen Web Tabanlı Eğitimde Kullanılan Araçlara \\ Yönelik Öğrenci Algılarını İçeren \\ Öğrenci Algı Anketi
}

\begin{abstract}
Bu anket; ODTÜ-BÖTE'den XXX Üniversitesi XXX Fakültesi’ne akıllı sınıf üzerinden verilen Temel Bilgisayar Bilimleri dersinde kullanılan yönelik düşüncelerinizi öğrenmek amacıyla hazırlanmıştır.

Anket verileri, Ortadoğu Teknik Üniversitesi Bilgisayar ve Öğretim Teknolojileri Eğitimi bölümünde sürdürülen bir tez kapsamında kullanılacaktır.

Cevaplar hiçbir şekilde öğrenci notlarını etkilemeyecek ve kesinlikle gizli tutulacaktır.

LÜTFEN CEVAPSIZ SORU BIRAKMAYINIZ.

Yardımlarınız için teşekkür ederiz.

İletişim için:

Erman Uzun

euzun@metu.edu.tr
\end{abstract}

\section{Akademik Danıșman:}

Prof. Dr. M. Yaşar ÖZDEN

Lütfen cinsiyetinizi belirtiniz.

Cinsiyet $\quad$ Erkek $\quad \mathrm{K} 1 \mathrm{z}$


BÖLÜM 1:

Bu bölümde, 7 adet teknoloji listelenmiştir. Her bir teknoloji için, yeterliliğinizi belirten en uygun seçeneği işaretleyiniz. Lütfen her teknoloji için belirtilen seçeneklerden sadece birini işaretleyiniz.

\begin{tabular}{|c|c|c|c|c|c|c|}
\hline & \\
\hline & & & $\begin{array}{c}\text { Hiç } \\
\text { Kullanmadım }\end{array}$ & Başlangıç & $\begin{array}{l}\text { Orta } \\
\text { Seviye }\end{array}$ & Oldukça İyi \\
\hline 1.1 & \multicolumn{2}{|c|}{$\begin{array}{l}\text { Web tarayıc1 } \\
\text { (Örnek: Internet Explorer, Firefox, Netscape, Opera) }\end{array}$} & $\mathrm{O}$ & $\mathrm{O}$ & C & $\mathrm{O}$ \\
\hline 1.2 & \multicolumn{2}{|c|}{$\begin{array}{l}\text { Arama Motoru } \\
\text { (Örnek: Google, Alta vista, Yahoo, MSN, Lycos) }\end{array}$} & $\mathrm{O}$ & $\mathrm{O}$ & $\mathrm{O}$ & C \\
\hline 1.3 & \multicolumn{2}{|c|}{$\begin{array}{l}\text { E-mail } \\
\text { (Örnek: Hotmail, Yahoo, Mail, Gmail, Outlook, vs.) }\end{array}$} & 0 & C & 0 & $\mathrm{C}$ \\
\hline 1.4 & \multicolumn{2}{|c|}{ Çevrimiçi Forumlar \& Web Günlüğü (Blog) } & 0 & $\mathrm{O}$ & 0 & O \\
\hline 1.5 & \multicolumn{2}{|c|}{$\begin{array}{l}\text { Çevrimiçi Chat Uygulamaları } \\
\text { (Örnek: IRC, MSN Messenger, Yahoo Messenger vs..) }\end{array}$} & $\mathrm{O}$ & $\mathrm{O}$ & C & $\mathrm{O}$ \\
\hline \multirow[t]{4}{*}{1.6} & \multicolumn{6}{|c|}{ Microsoft Office Uygulamaları } \\
\hline & 1.6.1 & Microsoft Word & C & O & $\mathrm{C}$ & $\mathrm{C}$ \\
\hline & 1.6.2 & Microsoft Excel & $\mathrm{C}$ & $\mathrm{O}$ & $\mathrm{O}$ & $\mathrm{O}$ \\
\hline & 1.6 .3 & Microsoft PowerPoint & 0 & $\mathrm{O}$ & 0 & 0 \\
\hline 1.7 & \multicolumn{2}{|c|}{$\begin{array}{l}\text { E-Öğrenme Uygulamaları } \\
\text { (Örnek: Microsoft SharePoint, Microsoft Class Server, } \\
\text { LiteSpeed Elearning Platform, vs.) }\end{array}$} & $\mathrm{C}$ & 0 & 0 & 0 \\
\hline
\end{tabular}




\section{BÖLÜM 2:}

Bu bölüm, çevrimiçi web destekli öğrenme araçları hakkında önceki deneyimlerinizi öğrenmek amacıyla hazırlanmış sorular içermektedir.

Lütfen her defasında sadece bir cevap seçeneğini işaretleyiniz.

\begin{tabular}{|c|c|c|c|}
\hline \# & Sorular & Evet & Hayır \\
\hline 2.1 & Bu dönemden önce, hiç web destekli veya çevrimiçi ders almış mıydınız? & 0 & $\mathrm{O}$ \\
\hline 2.2 & Bu dönemden önce, hiç uzaktan eğitim uygulaması içeren bir ders almış mıydınız? & 0 & 0 \\
\hline 2.3 & $\begin{array}{l}\text { Bu dönemden önce, internet kullanmanız gereken bir ders almış mıydınız? } \\
\text { (Örnek: Araştırma, ödev, proje çalışması, vs.) }\end{array}$ & 0 & G \\
\hline 2.4 & $\begin{array}{l}\text { Bu dönemden önce, E-Öğrenme Paylaşım Portalı kullanmanız gereken bir ders almış mıydınız? } \\
\text { (Örnek: Ders dokümanı paylaşmanız gereken uygulamalar, forumlar, chat, çevrimiçi sınavlar) }\end{array}$ & 8 & G \\
\hline
\end{tabular}




\section{BÖLÜM 3:}

Aşağıdaki durumlarda belirtilen durumlara ne kadar katıldığınızı veya katılmadığınızı belirtiniz. Lütfen her defasında sadece bir cevap seçeneğini işaretleyiniz.

\begin{tabular}{|c|c|c|c|c|c|c|}
\hline \multirow{2}{*}{\multicolumn{2}{|c|}{ Akıllı sınıf üzerinden verilen web tabanlı eğitimde kullanılan araçlar; }} & \\
\hline & & $\begin{array}{c}\text { Hiç } \\
\text { Katılmyorum }\end{array}$ & Katılmıyorum & Tarafsızım & Katılıyorum & $\begin{array}{c}\text { Oldukça } \\
\text { Katıllyorum }\end{array}$ \\
\hline 3.1 & ... eğitimsel aktivitelerimizi daha hızlı tamamlamamı sağladı. & $\mathrm{O}$ & $\mathrm{O}$ & $\mathrm{O}$ & $\mathrm{O}$ & $\mathrm{O}$ \\
\hline 3.2 & ... eğitimsel aktivitelerimizdeki performansımın artmasını sağladı. & $\mathrm{O}$ & $\mathrm{O}$ & $\mathrm{O}$ & $\mathrm{O}$ & $\mathrm{O}$ \\
\hline 3.3 & ... eğitimsel aktivitelerimizdeki katılımımın artmasını sağladı. & $\mathrm{C}$ & $\mathrm{C}$ & $\mathrm{B}$ & $\mathrm{O}$ & 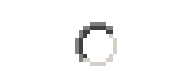 \\
\hline 3.4 & ... eğitimsel aktivitelerimize olan $\underline{\text { ilgimin }}$ artmasını sağladı. & $\mathrm{O}$ & G & C & $\mathrm{O}$ & $\mathrm{O}$ \\
\hline 3.5 & ... eğitimsel aktivitelerimizde üretkenliğimin artmasını sağladı. & $\mathrm{O}$ & $\mathrm{O}$ & $\mathrm{O}$ & $\mathrm{O}$ & $\mathrm{O}$ \\
\hline 3.6 & ... eğitimsel aktivitelerimizi daha eğlenceli hale getirdi. & $\mathrm{C}$ & $B$ & $B$ & $\mathrm{O}$ & 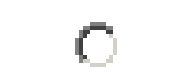 \\
\hline 3.7 & ... eğitimsel aktivitelerimize olan isteğimi azalttı. & O & $\mathrm{O}$ & $\mathrm{O}$ & $\mathrm{O}$ & 0 \\
\hline 3.8 & ... eğitimsel aktivitelerimizdeki etkinliğimi azalttı. & 0 & 0 & 0 & 0 & 0 \\
\hline
\end{tabular}




\begin{tabular}{|c|c|c|c|c|c|c|}
\hline 3.9 & ... daha kolay bir çalıșma ortamı kurulmasına yardımcı oldu. & $\mathrm{O}$ & 0 & $\mathrm{O}$ & $\mathrm{O}$ & $\mathrm{C}$ \\
\hline 3.10 & ... eğitimsel aktivitelerimize ulaşımımı kolaylaştırdı. & $\mathrm{C}$ & $\mathrm{O}$ & $\mathrm{O}$ & 0 & $\mathrm{C}$ \\
\hline 3.11 & ... eğitimsel aktivitelerimize karşı olan motivasyonumu arttırdı. & $\mathrm{O}$ & $\mathrm{O}$ & $\mathrm{O}$ & 0 & $\mathrm{O}$ \\
\hline 3.12 & ... eğitimsel aktivitelerimizle meşgul olma zamanımı arttırdı. & $\mathrm{O}$ & 0 & $\mathrm{O}$ & 0 & $\mathrm{C}$ \\
\hline 3.13 & ... eğitimsel aktivitelerimizle daha çok ilgilenme firsatı sağladı. & $\mathrm{O}$ & $\mathrm{O}$ & $\mathrm{O}$ & 0 & $\mathrm{C}$ \\
\hline 3.14 & ... eğitimsel aktivitelerimizdeki performansımı düşürdü. & $\mathrm{O}$ & $\mathrm{O}$ & $\mathrm{O}$ & 0 & $\mathrm{C}$ \\
\hline 3.15 & ... eğitimsel aktivitelerimizdeki çalıșma hızımı azalttı. & $\mathrm{O}$ & 0 & $\mathrm{O}$ & $\mathrm{C}$ & $\mathrm{C}$ \\
\hline 3.16 & ... eğitimsel aktivitelerimize karşı olan memnuniyetimi arttırdı. & $\mathrm{O}$ & 0 & $\mathrm{O}$ & 0 & $\mathrm{C}$ \\
\hline 3.17 & ... eğitimsel aktivitelerimizdeki çalışmalarımıza faydalı oldu. & $\mathrm{O}$ & 0 & 0 & $\mathrm{O}$ & $Q$ \\
\hline 3.18 & ... eğitimsel aktivelerimizdeki çalışma isteğimi arttırdı. & $\mathrm{O}$ & $\mathrm{O}$ & $\mathrm{O}$ & 0 & $\mathrm{O}$ \\
\hline 3.19 & 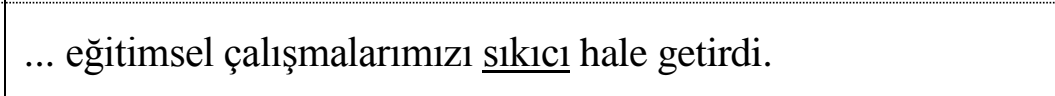 & $\mathrm{O}$ & $\mathrm{O}$ & 0 & 0 & $\mathrm{C}$ \\
\hline
\end{tabular}




\section{BÖLÜM 4:}

Aşağıdaki durumlarda belirtilen durumara ne kadar katıldığınızı veya katılmadığınızı belirtiniz.

Lütfen her defasında sadece bir cevap seçeneğini işaretleyiniz

\begin{tabular}{|c|c|c|c|c|c|c|}
\hline & & $\begin{array}{c}\text { Hiç } \\
\text { Katılmıyorum }\end{array}$ & Katılmıyorum & Tarafsızım & Katılıyorum & $\begin{array}{c}\text { Oldukça } \\
\text { Katılyyorum }\end{array}$ \\
\hline 4.1 & $\begin{array}{l}\text { Akıllı sınıf üzerinden verilen web tabanlı eğitimdeki araçları } \\
\text { kullanmayı öğrenmek benim için kolay oldu. }\end{array}$ & 0 & 0 & 0 & 0 & 0 \\
\hline 4.3 & $\begin{array}{l}\text { Akıllı sınıf üzerinden verilen web tabanlı eğitimdeki araçların kullanıcı } \\
\text { ara yüzü ve uyarı mesajları net ve anlașılırdı. }\end{array}$ & $\mathrm{O}$ & 0 & 0 & 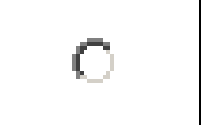 & 0 \\
\hline 4.4 & $\begin{array}{l}\text { Akıllı sınıf üzerinden verilen web tabanlı eğitimdeki araçların kullanıcı } \\
\text { ara yüzünün ve uyarı mesajlarının kullanımı kolaydı. }\end{array}$ & 0 & $\mathrm{O}$ & 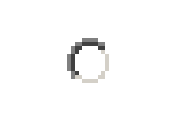 & $\mathrm{C}$ & 0 \\
\hline 4.5 & $\begin{array}{l}\text { Akıllı sınıf üzerinden verilen web tabanlı eğitimdeki araçlarını } \\
\text { öğrenmek benim için zor oldu. }\end{array}$ & 0 & 0 & $\mathrm{C}$ & $\mathrm{C}$ & 0 \\
\hline 4.6 & $\begin{array}{l}\text { Akıllı sınıf üzerinden verilen web tabanlı eğitimdeki araçlarının ara } \\
\text { yüzünde ve uyarı mesajlarında kullanılan terimler bana tanıdık geldi. }\end{array}$ & 0 & 0 & 0 & $\mathrm{C}$ & 0 \\
\hline 4.8 & $\begin{array}{l}\text { Akıllı sınıf üzerinden verilen web tabanlı eğitimdeki araçlarının } \\
\text { kullanımını kolay buldum. }\end{array}$ & 0 & 0 & 0 & 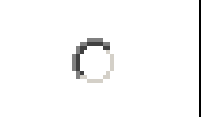 & 0 \\
\hline
\end{tabular}




\section{APPENDIX O}

\section{INTERVIEW PROTOCOL (FOR STUDENTS)}

ŞUBE:

Görüșülen:

Gün ve Zaman:

Görüşmeci:

Giriş:

Öncelikle dersleriniz arasındaki bu yoğun periyotta bana zaman ayırdığınız için çok teşekkür ederim. Bu dönem aldığınız BİO 116 Temel Bilgisayar Bilimleri dersine yönelik görüşlerinizi almak istiyorum. Uzaktan akıllı sınıf aracılığı ile verilen bu derste yaşanan problemleri ortaya çıkarmak ve bu problemlerin çözümüne yönelik neler yapılabileceğini belirlemeye çalıșıyorum. Böylelikle ileride yapılacak buna benzer çalışmalarda benzer sıkıntıların yaşanmaması için sizin bu süreç ile ilgili görüşleriniz büyük önem taşımaktadır. Öncelikle şunu özellikle belirtmek isterim ki bu görüşme sadece bu araştırma sürecinde araştırmacı tarafından incelenecektir, kimse ile paylaşılmayacaktır. Bu çalışma sonucunda oluşturulacak dokümanlarda isminiz dolaylı ya da doğrudan hiç bir şekilde geçmeyecektir. Hatta, görüşme sonunda istemediğiniz ve kayıttan çıkarılmasını istediğiniz kısımlar olursa bu kısımları da silebiliriz. Ayrıca isminiz hiçbir yerde doğrudan ya da dolaylı olarak geçmeyecektir. Eğer sizin içinde sakıncası yoksa görüşmeyi ses kayıt cihazı ile kaydetmek istiyorum. Yapılacak olan görüşme hakkında sormak istediğiniz herhangi bir soru yok ise görüşmeye başlayabiliriz. Görüşme yaklaşık olarak 20-25 dakika sürecektir, eğer kendiniz hazır hissediyorsanız ilk soru ile başlayalım.

Sorular:

- Lise eğitiminizi hangi tür lisede aldınız?

Sonda: Meslek Lisesi, Düz Lise, Anadolu Lisesi

- Kaç senedir XXX Fakültesinde öğrenim görüyorsun? 
- Daha önce hiç uzaktan eğitim ile bir ders almış mıydınız?

- Daha önce web tasarımı dersi almış mıydınız?

- Web Tasarımı dersinde dönem başında sizi en çok motive eden şey ne oldu? Sonda: Neden motive değildin? (İçerik ilgini mi çekmedi, ders hakkında yeteri kadar bilgi sahibi değil miydin?)

- Web Tasarımı dersine dönem icerisinde çalışırken hazırlanırken hangi kaynakları kullanıyordunuz?

- Materyaller ve kaynaklar sizin ihtiyaçlarınızı karşıladı mı?

Sonda: Eksikler nelerdi?

- Derste kullanılan kaynaklara erişim olanağınız nasıldı?

- Web Tasarımı dersinin içeriği ihtiyaç ve beklentilerini karşıladı mı?

Sonda: Hayır ise Neden? Ne tür eksikleri vardı?

Evet ise Neden? Hangi açılardan senin için yeterli oldu?

- Web Tasarımı dersinin sınıf ve laboratuvar da işlenişi, sunuluşu ve ders içi aktiviteleri senin ihtiyaç ve beklentilerini karşıladı mı?

Sonda: Hayır ise Neden? Ne tür eksikleri vardı?

Evet ise Neden? Hangi açılardan senin için yeterli oldu?

- Derse katılım, aktiviteler, kullanılan araçlar ve işleniş açısından bu dönem işlediğimiz dersi yüz yüze eğitim ile kıyaslayacak olursanız avantajları ve dezavantajları nelerdir?

- Bu güne kadar web tasarımı dersinde sinıfta ve laboratuvar da verimli bir şekilde ders işlemenize engel olan şeyler nelerdir? Ne tip sorunlarla karşılaştınız? Neden?

Sonda: Teknik eksiklikler, bilgisayar sayısı, bilgiye erişim, ders saati vs.

- Derste pek çok değişik teknolojik araç kullandınız bu araçlardan en sık kullandığınız üç tanesi nedir?

Sonda: Neden bu araçları kullanmayı tercih ettiniz?

- Bu araçları kullanma ve adaptasyon sürecinde ne tür sıkıntılar yaşadınız? Bu sikıntılar size nasıl etkiledi?

- Dersi almadan önce web tabanlı eğitime karşı olan tutumun nasıldı? Bu tutumun dönem içerisinde nasıl değişti?

Sonda: Sence uzaktan verilen web tabanlı eğitim etkili bir yöntem mi? Önündeki engeller neler? 
- Dersin içeriği, işlenişi ve kullanılan teknolojiler açısından değerlendirecek olursan. Ne tür değişiklikler önerirsin?

- Web tasarımı dersini iyileştirmek anlamında yaşanan problemler ve çözüm önerilerine yönelik eklemek istediğiniz birşey var mı? 


\section{OPEN CODING RESULTS (ACCOMPLISHMENTS OF THE NEW DESIGN)}

Supporting Learners

Instructor

Instructor support

Dreamspark

Dedicated time

Chatting with the instructor

Material support

Printable example

Video records of examples

Video conferencing experience

Improvement in technology

WBI experience

New tool (ExpressionStudio)

Learner responsibility

Increased virtual representations

Printable materials

Increased student responsibility

Communicating at a distance

Instructor as a subject matter expert

Good distance experience

Increased quality

Developing students skills

Homeworks and Project
Variety of resources

Licensed software

Video tutorials

Sense of responsibility

Pdf files

Learning outside the class

Course web site

Course content

Feel important

Distance course experience

Progress in the course

Project-based instruction

Improvement in students' skills

online learning ability

Variety of technology

Interaction

Anytime

Anywhere

Two way communication

Communicating with instructor

Active learning

Self-paced

Increased future expectation 


\section{APPENDIX Q}

\section{OPEN CODING RESULTS (PROBLEMS OF THE NEW DESIGN)}

Sound Problems

Internet connection

Password

Anxiety about failing the course

Feel alone

High expectancy from students

Not informed about students' skills

Reaching course records

Adaptation to distance course

Confusion in interaction

Adaptation to CMS

Support about CMS

Support in video-conference

Novelty effect

Beurocracy

Worries about the future of the school

Lack of printed material

Lack of their own study space

Lack of eye contact

Boredom

Synchronous communication

problems

Instructor control

Isolation

One-way communication

Lack of F2F interaction

Hard to adapt

Confusion to reach course materials

Split attention

Small projector screen

Social relation with instructor

Difficulty in doing lab assignment
Additional training about tools

Students' IT use habits

Fear of technology

Prejudice to Distance Education

High expectancy

Number of computers

Managing classroom

Lab activity support

Time consuming

Hard to take note

Needs more than computer literacy

Hard to ask question

Information overload

Complicated system

Weak school network infrastructure

Limited school computer infrastructure

Limited Internet Access (Quota)

Motivation

No prior e-learning experience

fear of innovation in a course

Limited familarity to DE

Interaction with instructor

Interaction between studnets

Limited collaboration

Limited timely technologic support

Additional responsibility for students

Dependent on technology

SES of students

PC belonging

Needs alternative plans

Unreliable internet connection 
Limited communication between peers

Learner-course material interaction Lack of confidence

Available time to use lab Available time to reach website Familarity to traditional courses Lack of incentives in school On-demand technologic support Poor internet connection speed Students' time management skills Problems in video conferencing Limited engagement
Needs computer competancy

Socialization

Program set up support

Self regulation of students

Computer with related softwares

Students' background skills

Support at home

Support at school

Adaptation to video conferancing

Curious about new course

Benefitting from instructor

Asynchronous communication problems 


\section{APPENDIX R}

\section{TURKISH TRANSLATIONS OF THE QUOTES}

[I-1] Derste bazı arkadaşların hakimiyeti var, onlar benim sormayı düşündüğüm sorular1 soruyorlar.

[I-2] Eğer ben bu dersi veriyor olsaydım, farklı şeyler yaparak öğrencilerin derse aktif katılımını sağlamaya çalışırdım. Bir danışman gibi yaklaşır ve onları farklı sorular ile yönlendirmeye çalışırdım.

[I-3] Ben uğraştırıcı sorular sorararak onların derse katılımını artırmaya çalışıyorum. Fakat eğer sorularınıza cevap alamıyorsanız, öğrencilerin katılımını unutuyor ve derse devam ediyorsunuz.

[I-4] Biz XXX hocanın bizden beklediği şekilde derse aktif katılamıyoruz. O sürekli bize bir sonraki aşama ile ilgili sorular soruyor ama çok az bazen hiç kimse cevap veremiyor.

[I-5] Bizim hocamız farklı bir metod kullanıyor, kodları bilgisayarda yazıyor ve bu not tutmayı kolaylaştırıyor... Aynı zamanda biz kodları bilgisayardan alabiliyoruz, bazen not tutmamiza gerek kalmiyor ve sinavdan önce daha lolay uygulama yapabiliyoruz...

[I-6] Öğrencilerin sadece belli bir kısmı odama soru sormak için geliyor... Çoğunun tahtaya yazdığım kodlama ile ilgili sıkıntıları oluyor, bazen bir noktalama işaretini unutuyorlar, ve bazende bilgisayarları ile iglili bir problem yaşıyorlar... 
[I-7] Hocamıza e-mail ile ulaşamıyoruz ama onu odasında bulabiliyoruz...

[I-8] Sınavdan önce üç arkadaşımla bir araya geliyoruz, birbirimize yakın oturuyoruz, ve örnek kodlar üzerinde çalışıyoruz...

[I-9] Bu tarz bir derste ben beraber çalışmaları için grup projeleri verirdim çünkü öğrencilerin birbirinin eksik kaldıkları noktaları kapatabileceğini düşünüyorum. Beraber çalışmak ve bildikleri yada bilmedikleri şeyler üzerinde tartışmak onların o konudaki bilgilerini artırabilir.

[I-10] Ben sorularımı arkadaşlarıma sormayı tercih etmem çünkü bence bu konuda asıl kaynak hoca olmalı ve doğru bilgi sadece ondan alınabilir

[I-11] Ders sırasında sadece not tutmak beni çok sıkıyor, ben kodu labda bilgisayarda yazmayı tercih ederim ama yapamıyorum...

[I-12] Dönem başında dönem bittiğinde yapabileceklerimiz hakkında bilgi sahibi değildik, ayrıca şunu nasıl kullanacağımı tam olarak söyleyemem, yada bana ileride ne ölçüde katkı sağlayacağını söyleyemem

[I-13] Labda ve sinifta defterlerimize not aliyoruz... Labda deneyemiyoruz bu durum hakikaten can sikıcı...

[I-14] Ders sırasında aslında pekçok şey öğreniyorum ama sınıf dışında bunları denemeye geldiğinde kodlamak istediğim şeyde tıkanıp kalıyorum yada bu kodların ne tür bir projede nasıl katkısı olacağını bilemiyorum. Bu nedenle ders dışında yeni kodları denemek istemiyorum...

[I-15] Dönem başında derse çok da motive değildim. Bu bir miktar okuldaki fiziksel altyapı problemlerinden kaynaklanıyor. Öncelikle bir bilgisayar edinemedim veben bir arkadaşımın bilgisayarında çalışıyorum ve bu çokda etkili değil... 
[I-16] Biz farklı altyapılardan geliyoruz, bazı arkadaşlar kodlamayı biliyor benim ise bu seneye kadar kodlamayı öğrenmek ile ilgili hiçbir çabm olmamıştı.

[I-17] Aslında bu dönem bu dersi bırakmayı düşünüyorum çünkü bir bilgisayarım yok ve yazın çalışıp para biriktirip bilgisayar almayı ve onda çalışmayı düşünüyorum.

[I-18] $\mathrm{Bu}$ derste hiç ödev yapmadık eğer bizi birşeyler zorlarsa belki daha iyi çalışabiliriz.

[I-19] Partik yapma anlamında grup projeleri final sınavı gibi bizi çalışmaya teşvik edebilir. Çünkü biz biraz kod biliyoruz ama bu bildiklerimizi gerçek bi rprojede uygulama şansımız yok.

[I-20] Eskiden Evde uygulama yapmaları için ödev verirdim ama öğrenciler bu tarz aktiviteleri yapmak için motive değiller ve ödev versemde sadece bir kısmı bununla ilgilenir.

[I-21] Şimdi bugun bunu öğreniyorum ama ben öğretmen olup olamayacağımı bilmiyorum çünkü KPSS bizim önümüde engel olacak... İleride ben bu sene gördüğüm konuları öğretmen şansımın olup olmayacağını bilmiyorum...

[I-22] Bazı öğrencilerin okula gelmek için otobüs parası verecek durumları yok, eğer ben onlara bir kitap önerirsem bu durum onları ekonomik olarak zorlar. Ayrıca bir kısmı kitabı edinebilirken bir kısmı edinemez...

[I-23] İnternette her türlü bilgiye ulaşılabiliyor... ben onları bir kitap yada ders notlarına yönlendirerek kısıtlamak istemiyorum

[I-24] Ben ve bazı arkadaşlar beraber internetten bazı videolar buluyoruz ki derste katkı sağlasın...

[I-25] Aslında eğer hocanın notlarının ekstra dokümanların, sınav bilgileri gibi şeylerin olduğu bir ders sitesi olsa bizim için çok faydalı olur. Herşeye tek bir adresten 
ulaşsak, bulsak, bu sayede saatlerimizi video ve farklı dokümanlar aramak için harcamamış oluruz aslında.

[I-26] Ben aslında şeyden emin değilim, ben öğretmen olduğumda bu sene öğrendiklerimi anlatıp anlatmayacağımdan emin değilim...

[I-27] Notepadde kod yazmak çok sıkıcı ve zaman kaybettiriyor bize. Küçük bir hatalı şey yazsam hatamı bulmak çok zaman alıyor. İki yıllık meslek yüksek okulunda ben buna benzer bir ders aldım ve bütün bu kodlama işleri için bir editör kullandık... Aynı içeri tekrar almaktansa ben geliştirilmiş bir halini yada yeni versiyonlarını almayı tercih ederdim...

[I-28] Meslek lisesinde daha önce web teknolojilerini gördük yania slında ben bu sene gördüğümüz pek çok şeye aşinayım...

[I-29] Heryıl aslında verdiğim dersler ve öğretim yolum ile ilgili kısa bir anket uyguluyorum ama geçen sene zaman darlığından ötürü bunu yapamadım...

[I-30] Derste kaynak olarak hocanın verdiği örnekleri kullanıyorum ama bazen hem dinleyip hemde not almak zor oluyor... Aslında bilgisayarda kodları yazıp çıktısını görebilesek daha iyi olurdu ama lablardaki bilgisayarlarda kod yazabileceğimiz probramlar yol hatta bazı bilgasayarlarda mouse biel yok...

[I-31] Tahtaya yazılan kodları ezberlemek için not tutuyorum fakat bunu yaparken hocanın sorularını bazen kaçırıyorum. Aslında, ÖĞRENCİ A ve ÖĞRENCİ F nin grubu sürekli hocaya soru soruyorlar ve hocanın sorularını cevaplıyorlar...

[I-32] Bizim hocamız farklı bir yöntem uyguluyor, tahtayı kullanmak yerine kod yazma sürecinde projektör kullanıyor. Bu bizim için önemli bir olanak ama eğer bizimde şansımız olsaydı, ben de labda daha fazla uygulama yapmak için kod yazmayı isterdim... 
[I-33] Geçen sen öğrenciler ödevler veriyordum... ama bu sene yoğun bir ders programım olmasından dolayı bu dönem ödev veremedim...

[I-34] Aslında koodları projektörde görebiliyoruz ama bizde kodları kendimiz yazabilsek daha iyi olacak. İki yıllık meslek yüksekteyken aynı dersi aldım ve birileri projektörde kodları yazıp yansıtırken bizde bilgisayarda kodlama yapıyorduk. Ayrıca hoca daha çok uygulama yapabilmemiz için ödev veriyordu...

[I-35] Eğer bu dersin hocası olsaydım ben dersi projeler üzerinden yeniden düzenlerdim. Öürencilere proje için bir web sayfası hazırlatırdım ve tecrübelerini, hatalarını yaşadıkları problemleri sınıfta sunmalarını isterdim. Diğer öğrencilerden geri bildirim verebilir yada diyebilirlerki hey ben onun yerinde olsam bu tarz şeyler yapardım, yada farklı iunları eklerdim şeklinde. Ama böyle bir yapı oluşturmak için esneklik şart. Zaman v eiçerik daha esnek olmalı...

[I-36] Belki de ders programını basit bir projeden karmaşı̆̆a doğru yeniden tasarlayabiliriz. Dönem başında öğrenciler basit bir sayfa tasarlarken, zaman geçtikçe geliştirip daha derste görecekleri yeni konularla bağlantılı karmaşık hale getirebilirler...

[I-37] Teknolojik problemlerimiz var. Böyle problemlerimiz var çünkü labda iki kişi bir bilgisayarın başında oturuyor. İki kişi paylaşıyor. Bazen bu bilgisayarlar bile çalışmıyor. Kullanamıyoruz. Çalışanlarda da farklı problemler oluyor, İnternete bağlanmıyor, hiçbir program yüklü olmuyorç Yada ben denk gelmedim bilmiyorum (;)

[I-38] Eğer labı kullanma şansımız olsaydı bilgisayarda kod yazmak ve denemek daha iyi olurduç Bu daha etkili olurdu...

[I-39] Bizim hocamız farklı bir yöntem uyguluyor, tahtayı kullanmak yerine kod yazma sürecinde projektör kullanıyor. Bu bizim için önemli bir olanak ama eğer bizimde şansımız olsaydı, ben de labda daha fazla uygulama yapmak için kod yazmayı isterdim. 
[I-40] Hatta bizim bilgisayarları ayakta tutmak için ne bir asistanımız var nede bir personelimizç Her türlü teknolojik problem ile kendiniz mücadele etmek zorundasinız...

[I-41] Benim bir bilgisayarım var ama internet erişimim yok bu nedenle dersle ilgili başka şeylere erişmek için arkadaşlarımın evine yada bir internet cafeye gitmek zorundayım...

[I-42] Ben aslında bu bölümün adamı değilim, ben kitap okumayı, şiir okumayı severim. Ben kendimi bilgissayar konusunda uzman olarakta görmüyorum...

[I-43] Dönem başında ben yeteri kadar motive değildim, bu ders ne ile ilgili onu bile bilmiyordum...

[I-44] Eğer ders içerisindeki süreçlerile uğraşabilecek olanaklarım olsaydı ve yeterli altyapı olsaydı, dersi değiştirmek isterdim.

[I-45] Bu tarz bir derste sorumluluğun büyük bir kısmı öğrencide. Eğer bir öğrenci daha fazla öğrenmek isterse bunun için daha fazla zaman ayırabilir. Sadece oturup not almak ile bu iş olmaz...

[I-46] Bu ders bizim için güzel bir başlangıç oldu, bugune kadar hiç böyle bir dersin parçası olmamıştım ama ileride büyük ihtimalle bu tarz derslere aşina olacağız...

[I-47] $\mathrm{Bu}$ tarz bir derse katılmaktansa ben yüz yüze eğitimi tercih ederim çünkü ben bu sisteme adapte olamadım. Her ihtiyacımı zolan şey için siteyi kullanmak, üstüne birde ben şeyi istiyorum hocadan uzakta olmaktansa karşına geçeyim oturayım üstüyorum...

[I-48] Video konferans sırasında pek çok problemle karşılaştık. Bağlanmaya çalışırken bir süre beklemek zorunda kaldık ve hatta bağlansak bile bazen ses ile ilgili problemler yaşadik... 
[I-49] Bu tarz bir çalışma öncü bir adım olsa da biz internetin eğitimsel amaçlı nasıl kullanılabileceğine yönelik pek çok şey öğrendik.

[I-50] Ben uzun zamandır bilgisayar ile haşır neşir olurum ama benim için bile bu sistemi kullanmak karmaşık geldi. Özellikle video konferansta uzakta olmak ve hoca ile iletişim kurmaya çalışmak farklı bir deneyimdi.

[I-51] $\mathrm{Bu}$ dersteki benim karşılaştığım en büyük problem bütün dokümanların internette olması. Herşey internet gerektiriyor, hatta dersin kendisi bile internete bağımlı. Ama ben yurtta yaşıyorum ve internet bağlantısı yokç $\mathrm{Bu}$ yüzden internet kafeye gitmek o kapalı, kalabalık ortamda saatlerimi geçrimek zorunda kaldım. Hatta orada ilgili yazılımlarda yüklü değil zaten deneme de yapamadım...

[I-52] Bazı arkadaşlarınızın bilgisayarı bile yok bu nedenle dersin sitesıne ulaşmanın tek yolu okuldaki bilgisayar labı... Bence ilk uzaktan ders deneyiminde bizim sisteme adapte olmamız için daha fazla zamana ihtiyacımız var...

[I-53] Ben iki yıllım meslek yüksekteyken uzaktan bir ders almıştım ama o bu kadar komplike bir sistem değildi. Biz orada bazı pdf dosyalarına erişebiliyorduk ama burada benim beklentilerimin çok ötesinde işeler yaptık, hatta ben dersteki herşeyi tam anlamıyla kullanmayı başarabildiğimi düşünmüyorum...

[I-54] Siteyi her ziyaret ettiğimde bizim için hazırlanmış yeni materyaller gördüm, ders videoları, pdfler, örnek aktiviteler falan. Dersin sitesi benim derste kullandığım en önemli araçtı, özellikle her yeni videonun yeni bir konuyu kapsaması çok faydaliyd1...

[I-55] Klasik olarak verilen derslerde ben utangaçlığımdan çok çektim, sorularım olurdu ama soramazdım ve birinin sormasını beklerdim. Ama chat için kullandığımız program. O çok farklıydı, beklenmedik bir zamanda hocayla denkgeliyorduk, ve sıkılmadan onunla konuşabiliyordum... 
[I-56] Ben Communicatorı hoca ve sizinle (asistanla) konuşmak için kullandım aöa pek çok arkadaşımız bilgisayarlarına kurarken problem yaşadılar.

[I-57] $\mathrm{Bu}$ dersteki benim karşılaştığım en büyük problem bütün dokümanların internette olması. Herşey internet gerektiriyor, hatta dersin kendisi bile internete bağımlı. Ama ben yurtta yaşıyorum ve internet bağlantısı yokç $\mathrm{Bu}$ yüzden internet kafeye gitmek o kapalı, kalabalık ortamda saatlerimi geçrimek zorunda kaldım. Hatta orada ilgili yazılımlarda yüklü değil zaten deneme de yapamadım...

[I-58] Bu tarz bir çalışma öncü bir adım olsa da biz internetin eğitimsel amaçlı nasıl kullanılabileceğine yönelik pek çok şey öğrendik.

[I-59] Hocamız web tasarımının farklı kullanımlarını gösterdi bize. Baştan sona web sayfasının nasıl tasarlanacağını açıkladıç Her hafta yeni eklenen şeylerle çalışan bir web siteis oluştu.

[I-60] Klasik olarak verilen derslerde ben utangaçlığımdan çok çektim, sorularım olurdu ama soramazdım ve birinin sormasını beklerdim. Ama chat için kullandığımız program. O çok farklıydı, beklenmedik bir zamanda hocayla denkgeliyorduk, ve sıkılmadan onunla konuşabiliyordum...

[I-61] Web sitesi üzerinden ulaşabildiğimiz derslerin video kayıtları benim için çok faydalıydı çünkü bağlantıda yaşanan problemlerden dolayı bazen dersin bir kısımını kaçırabiliyorduk...

[I-62] Dersin en büyük özelliği PDF dosyalarıydı. Çok sık kullandım çünkü yurtta internet erişimim yok. Bazılarının çıktısını aldım ve onlar üzerinde çalıştım, özellikle sinavdan önce...

[I-63] Bu ders için ekstra bir şey öneremeyeceğim. Bu tarz teknolojik ve ders ile ilgili desteğin sağlandığı bir ders hiç almadım. Ama siz böyle bizim diğer derslerden 
beklentimizi artırdınız. Biz şeyin mümkün olduğunu görmüş olduk teknolojinin kullanımını ve ek materyaller ile desteklenebileceğini.

[I-64] Bu ders bizim için güzel bir başlangıç oldu, bugune kadar hiç böyle bir dersin parçası olmamıştım ama ileride büyük ihtimalle bu tarz derslere aşina olacağız çünkü artık biliyoruz ki bu tarz bir teknolojik şeylerle, materyal desteği mümkün...

[I-65] Dönem başında siz bize bir program verdiniz ama biz onu bilgisayarlarımıza kuramadık. Sonrasında siz bize güncelleme problemi olmasın diye lisanslı Windows XP şifreleri yolladınızç Böylelikle biz bilgisayarlarımıza kurabildik...

[I-66] Dönem başında çok da motive değildim çünkü bu tarz bir dersin bizim okulumuzda verilebileceğine inanmamıştım. Herşeye rağmen bugün ders bitti, sınav ile birlikte. Gerçi internet bağlantısı ve video konferanslarda sorun yaşadık ama...

[I-67] İnternet üzerinden ders almak düşündüğümde mmm sadece bu bile benim için alışılmış bir şey değil. Daha önce böyle bir deneyimim olmamıştı. Aynı derste pek çok farklı şeyi kullandık. Şimdi biliyorumki bu bizim okulda yapılabilirmiş. Problemlerimiz olmasına rağmen şimdi biliyorumki okulun kısıtlı imkanları ile bunun gibi bir şey yapılabiliyormuş. Benim başka derslerde almam lazım bu şekilde internet üzerinden teknoloji destekli derslere...

[I-68] Okulumuzun var olan olanakları içerisinde bu dersi alabildik aslında. Şimdi diğer arkadaşlar ders notlarını dokümanları benden istiyorlar...

[I-69] Ben Communicatorı hoca ve sizinle (asistanla) konuşmak için kullandım aöa pek çok arkadaşımız bilgisayarlarına kurarken problem yaşadılar.

[I-70] Benim bu dersle ilgili itiraz ettiğim bir nokta...hoca ile istediğim kadar iletişim kuramadım. Ben hocanın kapısını tıklayıp, konuşmak isterim ama bu derste program kurmam ve hoca oradaysa sorumu sormam mümkün oluyor... 
[I-71] Ben tu tür bir ders almaktansa yüz yüze dersleri tercih ederim çünkü ben bu sisteme adapte olamadım,her ihtiyacımız olanın sitede olması oradan kullanmak, üstelik ben derste hocanın karşısında olmak isterim uzakta olmaktansa...

[I-72] Video konferansta çok problem yaşadık. Bağlanmaya çaşırken bür süre burada beklemek zorunda kaldık, hatta bağlandığımızda bile bazen ses ile ilgili problemler yaşadik...

[I-73] Bu bağlantı problemlerindan dolayı sanırım bazen projektörü okuyamıyorduk. Bu nedenle bazen önlere oturmak durumunda kaldık bazen sandalyey oturduk...

[I-74] Dönem başında Ankara'ya bağlanırken problemlerimiz oldu, problem olduğunda bazı arkadaşlar düzeltmeye çalıştı ve bazen XXX hocaya yardım için ulaşmaya çalıştılar...

[I-75] Dönem başında siz bize lisanslı Windows XP leri verene kadar programı kuramadık.

[I-76] Ben şu Msn tarzı programı hiç kuramadımç Defalarca denedim kendi bilgisayarımda ama olmadı. Arkadaşıma sorduğumda bana bir word dökümanı gösterdi, sonra 1-2 defa daha denedim olmadı bende pes ettim.

[I-77] $\mathrm{Bu}$ dersteki benim karşılaştığım en büyük problem bütün dokümanların internette olması. Herşey internet gerektiriyor, hatta dersin kendisi bile internete bağımlı. Ama ben yurtta yaşıyorum ve internet bağlantısı yokç $\mathrm{Bu}$ yüzden internet kafeye gitmek o kapalı, kalabalık ortamda saatlerimi geçrimek zorunda kaldım. Hatta orada ilgili yazılımlarda yüklü değil zaten deneme de yapamadım...

[I-78] Bazı arkadaşların bilgisayarı bile yok bu nedenle dersin sayfasına kısıtlı zamanlarda okulun labını kullanarak ulaşabiliyoruz.

[I-79] Bu tarz bir derste sorumluluğun büyük bir kısmı öğrencide. Eğer bir öğrenci daha fazla öğrenmek isterse bunun için daha fazla zaman ayırabilir. Sadece oturup not 
almak ile bu iş olmaz bu tarz bır ortamda. Biz aslında klasik eğitime alışmışız sadece oturup dinlemeye ve sınavdan önce çalışıp geçmeye. Bu sefer durum farklıydı, ödevler, projeler, sınavlar vard1, bir sürü video, doküman, site falan vard1...

[I-80] Ben iki yıllım meslek yüksekteyken uzaktan bir ders almıştım ama o bu kadar komplike bir sistem değildi. Biz orada bazı pdf dosyalarına erişebiliyorduk ama burada benim beklentilerimin çok ötesinde işeler yaptık, hatta ben dersteki herşeyi tam anlamıyla kullanmayı başarabildiğimi düşünmüyorum...

[I-81] Dönem başında bu derse motive değildim çünkü bu dersin bir sistemin denemesi olduğunu ve bizim fakültenin olanakları ile bunun bir macera olacağını düşünüyordum

[I-82] Ben uzun zamandır bilgisayar ile haşır neşir olurum ama benim için bile bu sistemi kullanmak karmaşık geldi. Özellikle video konferansta uzakta olmak ve hoca ile iletişim kurmaya çalışmak farklı bir deneyimdi ve bizim okulda yapılabileceğini düşünmüyordum. 


\section{CURRICULUM VITAE}

Department of Computer Education \& Instructional Technology

Middle East Technical University

Faculty of Education

06800, Çankaya, Ankara

TURKEY

Phone: +90 (312) 2103682

http://www.metu.edu.tr/ euzun

http://ermanuzun.blogspot.com/

euzun@metu.edu.tr

ermanuzun@outlook.com

\section{EMPLOYMENT HISTORY}

- 2001-2003 Tasarim Computer Ltd. Sti - Isparta - Technique Service

- 2003 Uluborlu Vocational High School - Uluborlu, Isparta - Teacher

- 2003- Present Computer Education and Instructional Technology, METU Research Assistant

\section{EDUCATION}

- March, 2010 - November, 2010: Visiting Research Fellow, Instructional Technology Program Educational Psychology and Leadership, College of Education, Texas Tech University, Lubbock, TX 79409, USA. Advisor: Dr. Fethi Inan

- 2004, January- Present: Ph.D. after B.Sc. Department of Computer Education and Instructional Technology, Faculty of Education, Middle East Technical University, Ankara.

- 2003 - 2004: English Preparation School, School of Foreign Languages, Department of Basic English Middle East Technical University, Ankara 
- 1999 - 2003: B.Sc., Computer Systems Teaching, Computer and Electronic Teaching Department, Faculty of Technical Education, Suleyman Demirel University.

\section{PUBLICATIONS}

- Aşkun, C.S, Baran, B., Karakuş, T.,Kursun, E., Uzun, E., Adıyaman, Z., Onat, G., Demirel, F., Uzun, S. \& Yalçınalp, S. (2006). Changing Face of Education: E-Learning (In Turkish), ISBN:978-975-6085-01-1, Ankara, Turkey: METU Alumni Association.

- Karakuş, T., Adıyaman, Z., Askun, C., S., Baran, B., Bayır G., Demirel F., Kurşun, E., Uzun, E., Uzun S., Yalçınalp, S. (2006) What people in Turkey think about e-Learning? Their awarness and preferences. International Open and Distance Learning (IODL) Syposium. Eskisehir, Turkey, 13 -15 October, 2006. Page: 585-597

- Yıldız, I., Karakuş, T., Kurşun, E., Uzun, E. \& Karaaslan, H. (2007). Random Assigned Collaborative Working in a Distance Education Course: Experience And Recommendations of Students. In Proceedings of World Conference on Educational Multimedia, Hypermedia and Telecommunications 2007 (pp. 4505-4510). Chesapeake, VA: AACE.

- Uzun, E., Karakuş, T., Kursun, E., \& Karaaslan H. (2007). Öğrenci Gözüyle Aşırma (İntihal): Neden ve Çözüm Önerileri. Akademik Bilisim, 2007 Bildiriler Kitapçı̆̆̆, 31 January -2 February, 2007, Kütahya, Türkiye, pp. $183-188$

- Uzun, E.; Kara, A.G. (2007). Why Turkey Needs to Integrate Virtual and Remote Laboratory Technology to Technical Vocational School of Higher Education System: A Situation Analysis," Proceeding of the 18th Annual IEEE International Symposium on Personal, Indoor and Mobile Radio Communications (PIMRC'07),pp.1-3, , Athens, Greece.

- Çağıltay, K., Yıldırım, S., Arslan, I., Gök, A., Gürel, G., Karakuş,T., Saltan, F., Uzun, E., Ülgen, E., Yıldız, I. (2007). Öğretim Teknolojilerinin Üniversitede Kullanımına Yönelik Alışkanlıklar ve Beklentiler: Betimleyici 
Bir Çalışma. Akademik Bilisim, 2007 Bildiriler Kitapçığı, 31 January -2 February, 2007, Kütahya, Türkiye, pp. 209-216.

- Arslan Ari, I., Gok, A., Uzun, E., Yıldız, I., Cagiltay, K. \& Yildirim, S. (2008). Students' 99 Suggestions about Technology Integration in Higher Education. In J. Luca \& E. Weippl (Eds.), Proceedings of World Conference on Educational Multimedia, Hypermedia and Telecommunications 2008, pp. 6236-6240. Chesapeake, VA: AACE.

- Uzun, E., Çağıltay, K.( 2008), Usability Study of Handwriting Recognition System for Text Entry in PDA's With Respect to Handedness in Adult User, Proceedings of the mLife 2008 Conference and Exhibitions, Antalya, Turkey.

- Karakus, T., Arslan-Ari, I., Uzun, E., Çagıltay, K. \& Yıldırım, S. (2009). An Investigation and Comparison of Students? and Instructors? Perspectives of ICT Use in Higher Education, In Simonson, M. R. (Ed.) In 32nd Proceedings of Association for Educational Communications and Technology. (pp. 117-120). Louisville, KY.

- Uzun, E. , Özden, M. Y. and Yıldırım, A. (2011) Problems Faced During the Design and Development of a Distant Web Design Course, Paper presented at the annual meeting of the AECT International Convention, Hyatt Regency Jacksonville Riverfront, Jacksonville, FL

- Uzun, E., Özden M.Y. (2012). Determining New Instructional Strategies for Web Design Course in Vocational Education with Respect to Instructional Technology Perspective. Procedia Social and Behavioral Sciences. Volume:47, pp.426-432. ELSEVIER. 